\title{
Kidney donation after cardiac death : exploring quantity and quality
}

Citation for published version (APA):

de Vries, E. E. (2013). Kidney donation after cardiac death : exploring quantity and quality. [Doctoral Thesis, Maastricht University]. Maastricht University. https://doi.org/10.26481/dis.20130906ev

Document status and date:

Published: 01/01/2013

DOI:

$10.26481 /$ dis.20130906ev

Document Version:

Publisher's PDF, also known as Version of record

\section{Please check the document version of this publication:}

- A submitted manuscript is the version of the article upon submission and before peer-review. There can be important differences between the submitted version and the official published version of record.

People interested in the research are advised to contact the author for the final version of the publication, or visit the DOI to the publisher's website.

- The final author version and the galley proof are versions of the publication after peer review.

- The final published version features the final layout of the paper including the volume, issue and page numbers.

Link to publication

\footnotetext{
General rights rights.

- You may freely distribute the URL identifying the publication in the public portal. please follow below link for the End User Agreement:

www.umlib.nl/taverne-license

Take down policy

If you believe that this document breaches copyright please contact us at:

repository@maastrichtuniversity.nl

providing details and we will investigate your claim.
}

Copyright and moral rights for the publications made accessible in the public portal are retained by the authors and/or other copyright owners and it is a condition of accessing publications that users recognise and abide by the legal requirements associated with these

- Users may download and print one copy of any publication from the public portal for the purpose of private study or research.

- You may not further distribute the material or use it for any profit-making activity or commercial gain

If the publication is distributed under the terms of Article $25 \mathrm{fa}$ of the Dutch Copyright Act, indicated by the "Taverne" license above, 


\section{Kidney donation}

\section{after cardiac death}

-EXPLORING QUANTITY AND QUALITY- 
Layout: Tiny Wouters

Cover: Gusti de Schipper

Photo cover: Eva de Vries (for you, Josephine van Hees)

Production: GVO drukkers \& vormgevers B.V. | Ponsen \& Looijen

(C) Eva de Vries, Maastricht 2013

No part of this book may be reproduced or transmitted in any form or by any means, without prior permission in writing by the author, or when appropriate, by the publishers of the publications.

Financial support by: 


\title{
Kidney donation
}

\author{
after cardiac death
}

\section{-EXPLORING QUANTITY AND QUALITY-}

\section{PROEFSCHRIFT}

ter verkrijging van de graad van doctor aan de Universiteit Maastricht, op gezag van de Rector Magnificus, Prof. Dr. L.L.G. Soete

volgens het besluit van het College van Decanen,

in het openbaar te verdedigen

op vrijdag 6 september 2013 om 12.00 uur

door

EVA DE VRIES 


\section{Promotor}

Prof. dr. L.W.E. van Heurn

\section{Beoordelingscommissie}

Prof. dr. C.H.C. Dejong (voorzitter)

Prof. dr. T.M. van Gulik, AMC Amsterdam

Prof. dr. P.E.V.A. van Kerrebroeck

Prof. dr. Talbot, Freeman Road Hospital, Newcastle

Prof. dr. L.J.I. Zimmermann 


\section{CONTENTS}

$\begin{array}{lll}\text { Part I } & \text { Exploring quantity; a pediatric perspective }\end{array}$

Chapter 1 General introduction 9

Chapter 2 Kidney transplantation and donation in children 29

$\begin{array}{lll}\text { Chapter } 3 & \text { Kidney donation from children after cardiac death } & 47\end{array}$

Chapter 4 Transplantation of kidneys from pediatric DCD donors: 61 a comparison with DBD donors

$\begin{array}{ll}\text { Part II } \quad \text { Exploring quality; viability testing } & 75\end{array}$

Chapter 5 Renovascular resistance of machine perfused DCD kidneys is $\quad 77$ is associated with primary non-function

Chapter 6 The value of machine perfusion biomarker concentration in 91 DCD kidney transplantations

Chapter 7 Measurement of renovascular circulating volume during 107 hypothermic organ perfusion

Chapter 8 Magnetic resonance imaging of renal oxygenation and function after normothermic ischemia reperfusion injury

Chapter 9 General discussion and summary

Samenvatting

List of publications

Dankwoord 153

Curriculum Vitae

Abbreviations 



\section{Part I}

Exploring quantity; a pediatric perspective

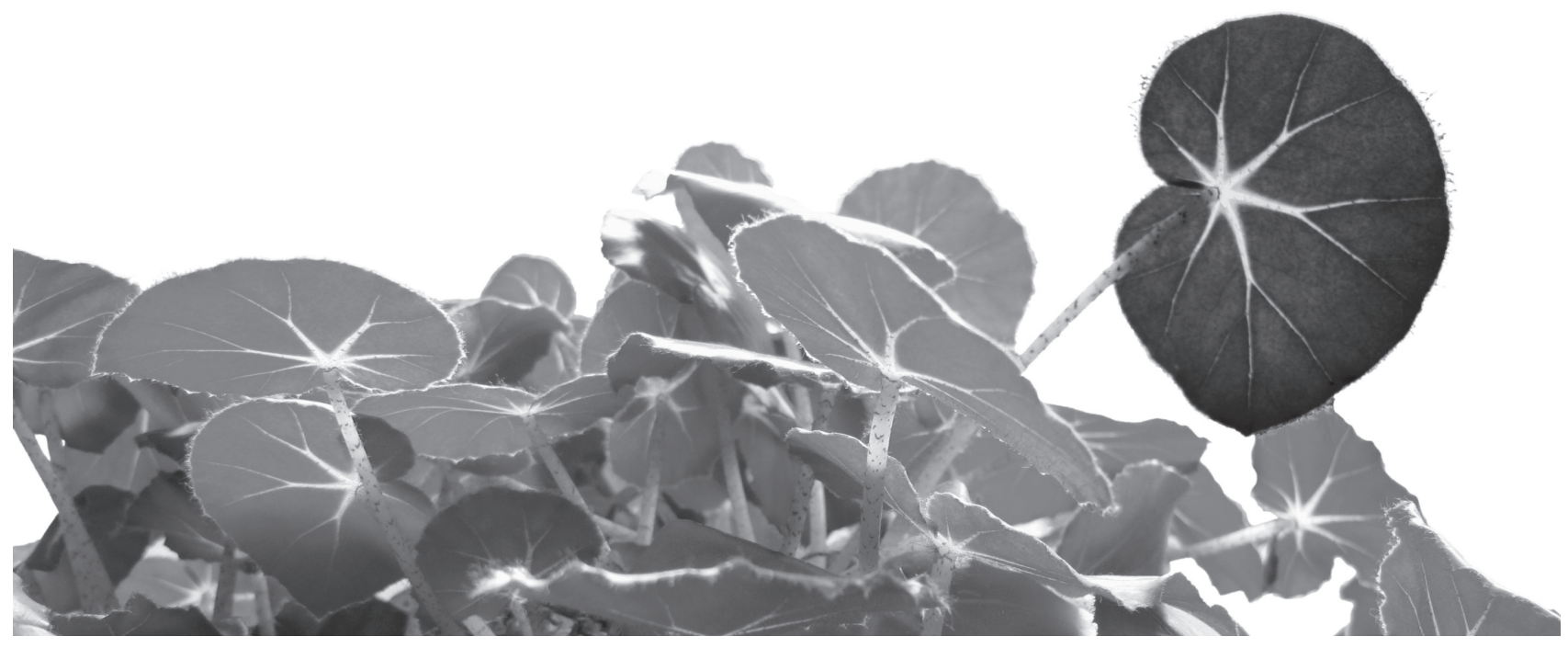




\section{Chapter 1}

General introduction

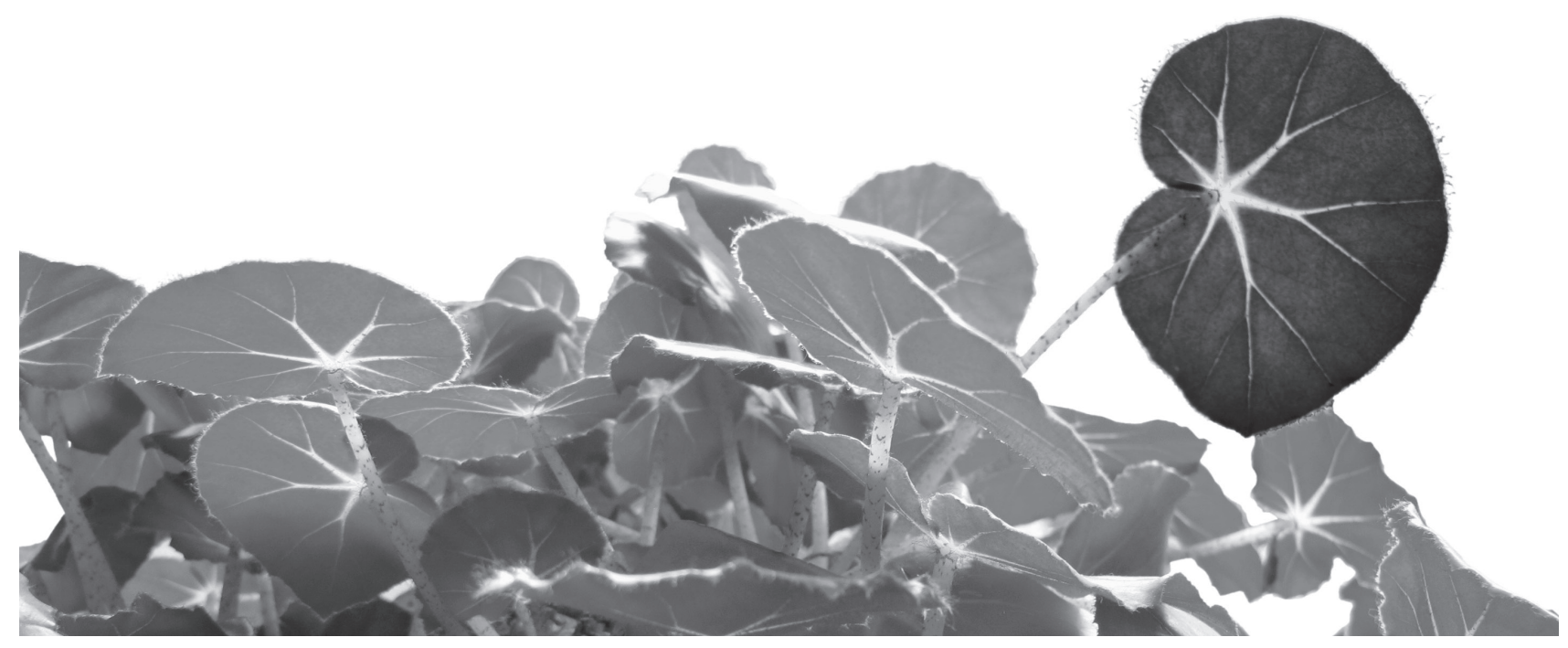




\section{INTRODUCTION}

Kidney transplantation improves the quality of life in patients with end stage renal disease, and increases survival compared to long-term dialysis treatment ${ }^{1,2}$. However, the number of available organ donors still does not meet the demand of the large number of patients on the waiting lists ${ }^{3}$. Waiting lists for kidney transplantation have dramatically increased from the outset of kidney transplantation from the early seventies until the year 2000 (Figure 1.1). In the past 10 years, the waiting list for kidney transplants has shown a delicate decrease, mostly due to the growing number of transplanted kidneys from living donors. Nevertheless, the mean waiting time for a donor kidney for patients on the waiting list is approximately 4 years ${ }^{3}$. This shortage of donor organs has raised interest to expand the donor pool beyond those obtained from living donors and donors after brain death (DBD), the two main donor sources from 1964 until now. Alternative sources of organs include donors after cardiac death (DCD), DBD donors with expanded donor criteria (including donors with associated morbidity and old aged donors), and pediatric donors. DCD donors (also referred to as non-heart-beating donors) suffer from a period of warm ischemia between cardiac arrest and cold flushing of the kidneys, and are therefore less frequently used. Procurement of kidneys from DCD donors holds the potential to expand the donor pool 2.5 to 4 times $^{4}$, which theoretically should suffice to stabilize or even reduce the waiting lists for kidney transplantation ${ }^{5}$.

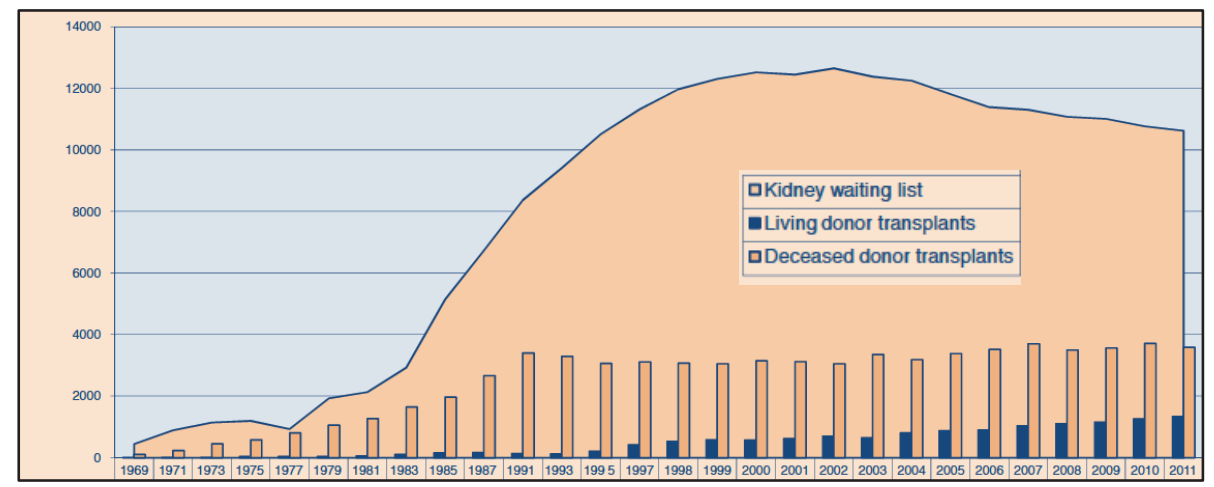

Figure 1.1 Dynamics of the Eurotransplant kidney transplant waiting list and transplants between 1969 and 2011. 


\section{HISTORY OF ORGAN DONATION}

In 1954, the first successful human transplantation was a kidney transplantation from a living donor to his identical twin brother by Dr. Joseph Murray (1919-2012) ${ }^{6}$. It is not surprising that the first renal transplant was from a living and identical twin donor. In this way, the problem of rejection was virtually eliminated because the donor and recipient were genetically identical and the 'living' graft hardly suffered from ischemia. Eight years later, Murray performed the first successful transplant from a cadaveric donor after cardiac death ${ }^{7}$. It functioned after an initial phase of delayed graft function at least during the first year after transplantation ${ }^{7}$. This was, however, a rare exception in this era of DCD kidney transplantation. All other attempts failed within 1 year, primarily due to problems with rejection and poor organ quality caused by warm ischemia $^{8}$. Until 1964 organs were procured from either living donors or from DCD donors. Subsequently, living donor kidney transplantation lost favour as concerns were raised about potential coercion of donors and commercialization of organ donation; DCD kidney transplantation lost favour because of its poor outcome.

Clinical transplantation was spurred not only by the use of better quality organs from brain dead donors, but also by improved techniques to preserve organs after their removal and by the use of immunosuppressive medication to prevent organ rejection in recipients ${ }^{9-11}$. However, even if every brain dead patient would be a suitable donor, the number of organs could still not meet the demand for donor kidneys from patients on the transplant waiting list ${ }^{12}$. In response to this growing imbalance between supply and demand a surge of new initiatives to increase the donor pool started. First the deceased donor pool was expanded with the use of 'expanded' DBD donor organs, with organs from older donors or donors with high blood pressure or diabetes. Pressure to increase the supply of organs caused the transplant community to re-examine organ retrieval from DCD donors ${ }^{9}$. In the 1980s, the once seemingly insoluble problems associated with DCD donation such as the warm ischemia period and the rapid deterioration of organs after cardiac arrest were being alleviated with improved donor preparation and organ preservation methods. Several transplant centers, including our own, have since popularized DCD transplantation. They have reported that the clinical outcome of DCD kidney transplantation is comparable to DBD grafts throughout the first 10 to 25 years after transplantation ${ }^{13-20}$. 


\section{EXPANSION OF THE DONOR POOL}

\section{Donation after brain death}

In an effort to expand the pool of kidneys for transplantation the original donor criteria have been extended. Old aged and more marginal donors are accepted for donation. Kidneys procured from older donors are associated with worse graft survival ${ }^{21,22}$. Therefore, for DBD donation these donors at some point have been labelled as expanded criteria donors. Expanded criteria donor kidneys are defined as those with a relative risk of graft failure greater than 1.7 , corresponding to a $70 \%$ higher risk of graft failure compared with ideal kidneys. Donors aged above 60 years and donors aged 50 59 years with at least two of three additional risk factors were considered as marginal $^{23}$. The three additional risk factors include cerebro-vascular accident as a cause of death, history of hypertension, and serum creatinine above $132 \mathrm{mmol} / \mathrm{l}$ prior to transplantation. Nevertheless, even transplantation of expanded donor kidneys is associated with a substantial survival advantage over maintenance dialysis treatment.

\section{Donation after cardiac death}

During the past decade DCD has evolved into routine clinical practice and currently supplies more than $10 \%$ of all deceased donor kidneys in the United States and up to $50 \%$ in the Netherlands. In contrary to donation after brain death, in which organs are provided by oxygenated blood until recovery, donation after cardiac death is characterized by cessation of the heart beat before the organs are preserved and harvested. Inevitably organs suffer an ischemic insult of unknown severity during the warm ischemia time, defined as the time from circulatory arrest (for controlled donors) or stop of resuscitation (for uncontrolled donors) until the initial cold flush of the kidneys. This time varies per donor and within DCD categories.

In 1995 four types of DCD donors were recognized by the participants of the first international conference on non-heart-beating donation in Maastricht (Table 1.1) ${ }^{24}$. Maastricht category 1 constitutes of patients who are declared dead outside the hospital and are subsequently transferred to the hospital with the purpose of organ donation. Maastricht category 2 donors are patients who die in the hospital after unsuccessful resuscitation, mostly in accident and emergency departments. Both situations occur unexpectedly and therefore are referred to as uncontrolled DCD donations with usually longer warm ischemia times. Maastricht category 3 donors are patients in intensive care units (ICU) who do not meet brain death criteria and in whom supportive treatment is withdrawn because of medical futility. These patients in whom cardiac arrest is awaited are referred to as controlled DCD donors. Maastricht category 4 donors are brain dead donors with cardiac arrest before organ 
procurement. Most DCD donors in the Netherlands are in the controlled group, where the timing of cardiac arrest and the retrieval of organs are carefully planned events.

DCD kidneys more often suffer from delayed graft function and primary nonfunction than DBD kidneys; although in most studies the higher incidence of primary non-function (PNF) does not reach statistical significance due to limited sample size. Primary non-function after kidney transplantation is a serious complication, since patients receiving these kidneys are unnecessarily exposed to the risks of surgery and immunosuppression and may become sensitized to donor antigens, reducing the opportunities for retransplantation ${ }^{25,26}$. Until recently it was unknown whether patients who receive a DCD kidney live longer than patients who receive conventional therapy, i.e. continue dialysis treatment with the option of later receiving a DBD kidney. In other words, it can be questioned if is it better to accept a DCD kidney with higher risk of failure than to await a DBD kidney. Our study group analyzed 2575 patients who were registered on the Dutch waiting list in a 5-year time period. We showed that standard criteria DCD kidney transplantation is associated with increased survival of patients who have end stage renal disease and are on the transplant waiting list $^{27}$.

Table $1.1 \quad$ Maastricht categories of donation after cardiac death.

\begin{tabular}{lll}
\hline Category & Definition & Type \\
\hline 1 & Dead on arrival & Uncontrolled \\
2 & Unsuccessful resuscitation & Uncontrolled \\
3 & Awaiting cardiac arrest & Controlled \\
4 & Cardiac arrest while brain dead & Controlled / Uncontrolled \\
\hline
\end{tabular}

\section{Pediatric donation after cardiac death}

Next to older donors, pediatric DCD programs may as well contribute to an expansion of the donor pool ${ }^{28}$. Up to $75 \%$ of deaths in pediatric intensive care units are planned withdrawals of supportive treatment ${ }^{29,30}$. Nine to $25 \%$ of these patients meet criteria for DCD donation ${ }^{30,31}$. Consequently, this has the potential to increase the donor pool by 6 to $58 \%{ }^{30-32}$. In the Netherlands DCD donors have provided more than $30 \%$ of transplanted deceased pediatric kidneys in the past 11 years. Throughout the world however, since results of pediatric DCD transplantation are relatively unknown, there is reluctance to use pediatric DCD kidneys for transplantation ${ }^{28,33,34}$. Next to the lack of published results of pediatric DCD kidney transplantation, ethical concerns may be responsible for the reluctance to initiate pediatric DCD programs ${ }^{28,33,35-38}$.

Literature on pediatric kidney donation after cardiac death is scarce. The Children's Hospital of Philadelphia described the results of transplantation of 23 pediatric DCD kidneys. The donor age ranged from one to 17 years. Ten out of 12 cases of withdrawal 
occurred on the operating room and they applied a no touch period of 5 minutes. In nine cases the family initiated the donation question. One kidney had failed one year after transplantation ${ }^{39}$.

\section{ETHICAL CONSIDERATIONS}

\section{In general}

The donor must be dead before organ procurement as well as all invasive measures associated with procurement, can be performed (dead donor rule) ${ }^{40-42}$. The diagnosis of death requires the determination of both cessation of functions and irreversibility ${ }^{42}$. Cessation of functions is recognized by an appropriate clinical examination that reveals the absence of responsiveness, heart sounds, pulse and respiratory effort. In a US national meeting on DCD donation it was concluded that absence of circulation by monitoring the arterial pulse pressure is sufficient for diagnosis of death and that electrocardiographic silence is not required ${ }^{41}$. Irreversibility is recognized by persistent cessation of function during an appropriate period of observation. Based on a cardiopulmonary principle, DCD donor death occurs when respiration and circulation have ceased and cardiopulmonary function will not resume spontaneously. Ethical commentaries have stated that controlled DCD donation violates the dead donor rule because circulatory arrest may be reversed if cardiopulmonary resuscitation was to be initiated $^{43}$. However, in the context of withdrawal of supportive treatment in the ICU cardiopulmonary resuscitation is not intended. Consensus within the transplant community defines irreversibility as cessation of function without the capability of spontaneous recovery ${ }^{41}$. The Ethics Committee of the American College of Critical Care Medicine states that no less than 2 minutes is acceptable but no more than 5 minutes is necessary (no-touch period) between cardiac arrest and the start of organ preservation measures ${ }^{44}$. In the Netherlands, before the end of the no-touch period it is not allowed to influence the dying process, including the administration of additional sedation and heparin or the insertion of preservation catheters, which is done in several centers in the United States to optimize the donor ${ }^{45}$. After the period of notouch the donor team is allowed to start with the donor procedure. In this way, the treatment of the dying patient and the donation process are completely separated. Nevertheless, DCD may interfere with the end of life care as clinical practice is gradually deviating from the published guidelines ${ }^{43}$.

\section{Pediatric donors}

As mentioned before pediatric DCD programs may contribute to a significant expansion of the donor pool ${ }^{28}$ as up to $75 \%$ of deaths in pediatric intensive care units 
are planned withdrawals of supportive treatment ${ }^{29}$. Since results of pediatric DCD transplantation are relatively unknown, there is reluctance to use pediatric DCD kidneys for transplantation ${ }^{28,33,34}$. In the Netherlands DCD donors have provided more than $30 \%$ of transplanted deceased pediatric kidneys in the past 11 years. Next to the lack of published results of pediatric DCD kidney transplantation, ethical concerns may be responsible for the reluctance to initiate pediatric DCD programs ${ }^{35-38}$. Ethical concerns include changes in the end of life care of a child and the greater difficulty in meeting consent requirements and the heavy emotional burden in case of a dying child. However, in clinical practice the majority of parents choose for organ donation when this possibility is discussed in children considered for withdrawal of treatment ${ }^{46,47}$. Organ donation may even have a beneficial effect on the bereavement process of donor families ${ }^{48,49}$.

\section{ORGAN PROCUREMENT}

\section{In situ preservation}

DCD organs are inevitably subjected to a period of warm ischemia from circulatory arrest until organ preservation. During this period, cell death pathways are activated which set the stage for graft injury at reperfusion ${ }^{50}$. Prolonged warm ischemia time is associated with reduced graft survival ${ }^{51,52}$. Several techniques have been developed to reduce warm ischemic injury of DCD organs before procurement, either by applying topical or intravascular cooling or by re-establishing blood flow by mechanical resuscitation or extracorporeal circulation ${ }^{53-65}$. Over the past decades, our group has generally used in situ perfusion with double-balloon triple-lumen (DBTL) catheters for procurement of DCD kidneys (Figure 1.2) ${ }^{66}$. This catheter is introduced via the femoral artery into the aorta, and subsequent inflation of the two balloons allows selective perfusion of the abdominal aorta, flushing and cooling of the kidneys. This technique is minimally invasive, can be performed in the emergency department and in the ICU, and is intended for fast and effective use by surgeons with limited experience in transplant surgery. In situ perfusion provides additional time to make necessary arrangements for legal, logistical and medical requirements for organ procurement from uncontrolled DCD donors. For controlled DCD donors however, logistical requirements for rapid laparotomy and direct aortic cannulation in the operating room can be arranged before withdrawal of supportive treatment ${ }^{61}$. Histidine tryptophan ketoglutarate (HTK) solution is used for perfusion since its low viscosity facilitates flush out at high flow rates. Addition of heparin and streptokinase to the perfusion solution results in thrombolysis and improves graft quality ${ }^{67,68}$. Administration of a vasodilator 
such as phentolamine may prevent renal vasospasm and increase perfusion efficacy $^{53,69,70}$.
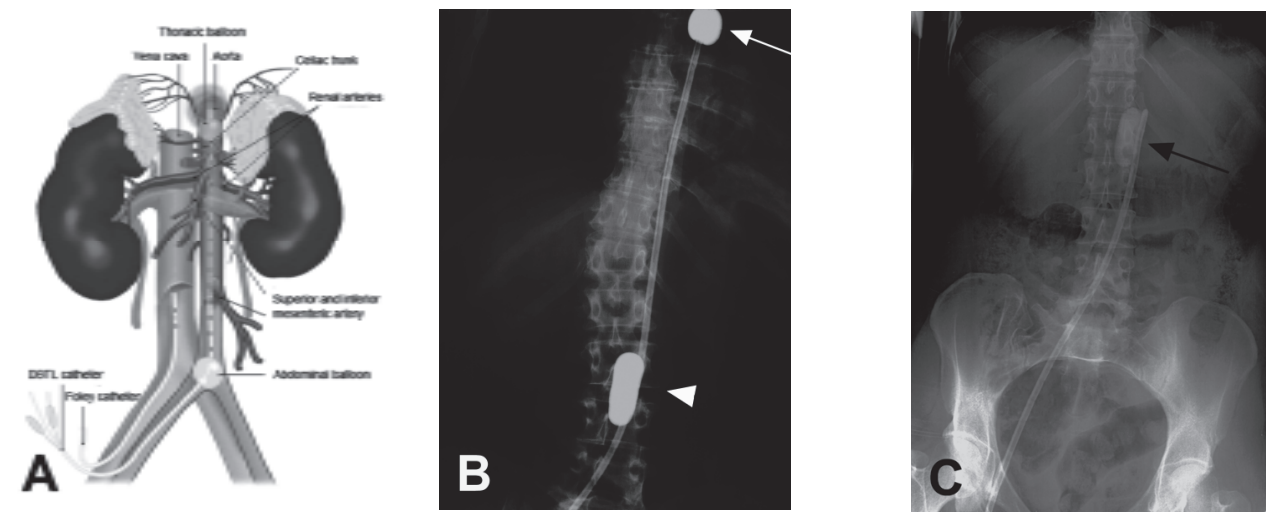

Figure 1.2 In situ preservation technique. (A) After introduction of the double-balloon triple-lumen catheter via the femoral artery, the abdominal aorta including the renal arteries can be selectively perfused, flushing and cooling the kidneys (adapted from Kootstra and Van Hooff, Ned Tijdschr Geneeskd, 1998) ${ }^{71}$. (B) Correct position of DBTL catheter visualized by an X-ray from the heart to the umbilicus. The abdominal balloon (arrowhead) is located at the level of the aortic bifurcation and the thoracic balloon (arrow) above the level of the diaphragm. (C) Malposition of DBTL catheter. The abdominal balloon was not sufficiently inflated and pulled back into the iliac artery. The thoracic balloon (arrow) lies at the level of the renal arteries, obstructing flush-out of the kidneys.

\section{Cold ischemic injury}

Ischemic injury is reduced by a low temperature of tissues and organs. Therefore kidneys are cooled down to approximately 4 degrees Celsius to reduce metabolism. Animal studies with prolonged cold ischemia following warm ischemic injury, in the period between recovery of the organs and transplantation, were associated with donor kidneys which were less suitable for transplantation ${ }^{72,73}$. Ischemic injury is reduced by a low temperature, but cold ischemia time remains an important factor to predict transplant outcome. In DCD kidneys cold ischemic injury is added to the inevitable warm ischemic injury after cardiac arrest with potentially additional detrimental effect on organ viability. The adverse effects of prolonged cold ischemia on graft outcome are well documented and include higher incidences of delayed graft function and acute rejection and a reduction of long-term graft survival ${ }^{74-80}$. Although the strength of the association between cold ischemia time and delayed graft function varies in different publications, a recent analysis of the UK transplant registry indicates that cold ischemia time ( $>24 \mathrm{~h}$ vs. $<12 \mathrm{~h}$ ) was associated with poorer graft survival ${ }^{81}$. Kidneys from DBD and DCD donors are affected to the same extent. Machine 
preservation is a technique by which cold ischemic damage during cold storage can be reduced.

\section{Organ preservation}

Organ preservation is defined as the way organs are protected from further damage in the period from organ procurement to transplantation. In the early years of transplantation organs were not preserved: the donor graft was rushed from the donor to the recipient to keep the ischemia time to a minimum. Without adequate preservation, it is virtually impossible to maintain organ viability if the graft is transported between the donor and the recipient.

Static cold storage has been the golden standard for organ preservation in the last decades with University of Wisconsin solution as the usually preferred preservation medium $^{82}$. This method combines ease of use with satisfactory post-transplant outcome, especially due to improvements in preservation fluid composition. Along with the re-introduction of DCD programs a renewed interest rose in hypothermic

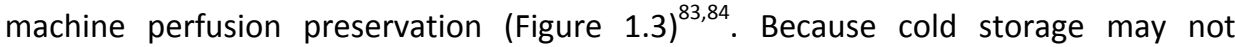
adequately preserve a graft with warm ischemic damage, machine perfusion has been studied extensively. There has been considerable debate about the relative merits of either technology. Randomized clinical trials comparing the two preservation modalities, cold storage and machine preservation, have often been underpowered to detect clinically important differences in graft outcome. A meta-analysis of these trials showed that a $20 \%$ reduction in the relative risk of delayed graft function (DGF) of both DBD and DCD donors can be achieved by using machine perfusion rather than cold storage ${ }^{85}$. This conclusion was confirmed by a registry analysis of 907 paired kidneys transplanted in the United States, with DGF in $26 \%$ of cold stored kidneys versus $19 \%$ of machine perfused kidneys procured from the same donors ${ }^{86}$. No difference in longterm graft survival was observed in this study. In contrast, a recent analysis from the Collaborative Transplant Study suggests that machine perfusion is associated with inferior long-term outcome ${ }^{79}$.This may be explained by the tendency of transplant centers to pump only marginal kidneys which may be hard to account for in multivariate analyses of graft outcome. To provide definitive evidence of the superiority of either preservation method, a large multi-center randomized clinical trial was initiated in which kidneys from 336 deceased donors were preserved by machine perfusion or cold storage using pair wise randomization ${ }^{87}$. Kidneys that were preserved with machine perfusion showed a reduced incidence of delayed graft function (21 vs. $27 \%, P=0.01$ ) and superior graft survival at 1 year after transplantation (94 vs. $90 \%$, $P=0.04)$ than their cold-stored counterparts. The treatment effect of machine perfusion was similar for DCD and DBD donors. 


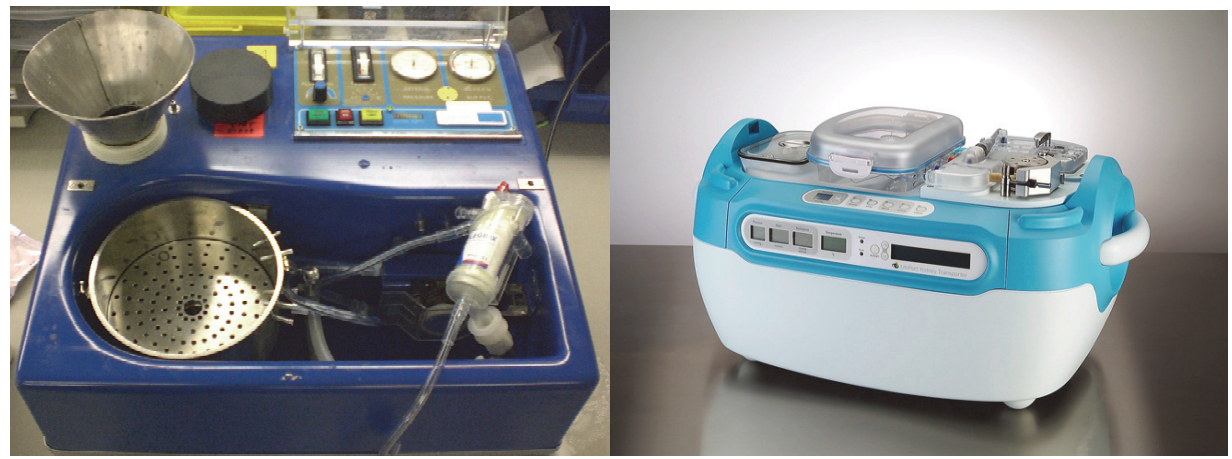

Figure 1.3 Left picture: Gambro machine, used from 1981 until 2007. Right picture: Lifeport machine, used from 2007 until now.

\section{ORGAN VIABILITY TESTING}

\section{Machine perfusion parameters}

Machine perfusion parameters are potential predictors for organ viability ${ }^{88-93}$. Most widely used parameters include renovascular resistance, flow rate and pump pressure. Flow rate and pump pressure are measured with the preservation machine. Renovascular resistance can be calculated by dividing mean pressure by the registered flow $^{94}$. These parameters have been advocated to predict graft function after transplantation $^{90,95-100}$ and can be especially important in marginal kidneys with an increased risk of developing PNF. In some centers machine perfusion parameters are used to discard kidneys. However, although flow rate, pump pressure and renovascular resistance are often associated with short-term graft function their independent predictive value for graft function is $l_{0} w^{74,93,95,100-102}$. The evidence that machine perfusion parameters can be used directly to discard organs without discarding too many viable kidneys is very limited. In this thesis, we studied the association between renal resistance of $D C D$ donors during machine perfusion and primary non-function (chapter 5).

\section{Machine perfusion biomarkers}

Measurement of biomarkers in the preservation solution, such as $\alpha$-glutathione S-transferase (GST), fatty-acid binding proteins (FABP's) or lactate dehydrogenase (LDH), is another method to test organ viability. These markers may be useful to select viable DCD kidneys for transplantation ${ }^{92,103-105}$. GST, formerly known as ligandin, is a cystolic enzyme. In the kidney, the a-isoenzyme is exclusively located in the proximal 
tubules and its release indicates specific injury to these structures. As acute tubular necrosis is one of the major causes of DGF, GST has been postulated to predict shortterm outcome. Heart-type fatty acid binding protein (H-FABP) is a cytosolic protein, localized in the distal tubules and is involved in transportation of free fatty acids from cytosol to mitochondria for catabolism. H-FABP is released in an early stage following tissue injury to the kidneys ${ }^{106}$. Its clinical value as perfusate viability marker is relatively unknown. LDH is found in almost all body tissues and is therefore a non-specific cellular injury marker. LDH measured in machine perfusate is either released by the perfused kidney or by haemolytic erythrocytes from the capillaries of the perfused blood. High concentrations of $\mathrm{LDH}$ can therefore be associated with a poor preservation immediately after cardiac arrest and poor outcome. However, the value of machine perfusion biomarkers remains unanswered since little evidence has been published $^{92,106-108}$. We therefore evaluated the predictive value of GST, H-FABP and LDH (Chapter 6).

Renovascular circulating volume measurement during machine perfusion is a technique which potentially can be used in pre-transplant viability testing and which has not been used before in transplantation. Ultrasound dilution, originally used to measure circulating volume in hemodialyzer fibre bundles ${ }^{109-111}$, is studied to determine renovascular circulating volume in machine perfused kidneys. Using the ultrasound dilution technique, renovascular circulating volume is measured by determining the dilution of an injected saline bolus with ultrasound flow probes attached to the renal artery and vein. In hemodialyzer volume measurement, the dilution technique is accurate and its results reproducible, however it has not yet been used to measure circulating volume in machine perfused kidneys. In this thesis we studied this dilution technique to measure renovascular circulating volume in machine perfused kidneys and determined if renovascular circulating volume is associated with warm ischemia time in DCD kidneys (chapter 7).

\section{Ischemia reperfusion injury}

Ischemia reperfusion (I/R) injury is the major cause of acute renal failure after $D C D$ kidney transplantation. This process starts if blood flow is reintroduced to the ischemic kidney. Although necessary to rescue the organ from necrosis and permanent loss of function it leads to acute cellular injury and severe renal dysfunction ${ }^{112-114}$. This $I / R$ injury, a known prognostic factor of graft survival, is associated with delayed graft function, and is one of the major risk factors for acute rejection and the development of chronic graft nephropathy ${ }^{112,115-117}$. The mechanisms of ischemic renal failure are complex and involve multiple mediators, such as reactive oxygen species, activation of adhesion molecules/chemokines, leukocyte recruitment, ultimately leading to tubular 
injury, endothelial dysfunction, and inflammation. Because of prolonged warm ischemia times, kidneys from DCD donors are associated with an increased rate of PNF and DGF. Ischemic damage of the tubules is governed by the intrinsic vulnerability of the various nephron segments and by the tissue gradients of oxygenation. Glomeruli and collecting ducts are relatively resistant to a lack of oxygen. By contrast, both proximal and distal tubules (especially medullary thick limbs) in the outer medulla of the kidney are intrinsically susceptible to hypoxia (Figure 1.4$)^{118-120}$. This is caused by reduced flow, stasis, and red and white blood cell accumulation. In addition, the medulla is most susceptible to I/R injury since it is hypoxic even in the physiological situation due to slow blood flow and $\mathrm{O}_{2}$ diffusion in the vasa recta ${ }^{118,121}$. In this normal situation the medullary partial pressure of oxygen is in the range of 10 to $20 \mathrm{mmHg}$, contrasting with the partial pressure of oxygen in the cortex, which is approximately $50 \mathrm{mmHg}$.

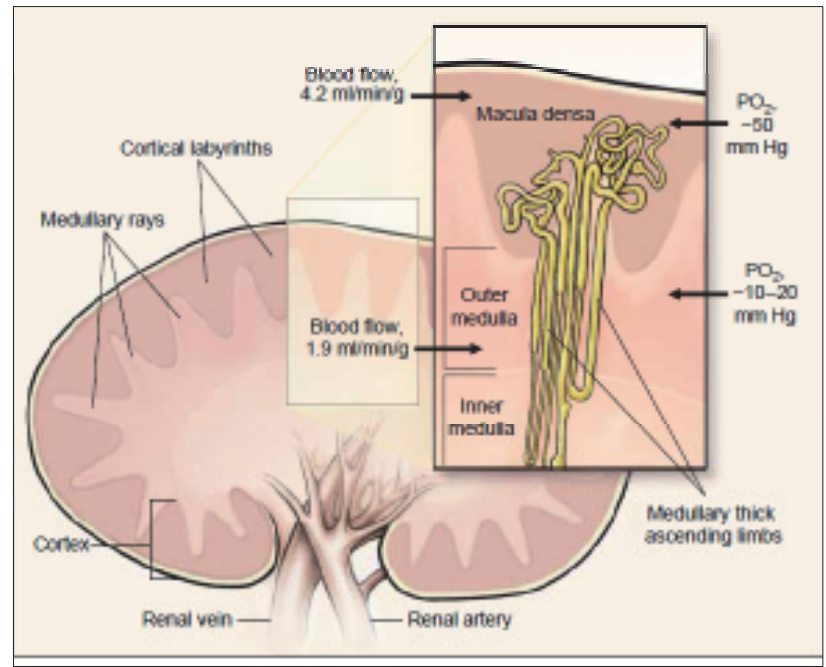

Figure 1.4 Renal cortex and medulla. The cortex, that optimizes glomerular filtration, is well oxygenated, except for the medullary-ray areas with glomeruli, which are supplied by venous blood ascending from the medulla. The medulla, whose poor blood supply optimizes the concentration of the urine, is poorly oxygenated. Medullary hypoxia results both from exchange of oxygen within the vasa recta and from the consumption of oxygen by the medullary thick ascending limbs.

\section{MEASUREMENT OF RENAL OXYGENATION}

To improve the clinical outcome of ischemically damaged kidneys, novel therapies are developed to limit I/R injury ${ }^{122}$. To assess their therapeutic potential non invasively at 
an early stage, new imaging methods are required that allow the evaluation of the function of different renal compartments in both preclinical and clinical settings. In addition, longitudinal monitoring of renal oxygenation in the various nephron segments and renal performance after $\mathrm{I} / \mathrm{R}$ injury may provide more insight into the long-term pathophysiological development, which in turn, may aid in the improvement of therapies directed against I/R injury and acute renal failure.

$\mathrm{MRI}$ is the most all-round noninvasive imaging method available today. Advantages are a superior spatial resolution and soft tissue contrast, which allow the differentiation between specific anatomical regions of the kidney such as the cortex and the inner and outer medulla. A nephrological application of MRI is described in Chapter 7, where quantification of renal oxygenation and function using blood oxygen level dependent (BOLD) and dynamic contrast-enhanced $\mathrm{MRI}$, respectively, were applied to study renal $\mathrm{I} / \mathrm{R}$ injury. This method can be applied to study the potentially beneficial effects of novel treatment aimed at reducing renal I/R injury. BOLD MRI is based on endogenous contrast and can therefore be safely repeated in patients with impaired renal function. As an alternative measure of the extent of renal injury after $I / R$, dynamic contrast-enhanced (DCE) MRI measurements to estimate local renal perfusion can be performed. DCE MRI measurements aim to detect abnormal contrast agent wash-in and wash-out kinetics in diseased compared with healthy tissue. Subsequent analysis of the dynamic signal enhancement curves using pharmacokinetic multicompartment modelling provides quantitative information on tissue perfusion and, to correct for inflow effects, bolus length or cardiac function ${ }^{123-125}$.

\section{AIM OF THE THESIS}

This aim of this thesis is twofold, firstly to determine if the number of DCD kidneys can be enlarged and secondly, if the quality of DCD kidneys can be improved.

Part I: To improve the quantity of DCD donor kidneys we examined the use and outcome of pediatric DCD kidneys, as pediatric patients considered for withdrawal of treatment are not fully utilized as a donor group. We reported the 10-year experience in the Netherlands, early results, strategy and ethical concerns of all transplanted pediatric DCD donor kidneys. Additionally we compared the results of pediatric DCD donor kidneys with those from pediatric DBD donors transplanted during the same time period. We hope these studies encourage centers to start pediatric DCD programs throughout the world.

Part II: To improve quality of transplanted DCD donor kidneys we examined different methods to predict graft function after transplantation. In the pre-transplant setting we aimed to optimize viability testing. We first questioned if intrarenal resistance during machine perfusion is associated with primary non-function and if this 
parameter should be used in the decision to accept or discard a kidney. Second, we evaluated the predictive value of the concentration of different perfusate biomarkers, GST, LDH, and H-FABP. Third, we determined the validity of renovascular circulating volume measurement with an ultrasound dilution technique in machine perfused kidneys and whether differences in warm ischemia time are reflected by renovascular circulating volume. To be able to assess transplanted grafts in the post-transplantation phase we studied if MRI is useful in measurement of renal oxygenation and function after ischemia reperfusion injury.

The purpose of the thesis, improving quality and quantity, cannot be fully separated in two and may even be seen as one goal. If the quality of DCD transplantation improves, the threshold to accept a kidney for transplantation will be lowered, then more kidneys are transplanted which increases quantity. 


\section{REFERENCES}

1. Wolfe RA, Ashby VB, Milford EL, Ojo AO, Ettenger RE, Agodoa LY, et al. Comparison of mortality in all patients on dialysis, patients on dialysis awaiting transplantation, and recipients of a first cadaveric transplant. N Engl J Med 1999;341:1725-30.

2. Evans RW, Manninen DL, Garrison LP, Jr., Hart LG, Blagg CR, Gutman RA, et al. The quality of life of patients with end-stage renal disease. N Engl J Med 1985;312:553-9.

3. Eurotransplant. Annula Report 2009/Eurotransplant International Foundation-Leiden. www.eurotransplant.org 2009.

4. Daemen JW, Oomen AP, Kelders WP, Kootstra G. The potential pool of non-heart-beating kidney donors. Clin Transplant 1997;11:149-54.

5. Terasaki PI, Cho YW, Cecka JM. Strategy for eliminating the kidney shortage. Clin Transpl 1997:265-7.

6. Merrill JP, Murray JE, Harrison JH, Guild WR. Successful homotransplantation of the human kidney between identical twins. J Am Med Assoc 1956;160:277-82.

7. Merrill JP, Murray JE, Takacs FJ, Hager EB, Wilson RE, Dammin GJ. Successful transplantation of kidney from a human cadaver. JAMA 1963;185:347-53.

8. Human Kidney Transplant Conference. Transplantation 1964;2:147-55.

9. Abt PL, Fisher CA, Singhal AK. Donation after cardiac death in the US: history and use. J Am Coll Surg 2006;203:208-25.

10. Cyclosporin a as sole immunosuppressive agent in recipients of kidney allografts from cadaver donors. Preliminary results of a European multicentre trial. Lancet 1982;2:57-60.

11. Rosenthal JT, Hakala TR, Iwatsuki S, Shaw BW, Jr., Starzl TE. Cadaveric renal transplantation under cyclosporine-steroid therapy. Surg Gynecol Obstet 1983;157:309-15.

12. Sheehy E, Conrad SL, Brigham LE, Luskin R, Weber P, Eakin M, et al. Estimating the number of potential organ donors in the United States. N Engl J Med 2003;349:667-74.

13. Wijnen RM, Booster MH, Stubenitsky BM, de Boer J, Heineman E, Kootstra G. Outcome of transplantation of non-heart-beating donor kidneys. Lancet 1995;345:1067-70.

14. Cho YW, Terasaki PI, Cecka JM, Gjertson DW. Transplantation of kidneys from donors whose hearts have stopped beating. N Engl J Med 1998;338:221-5.

15. Sanchez-Fructuoso Al, Marques M, Prats D, Conesa J, Calvo N, Perez-Contin MJ, et al. Victims of cardiac arrest occurring outside the hospital: a source of transplantable kidneys. Ann Intern Med 2006;145:157-64.

16. Weber M, Dindo D, Demartines N, Ambuhl PM, Clavien PA. Kidney transplantation from donors without a heartbeat. N Engl J Med 2002;347:248-55.

17. Cooper JT, Chin LT, Krieger NR, Fernandez LA, Foley DP, Becker YT, et al. Donation after cardiac death: the university of wisconsin experience with renal transplantation. Am J Transplant 2004;4:1490-4.

18. Gok MA, Buckley PE, Shenton BK, Balupuri S, El-Sheikh MA, Robertson $H$, et al. Long-term renal function in kidneys from non-heart-beating donors: A single-center experience. Transplantation 2002;74:664-9.

19. Barlow AD, Metcalfe MS, Johari $Y$, Elwell R, Veitch PS, Nicholson ML. Case-matched comparison of long-term results of non-heart beating and heart-beating donor renal transplants. Br J Surg 2009; 96:685-91.

20. Snoeijs MG, Winkens B, Heemskerk MB, Hoitsma AJ, Christiaans MH, Buurman WA, et al. Kidney transplantation from donors after cardiac death: A 25-year experience. Transplantation 2010;90: 1106-12.

21. Ojo AO, Hanson JA, Meier-Kriesche H, Okechukwu CN, Wolfe RA, Leichtman AB, et al. Survival in recipients of marginal cadaveric donor kidneys compared with other recipients and wait-listed transplant candidates. J Am Soc Nephrol 2001;12:589-97.

22. Miranda B, Fernandez Lucas M, de Felipe C, Naya M, Gonzalez-Posada JM, Matesanz R. Organ donation in Spain. Nephrol Dial Transplant 1999;14 Suppl 3:15-21.

23. Rosengard BR, Feng S, Alfrey EJ, Zaroff JG, Emond JC, Henry ML, et al. Report of the Crystal City meeting to maximize the use of organs recovered from the cadaver donor. Am J Transplant 2002;2:701-11. 
24. Kootstra G, Daemen JH, Oomen AP. Categories of non-heart-beating donors. Transplant Proc 1995;27:2893-4.

25. Billen EV, Christiaans MH, Lee J, van den Berg-Loonen EM. Donor-directed HLA antibodies before and after transplantectomy detected by the luminex single antigen assay. Transplantation 2009;87:563-9.

26. Meier-Kriesche HU, Scornik JC, Susskind B, Rehman S, Schold JD. A lifetime versus a graft life approach redefines the importance of HLA matching in kidney transplant patients. Transplantation 2009;88: 23-9.

27. Snoeijs MG, Schaubel DE, Hene R, Hoitsma AJ, Idu MM, ljzermans JN, et al. Kidneys from donors after cardiac death provide survival benefit. J Am Soc Nephrol 2010;21:1015-21.

28. Mazor R, Baden HP. Trends in pediatric organ donation after cardiac death. Pediatrics 2007;120: e960-6.

29. Ferguson M, Zuk J. Organ donation after cardiac death: a new trend in pediatrics. J Pediatr Gastroenterol Nutr 2003;37:219-20.

30. Durall AL, Laussen PC, Randolph AG. Potential for donation after cardiac death in a children's hospital. Pediatrics 2007;119:e219-24.

31. Koogler T, Costarino AT, Jr. The potential benefits of the pediatric nonheartbeating organ donor. Pediatrics 1998;101:1049-52.

32. Pleacher KM, Roach ES, Van der Werf W, Antommaria AH, Bratton SL. Impact of a pediatric donation after cardiac death program. Pediatr Crit Care Med 2009;10:166-70.

33. Hardart G. Pediatric organ donation after cardiac death--still in its infancy. Crit Care Med 2008; 36:1956-7.

34. Kolovos NS, Webster P, Bratton SL. Donation after cardiac death in pediatric critical care. Pediatr Crit Care Med 2007;8:47-9.

35. Harrison $\mathrm{CH}$, Laussen PC. Controversy and consensus on pediatric donation after cardiac death: ethical issues and institutional process. Transplant Proc 2008;40:1044-7.

36. Joffe AR, Anton NR, deCaen AR. Survey of pediatricians' opinions on donation after cardiac death: are the donors dead? Pediatrics 2008;122:e967-74.

37. Curley MA, Harrison CH, Craig N, Lillehei CW, Micheli A, Laussen PC. Pediatric staff perspectives on organ donation after cardiac death in children. Pediatr Crit Care Med 2007;8:212-9.

38. Mathur M, Taylor S, Tiras K, Wilson M, Abd-Allah S. Pediatric critical care nurses' perceptions, knowledge, and attitudes regarding organ donation after cardiac death. Pediatr Crit Care Med 2008;9:261-9.

39. Naim MY, Hoehn KS, Hasz RD, White LS, Helfaer MA, Nelson RM. The Children's Hospital of Philadelphia's experience with donation after cardiac death. Crit Care Med 2008;36:1729-33.

40. Bernat JL, Culver CM, Gert B. On the definition and criterion of death. Ann Intern Med 1981;94: 389-94.

41. Bernat JL, D'Alessandro AM, Port FK, Bleck TP, Heard SO, Medina J, et al. Report of a National Conference on Donation after cardiac death. Am J Transplant 2006;6:281-91.

42. Guidelines for the determination of death. Report of the medical consultants on the diagnosis of death to the President's Commission for the Study of Ethical Problems in Medicine and Biomedical and Behavioral Research. JAMA 1981;246:2184-6.

43. Rady MY, Verheijde JL, McGregor J. Organ donation after circulatory death: the forgotten donor? Crit Care 2006;10:166.

44. Recommendations for nonheartbeating organ donation. A position paper by the Ethics Committee, American College of Critical Care Medicine, Society of Critical Care Medicine. Crit Care Med 2001;29:1826-31.

45. Antommaria AH, Trotochaud K, Kinlaw K, Hopkins PN, Frader J. Policies on donation after cardiac death at children's hospitals: a mixed-methods analysis of variation. JAMA 2009;301:1902-8.

46. Kaplan B MG, Koogler TK. Parents'/guardians' views on donation after cardiac death. Crit Care Med 2004;32(Suppl):A89.

47. Morris JA, Jr., Wilcox TR, Frist WH. Pediatric organ donation: the paradox of organ shortage despite the remarkable willingness of families to donate. Pediatrics 1992;89:411-5. 
48. Merchant SJ, Yoshida EM, Lee TK, Richardson P, Karlsbjerg KM, Cheung E. Exploring the psychological effects of deceased organ donation on the families of the organ donors. Clin Transplant 2008;22: 341-7.

49. Diekema DS. Parental refusals of medical treatment: the harm principle as threshold for state intervention. Theor Med Bioeth 2004;25:243-64.

50. Wolfs TG, de Vries B, Walter SJ, Peutz-Kootstra CJ, van Heurn LW, Oosterhof GO, et al. Apoptotic cell death is initiated during normothermic ischemia in human kidneys. Am J Transplant 2005;5:68-75.

51. Shiroki R, Hoshinaga K, Higuchi T, Tsukiashi Y, Kubota Y, Maruyama T, et al. Prolonged warm ischemia affects long-term prognosis of kidney transplant allografts from non-heart-beating donors. Transplant Proc 1998;30:111-3.

52. Nishikido M, Noguchi M, Koga S, Kanetake H, Matsuya F, Hayashi M, et al. Kidney transplantation from non-heart-beating donors: analysis of organ procurement and outcome. Transplant Proc 2004;36: 1888-90.

53. Garcia-Rinaldi R, Lefrak EA, Defore WW, Feldman L, Noon GP, Jachimczyk JA, et al. In situ preservation of cadaver kidneys for transplantation: laboratory observations and clinical application. Ann Surg 1975;182:576-84.

54. Lloveras J, Puig JM, Cerda M, Rico N, Mir M, Rovira A, et al. Optimization of in situ renal perfusion of non--heart-beating donors: four-lumen catheter developed for continuous perfusion pressure determination. Transplant Proc 1993;25:3169-70.

55. Valero R, Cabrer C, Oppenheimer F, Trias E, Sanchez-Ibanez J, De Cabo FM, et al. Normothermic recirculation reduces primary graft dysfunction of kidneys obtained from non-heart-beating donors. Transpl Int 2000;13:303-10.

56. Orloff MS, Reed Al, Erturk E, Kruk RA, Paprocki SA, Cimbalo SC, et al. Nonheartbeating cadaveric organ donation. Ann Surg 1994;220:578-83; discussion 83-5.

57. Kowalski AE, Light JA, Ritchie WO, Sasaki TM, Callender CO, Gage F. A new approach for increasing the organ supply. Clin Transplant 1996;10:653-7.

58. Anaise D, Smith R, Ishimaru M, Waltzer WC, Shabtai M, Hurley S, et al. An approach to organ salvage from non-heartbeating cadaver donors under existing legal and ethical requirements for transplantation. Transplantation 1990;49:290-4.

59. Magliocca JF, Magee JC, Rowe SA, Gravel MT, Chenault RH, 2nd, Merion RM, et al. Extracorporeal support for organ donation after cardiac death effectively expands the donor pool. J Trauma 2005; 58:1095-101; discussion 101-2.

60. Ko WJ, Chen YS, Tsai PR, Lee PH. Extracorporeal membrane oxygenation support of donor abdominal organs in non-heart-beating donors. Clin Transplant 2000;14:152-6.

61. Casavilla A, Ramirez C, Shapiro R, Nghiem D, Miracle K, Bronsther O, et al. Experience with liver and kidney allografts from non-heart-beating donors. Transplantation 1995;59:197-203.

62. Koyama I, Hoshino T, Nagashima N, Adachi H, Ueda K, Omoto R. A new approach to kidney procurement from non-heart-beating donors: core cooling on cardiopulmonary bypass. Transplant Proc 1989;21:1203-5.

63. Alvarez-Rodriguez J, del Barrio-Yesa R, Torrente-Sierra J, Prats-Sanchez MD, Barrientos Guzman A. Posttransplant long-term outcome of kidneys obtained from asystolic donors maintained under extracorporeal cardiopulmonary bypass. Transplant Proc 1995;27:2903-4; discussion 4-5.

64. Farney AC, Singh RP, Hines MH, Rogers J, Hartmann EL, Reeves-Daniel A, et al. Experience in renal and extrarenal transplantation with donation after cardiac death donors with selective use of extracorporeal support. J Am Coll Surg 2008;206:1028-37; discussion 37.

65. Morozumi J, Sakurai E, Matsuno N, Ito M, Yokoyama T, Ohtaka Y, et al. Successful kidney transplantation from donation after cardiac death using a load-distributing-band chest compression device during long warm ischemic time. Resuscitation 2009;80:278-80.

66. Booster $\mathrm{MH}$, Wijnen RM, Vroemen JP, van Hooff JP, Kootstra G. In situ preservation of kidneys from non-heart-beating donors--a proposal for a standardized protocol. Transplantation 1993;56:613-7.

67. Gok MA, Shenton BK, Buckley PE, Peaston R, Cornell C, Soomro N, et al. How to improve the quality of kidneys from non-heart-beating donors: a randomised controlled trial of thrombolysis in non-heartbeating donors. Transplantation 2003;76:1714-9. 
68. Yamauchi J, Schramm R, Richter S, Vollmar B, Menger MD, Minor T. Improvement of microvascular graft equilibration and preservation in non-heart-beating donors by warm preflush with streptokinase. Transplantation 2003;75:449-53.

69. Belzer FO, Kountz SL. Preservation and transplantation of human cadaver kidneys: a two-year experience. Ann Surg 1970;172:394-404.

70. Belzer FO, Reed TW, Pryor JP, Kountz SL, Dunphy JE. Cause of renal injury in kidneys obtained from cadaver donors. Surg Gynecol Obstet 1970;130:467-77.

71. Kootstra G, van Hooff JP. [In-situ preservation of kidneys of 'non-heart-beating' donors: a possible way to offset the shortage of donor kidneys]. Ned Tijdschr Geneeskd 1998;142:2838-43.

72. Dittrich S, Groneberg DA, von Loeper J, Lippek F, Hegemann O, Grosse-Siestrup C, et al. Influence of cold storage on renal ischemia reperfusion injury after non-heart-beating donor explantation. Nephron Exp Nephrol 2004;96:e97-102.

73. Brasile L, Stubenitsky BM, Booster MH, Arenada D, Haisch C, Kootstra G. Hypothermia--a limiting factor in using warm ischemically damaged kidneys. Am J Transplant 2001;1:316-20.

74. Ojo AO, Wolfe RA, Held PJ, Port FK, Schmouder RL. Delayed graft function: risk factors and implications for renal allograft survival. Transplantation 1997;63:968-74.

75. Salahudeen AK, Haider N, May W. Cold ischemia and the reduced long-term survival of cadaveric renal allografts. Kidney Int 2004;65:713-8.

76. Quiroga I, McShane P, Koo DD, Gray D, Friend PJ, Fuggle S, et al. Major effects of delayed graft function and cold ischaemia time on renal allograft survival. Nephrol Dial Transplant 2006;21: 1689-96.

77. Giblin L, O'Kelly P, Little D, Hickey D, Donohue J, Walshe JJ, et al. A comparison of long-term graft survival rates between the first and second donor kidney transplanted--the effect of a longer cold ischaemic time for the second kidney. Am J Transplant 2005;5:1071-5.

78. Peters TG, Shaver TR, Ames JEt, Santiago-Delpin EA, Jones KW, Blanton JW. Cold ischemia and outcome in 17,937 cadaveric kidney transplants. Transplantation 1995;59:191-6.

79. Opelz G, Dohler B. Multicenter analysis of kidney preservation. Transplantation 2007;83:247-53.

80. Yarlagadda SG, Coca SG, Formica RN, Jr., Poggio ED, Parikh CR. Association between delayed graft function and allograft and patient survival: a systematic review and meta-analysis. Nephrol Dial Transplant 2009;24:1039-47.

81. Summers DM, Johnson RJ, Hudson A, Collett D, Watson CJ, Bradley JA. Effect of donor age and cold storage time on outcome in recipients of kidneys donated after circulatory death in the UK: a cohort study. Lancet. 2012;381:727-34.

82. Ploeg RJ, van Bockel JH, Langendijk PT, Groenewegen M, van der Woude FJ, Persijn GG, et al. Effect of preservation solution on results of cadaveric kidney transplantation. The European Multicentre Study Group. Lancet 1992;340:129-37.

83. Belzer FO, Ashby BS, Dunphy JE. 24-hour and 72-hour preservation of canine kidneys. Lancet 1967;2:536-8.

84. St Peter SD, Imber CJ, Friend PJ. Liver and kidney preservation by perfusion. Lancet 2002;359:604-13.

85. Wight JP, Chilcott JB, Holmes MW, Brewer N. Pulsatile machine perfusion vs. cold storage of kidneys for transplantation: a rapid and systematic review. Clin Transplant 2003;17:293-307.

86. Schold JD, Kaplan B, Howard RJ, Reed AI, Foley DP, Meier-Kriesche HU. Are we frozen in time? Analysis of the utilization and efficacy of pulsatile perfusion in renal transplantation. Am J Transplant 2005;5:1681-8.

87. Moers C, Smits JM, Maathuis MH, Treckmann J, van Gelder F, Napieralski BP, et al. Machine perfusion or cold storage in deceased-donor kidney transplantation. N Engl J Med 2009;360:7-19.

88. Kootstra G. The asystolic, or non-heartbeating, donor. Transplantation 1997;63:917-21.

89. Balupuri S, Mantle D, Mohamed M, Shenton B, Gok M, Soomro N, et al. Machine perfusion and viability assessment of non-heart-beating donor kidneys-a single-centre result. Transplant Proc 2001; 33:1119-20.

90. Brook NR, Knight AJ, Nicholson ML. Intra-renal resistance reflects warm ischaemic damage, and is further increased by static cold storage: a model of non-heart-beating donor kidneys. Med Sci Monit 2003;9:BR271-5.

91. Daemen JH, Heineman E, Kootstra G. Viability assessment of non-heart-beating donor kidneys during machine preservation. Transplant Proc 1995;27:2906-7; discussion 7-8. 
92. Daemen JW, Oomen AP, Janssen MA, van de Schoot L, van Kreel BK, Heineman E, et al. Glutathione Stransferase as predictor of functional outcome in transplantation of machine-preserved non-heartbeating donor kidneys. Transplantation 1997;63:89-93.

93. Gok MA, Pelsers M, Glatz JF, Bhatti AA, Shenton BK, Peaston R, et al. Comparison of perfusate activities of glutathione $\mathrm{S}$-transferase, alanine aminopeptidase and fatty acid binding protein in the assessment of non-heart-beating donor kidneys. Ann Clin Biochem 2003;40:252-8.

94. de Vries EE, Hoogland ERP, Winkens B, Snoeijs MG, van Heurn LWE. Renovascular resistance of machine perfused DCD kidneys is associated with primary non-function. Am J Transplant. 2011; 11:2685-91.

95. Mozes MF, Skolek RB, Korf BC. Use of perfusion parameters in predicting outcomes of machinepreserved kidneys. Transplant Proc 2005;37:350-1.

96. Nyberg SL, Matas AJ, Kremers WK, Thostenson JD, Larson TS, Prieto M, et al. Improved scoring system to assess adult donors for cadaver renal transplantation. Am J Transplant 2003;3:715-21.

97. Matsuno N, Konno O, Mejit A, Jyojima Y, Akashi I, Nakamura Y, et al. Application of machine perfusion preservation as a viability test for marginal kidney graft. Transplantation 2006;82:1425-8.

98. Sung RS, Christensen LL, Leichtman AB, Greenstein SM, Distant DA, Wynn JJ, et al. Determinants of discard of expanded criteria donor kidneys: impact of biopsy and machine perfusion. Am J Transplant 2008;8:783-92.

99. Sonnenday CJ, Cooper M, Kraus E, Gage F, Handley C, Montgomery RA. The hazards of basing acceptance of cadaveric renal allografts on pulsatile perfusion parameters alone. Transplantation 2003;75:2029-33.

100. Guarrera JV, Goldstein MJ, Samstein B, Henry S, Reverte C, Arrington B, et al. 'When good kidneys pump badly': outcomes of deceased donor renal allografts with poor pulsatile perfusion characteristics. Transpl Int 2009;23:444-6.

101. Jochmans I, Moers C, Smits JM, Leuvenink HG, Treckmann J, Paul A, et al. The prognostic value of renal resistance during hypothermic machine perfusion of deceased donor kidneys. Am J Transplant 2011; 11:2214-20.

102. Bagul A, Hosgood SA, Kaushik M, Kay MD, Waller HL, Nicholson ML. Experimental renal preservation by normothermic resuscitation perfusion with autologous blood. Br J Surg 2008;95:111-8.

103. Balupuri S, Buckley P, Snowden C, Mustafa M, Sen B, Griffiths P, et al. The trouble with kidneys derived from the non heart-beating donor: a single center 10-year experience. Transplantation 2000;69:842-6.

104. Gok MA, Pelsers M, Glatz JF, Shenton BK, Peaston R, Cornell C, et al. Use of two biomarkers of renal ischemia to assess machine-perfused non-heart-beating donor kidneys. Clin Chem 2003;49:172-5.

105. de Vries B, Snoeijs MG, von Bonsdorff L, Ernest van Heurn LW, Parkkinen J, Buurman WA. Redox-active iron released during machine perfusion predicts viability of ischemically injured deceased donor kidneys. Am J Transplant 2006;6:2686-93.

106. Gok MA, Pelzers M, Glatz JF, Shenton BK, Buckley PE, Peaston R, et al. Do tissue damage biomarkers used to assess machine-perfused NHBD kidneys predict long-term renal function post-transplant? Clin Chim Acta 2003;338:33-43.

107. Moers C, Varnav OC, van Heurn E, Jochmans I, Kirste GR, Rahmel A, et al. The value of machine perfusion perfusate biomarkers for predicting kidney transplant outcome. Transplantation. 2010;90: 966-73..

108. Kievit JK, Nederstigt AP, Oomen AP, Janssen MA, Schoot L, Kootstra G. Release of alpha-glutathione Stransferase (alpha GST) and pi-glutathione S-transferase (pi GST) from ischemic damaged kidneys into the machine perfusate--relevance to viability assessment. Transplant Proc 1997;29:3591-3.

109. Krivitski NM. Theory and validation of access flow measurement by dilution technique during hemodialysis. Kidney Int 1995;48:244-50.

110. Krivitski NM, Kislukhin VV, Snyder JW, MacGibbon DR, Kuznetsova OA, Reasons AM, et al. In vivo measurement of hemodialyzer fiber bundle volume: theory and validation. Kidney Int 1998;54: 1751-8.

111. Krivitski NM. Novel method to measure access flow during hemodialysis by ultrasound velocity dilution technique. Asaio J 1995;41:M741-5.

112. Perico N, Cattaneo D, Sayegh MH, Remuzzi G. Delayed graft function in kidney transplantation. Lancet 2004;364:1814-27. 
113. Schrier RW, Wang W, Poole B, Mitra A. Acute renal failure: definitions, diagnosis, pathogenesis, and therapy. J Clin Invest 2004;114:5-14.

114. Thadhani R, Pascual M, Bonventre JV. Acute renal failure. N Engl J Med 1996;334:1448-60.

115. Nankivell BJ, Chapman JR. Chronic allograft nephropathy: current concepts and future directions. Transplantation 2006;81:643-54.

116. Rouschop KM, Leemans JC. Ischemia-reperfusion treatment: opportunities point to modulation of the inflammatory response. Kidney Int 2008;73:1333-5.

117. Freitas MC, Uchida Y, Lassman C, Danovitch GM, Busuttil RW, Kupiec-Weglinski JW. Type I interferon pathway mediates renal ischemia/reperfusion injury. Transplantation 2011;92:131-8.

118. Brezis M, Rosen S. Hypoxia of the renal medulla--its implications for disease. N Engl J Med 1995; 332:647-55.

119. Brezis M, Rosen S, Silva P, Epstein FH. Selective vulnerability of the medullary thick ascending limb to anoxia in the isolated perfused rat kidney. J Clin Invest 1984;73:182-90.

120. Ruegg CE, Mandel L. Bulk isolation of renal PCT and PST. II. Differential responses to anoxia or hypoxia. Am J Physiol 1990;259:F176-85.

121. Chou SY, Porush JG, Faubert PF. Renal medullary circulation: hormonal control. Kidney Int 1990;37: 1-13.

122. Aydin Z, van Zonneveld AJ, de Fijter JW, Rabelink TJ. New horizons in prevention and treatment of ischaemic injury to kidney transplants. Nephrol Dial Transplant 2007;22:342-6.

123. Dujardin M, Sourbron S, Luypaert R, Verbeelen D, Stadnik T. Quantification of renal perfusion and function on a voxel-by-voxel basis: a feasibility study. Magn Reson Med 2005;54:841-9.

124. Michaely HJ, Sourbron S, Dietrich O, Attenberger U, Reiser MF, Schoenberg SO. Functional renal MR imaging: an overview. Abdom Imaging 2007;32:758-71

125. Sourbron SP, Michaely HJ, Reiser MF, Schoenberg SO. MRI-measurement of perfusion and glomerular filtration in the human kidney with a separable compartment model. Invest Radiol 2008;43:40-8. 


\section{ABSTRACT}

It has been shown that kidney transplantation results in superior life expectancy and quality of life compared with dialysis treatment for patients with end stage renal disease. However, kidney transplantation in children differs in many aspects from adult kidney transplantation. This review focuses on specific issues of surgical care associated with kidney transplantation in children, including timing of transplantation, technical considerations, patient and graft survival, growth retardation and post-transplant malignancy. At the same time, there is a large discrepancy between the number of available donor kidneys and the number of patients on the waiting list for kidney transplantation. There is a general reluctance to use pediatric donor kidneys, because of relatively frequent complications such as graft thrombosis and early graft failure. We review the specific aspects of kidney transplantation from pediatric donors such as the incidence of graft thrombosis, hyperfiltration injury and 'en bloc' transplantation of two kidneys from one donor with an excellent long-term outcome, which is comparable with adult donor kidney transplantation. We also discuss the potential use of pediatric non-heart-beating donor kidneys, from donors whose heart stopped beating with the preservation techniques used. 


\section{INTRODUCTION}

Kidney transplantation is the treatment of choice in children with end stage renal disease (ESRD) with long-term benefits in patient survival and quality of life compared with dialysis. In children, kidney transplantation is associated with a number of specific problems such as a higher chance of graft failure, post transplant malignancy, growth retardation, and it may be a technical challenge to transplant a relatively large adult size kidney into a small pediatric abdominal cavity. These factors play an important role to decide at which age children with ESRD are preferably transplanted. Specific aspects and the outcome of kidney transplantation in the pediatric age group are addressed.

There is a large discrepancy between the number of available donor kidneys and the number of patients on the waiting list for kidney transplantation. To expand the donor pool, organs from marginal donors are increasingly used including organs from older donors and non-heart-beating (NHB) donors, donors who do not meet the brain death criteria but die after cardiac arrest. Kidneys from pediatric donors may also be suitable for transplantation, including pediatric kidneys from donors who meet the brain death criteria and kidneys from NHB donors. Special issues of pediatric organ donation are discussed.

\section{TIMING}

There is no absolute minimum age for pediatric kidney transplantation. Before 1980, infants and young children were only rarely transplanted because the relatively high risk of early graft loss and the high mortality which exceeded $20 \%$ in some series of children in this age group ${ }^{1,2}$. However, more recently the results of renal transplantation in children have improved so that even infants with ESRD may be suitable candidates for renal transplantation. Many centers still prefer an age above 2 years and a weight above $15 \mathrm{~kg}$, but infants aged 6 months and weighing $<5 \mathrm{~kg}$ have been successfully transplanted ${ }^{3}$.

One of the potential limitations for renal transplantation in children is the size of the donor kidney. In the United States more than $50 \%$ of the kidneys transplanted in children are from living, thus adult donors ${ }^{4}$. In the Eurotransplant region (Austria, Belgium, Croatia, Germany, Luxemburg, the Netherlands, Slovenia), this percentage is $20 \%$, but is increasing ${ }^{5}$. Transplantation of kidneys from donors younger than 5 years of age are preferably avoided in children as the risk of early graft failure is increased ${ }^{6}$. Therefore, adult size donor kidneys are almost universally used. Adult sized kidneys are placed into the pediatric abdominal cavity, usually without significant tension or respiratory compromise if the abdomen is closed. 
A second potential disadvantage of kidney transplantation in infants and young children is the small blood volume and low cardiac output. These may be inadequate to guarantee sufficient perfusion of an adult size kidney, which is used to the higher blood pressure of the donor. Particularly ischemically damaged grafts may easily fail if the early post transplant blood pressure is too low ${ }^{7}$.

Delay of kidney transplantation is associated with the loss of precious years of growth potential ${ }^{3}$. Furthermore, transplanted children have a superior quality of life and avoid complications, which are associated with dialysis such as dialysis peritonitis or venous access problems. The optimal moment to transplant a child with ESRD is just before dialysis becomes necessary, if there is a donor available. With a goal to transplant an adult size kidney the general approach of the Stanford group is to perform the transplantation in children of approximately $10 \mathrm{~kg}$ and at least 6 months of age ${ }^{3}$. In children who do not tolerate dialysis or do not grow, transplantation can be done at lesser weight.

\section{TECHNICAL CONSIDERATIONS}

In adults the most common approach to transplant a kidney is extraperitoneally with an incision above the left or right groin. Kidneys are anastomosed with the common or external iliac artery and vein. In children this approach carries two disadvantages. First, there is a size mismatch between the available extraperitoneal space and the adult sized donor kidney, and, secondly, the recipient artery may be small compared with the artery of the graft, which makes the vascular anastomosis more difficult and may jeopardise the blood pressure and blood flow that is required for the donor kidney to survive. Therefore kidney transplantation in children below the age of 5 years is generally done through a midline incision and the graft is placed into the peritoneal cavity. The donor vein is anastomosed with the caval vein of the recipient, which is clamped during the venous anastomosis. Immediately after the venous anastomosis has been completed, the clamp on the caval vein is released and the renal vein is selectively clamped with a bull dog. Next, the donor artery is either anastomosed with the distal aorta, to obtain the best arterial inflow, or with one of the common iliac arteries. The latter avoids a complete occlusion of the aorta, which is associated with temporary acidosis of both lower extremities. The decision which artery is chosen depends on the size of the arteries and the position of the renal graft. The cold graft is placed in the preferred position. The donor vessels are often amputated and may be spatulated to ensure a wide anastomosis and to avoid kinking, which may lead to impaired blood flow and to non-function of the graft. It is questionable if the graft has to be additionally cooled during the anastomosis time. It often requires a longer period of time to make an anastomosis in children than in adults, but given the size of the 
kidney and the absence of flow, the warming up is probably slow and unless there are technical difficulties the anastomosis time is not a risk factor for graft failure.

The ureter of an adult size kidney is long and wide enough to obtain a wide ureterbladder anastomosis. The ureter is cut and shortened to obtain the best vascularisation of the anastomosis. Interrupted sutures of a spatulated ureter further minimise the risk of ureteral stenosis. Temporary ureteral stenting may reduce the risk of ureteral stenosis, but is associated with a higher risk of urinary infection. This can, however, be successfully treated with antibiotics ${ }^{8}$. A further disadvantage of a stent is the need to remove it some weeks after transplantation.

Particularly in young children one of the main causes of ESRD is obstructive uropathy. Outflow obstruction, small capacity or poor function of the bladder predisposes to vesicoureteral reflux of the transplanted kidney. In these patients an antireflux procedure is imperative. There are different intra- and extravesical techniques to make a ureter-bladder anastomosis; the choice depends on the anatomy and previous surgery.

\section{PATIENT AND GRAFT SURVIVAL}

The life expectancy of children with ESRD and a renal transplantation is an estimated 20 to 25 years shorter than of the normal population ${ }^{9}$. The high mortality in children is caused by associated cardiovascular disease and less frequently by infection ${ }^{10,11}$. Superior long-term results of kidney transplantation and prolonged immunosuppressive treatment may increase the future incidence of malignancy as important cause of transplant recipient death. It should be considered that the relatively poor long-term survival of children with ESRD is based on the relatively few and retrospective results. The results of pediatric transplantation and immunosuppression have improved substantially over the last decades with unknown effects on late survival. Presently, the 5-year patient survival after transplantation of children with ESRD is higher than $95 \%$ with only minimal difference between recipients of living and deceased donor grafts.

Graft survival following pediatric transplantation is highly dependent on donor source. Living donor recipients have better graft survival than deceased donor recipients. In the United States, Eurotransplant region and centers in the United kingdom the 5-year graft survival of living donor recipients is between 80 and $90 \%{ }^{5,12,13}$. For deceased donor kidney recipients the 5 -year graft survival is $10-20 \%$ less than for living donor grafts depending on other risk factors such as recipient age, dialysis and the cause of ESRD.

The most common cause of graft failure in young recipients in the first year after transplantation is graft thrombosis. This complication results in almost universal graft 
loss $^{14}$. Its incidence in children is between 2 and 3\%, but may be as high as $10 \%$ in children younger than 5 years ${ }^{15}$. The risk of graft thrombosis is further associated with previous treatment of peritoneal dialysis, deceased donor source, prior transplantation and prolonged cold ischemia time. The use of the interleukin (IL)-2 receptor antagonists basiliximab and daclizumab as induction immunosuppressive therapy decreases the risk of graft failure due to thrombosis compared with other immunosuppression as OKT ${ }^{15}$. Acute rejection is a second important cause for early graft loss and depends amongst others on HLA-matching and the immunosuppressive regimen.

Despite the higher incidence of graft thrombosis and the inferior graft survival in the first year after transplantation, children aged 5 years or less have an excellent longterm graft outcome. Survival curves show a long-term graft survival advantage in recipients aged 5 years or less compared with older children and adolescents. This advantage is shown clearly by the United Network for Organ Sharing (UNOS) data with an estimated graft half-life of more than 26 years in living graft recipients ${ }^{16}$. In contrast, the half life of a living donor graft in adolescents is below 10 years which is less than the graft survival in children aged 6-12 years and adults. This relatively poor outcome is caused by long-term adverse events rather than events in the first year after transplantation as the initial results of adolescent transplantation are excellent ${ }^{17}$. Poor compliance to immunosuppression is only partly responsible for the high incidence of graft loss ${ }^{18}$. In adolescents rejection reversal outcomes are worse than in other age groups which supports the opinion that more vigorous immune response which decreases at older age may play an important role ${ }^{4,19,20}$.

The most important cause of late graft failure is chronic rejection that accounts for almost one third of the graft losses in a series of 7123 pediatric transplant recipients ${ }^{21}$. Acute rejection is a strong correlate and risk factor for chronic rejection graft loss. Prior to transplantation and, in the United States, African American recipient are additional risk factors ${ }^{21}$. Long-term graft survival is better in non-dialysed than in previously dialysed patients and largely depends on the duration of dialysis ${ }^{22-24}$. In a group of 1113 European pediatric kidney transplant recipients the relative risk of graft failure increased with $67 \%$ in children with more than 2 years of dialysis compared with children with a pre-emptive transplantation ${ }^{5}$. Long-term graft survival further depends on the underlying disease, which prevalence is listed in Table 2.1. Structural abnormalities such as reflux, posterior urethral valves and congenital kidney disease have a better outcome than ESRD caused by focal segmental glomerulosclerosis (FSGS), membranoproliferative glomerulonephritis type II (MPGN II), or haemolytic uremic syndrome (HUS) $)^{13,25,26}$. In recipients with the original diagnosis FSGS, the disease recurs in $30-40 \%$ after transplantation. The percentage is adversely affected by young age at presentation and rapid progression to ESRD. In half of the patients with 
recurrence the graft fails. Therefore, the 5 -year graft survival in recipients with FSGS is approximately $10 \%$ less than in other pediatric transplant recipients. MPGN is a rare kidney disease with complement deposits within the glomerular basement membrane and usually progresses to kidney failure. After transplantation it recurs in most patients with a significantly worse 5-year graft survival than other pediatric transplant recipients: $50 \%$ versus $74 \%$, respectively ${ }^{26}$. Recurrence of HUS is reported in $50 \%$ to $70 \%$ of the transplanted patients and is particularly high in atypical, no diarrhoeal HUS. Moreover, there is a relatively very high incidence of early artery or vein thrombosis so that in $50 \%$ of patients with HUS graft loss will occur within a year after transplantation $^{27}$.

Residual voiding disorders in patients with neuropathies may also jeopardise late graft function due to high pressure reflux or recurrent urinary tract infection ${ }^{28}$. However, bladder augmentation or urinary diversion prior to transplantation reduces the risk of graft loss so that voiding disorders hardly influence eventual graft function or graft survival.

Table 2.1 Primary kidney disease of transplanted children with end stage renal disease.

\begin{tabular}{lc}
\hline End stage renal disease & Prevalence \\
\hline Structural and cystic disease & $53-57 \%$ \\
Glomerulonephritis & $22-27 \%$ \\
Metabolic disease & $3-5 \%$ \\
Congenital nephritic syndrome & $3-4 \%$ \\
Other & $6-10 \%$ \\
Unknown & $3-8 \%$ \\
\hline
\end{tabular}

\section{GROWTH}

Growth retardation is an important side effect of chronic renal insufficiency. It is caused by nutritional deficiencies, metabolic disturbances and effects on the growth hormone axis. Dialysis does not improve growth velocity or pubertal development ${ }^{29}$. Despite the pre-transplant use of growth hormone, the majority of young adults with ESRD have a height below -2SD score ${ }^{30}$.

Renal transplantation may increase growth velocity in children with ESRD with eventual increase in the adult height. Factors that influence catch-up growth are age and height at the moment of renal failure, the moment of transplantation, level of transplant function and dose and frequency of corticosteroid treatment ${ }^{31,32}$. Children younger than 4 years have the largest benefits from transplantation. Their growth velocity increases with more than $3 \mathrm{~cm} /$ year compared with children on dialysis ${ }^{33}$. In children who receive a transplant post-puberty, acceleration of growth velocity and 
adult height are much less than in children who are transplanted at younger age. Despite the positive influence of renal transplantation on growth velocity, the final adult height of children with ESRD remains less than of the normal population.

Corticosteroids, given after transplantation, have a negative influence on longitudinal growth that can be diminished by steroid-free immunosuppression or by the reduction of the frequency of administration from once daily to alternate daily ${ }^{34,35}$. The post-transplantation administration of growth hormone improves growth velocity in both pre-pubertal and pubertal children without effect on renal function or increase of the occurrence of acute rejections ${ }^{36,37}$.

\section{POST TRANSPLANT MALIGNANCY}

Malignancy is a major cause of post-transplant mortality and morbidity. With the increased post-transplant survival its incidence has increased in the last decades and the mortality in adult renal transplant recipients may be as high as $20 \%, 10$ years after transplantation $^{38}$. In pediatric transplant recipients the incidence of malignancy is lower but the number of transplant patients with long-term follow-up is relatively small and the incidence is rising ${ }^{39}$. In children with ESRD the probability of developing a malignancy within 25 years after renal replacement therapy is estimated at $17 \%$.

The majority of malignancies in renal pediatric transplant patients are skin cancers (40-50\%), predominantly squamous cell carcinoma, and post-transplant lymphoproliferative disorders (PTLD) in approximately $30 \%$ of the transplanted patients. Other relatively common malignancies include gynecological tumors and Kaposi's sarcoma. Post transplant malignancy is related to the cumulative doses of immunosuppression. The immune surveillance is decreased while the depressed immune system is stimulated by antigens from the transplanted tissue or organ, repeated infections and possible blood transfusions ${ }^{40}$. PTLD is promoted by a primary infection with Epstein Barr virus (EBV) infection, which may be transferred from an EBV positive donor organ to an EBV negative recipient. Most people are already infected with EBV during childhood (or at birth, from mother to child), hardly causing any symptoms. Therefore, the incidence of PTLD is greater in EBV-seronegative patients. However, EBV can also become more pathogenic in previously infected asymptomatic patients. The risk of PTLD depends on the patients age, on the immunosuppressive regimen and is greatest in the first year post-transplantation.

The risk of malignancy can be reduced by appropriate low dosing of immunosuppressive medication and by the use of less carcinogenic immunosuppressive agents such as sirolimus. Antiviral therapy to reduce PTLD in children after EBV-positive solid-organ transplantation seems logical but its value to prevent malignancy has not been proven. The treatment of post-transplantation malignancies 
includes local excision of skin cancer and anti-CD 20 antibodies or chemotherapy for refractory PTLD. Standard chemotherapy for non-Hodgkin lymphoma shows a high percentage of complete remission, but approximately $30 \%$ of the children still die within 2 years ${ }^{41}$.

\section{PEDIATRIC DONORS}

The first pediatric donor kidney transplantation was described in 1964. In the following decade, the number of pediatric donor kidneys increased but the quality of the organs was generally considered as poor with a relatively short graft survival and a high incidence of complications. In 1974, it was concluded from an analysis of the American College of Surgeons/ National Institutes of Health Transplant Registry (ACS/NIH) database that these kidneys had an inferior but, given a shortage of donor organs, acceptable level of function in adults ${ }^{42}$. Since then, improved transplantation techniques and superior immunosuppression have improved the results of transplantation from pediatric donor kidneys, so that, apart from kidneys from donors younger than 5 years, this group of kidneys is increasingly seen as a valuable expansion of the donor pool. There is still reluctance to transplant donor kidneys from children aged $<5$ years. The multisystem failure towards the end of life due to extensive medical treatment for young patients, the technical surgical challenge, the high incidence of arterial and venous thrombosis, the relatively high incidence of early rejection and potential hyperfiltration damage to the transplanted kidney are risk factors for graft failure or may compromise graft function ${ }^{6,43-46}$. Moreover, the renal mass of the small pediatric donor kidney may be insufficient to meet the metabolic demands of the larger recipient. There is a strong correlation between initial renal mass and the eventual graft function in adults ${ }^{47}$. On the other hand, young donor kidneys exhibit better capacity to adapt to the recipient organism. They are able to increase glomerular filtration, caused by a suggested reserve capacity for growth or compensatory hypertrophy ${ }^{48}$.

The number of available pediatric donor kidneys has decreased over the last two decades. Data from the Organ Procurement and Transplantation Network (OPTN) in the United States shows that the percentage of the available pediatric donor kidneys from the total number of deceased donor kidneys has decreased from $27 \%$ in 1988 , to $19 \%$ in 1998 and to $10 \%$ in 2008 (donor age 0-17 years) ${ }^{12}$. Also, in the Eurotransplant region the proportion of pediatric donors has decreased from $9 \%$ in 1994 to $3.6 \%$ in 2007 (donor age 0-15 years) ${ }^{49}$. The distribution within this pediatric donor cohort remains the same with the vast majority of donors between the ages 11 and 18 years ${ }^{12}$. The reason of the relatively decreased number of pediatric donors remains unknown, but extension of the adult donor criteria with donors of old age and non- 
heart beating (NHB) donors, and safety measures for children such as helmets for cyclists and seat belts in cars, with consequently a reduction of the number of brain dead children, may play an important role.

\section{HEART BEATING AND NHB DONOR KIDNEYS}

The majority of the pediatric organ donors are organs from heart beating (HB) donors, donors after brain death ${ }^{12}$. The organs are procured from a ventilated patient with intact circulation, so that the warm ischemia time of the donor organs is very limited. Depending on the age of the donor, kidneys are procured as single kidneys or 'en bloc', so that both donor kidneys can be used in one recipient.

The minority of pediatric donor kidneys are obtained from NHB donors, donors who die after cardiac arrest. NHB donation is applied when brain death cannot be assessed or if the criteria for brain death are not met. Owing to the shortage of donor organs, NHB donation has been popularized over the last decade. Presently, $10-20 \%$ of the adult donor kidneys in selected centers in the United States are from NHB donors; this percentage is increasing rapidly. In the Netherlands this percentage has even mounted to $50 \%$ for adults. Although implementation of NHB donor programs within adult hospitals has substantially increased over the last few years, advancement in children's hospitals lags behind. More attention is drawn to find ways to implement protocols for pediatric NHB donation in the critical care setting of many centers. The percentage of pediatric NHB donors of the total number of pediatric donors in the United States has increased from $<1 \%$ in 1997 to $8 \%$ in $2006^{12}$. In the Netherlands $20 \%$ of pediatric donor kidneys in the past 20 years has been from NHB donors ${ }^{49}$.

Non-heart-beating donors can be categorised in to four groups, which are listed in Table $2.2^{50}$. Donation after withdrawal from treatment (category 3 ), usually when ventilator support is discontinued in the intensive care unit (ICU), or after cardiac arrest in brain dead donors (category 4) are considered as 'controlled donation', while donation of patients who have died outside the hospital (category 1 ) or who die after failed resuscitation (category 2 ) are referred to as uncontrolled. In the latter two the inevitable period of warm ischemia after circulatory arrest is not exactly known so that the warm ischemic damage to the organs has to be estimated. To minimise warm ischemic damage to the organs it is essential to cool the organs as fast as possible. Different preservation techniques are possible. 
Table 2.2 The Maastricht Categories of NHB Donors.

\begin{tabular}{cl}
\hline Category & Description \\
\hline 1 & Dead on arrival \\
2 & Unsuccessful resuscitation \\
3 & Awaiting cardiac arrest \\
4 & Cardiac arrest while brain dead \\
\hline
\end{tabular}

\section{PRESERVATION TECHNIQUES}

In controlled donors treatment can be discontinued in the operating theatre or in the ICU.

When the heart has stopped beating, patient death is declared by an independent physician. After an obligatory no-touch period of 5 minutes without invasive actions to ensure irreversible brain damage that can be compared with brain death, a laparotomy can be performed to insert preservation catheters into one of the common iliac arteries or into the aorta. In this way, cold preservation fluid can be infused to preserve the organs. Next, the aorta is clamped below the diaphragm and the abdominal organs are additionally cooled by pouring cold saline into the peritoneal cavity. Patients who die in the ICU can be rushed to the operating theatres as soon as possible after death. It is essential that the procedure and the need for urgent preservation of the organs be carefully discussed with the parents or relatives.

In uncontrolled donors or if the parents are reluctant to a rush from the ICU, organs can be preserved at the bedside after the declaration of death with the help of a double-balloon triple-lumen (DBTL) catheter ${ }^{51}$. This catheter allows organ preservation with the help of a minimal surgical procedure. The aorta is occluded proximally and at the bifurcation and the organs with the origin between the balloons are cooled (Figure $2.1)^{52}$. A 16 Ch DBTL catheter is available for adults and adolescents with an intraballoon distance of $25 \mathrm{~cm}$ and a fully inflated balloon diameter of $40 \mathrm{~mm}$ (AJ6516, Porgès, France) and a smaller $12 \mathrm{Ch}$ catheter for children between 5 years and approximately 12 years of age, with an intra-balloon distance of $15 \mathrm{~cm}$ and a balloon diameter of $30 \mathrm{~mm}$ (61.630.12.080, Meddev, Holm, Germany). The choice for either catheter depends on the sex and the size of the child. The DBTL catheter is introduced into one of the femoral arteries through an arteriotomy. The abdominal balloon of the catheter is inflated with half of the maximum volume so that the balloon can be retracted until it hooks onto the aortic bifurcation. Subsequently, both the abdominal and the thoracic balloons are fully inflated and blood is drawn for chemistry, virological screening, and blood group typing. An infusion system is connected to the catheter and cold perfusate is infused until donor nephrectomy in the operating theatres. A Foley catheter into the femoral vein allows perfusate outflow. After the catheters have 
been fixed and the inguinal wound has been closed the parents or relatives have the opportunity to visit the deceased patient, before the patient goes to the operating theatre to procure the organs. According to Dutch legislation, in situ preservation is allowed before consent for donation is obtained from the relatives ${ }^{53}$. In case the relatives are not immediately available, this minimally invasive procedure ensures organ viability and empowers families with the opportunity to decide about donation $^{54}$.

A third method to preserve organs from NHB donors is to connect the donor to an extra corporeal membrane oxygenator (ECMO). This procedure is relatively complicated and has not been reported for children.

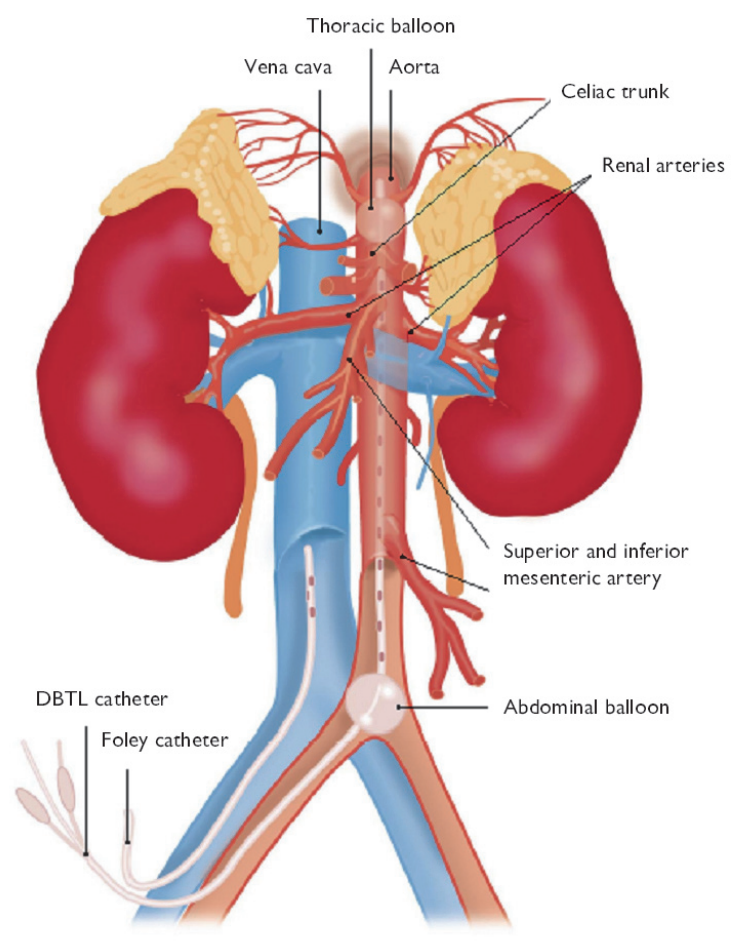

Figure 2.1 In situ preservation.

\section{GRAFT SURVIVAL}

Early graft survival of pediatric donor kidneys is slightly lower than for adult donor kidneys, particularly for kidneys from the youngest donors. This difference is to a large extent caused by graft thrombosis, which is reported in $3.1-12.5 \%$ of the cases ${ }^{6,55-58}$. In 
the majority of the recipients with graft thrombosis, it is present within a week after transplantation, but it can also occur in a later stage $e^{6}$. It requires a meticulous surgical technique to anastomose a relatively small artery or vein. The anastomosis is easier if an aortic donor patch is used for the anastomosis instead of using the small, usually spatulated renal artery itself with a subsequent reduction in graft thrombosis. Other possible causes of graft thrombosis include a difference in blood pressure and vessel size between the donor and the recipient with turbulent and inadequate perfusion of the graft, torsion of the kidney and progressive thrombosis of a blind end of the aorta in 'en bloc' transplanted double kidneys ${ }^{59}$.

Hyperfiltration, a consequence of the dissimilarity between donor and recipient weight, is one of the causes of late graft failure in recipients of pediatric donor kidneys. If the number of donor glomeruli is too small to filter the recipient's blood volume adequately, the graft adapts to the recipient's weight by hyperfiltration. This is invariably associated with the glomerular hypertrophy followed by glomerular sclerosis and progressive worsening of kidney function, eventually leading to exhaustion. Transplantation of a bigger nephron mass could prevent kidneys from hyperfiltration $^{48,60-62}$. One of the methods to prevent hyperfiltration in kidneys with a relatively small number of glomeruli such as kidneys from young children is by transplanting double grafts. This technique has been described in 1969 when a child received an 'en bloc' kidney graft from an anencephalic infant and which has functioned for more than 30 years ${ }^{63}$. 'En bloc' transplantation is increasingly used for kidneys from donors at young age with favourable results. Improved surgical techniques to transplant 'en bloc' kidneys have further enhanced pediatric kidney donor transplant survival. Age, kidney size, and donor weight are used to decide if donor kidneys should be transplanted as double grafts or as two single grafts for two different recipients including donor age $<1,<2,<3$ or $<5$ years, graft length $<6 \mathrm{~cm}$, and donor weight $<14 \mathrm{~kg}$ and $<21 \mathrm{~kg}^{55-57,64-69}$.

Early graft survival of pediatric donor transplants is slightly lower than of adult donor kidney transplants. An analysis of the UNOS in 12,838 patients shows a small but significant difference in graft survival between pediatric donors and adult donors in favour of the adult group. One and 5-year graft survival of 82 and $62 \%$ respectively, is reported after kidney transplantation from donors younger than 18 years and 84 and $62 \%$ after kidney transplantation from adult donors aged $18-50^{56,64}$. Kidneys from the youngest donors ( $0-5$ years) have lowest graft survival of 74 and $56 \%$ at 1 and 5 years $(n=2,198)$. A comparison of graft survival of 1175 single transplants from pediatric donors and 24,530 single kidney transplants using 'ideal' deceased kidney donors between age 19 and 36 years demonstrated that recipients of kidneys from pediatric donors were at a significantly increased risk for graft loss. On the other hand double 'en bloc' transplanted kidneys from the youngest donor group, have similar graft 
survival as ideal donors ${ }^{56,64}$. A limited number of relatively small series of pediatric donor kidneys even report a significantly better long-term outcome for 'en-bloc' transplanted double pediatric kidneys once they survive the early postoperative course with 5 -year survival rates of 76 and $82 \%{ }^{57,58}$. In these analyses survival is censored for early graft loss.

Little is known about the graft survival of NHB pediatric donor kidneys. Only a small series of 24 patients who received a pediatric NHB donor kidney shows excellent graft survival which is comparable with the results of transplantation of adult NHB donor kidneys ${ }^{65}$. 


\section{REFERENCES}

1. Kari JA, Romagnoli J, Duffy P, Fernando ON, Rees L, Trompeter RS. Renal transplantation in children under 5 years of age. Pediatr Nephrol. 1999;13:730-6.

2. Najarian JS, Frey DJ, Matas AJ, Gillingham KJ, So SS, Cook M, et al. Renal transplantation in infants. Ann Surg. 1990;212:353-65; discussion 66-7.

3. Salvatierra $\mathrm{O}, \mathrm{Jr}$., Millan $\mathrm{M}$, Concepcion W. Pediatric renal transplantation with considerations for successful outcomes. Semin Pediatr Surg. 2006;15:208-17.

4. Hwang AH, Cho YW, Cicciarelli J, Mentser M, Iwaki Y, Hardy BE. Risk factors for short- and long-term survival of primary cadaveric renal allografts in pediatric recipients: a UNOS analysis. Transplantation. 2005;80:466-70.

5. Cransberg K, Smits JM, Offner G, Nauta J, Persijn GG. Kidney transplantation without prior dialysis in children: the Eurotransplant experience. Am J Transplant. 2006;6:1858-64.

6. Singh A, Stablein D, Tejani A. Risk factors for vascular thrombosis in pediatric renal transplantation: a special report of the North American Pediatric Renal Transplant Cooperative Study. Transplantation. 1997;63:1263-7.

7. Snoeijs MG, Wiermans B, Christiaans MH, van Hooff JP, Timmerman BE, Schurink GW, et al. Recipient hemodynamics during non-heart-beating donor kidney transplantation are major predictors of primary nonfunction. Am J Transplant. 2007;7:1158-66.

8. Wilson $\mathrm{CH}$, Bhatti $\mathrm{AA}$, Rix DA, Manas $\mathrm{DM}$. Routine intraoperative stenting for renal transplant recipients. Transplantation. 2005;80:877-82.

9. Levey AS. Controlling the epidemic of cardiovascular disease in chronic renal disease: where do we start? Am J Kidney Dis. 1998;32(5 Suppl 3):S5-13.

10. Groothoff JW, Gruppen MP, Offringa M, Hutten J, Lilien MR, Van De Kar NJ, et al. Mortality and causes of death of end-stage renal disease in children: a Dutch cohort study. Kidney Int. 2002;61:621-9.

11. Oh J, Wunsch R, Turzer M, Bahner M, Raggi P, Querfeld $U$, et al. Advanced coronary and carotid arteriopathy in young adults with childhood-onset chronic renal failure. Circulation. 2002;106:100-5.

12. Magee JC, Krishnan SM, Benfield MR, Hsu DT, Shneider BL. Pediatric transplantation in the United States, 1997-2006. Am J Transplant. 2008;8:935-45.

13. Rees L, Shroff R, Hutchinson C, Fernando ON, Trompeter RS. Long-term outcome of paediatric renal transplantation: follow-up of 300 children from 1973 to 2000. Nephron Clin Pract. 2007;105:c68-76.

14. Smith JM, Stablein D, Singh A, Harmon W, McDonald RA. Decreased risk of renal allograft thrombosis associated with interleukin-2 receptor antagonists: a report of the NAPRTCS. Am J Transplant. 2006;6: 585-8.

15. McDonald RA, Smith JM, Stablein D, Harmon WE. Pretransplant peritoneal dialysis and graft thrombosis following pediatric kidney transplantation: a NAPRTCS report. Pediatr Transplant. 2003;7: 204-8.

16. Sarwal MM, Cecka JM, Millan MT, Salvatierra O, Jr. Adult-size kidneys without acute tubular necrosis provide exceedingly superior long-term graft outcomes for infants and small children: a single center and UNOS analysis. United Network for Organ Sharing. Transplantation. 2000;70:1728-36.

17. Magee JC, Bucuvalas JC, Farmer DG, Harmon WE, Hulbert-Shearon TE, Mendeloff EN. Pediatric transplantation. Am J Transplant. 2004;4 Suppl 9:54-71.

18. Cecka JM, Gjertson DW, Terasaki PI. Pediatric renal transplantation: a review of the UNOS data. United Network for Organ Sharing. Pediatr Transplant. 1997;1:55-64.

19. Smith JM, Ho PL, McDonald RA. Renal transplant outcomes in adolescents: a report of the North American Pediatric Renal Transplant Cooperative Study. Pediatr Transplant. 2002;6:493-9.

20. Burns EA, Leventhal EA. Aging, immunity, and cancer. Cancer Control. 2000;7:513-22.

21. Tejani A, Ho PL, Emmett L, Stablein DM. Reduction in acute rejections decreases chronic rejection graft failure in children: a report of the North American Pediatric Renal Transplant Cooperative Study (NAPRTCS). Am J Transplant. 2002;2:142-7.

22. Meier-Kriesche HU, Kaplan B. Waiting time on dialysis as the strongest modifiable risk factor for renal transplant outcomes: a paired donor kidney analysis. Transplantation. 2002;74:1377-81.

23. Cosio FG, Alamir A, Yim S, Pesavento TE, Falkenhain ME, Henry ML, et al. Patient survival after renal transplantation: I. The impact of dialysis pre-transplant. Kidney Int. 1998;53:767-72. 
24. Kennedy SE, Mackie FE, Rosenberg AR, McDonald SP. Waiting time and outcome of kidney transplantation in adolescents. Transplantation. 2006;82:1046-50.

25. Fine RN. Recurrence of nephrotic syndrome/focal segmental glomerulosclerosis following renal transplantation in children. Pediatr Nephrol. 2007;22:496-502.

26. Braun MC, Stablein DM, Hamiwka LA, Bell L, Bartosh SM, Strife CF. Recurrence of membranoproliferative glomerulonephritis type II in renal allografts: The North American Pediatric Renal Transplant Cooperative Study experience. J Am Soc Nephrol. 2005;16:2225-33.

27. Sellier-Leclerc AL, Fremeaux-Bacchi V, Dragon-Durey MA, Macher MA, Niaudet P, Guest G, et al. Differential impact of complement mutations on clinical characteristics in atypical hemolytic uremic syndrome. J Am Soc Nephrol. 2007;18:2392-400.

28. Adams J, Mehls O, Wiesel M. Pediatric renal transplantation and the dysfunctional bladder. Transpl Int. 2004;17:596-602.

29. Hutchings RH, Hickman R, Scribner BH. Chronic hemodialysis in a pre-adolescent. Pediatrics. 1966;37: 68-73.

30. Fine RN, Ho M, Tejani A. The contribution of renal transplantation to final adult height: a report of the North American Pediatric Renal Transplant Cooperative Study (NAPRTCS). Pediatr Nephrol. 2001;16: 951-6.

31. Qvist E, Marttinen E, Ronnholm K, Antikainen M, Jalanko H, Sipila I, et al. Growth after renal transplantation in infancy or early childhood. Pediatr Nephrol. 2002;17:438-43.

32. Tejani A, Fine R, Alexander S, Harmon W, Stablein D. Factors predictive of sustained growth in children after renal transplantation. The North American Pediatric Renal Transplant Cooperative Study. J Pediatr. 1993;122:397-402.

33. Turenne MN, Port FK, Strawderman RL, Ettenger RB, Alexander SR, Lewy JE, et al. Growth rates in pediatric dialysis patients and renal transplant recipients. Am J Kidney Dis. 1997;30:193-203.

34. Hokken-Koelega AC, de Muinck Keizer-Schrama SM, Drop SL. Effects of alternate-day or daily prednisone treatment on $\mathrm{GH}$ and cortisol levels in growth-retarded children after renal transplantation. J Pediatr Endocrinol. 1994;7:119-25.

35. Sarwal MM, Vidhun JR, Alexander SR, Satterwhite T, Millan M, Salvatierra O, Jr. Continued superior outcomes with modification and lengthened follow-up of a steroid-avoidance pilot with extended daclizumab induction in pediatric renal transplantation. Transplantation. 2003;76:1331-9.

36. Haffner D, Schaefer F, Nissel R, Wuhl E, Tonshoff B, Mehls O. Effect of growth hormone treatment on the adult height of children with chronic renal failure. German Study Group for Growth Hormone Treatment in Chronic Renal Failure. New Engl J Med. 2000;343:923-30.

37. Fine RN, Stablein D, Cohen AH, Tejani A, Kohaut E. Recombinant human growth hormone post-renal transplantation in children: a randomized controlled study of the NAPRTCS. Kidney Int. 2002;62: 688-96.

38. Penn I. Kaposi's sarcoma in transplant recipients. Transplantation. 1997;64:669-73.

39. Giessing M, Muller D, Winkelmann B, Roigas J, Loening SA. Kidney transplantation in children and adolescents. Transplant Proc. 2007;39:2197-201.

40. Buell JF, Gross TG, Thomas MJ, Neff G, Muthiah C, Alloway R, et al. Malignancy in pediatric transplant recipients. Semin Pediatr Surg. 2006;15:179-87.

41. Gross TG, Bucuvalas JC, Park JR, Greiner TC, Hinrich SH, Kaufman SS, et al. Low-dose chemotherapy for Epstein-Barr virus-positive post-transplantation lymphoproliferative disease in children after solid organ transplantation. J Clin Oncol. 2005;23:6481-8.

42. Merkel FK, Ing TS, Ahmadian Y, Lewy P, Ambruster K, Oyama J, et al. Transplantation in and of the young. J Urol. 1974;111:679-86.

43. Hayes JM, Novick AC, Streem SB, Hodge EE, Bretan PN, Graneto D, et al. The use of single pediatric cadaver kidneys for transplantation. Transplantation. 1988;45:106-10.

44. Nghiem DD. En bloc transplantation of kidneys from donors weighing less than $15 \mathrm{~kg}$. into adult recipients. J Urol. 1991;145:14-6.

45. Terasaki PI, Gjertson DW, Cecka JM, Takemoto S, Cho YW. Significance of the donor age effect on kidney transplants. Clin Transplant. 1997;11:366-72.

46. Modlin C, Novick AC, Goormastic M, Hodge E, Mastrioanni B, Myles J. Long-term results with single pediatric donor kidney transplants in adult recipients. J Urol. 1996;156:890-5. 
47. Kim YS, Moon JI, Kim DK, Kim SI, Park K. Ratio of donor kidney weight to recipient bodyweight as an index of graft function. Lancet. 2001;357:1180-1.

48. Feltran Lde S, Nogueira PC, Bocaletti AP, Christofalo DM, Ajzen SA, Pacheco-Silva A. Assessment of factors determining graft size in transplant of cadaver kidneys from child donors. Transplantation. 2005;79:1731-6.

49. NTS. NTS: Annual Reports 1994-2007. Dutch Transplant Foundation. 2007.

50. Kootstra G, Daemen JH, Oomen AP. Categories of non-heart-beating donors. Transplant Proc. 1995; 27:2893-4.

51. Snoeijs MG, Dekkers AJ, Buurman WA, van den Akker L, Welten RJ, Schurink GW, et al. In situ preservation of kidneys from donors after cardiac death: results and complications. Ann Surg. 2007; 246:844-52.

52. Kootstra G, van Hooff JP. [In-situ preservation of kidneys of 'non-heart-beating' donors: a possible way to offset the shortage of donor kidneys]. Ned Tijdschr Geneeskd. 1998;142:2838-43.

53. Kootstra G, van Heurn E. Non-heartbeating donation of kidneys for transplantation. Nat Clin Pract Nephrol. 2007;3:154-63.

54. Kowalski AE, Light JA, Ritchie WO, Sasaki TM, Callender CO, Gage F. A new approach for increasing the organ supply. Clin Transplant. 1996;10:653-7.

55. Dharnidharka VR, Stevens G, Howard RJ. En-bloc kidney transplantation in the United states: an analysis of united network of organ sharing (UNOS) data from 1987 to 2003. Am J Transplant. 2005;5: 1513-7.

56. Bresnahan BA, McBride MA, Cherikh WS, Hariharan S. Risk factors for renal allograft survival from pediatric cadaver donors: an analysis of united network for organ sharing data. Transplantation. 2001; 72:256-61.

57. Sureshkumar KK, Reddy CS, Nghiem DD, Sandroni SE, Carpenter BJ. Superiority of pediatric en bloc renal allografts over living donor kidneys: a long-term functional study. Transplantation. 2006;82: 348-53.

58. Sanchez-Fructuoso Al, Prats D, Perez-Contin MJ, Marques M, Torrente J, Conesa J, et al. Increasing the donor pool using en bloc pediatric kidneys for transplant. Transplantation. 2003;76:1180-4.

59. Mohanka R, Basu A, Shapiro R, Kayler LK. Single Versus En Bloc Kidney Transplantation From Pediatric Donors Less Than or Equal to $15 \mathrm{~kg}$. Transplantation. 2008;86:264-8.

60. Brenner BM, Meyer TW, Hostetter TH. Dietary protein intake and the progressive nature of kidney disease: the role of hemodynamically mediated glomerular injury in the pathogenesis of progressive glomerular sclerosis in aging, renal ablation, and intrinsic renal disease. New Engl J Med. 1982;307: 652-9.

61. Brenner BM, Lawler EV, Mackenzie HS. The hyperfiltration theory: a paradigm shift in nephrology. Kidney Int. 1996;49:1774-7.

62. Terasaki PI, Koyama H, Cecka JM, Gjertson DW. The hyperfiltration hypothesis in human renal transplantation. Transplantation. 1994;57:1450-4.

63. Martin LW, Gonzalez LL, West CD, Swartz RA, Sutorius DJ. Homotransplantation of both kidneys from an anencephalic monster to a 17 pound boy with Eagle-Barret syndrome. Surgery. 1969;66:603-7.

64. Pelletier SJ, Guidinger MK, Merion RM, Englesbe MJ, Wolfe RA, Magee JC, et al. Recovery and utilization of deceased donor kidneys from small pediatric donors. Am J Transplant. 2006;6:1646-52.

65. Naim MY, Hoehn KS, Hasz RD, White LS, Helfaer MA, Nelson RM. The Children's Hospital of Philadelphia's experience with donation after cardiac death. Crit Care Med. 2008;36:1729-33. 


\title{
Chapter 3
}

\section{Kidney donation from children}

\author{
after cardiac death
}

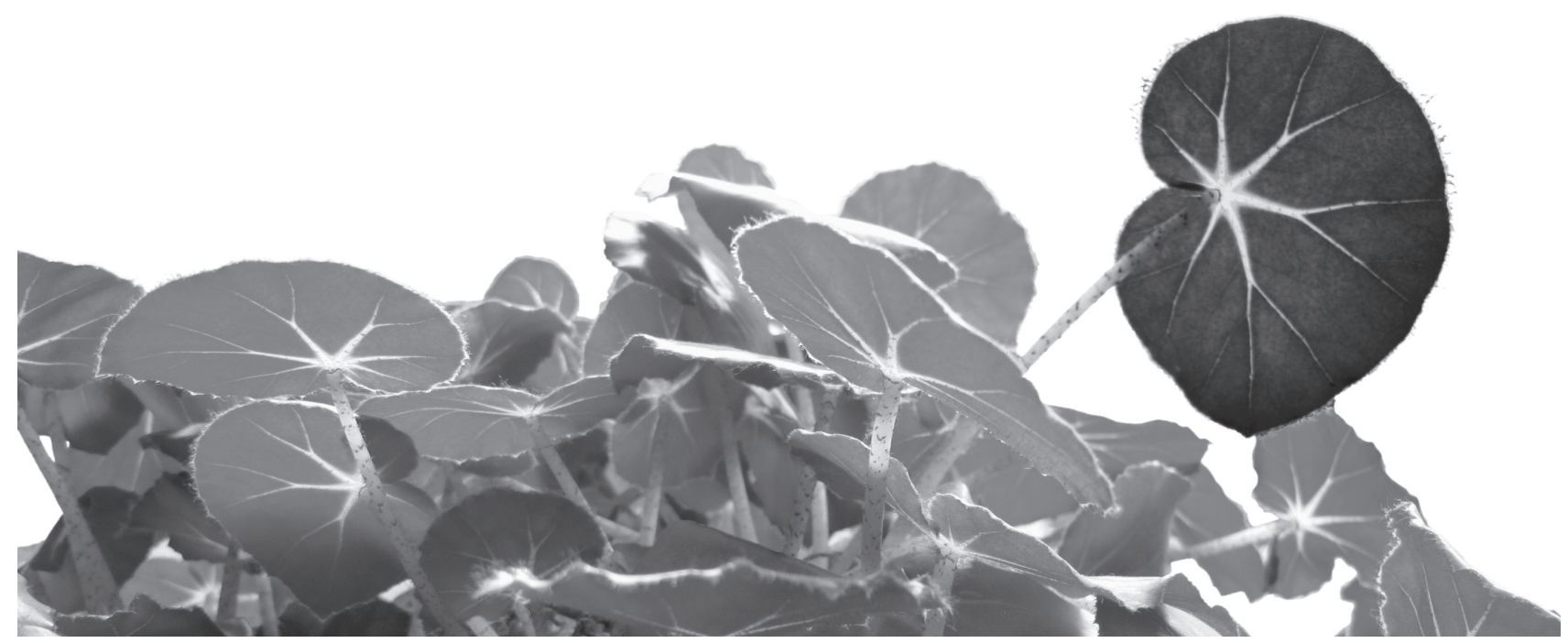

EE de Vries, MGJ Snoeijs, LWE van Heurn

Critical Care Medicine 2010;38:249-53 


\section{ABSTRACT}

Objective Pediatric kidney donation after cardiac death (DCD) is an underutilized donor source due to ethical concerns and limited knowledge of the outcome after transplantation. The purpose of this study was to report the Dutch experience of kidney transplantation using pediatric DCD.

Design Observational cohort study of a series of consecutive kidney transplantations from pediatric DCD from January 1995 to July 2006.

Setting Kidneys were procured in seven Dutch procurement areas.Patients Recipients of kidneys from donors after cardiac death aged 2-17 years.

Measurements and Main results. Prospectively collected data from the Dutch Organ Transplant Registry were analyzed. Donor, graft and recipient characteristics of all pediatric DCD kidney transplantations were documented. Recipients were followed-up for glomerular filtration rate, graft and patient survival. Eighty-eight patients were transplanted with 90 pediatric DCD kidneys, which was $31 \%$ of the total number of transplanted pediatric donor kidneys. In $77 \%$ of recipients, organs were procured from controlled donors, after withdrawal of supportive treatment. Of all donors, $9 \%$ was younger than 6 years of age. Two patients received their graft pre-emptively. In the others the incidence of immediate function (IF), delayed graft function (DGF) and primary non-function was $49 \%, 44 \%$ and $7 \%$, respectively. Warm ischemia time $\geq 25$ minutes was associated with PNF. Overall graft and patient survival 5 years after transplantation were $80 \%$ and $88 \%$, respectively. Graft survival after IF and DGF was not different.

Conclusions Kidneys from pediatric DCD are suitable for transplantation and may substantially expand the donor pool with good transplant outcome. 


\section{INTRODUCTION}

Renal transplantation is the treatment of choice for patients with end stage renal disease. There is a discrepancy between the number of patients waiting for kidney transplantation and the number of deceased organ donors available. The mortality in patients on dialysis awaiting transplantation is high ${ }^{1}$. Consequently, alternative donor sources are being explored. Implementation of donation after cardiac death (DCD) programs in the adults, have substantially increased the total number of kidney transplantations ${ }^{2}$. Although outcome of grafts from DCD donors is less favorable than the outcome of grafts from traditional donors, DCD donation has proven to be a valuable extension of the donor pool ${ }^{1,3-5}$. Compared to adult DCD kidney transplantation pediatric DCD kidney transplantation lags behind. There are ethical concerns about pediatric $D C D$, which may be responsible for absence of pediatric $D C D$ protocols ${ }^{6-8}$. Furthermore, the results of pediatric DCD kidney transplantation are relatively unknown ${ }^{9}$ and only small series have been reported ${ }^{10,11}$.

The purpose of this study was to review the Dutch experience with pediatric DCD kidney transplantation donors. We describe the setting in which DCD kidney donation in children has become part of acceptable end of life care for potential pediatric donors, parents and health care workers without compromising graft function after transplantation.

\section{MATERIALS AND METHODS}

\section{Study design}

All patients who received a pediatric DCD kidney in one of the seven Dutch transplant centers between January 1995 and July 2006 were included into the study. We examined patient and graft survival, searched for characteristics associated with primary non-function (PNF) and compared the outcome of grafts with immediate function (IF) and delayed graft function (DGF).

Donation after cardiac death DCD kidneys were procured from Maastricht category 2 and 3 donors (Table 3.1) . $^{12}$. Maastricht category 2 donation is usually performed in the emergency room after failed resuscitation with in situ preservation (ISP) ${ }^{13,14}$. Preservation measures were started after a period of 5-10 minutes 'no touch', the interval between cessation of cardiopulmonary resuscitation and the moment that preservation measures are started. 
Table $3.1 \quad$ Maastricht categories of donors after cardiac death.

\begin{tabular}{ll}
\hline Maastricht category & Description \\
\hline 1 & Dead on arrival (uncontrolled) \\
2 & Unsuccessful resuscitation (uncontrolled) \\
3 & Awaiting cardiac arrest (controlled) \\
4 & Cardiac arrest while brain death (controlled) \\
\hline
\end{tabular}

ISP is a method to preserve organs with a minimally invasive procedure. Vascular access is obtained via the femoral artery and a cut down in the groin. A double-balloon triple lumen (DBTL) catheter is inserted into the aorta. After inflation of the abdominal balloon with half of the maximum volume the catheter is withdrawn until the abdominal balloon hooks on the aortic bifurcation ${ }^{15}$. Subsequently, both the abdominal and thoracic balloon is fully inflated so that the thoracic balloon occludes the aorta proximally to the kidneys and the abdominal balloon at the aorta's bifurcation. The third lumen of the catheter is used to flush the organs with their arterial origin between the balloons (Figure 3.1). For adolescents, a $16 \mathrm{Ch}$ DBTL catheter with an balloon distance of $25 \mathrm{~cm}$ and a fully inflated balloon diameter of $40 \mathrm{~mm}$ (AJ6516, Porgès, France) is available. For children between approximately 5 and 12 years of age a smaller $12 \mathrm{Ch}$ catheter with a balloon distance of $15 \mathrm{~cm}$ and a balloon diameter of $30 \mathrm{~mm}$ (61.630.12.080, Meddev, Holm, Germany) can be used. An infusion system is connected to the catheter and cold perfusate infused until donor nephrectomy. To reduce the chance of capillary occlusion and warm ischemic damage to the organs heparin and streptokinase are administered at the initial flush after the aortic cannula has been inserted. A Foley catheter into the femoral vein allows perfusate outflow. Within two hours after starting ISP, the deceased is taken to the operating room.

In Maastricht category 3 donors, withdrawal of life support usually takes place in the intensive care unit (ICU), the common practice in the Netherlands. This is only possible if the ICU is in the vicinity of the operating room. After cardiac arrest and the no-touch period the patient is transported to the operating room where prepared surgical staff is waiting. Laparotomy is performed with direct cannulation of the aorta and preservation of the aorta is started. After flushing and cooling the organs are procured and either stored on melting ice or preserved on a machine. After procurement of organs, patients are taken back to the ICU where family can spend more time with their lost relative. In patients whose heart does not stop beating within two hours after withdrawal of treatment efforts to donate the organs are abandoned. 


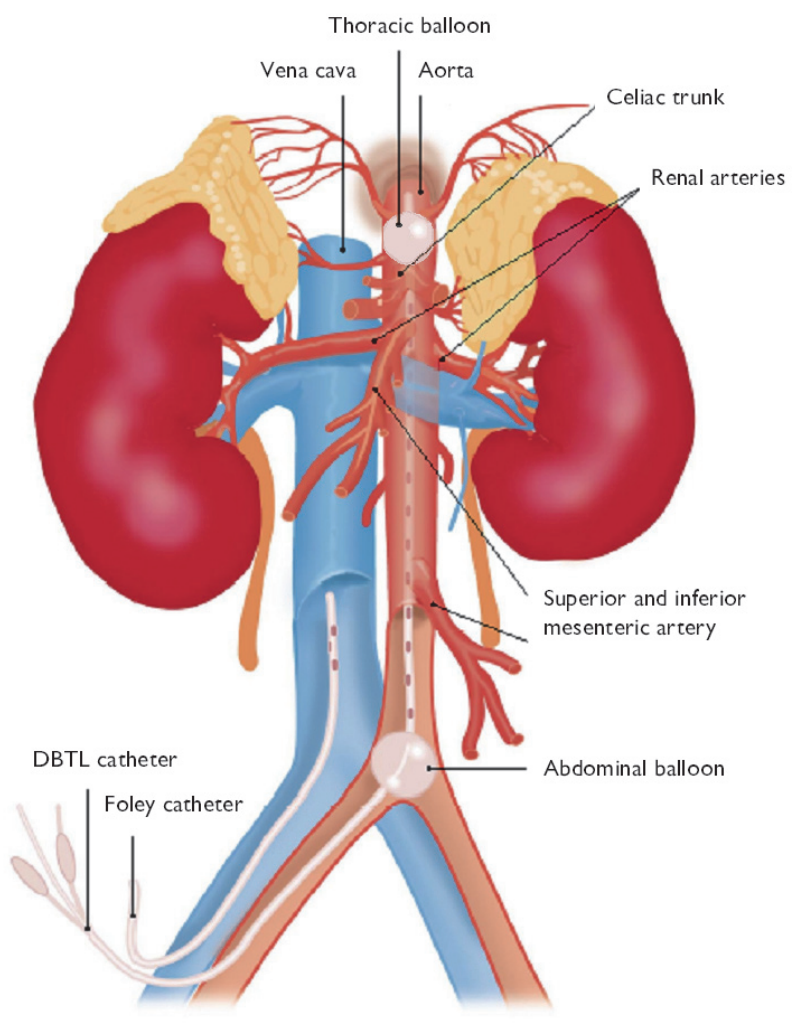

Figure 3.1 In situ preservation technique.

Reproduced with permission from “Nederlands Tijdschrift voor Geneeskunde"15.

\section{Patients}

Data for this observational study were obtained from the Dutch Organ Transplant Registry (NOTR). Recipients from DCD donors $<18$ years of age, transplanted between January 1995 and July 2006, were included in this study. Follow-up ended January $1^{\text {st }}$ 2007. Donor, graft and recipient characteristics were prospectively documented. The glomerular filtration rate (GFR) of the donor was estimated by the Counahan Barrett formula, used to estimate GFR in children ${ }^{16}$. The following graft characteristics were recorded: warm ischemia time (WIT), the time from circulatory arrest or stop of resuscitation until the initial cold flush of the kidneys; cold ischemia time (CIT), the period between the initial flush and the start of first anastomosis of the recipient operation and the anastomosis period, the time to complete both vascular anastomoses. 
Short-term graft function after transplantation was classified as 1) PNF: inadequate renal function necessitating continuation of dialysis or retransplantation; 2) DGF: renal function, which was ultimately life sustaining but required temporary dialysis after transplantation; and 3) IF: immediate renal function without the need of postoperative dialysis. Recipients were followed up for GFR (which was estimated by the abbreviated MDRD formula for the adult recipients) ${ }^{17}$ and for graft and patient survival. GFR was reported three months after transplantation and yearly thereafter. Allograft failure date was defined as the date of return to dialysis.

\section{Statistical analysis}

Quantitative variables were presented as mean \pm standard deviation when normally distributed. If not normally distributed, variables were presented as median and range. Categorical variables were presented as percentages. Kaplan-Meier analysis was used to compute overall graft and patient survival. Comparison of survival between groups was performed using the log-rank statistic. To identify covariates associated with PNF univariable logistic regression analysis was performed. Graft function determined by GFR between the DGF and IF group was compared with an independent sample t-test when variances were equal. If variances were not equal the Mann-Whitney $U$ test was used. Patients undergoing pre-emptive kidney transplantation were excluded from this analysis because dialysis dependency could not be used to define short-term graft function. Graft survival was censored for recipient death with a functioning graft. A pvalue $<0.05$ was considered evidence of statical significant difference.

\section{Ethics}

Collection, storage and use of patient data were performed in agreement with the code of conduct 'Use of data in health research' put forward by The Federation of Dutch Medical Scientific Societies (http://www.federa.org/).

\section{RESULTS}

\section{Patients}

In the study period, 88 patients (aged 1 to 75 years) with end stage renal disease were transplanted with pediatric DCD kidneys from 49 donors from 7 procurement regions. Two recipients received en bloc kidneys of donors aged 2 and 3 years, respectively. Figure 3.2 illustrates the increasing annual proportion of pediatric DCD kidney transplantation compared to the total number of pediatric donor kidney transplantations over the past 11 years. During the study period $31 \%$ of pediatric kidneys were procured from DCD donors. 


\section{Use of pediatric DCD and DBD kidneys}

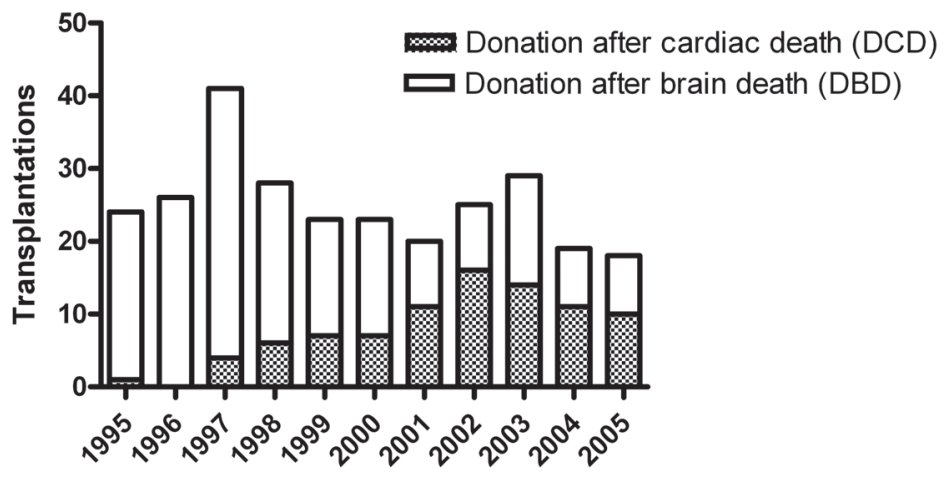

Figure 3.2 Number of transplantations using pediatric donation after cardiac death (DCD) and donation after brain death (DBD) kidneys. Bar chart with stacked columns.

Donor, graft and recipient characteristics are summarized in Table 3.2. Donor age ranged from 2 to 17 years with $9 \%$ of donors aged 5 years or younger. Most recipients, $\mathrm{n}=77(88 \%)$, were transplanted with Maastricht category 3 donor kidneys. Trauma was the cause of death for 67 recipients (77\%); other causes of death included cerebrovascular accident (11\%), status epilepticus (5\%), respiratory failure $(4 \%)$ and suicide (3\%). In $62 \%$ of the donors the warm ischemia time was less than 25 minutes (mean $23 \pm 10$ ). The mean recipient age was $50 \pm 15$ years with a mean duration of dialysis $3.9 \pm 2.2$ years.

Table 3.2 Transplant characteristics and their association with primary non-function (PNF) ${ }^{\mathrm{a}}$

\begin{tabular}{lccc}
\hline & $(\mathrm{n}=88)$ & OR $(95 \% \mathrm{Cl})$ PNF $(\mathrm{n}=6)$ & P-value \\
\hline Donor related & & & \\
Single/en bloc & $86 / 2(98 / 2 \%)$ & $\mathrm{b}$ & 0.99 \\
Age $(\mathrm{y})$ & $15(2-17)$ & $1.03(0.81-1.31)$ & 0.80 \\
Gender (M/F) & $54 / 34(61 / 39 \%)$ & $1.65(0.31-8.66)$ & 0.56 \\
eGFR (ml/min/1.73 $\left.\mathrm{m}^{2}\right)$ & $97(42-290)$ & $0.98(0.94-1.01)$ & 0.22 \\
Maastricht category (3/2) & $77 / 11(88 / 12 \%)$ & $1.5(0.16-14.4)$ & 0.72 \\
Cause of death (trauma/other) & $68 / 20(77 / 23 \%)$ & $1.78(0.30-10.5)$ & 0.53 \\
Graft related & & & 0.046 \\
Warm ischemia time $<25 / \geq 25(\mathrm{~min})$ & $55 / 33(62 / 38 \%)$ & $9.42(1.05-85.0)$ & 0.50 \\
Cold ischemia time $(\mathrm{h})$ & $22 \pm 5$ & $1.06(0.89-1.26)$ & 0.95 \\
Anastomosis period (min) & $34 \pm 10$ & $0.98(0.91-1.09)$ & \\
Recipient related & & & 0.18 \\
Age (y) & $50 \pm 15$ & $1.05(0.98-1.14)$ & 0.98 \\
Gender (M/F) & $40 / 48(67 / 33 \%)$ & $1.02(0.18-5.91)$ & \\
\hline
\end{tabular}

${ }^{\text {a }}$ Continuous values are presented as median (range) or as mean \pm standard deviation. OR denotes for odds ratio, $\mathrm{Cl}$ for confidence interval. In case of categorical variables, the reference category for the odds ratio is 
the first mentioned. ${ }^{b}$ Odds ratio could not be estimated because one of the groups was too small.

\section{Short-term graft function}

In two patients who received a pre-emptive transplantation short-term graft function could not be assessed. In the others IF was present in 42 recipients (49\%), DGF in 38 recipients (44\%) and PNF in 6 recipients (7\%). Both en bloc transplanted kidneys functioned immediately. Maastricht category 2 donor kidney transplants $(n=11)$ resulted in DGF in 9 patients, one donor kidney never functioned. Table 3.2 shows the unadjusted odds ratios for all potential risk factors associated with PNF using a univariable logistic regression analysis. WIT was a statistically significant risk factor for PNF with an odds ratio of 9.42 (95 Cl: 1.05-85.0; $p<0.05$ ) for WIT $\geq 25$ minutes compared to a shorter WIT.

\section{Long-term graft function}

The median follow-up period after transplantation was 3.9 (range 0.0- 24.9) years, including eleven patients with incomplete follow-up. These patients were censored after a mean follow up time of 1.7 (range 0.0-4.0) years.

The death-censored graft survival at 1 and 5 years after transplantation was 87 and $80 \%$ (PNF included), respectively and the patient survival 97 and $88 \%$, respectively. The mean GFR increased during the first five years after transplantation and was equal for kidneys with IF and DGF at 3 months ( $49 \pm 17$ vs. $\left.50 \pm 22 \mathrm{ml} / \mathrm{min} / 1.73 \mathrm{~m}^{2} ; p=0.95\right), 1$ year $\left(58 \pm 16\right.$ vs. $\left.57 \pm 19 \mathrm{ml} / \mathrm{min} / 1.73 \mathrm{~m}^{2} ; \mathrm{p}=0.84\right)$ and 5 years $(61 \pm 13 \mathrm{vs} .65 \pm 15 \mathrm{ml} / \mathrm{min} / 1.73$ $\mathrm{m}^{2} ; \mathrm{p}=0.43$ ) after transplantation. Graft and patient survival in the IF and DGF groups were not significantly different (Figure 3.3).

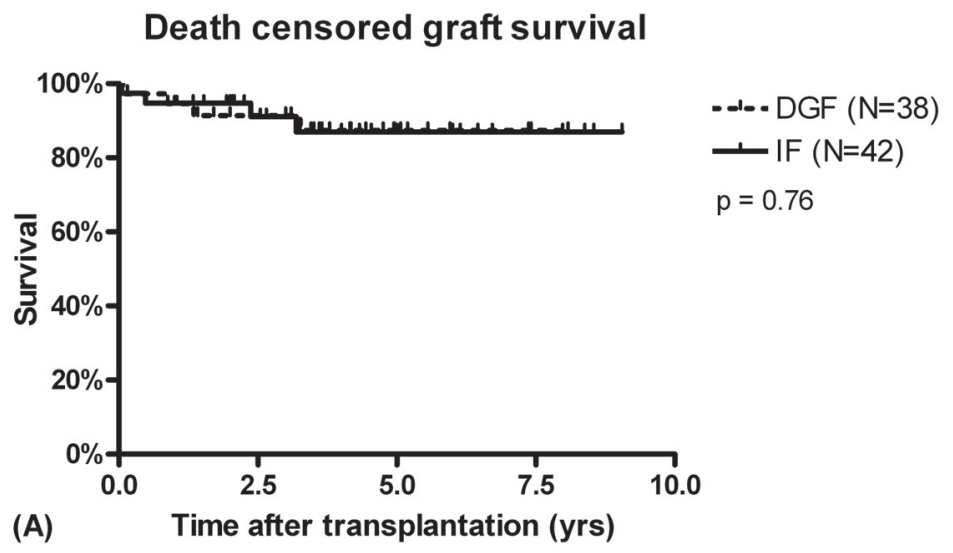




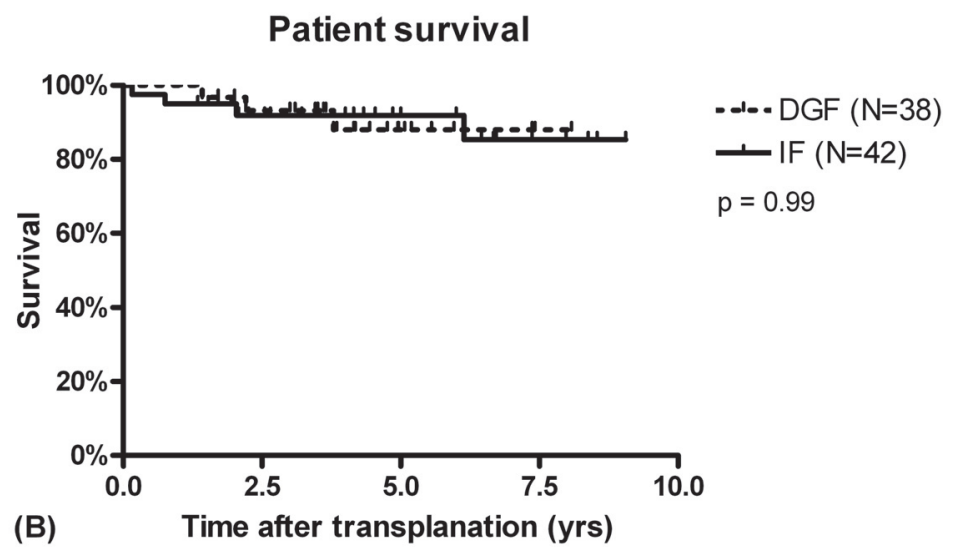

Figure 3.3 Graft and patient survival curves after transplantation of pediatric DCD (donation after cardiac death) kidneys.

Death-censored graft and patient survival of kidneys from pediatric DCD donors with delayed graft function (DGF, dashed line) and immediate function (IF, solid line) estimated by the Kaplan-Meier method. Pre-emptive transplantations and recipients with primary non-function were excluded. (A) Graft survival in the DGF and IF group was similar (log rank test, p=0.76). (B) Patient survival in both study groups was similar (log rank test, $p=0.99$ ).

\section{DISCUSSION}

Pediatric DCD programs may contribute to a significant expansion of the donor pool ${ }^{18}$ as up to $75 \%$ of deaths in pediatric intensive care units are planned withdrawals of supportive treatment ${ }^{19}$. Since results of pediatric DCD transplantation are relatively unknown there is reluctance to use pediatric DCD kidneys for transplantation ${ }^{9,18,20}$. In the Netherlands DCD donors have provided more than $30 \%$ of transplanted deceased pediatric kidneys in the past 11 years. Therefore we have presented the results of pediatric DCD donation in the Netherlands.

Next to the lack of published results of pediatric DCD kidney transplantation, ethical concerns may be responsible for the reluctance to initiate pediatric $D C D$ programs ${ }^{6,7,9,18,21,22}$. A survey among pediatricians showed considerable disagreement whether a potential pediatric DCD donor can be declared dead after cardiac arrest and 5 minutes 'no-touch'" . The Ethics committee of the American College of Critical Care Medicine states that no less than 2 minutes is acceptable but no more than 5 minutes is necessary ${ }^{23}$. In the Netherlands preservation measures in both Maastricht category 2 and category 3 donors are only initiated after a period of 5 to 10 minutes no touch 
after cardiac arrest. Before this time period has elapsed it is not allowed to do anything to the patient, which may influence the dying process including the administration of additional sedation and heparin or the insertion of preservation catheters, which is done in several centers in the United States ${ }^{24}$. The moment of cardiac arrest is determined by the intensive care physician, based on the absence of heart sounds, breathing and arterial pulse. After the period of no touch the donor team is allowed to start with the donor procedure. This way, the treatment of the dying patient and the donation process are completely separated.

Consent for organ donation in category 3 donors is obtained before withdrawal of treatment. In category 2 donors it is extremely difficult to ask for consent during resuscitation or during the no touch period. Therefore consent for donation in category 2 donors who have not registered with the national donor registry is obtained after ISP has started. In the Netherlands this is legally possible and provides families more time to decide whether to consent for donation or not. In clinical practice, the majority of parents choose for organ donation when this possibility is discussed in children in whom treatment will be discontinued ${ }^{25,26}$. Organ donation may even have a beneficial effect on the bereavement process of donor families ${ }^{27}$.

DCD may interfere with the end of life care. To shorten the interval between cardiac arrest and the procurement of the organs in Maastricht category 3 donors, treatment is often withdrawn in the operating room, with or without parents. This may interfere with the perceived quality of end of life care ${ }^{10,20,28,29}$. Moreover, 15 to $20 \%$ of the potential donors do not sustain cardiac arrest within 2 hours after all treatment has been stopped and this group of patients has to be taken back to the ICU. There are other techniques to adequately preserve organs, which interfere less with end of life care. Also in Maastricht category 3 donors it is possible to use ISP, which can be easily done in the ICU. However, laparotomy with direct cannulation in the operating room has been shown to be associated with reduced ischemic damage, lower discard rate and superior graft survival in comparison with the in situ preservation technique ${ }^{13}$. To achieve optimal end of life care supportive treatment is in the Netherlands usually withdrawn in the ICU. Thereafter patients are rapidly transported to the operating room. By performing a laparotomy with direct aortic cannulation warm ischemia time can be limited to 15-25 minutes, which is less than the 25 minutes after which the incidence of PNF increases. Obviously, it is essential to fully inform relatives about the procedure, but this approach allows them to experience more natural end of life care. A study of DCD liver transplantation with similar transplant function after withdrawal in the ICU and in the operating room supports this choice ${ }^{30}$. Therefore we encourage withdrawal of life support in the ICU to obtain the best balance between the procurement of good quality organs and the traditional end of life care. 
The graft and patient survival in this study are in line with results of a 23 patient single center study of pediatric DCD kidney transplantation from Philadelphia, concluding that pediatric donation after cardiac death can be performed successfully ${ }^{10}$. Our results compare favorably with the graft and patient survival of adult DCD kidney transplantation $^{3,31}$ and transplantation of pediatric donation after brain death (DBD) kidneys, as shown by the UNOS database ${ }^{32}$. The latter shows a graft survival of $82 \%$ and $62 \%$ after 1 and 5 years, respectively. In our study the 1 and 5 year death-censored graft survival for pediatric DCD kidneys was $87 \%$ and $80 \%$, respectively, which emphasizes the excellent results of this group of donor kidneys.

The incidence of PNF in recipients of deceased pediatric donor kidneys is relatively high. The surgical challenge of small vascular anastomosis and the relatively low flow of a small sized pediatric kidney may result in early graft loss ${ }^{32,33}$. Moreover, DCD kidney transplantation itself has an increased risk of PNF, which varies from $4-25 \%^{2,3,34-36}$. The incidence of PNF in our group of pediatric DCD transplants compares well with the results of adult DCD kidney transplantation in the Netherlands in the same period of time period, with a PNF percentage of $11 \%^{37}$.

\section{CONCLUSIONS}

In the current study we present the largest series of kidney transplantations from pediatric donors after cardiac death (DCD). Pediatric DCD transplantation has resulted in an expansion of the donor pool with more than $30 \%$ and the outcome of pediatric DCD transplantation was excellent. Therefore, pediatric DCD can safely be added to the existing donor pool, resulting in decreased waiting times and mortality rates for patients on the waiting list for kidney transplantation. 


\section{REFERENCES}

1. Wolfe RA, Ashby VB, Milford EL, Ojo AO, Ettenger RE, Agodoa LY, Held PJ, Port FK.: Comparison of mortality in all patients on dialysis, patients on dialysis awaiting transplantation, and recipients of a first cadaveric transplant. New Engl J Med 1999;341:1725-30.

2. Sanchez-Fructuoso Al, Prats D, Torrente J, Perez-Contin MJ, Fernandez C, Alvarez J, Barrientos A. Renal transplantation from non-heart beating donors: a promising alternative to enlarge the donor pool. J Am Soc Nephrol 2000;11:350-8.

3. Weber M, Dindo D, Demartines N, Ambuhl PM, Clavien PA. Kidney transplantation from donors without a heartbeat. New Engl J Med 2002;347:248-55.

4. Daemen JW, Oomen AP, Kelders WP, Kootstra G. The potential pool of non-heart-beating kidney donors. Clin Transplant 1997;11:149-54.

5. Terasaki PI, Cho YW, Cecka JM. Strategy for eliminating the kidney shortage. Clin Transplant 1997: 265-7.

6. Harrison $\mathrm{CH}$, Laussen PC. Controversy and consensus on pediatric donation after cardiac death: ethical issues and institutional process. Transplant Proc 2008;40:1044-7.

7. Joffe AR, Anton NR, deCaen AR. Survey of pediatricians' opinions on donation after cardiac death: are the donors dead? Pediatrics 2008;122:e967-74.

8. Iltis AS, Rie MA, Wall A. Organ donation, patients' rights, and medical responsibilities at the end of life. Crit Care Med 2009;37:310-5.

9. Hardart G. Pediatric organ donation after cardiac death--still in its infancy. Crit Care Med 2008;36: 1956-7.

10. Naim MY, Hoehn KS, Hasz RD, White LS, Helfaer MA, Nelson RM. The Children's Hospital of Philadelphia's experience with donation after cardiac death. Crit Care Med 2008;36:1729-33.

11. Nakatani T, Uchida J, Yamazaki T, Iwai T, Naganuma T, Kim T, Sugimura K. Cadaveric renal transplantation from a non-heart-beating pediatric donor into adult recipients. Urol Int. 2003;70: 216-8.

12. Kootstra G, Daemen JH, Oomen AP. Categories of non-heart-beating donors. Transplant Proc 1995;27: 2893-4.

13. Snoeijs MG, Dekkers AJ, Buurman WA, van den Akker L, Welten RJ, Schurink GW, van Heurn LW. In situ preservation of kidneys from donors after cardiac death: results and complications. Ann Surg 2007; 246:844-52.

14. Kootstra G, van Heurn E. Non-heartbeating donation of kidneys for transplantation. Nat clin pract Nephrol 2007;3:154-63.

15. Kootstra G, van Hooff JP: [In-situ preservation of kidneys of 'non-heart-beating' donors: a possible way to offset the shortage of donor kidneys]. Ned Tijdschr Geneeskd 1998;142:2838-43.

16. Mattman A, Eintracht S, Mock T, Schick G, Seccombe DW, Hurley RM, White CT. Estimating pediatric glomerular filtration rates in the era of chronic kidney disease staging. J Am Soc Nephrol 2006;17: 487-96.

17. Poge U, Gerhardt T, Palmedo H, Klehr HU, Sauerbruch T, Woitas RP. MDRD equations for estimation of GFR in renal transplant recipients. Am J Transplant 2005;5:1306-11.

18. Mazor R, Baden HP: Trends in pediatric organ donation after cardiac death. Pediatrics 2007; 120: e960-6.

19. Ferguson M, Zuk J. Organ donation after cardiac death: a new trend in pediatrics. J Pediatr Gastroenterol Nutr 2003;37:219-20.

20. Kolovos NS, Webster P, Bratton SL. Donation after cardiac death in pediatric critical care. Pediatr Crit Care Med 2007;8:47-9.

21. Curley MA, Harrison CH, Craig N, Lillehei CW, Micheli A, Laussen PC. Pediatric staff perspectives on organ donation after cardiac death in children. Pediatr Crit Care Med 2007;8:212-9.

22. Mathur M, Taylor S, Tiras K, Wilson M, Abd-Allah S. Pediatric critical care nurses' perceptions, knowledge, and attitudes regarding organ donation after cardiac death. Pediatr Crit Care Med 2008;9: 261-9. 
23. Recommendations for nonheartbeating organ donation. A position paper by the Ethics Committee, American College of Critical Care Medicine, Society of Critical Care Medicine. Crit Care Med 2001;29: 1826-31.

24. Antommaria AH, Trotochaud K, Kinlaw K, Hopkins PN, Frader J. Policies on donation after cardiac death at children's hospitals: a mixed-methods analysis of variation. JAMA 2009;301:1902-8.

25. Kaplan B MG, Koogler TK. Parents'/guardians' views on donation after cardiac death. Crit Care Med 2004;32(Suppl):A89.

26. Morris JA, Jr., Wilcox TR, Frist WH. Pediatric organ donation: the paradox of organ shortage despite the remarkable willingness of families to donate. Pediatrics 1992;89:411-5.

27. Merchant SJ, Yoshida EM, Lee TK, Richardson P, Karlsbjerg KM, Cheung E. Exploring the psychological effects of deceased organ donation on the families of the organ donors. Clin Transplant 2008;22: 341-7.

28. Nishikido M, Noguchi M, Koga S, Kanetake H, Matsuya F, Hayashi M, Hori T, Shindo K. Kidney transplantation from non-heart-beating donors: analysis of organ procurement and outcome. Transplant Proc 2004;36:1888-90.

29. Aulisio MP, Devita M, Luebke D. Taking values seriously: Ethical challenges in organ donation and transplantation for critical care professionals. Crit Care Med 2007;35(2 Suppl):S95-101.

30. Olson L, Kisthard J, Cravero L, Fung J, Eghtesad B, Savo A, Levy A, Polissar N, Marks W. Livers transplanted from donors after cardiac death occurring in the ICU or the operating room have excellent outcomes. Transplant Proc 2005;37:1188-93.

31. Nicholson ML, Metcalfe MS, White SA, Waller JR, Doughman TM, Horsburgh T, Feehally J, Carr SJ, Veitch PS. A comparison of the results of renal transplantation from non-heart-beating, conventional cadaveric, and living donors. Kidney Int 2000;58:2585-91.

32. Bresnahan BA, McBride MA, Cherikh WS, Hariharan S. Risk factors for renal allograft survival from pediatric cadaver donors: an analysis of united network for organ sharing data. Transplantation 2001; 72:256-61.

33. Singh A, Stablein D, Tejani A. Risk factors for vascular thrombosis in pediatric renal transplantation: a special report of the North American Pediatric Renal Transplant Cooperative Study. Transplantation 1997;63:1263-7.

34. Wijnen RM, Booster MH, Stubenitsky BM, de Boer J, Heineman E, Kootstra G. Outcome of transplantation of non-heart-beating donor kidneys. Lancet 1995;345:1067-70.

35. Varty K, Veitch PS, Morgan JD, Bell PR. Kidney retrieval from asystolic donors: a valuable and viable source of additional organs. Br J Surg 1994;81:1459-60.

36. Cho YW, Terasaki PI, Cecka JM, Gjertson DW. Transplantation of kidneys from donors whose hearts have stopped beating. New Engl J Med 1998;338:221-5.

37. Keizer KM, de Fijter JW, Haase-Kromwijk BJ, Weimar W. Non-heart-beating donor kidneys in the Netherlands: allocation and outcome of transplantation. Transplantation 2005;79:1195-9. 


\section{Chapter 4}

\section{Transplantation of kidneys from pediatric DCD donors: a comparison with DBD donors}

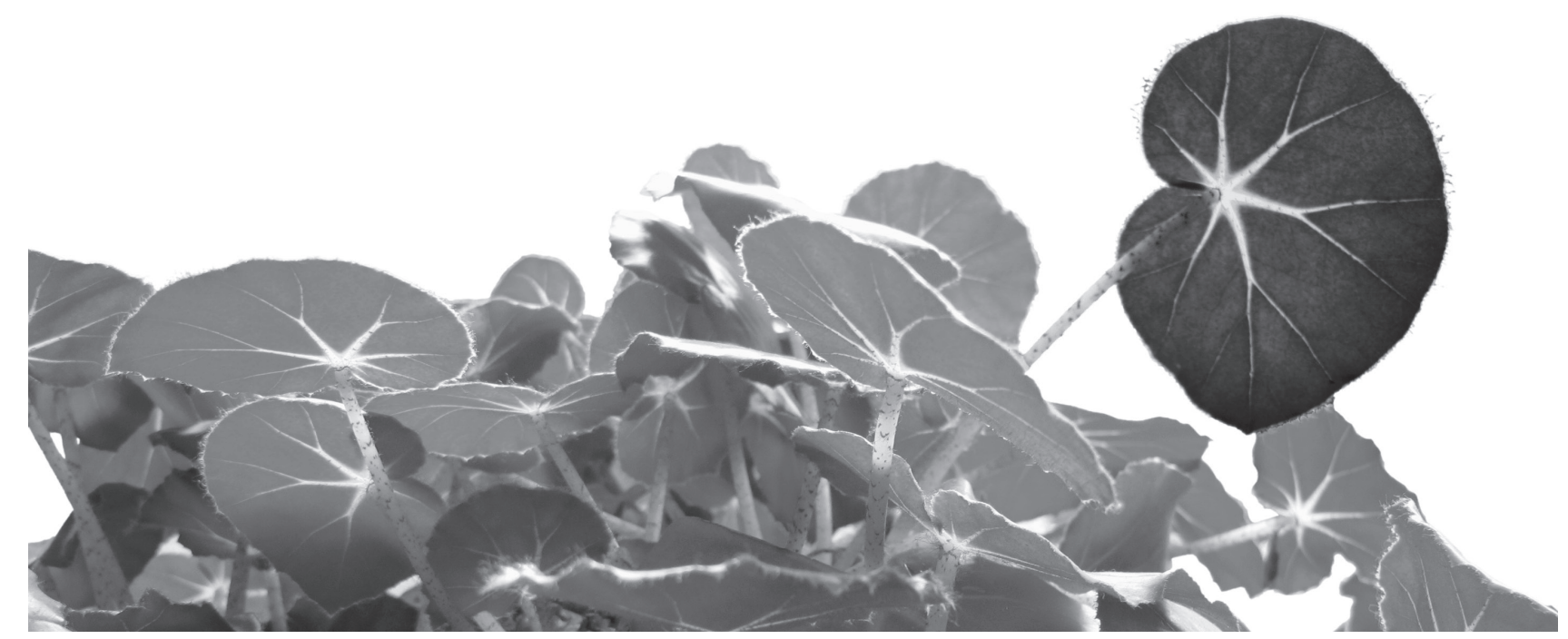

EE de Vries, ERP Hoogland, TJ Wind, MGJ Snoeijs, LWE van Heurn

Nephrology Dialysis Transplantation 2013;28:220-6 


\section{ABSTRACT}

Background Although acceptable outcomes have been reported in kidney transplantation from donation after cardiac death (DCD); little is known about kidney transplantation from pediatric DCD. The objective of this study was to compare the outcome of kidney transplantation using pediatric DCD with the outcome of pediatric donation after brain death (DBD).

Methods Recipients from DCD and DBD donors $<18$ years of age transplanted in the Netherlands between January 1981 and July 2006 were included in this study. Ninety-one patients were transplanted with kidneys from pediatric DCD donors and 405 patients received grafts from pediatric DBD donors.

Results Grafts from DCD donors were associated with higher percentage of primary non-function $(9 \%$ vs. $2 \%, p<0.01)$ and delayed graft function $(48 \%$ vs. $8 \%, p<0.001)$ compared with DBD donor grafts. Estimated glomerular filtration rate did not differ between groups (57 \pm 17 vs. $58 \pm 21 \mathrm{ml} / \mathrm{min}$ at 1 year and $62 \pm 14$ vs. $57 \pm 22 \mathrm{ml} / \mathrm{min}$ at 5 years, respectively). After correction for confounding variables the risk of graft failure was higher in the DCD group (hazard ratio 2.440 [95\% $\mathrm{Cl} 1.280$ to $4.650 ; \mathrm{p}=0.007]$ ). Patient survival, however, was similar between groups (hazard ratio 1.559 [95\% $\mathrm{Cl} 0.848$ to $2.867 ; \mathrm{p}=0.153$ ]).

Conclusions Pediatric DCD kidneys represent a valuable source of donor kidneys that has not been fully utilized. Although transplantation of pediatric DCD kidneys is associated with a higher risk of graft failure than transplantation of pediatric DBD kidneys, results are comparable with adult donors. We therefore conclude that pediatric DCD kidneys can be safely added to the donor pool. 


\section{INTRODUCTION}

Renal transplantation is the treatment of choice for patients with end stage renal disease (ESRD) and improves their long-term survival. However, the number of potential kidney transplant recipients has grown much faster than the number of kidneys available. Therefore, alternative sources of organs are being explored including donation after cardiac death (DCD) and pediatric donation.

Historically, donation after cardiac death (DCD) was the primary donor source in clinical transplantation. Since brain death was defined in 1968, the vast majority of donor organs have been procured by donation after brain death (DBD) with the advantage that the period of warm ischemia is reduced to a minimum ${ }^{1,2}$. However, owing to the disparity between available donor kidneys and patients on the waiting list, a renewed interest in DCD has developed. DCD donors usually experience a variable period of hypotension followed by a complete lack of perfusion from the time of circulatory arrest to the start of intravascular cooling. These periods of ischemia affect the outcome of transplanted grafts. Nevertheless, long-term graft and patient survival have been reported to be similar among kidneys transplanted after DCD and DBD $^{3-5}$.

Another way to expand the donor pool is procuring organs from pediatric donors. However, transplantation of pediatric donor kidneys is associated with higher complication rates such as early graft failure due to graft thrombosis, early rejection and hyperfiltration injury ${ }^{6-8}$. The United Network of Organ Sharing shows that pediatric donor kidneys from donors younger than 18 years of age have a small but significantly worse outcome than adult kidneys ${ }^{9}$. Still, the outcome was acceptable considering the alternative of prolonging dialysis treatment.

The ethical aspects of pediatric DCD are extensively described; nevertheless, the literature on outcome of pediatric DCD kidney transplantation is scanty ${ }^{10}$. No studies comparing DCD and DBD in pediatric kidney transplantation are available. Therefore, we examined whether additional ischemic damage influences the outcome of transplanted pediatric kidneys. We report the results of pediatric DCD compared with pediatric DBD transplantation in the Netherlands over a 25 -year time period. Shortand medium-term graft function, as well as long-term graft- and patient survival, were compared between groups. 


\section{PATIENTS AND METHODS}

\section{Study design and data source}

All patients with ESRD who received a kidney from a deceased pediatric donor in one of all seven Dutch transplant centers between January 1981 and July 2006 were reviewed retrospectively. Kidneys were procured from "controlled" donors after withdrawal of treatment (category 3 ) and from "uncontrolled" donors after stop of resuscitation (category 2 ), according to the Maastricht criteria ${ }^{11}$. We have described the technique of organ procurement in detail previously ${ }^{12-14}$. Procurement techniques include in situ preservation with a double-balloon triple lumen catheter or direct cannulation of the aorta by laparotomy. Both these techniques are performed after a no-touch period of at least 5 minutes in which no resuscitation took place or invasive or medical treatment was given. In the early study period (1981-89) both DCD and DBD kidneys were preserved with Eurocollins solution, and thereafter, DCD kidneys were predominantly preserved with histidine tryptophan ketoglutarate and DBD kidneys with University of Wisconsin preservation fluid. DBD kidneys were stored on ice. DCD kidneys donated in Maastricht were machine preserved $(n=12)$. The results were compared with the results of all pediatric DBD kidney recipients in the Netherlands in the same time period.

\section{Immunosuppressive therapy}

The immunosuppressive regimen evolved over the study period as different trials were conducted. Immunosuppression was based mainly on a combination of a calcineurin inhibitor and prednisolone. Depending on the protocol at the time, these were combined with azathioprine, mycophenolate mofetil, sirolimus or daclizumab in recipients with an increased immunological risk (e.g. HLA immunization and retransplants). Patients with mild-to-moderate rejection were given prednisolone; vascular and steroid-resistant rejections were treated with antithymocyte globulins.

\section{Patients}

Data for this observational study were collected from the Dutch organ transplant registry (NOTR). Recipients from DCD and DBD donors $<18$ years of age, transplanted between January 1981 and July 2006, were included in this study. Follow-up ended January $1^{\text {st }}$ 2007. Donor, graft and recipient characteristics were prospectively documented. The glomerular filtration rate (GFR) of the donor was estimated by the Counahan Barrett formula, used to estimate GFR in children ${ }^{15}$. The following graft characteristics were recorded: warm ischemia time, the time from circulatory arrest (category 3 donors) or stop of resuscitation (category 2 donors) until the initial cold 
flush of the kidneys; cold ischemia time, the period between the initial flush and the start of first anastomosis of the recipient operation and the anastomosis period, the time to complete both vascular anastomoses. Circulatory arrest was diagnosed after cessation of heart beat and the absence of an arterial pulse.

Short-term graft function after transplantation was classified as 1) primary nonfunction (PNF): inadequate renal function necessitating continuation of dialysis or retransplantation; 2) delayed graft function (DGF): renal function that was ultimately life sustaining but required temporary dialysis after transplantation within 1 week of transplantation; and 3) IF: immediate renal function without the need of postoperative dialysis. Recipients were followed up for GFR (which was estimated by the abbreviated MDRD formula for the adult recipients ${ }^{16}$ ), and for graft and patient survival. GFR was reported 3 months after transplantation and yearly thereafter. Allograft failure date was defined as the date of return to dialysis.

The mean follow-up time was 8.1 years, and $18 \%$ was of patients were lost to follow-up (13\% in the DCD group and $19 \%$ in the DBD group). Short-term outcome, graft function and graft- and patient survival of DCD kidney transplants were compared with DBD kidney transplants.

\section{Statistical analysis}

Continuous variables were presented as mean \pm standard deviation if normally distributed, and as median and range otherwise. Categorical variables were presented as percentages. Baseline characteristics between groups were compared with the Student's t-test for normally distributed continuous variables, with the Mann-Whitney U-test if the distribution was not normal, and with the Pearson's Chi-square test for categorical variables. Comparison of the outcome measures (PNF and DGF) between groups was performed with correction for potential confounders in multivariable regression models. First, each characteristic with $p<0.20$ was added separately to a univariable regression model. Second, for PNF and DGF, two and six variables, respectively, with lowest $p$-values in the univariable regression analyses, were added to a multivariable model to study associations with the outcome measures. Continuous variables were categorized by cut offs to meet linearity assumptions. All the variables were tested for multicollinearity. Graft and patient survival were compared between groups by a multivariable Cox regression analysis. The incidence of DGF and PNF in both DCD and DBD kidney transplantation groups was compared with exclusion of preemptive transplanted patients because short-term graft function cannot be determined as DGF or IF as formulated. The afore-mentioned multivariable model was repeated for PNF and for GFR but as a linear regression; recipients with PNF were excluded from this analysis. Logrank tests were performed to compare graft and patient survival between the DCD and the DBD groups. A p-value $<0.05$ was considered 
statistically significant. Statistical analysis was performed with SPSS for Windows version 15.0 .

\section{Ethics}

Collection, storage and use of patient data were performed in agreement with the code of conduct 'Use of data in health research' put forward by The federation of Dutch medical scientific societies (http://www.federa.org/).

\section{RESULTS}

Between January 1981 and July 2006496 patients with ESRD received a pediatric donor kidney in the Netherlands, 91 received a graft from a DCD donor and 405 recipients were transplanted with kidneys from DBD donors. Twelve percent of the DCD kidneys were from Maastricht category 2: uncontrolled donors after unsuccessful resuscitation.

Donor, graft and recipient characteristics are shown in Table 4.1. In both groups a small percentage of the recipients received two kidneys from one donor; their kidneys were transplanted en bloc [DCD 2 (2\%), DBD 5 (1\%)]. The mean donor age was 14 years in the DCD group and 13 years in the DBD group, with $11(12 \%)$ and $41(10 \%)$ donors under the age of 6 years, respectively $(p=0.62)$. The mean year of transplantation was later in the DCD group than in the DBD group, 2001 versus 1994, respectively, $p<0.001$. For DCD donors, the average warm ischemia time was 23 minutes, whereas for DBD donors this period of warm ischemia was close to 0 . The cold ischemia time was shorter in the DCD group than in the DBD group, $22 \pm 5$ vs. $24 \pm 8 \mathrm{~h}(p=0.01)$ and recipients of DCD kidneys were older than DBD kidney recipients, $50 \pm 15$ vs. $40 \pm 18$ years $(p<0.01)$, respectively. Among recipients in the DCD group, a significantly higher percentage of patients had panel reactive antibodies $\geq 5(n=6,7 \%)$ than in the DBD group ( $n=66,17 \%)(p=0.01)$. Recipients from DCD kidneys were 1.6 years longer on dialysis, resulting in a mean period of $3.9 \pm 2.3$ years on the waiting list before transplantation. Immunosuppressive regimen, use of induction therapy $(p \leq 0.001)$, mycophenolate mofetil ( $p \leq 0.001)$, and use of cyclosporine or tacrolimus $(p=0.01)$ differed significantly between groups. 
Table 4.1 Transplant characteristics.

\begin{tabular}{|c|c|c|c|c|c|}
\hline & $\mathrm{n}$ & $\operatorname{DCD}(\mathrm{n}=91)$ & $\mathrm{n}$ & $\operatorname{DBD}(n=405)$ & p-value \\
\hline \multicolumn{6}{|l|}{ Donor related } \\
\hline En bloc & 91 & $2(2 \%)$ & 405 & $5(1 \%)$ & 0.62 \\
\hline Age, year & 91 & $14(0-17)$ & 405 & $13(0-17)$ & 0.13 \\
\hline Transplantation year & 91 & $2001 \pm 4$ & 405 & $1994 \pm 6$ & $<0.001$ \\
\hline Gender (male) & 91 & $54(59 \%)$ & 405 & $243(60 \%)$ & 1.00 \\
\hline Donor height $(\mathrm{cm})$ & 91 & $168(49-195)$ & 405 & $165(70-200)$ & 0.17 \\
\hline GFR (Counahan Barrett) & 89 & $102 \pm 45$ & 399 & $97 \pm 37$ & 0.24 \\
\hline Category DCD (2/3) & 83 & $10 / 73(12 / 88 \%)$ & - & - & - \\
\hline Cause of death (trauma) & 91 & $70(77 \%)$ & 405 & $291(72 \%)$ & 0.36 \\
\hline \multicolumn{6}{|l|}{ Graft related } \\
\hline Warm ischemia time (min) & 84 & $23 \pm 10$ & - & - & - \\
\hline Cold ischemia time (h) & 83 & $22 \pm 5$ & 380 & $24 \pm 8$ & 0.01 \\
\hline Anastomosis period (min) & 82 & $34 \pm 10$ & 373 & $35 \pm 11$ & 0.61 \\
\hline \multicolumn{6}{|l|}{ Recipient related } \\
\hline Age & 91 & $50 \pm 15$ & 405 & $40 \pm 18$ & $<0.01$ \\
\hline Gender (male) & 91 & $60(66 \%)$ & 405 & 238 (59\%) & 0.24 \\
\hline ESRD (vascular) & 91 & $14(15 \%)$ & 405 & $84(21 \%)$ & 1.00 \\
\hline Retransplant (yes) & 91 & $10(11 \%)$ & 405 & $57(14 \%)$ & 0.50 \\
\hline PRA $(\geq 5)$ & 91 & $6(7 \%)$ & 394 & $66(17 \%)$ & 0.01 \\
\hline Total HLA mismatches & 91 & $2.4 \pm 1.0$ & 405 & $2.5 \pm 1.2$ & 0.68 \\
\hline Pre-emptive (yes) & 91 & $2(2 \%)$ & 405 & $16(4 \%)$ & 0.55 \\
\hline Duration of dialysis (y) & 91 & $3.9 \pm 2.3$ & 402 & $2.3(0-18)$ & $<0.001$ \\
\hline Induction therapy & 91 & $29(32 \%)$ & 396 & $32(8 \%)$ & $<0.001$ \\
\hline Mycophenolate mofetil & 91 & $69(76 \%)$ & 396 & $106(27 \%)$ & $<0.001$ \\
\hline Cyclosporine/tacrolimus & 91 & $87(96 \%)$ & 396 & 337 (85\%) & 0.01 \\
\hline Corticosteroids & 91 & $87(96 \%)$ & 396 & $386(98 \%)$ & 0.48 \\
\hline
\end{tabular}

Continuous values are presented as median (range) or as mean \pm SD and categorical variables are presented as number. ESRD: end stage renal disease, PRA: panel reactive antibody.

\section{Short-term graft function}

The short-term outcome of transplantation in the two groups is shown in Table 4.2. The DCD group, compared with the DBD group, showed a higher percentage of PNF $(n=8,9 \%$ vs. $n=8,2 \%, p<0.01)$. The cause of PNF in the DCD and DBD group was thrombosis (DCD: $n=4,50 \%$; DBD: $n=6,88 \%$ ), technical surgical problems (DCD: $n=3$, $38 \%$; DBD: $n=1,13 \%$ ), and unknown (DCD: $n=1,13 \%$; DBD: $0 \%$ ), and was not significantly different between groups $(p=0.28)$. In a multivariable logistic regression model, donor type (DCD) and donor age younger than 10 years were independent predictors of PNF with an odds ratio of 5.837 [95\% Cl 2.040 to $16.689 ; p=0.001$ ] and 4.621 [95\% Cl 1.616 to 13.216; $p=0.004$ ], respectively (Table 4.3). Survival of patients receiving grafts with PNF was not significantly different from recipients of functioning grafts ( 80 vs. $86 \%$ after 5 years, respectively; $p=0.41$ ). An additional univariable analysis within the $D C D$ group showed that donor age $\leq 5$ years is significantly associated with PNF ( $p=0.035)$. The proportion of DCD transplantation increased over time. As the quality of DCD transplantation may have improved, we performed a 
univariable sub analysis for the era 2000-2006. Also in this era the odds ratio suggests that there is an association between donor type (DCD) and PNF (OR $3.322[\mathrm{Cl} 0.359$ to 30.704, $p=0.290])$, but it did not reach significance.

Also DGF occurred more often in the DCD group compared with the DBD group ( $48 \%$ vs. $8 \%, p<0.001)$. Donor type (DCD), warm ischemia time and cold ischemia time were independent predictors of DGF with an odds ratio of 7.709 [95\% Cl 2.342 to 25.380; $p=0.001$ ], 1.053 [95\% Cl 1.011 to 1.098; $p=0.014$ ], and 1.092 [95\% $\mathrm{Cl} 1.045$ to $1.142 ; p<0.001]$, respectively. The mean duration of postoperative dialysis after transplantation in patients with DGF was 13 days in the DCD group and 9 days in the DBD group $(p=0.03)$.

Table 4.2 Short-term graft function.

\begin{tabular}{lccccc}
\hline & $\mathrm{n}$ & $\mathrm{DCD}$ & $\mathrm{n}$ & $\mathrm{DBD}$ & $\mathrm{p}$-value \\
\hline Primary non-function & 89 & $8(9 \%)$ & 389 & $8(2 \%)$ & $<0.01$ \\
Delayed graft function & 81 & $39(48 \%)$ & 378 & $31(8 \%)$ & $<0.001$ \\
Postoperative dialysis (days) & 36 & $13 \pm 7$ & 20 & $9 \pm 6.5$ & 0.03 \\
\hline
\end{tabular}

Categorical variables are presented as percentages; continuous variables as mean \pm SD.

Table 4.3 Multivariable logistic regression analysis of risk factors of primary non-function.

\begin{tabular}{|c|c|c|c|c|c|}
\hline \multirow[t]{2}{*}{ PNF } & & \multicolumn{2}{|c|}{ Univariable analysis } & \multicolumn{2}{|c|}{ Multivariable analysis } \\
\hline & & OR $(95 \% \mathrm{Cl})$ & $p$-value & OR $(95 \% \mathrm{Cl})$ & $\mathrm{p}$-value \\
\hline \multicolumn{6}{|l|}{ Donor related } \\
\hline Donor type (DCD/DBD) & $\begin{array}{c}91 / 405 \\
(18 / 82 \%)\end{array}$ & $4.590(1.675-12.582)$ & 0.003 & $5.837(2.040-16.689)$ & 0.001 \\
\hline Donor age $(<10$ or $\geq 10$ y) & $\begin{array}{l}114 / 382 \\
(23 / 77 \%)\end{array}$ & 3.549 (1.300 - 9.689) & 0.013 & $4.621(1.616-13.216)$ & 0.004 \\
\hline Tx year (<1995 or $\geq 1995)$ & $\begin{array}{l}216 / 280 \\
(44 / 56 \%)\end{array}$ & $1.252(0.447-3.501)$ & 0.669 & & \\
\hline Gender (male/female) & $\begin{array}{l}297 / 199 \\
(60 / 40 \%)\end{array}$ & $1.939(0.710-5.297)$ & 0.197 & & \\
\hline $\begin{array}{r}\text { Predonation eGFR } \\
\left(\mathrm{ml} / \mathrm{min} / 1.73 \mathrm{~m}^{2}\right)\end{array}$ & $100 \pm 38$ & 1.009 (0.999 - 1.018) & 0.067 & & \\
\hline \multicolumn{6}{|l|}{ Graft related } \\
\hline Warm ischemia time (min) & $23 \pm 10$ & $1.063(0.993-1.138)$ & 0.077 & & \\
\hline Cold ischemia time $(\mathrm{h})$ & $24 \pm 8$ & $1.030(0.968-1.097)$ & 0.352 & & \\
\hline Anastomosis time (min) & $34 \pm 11$ & $1.027(0.990-1.066)$ & 0.159 & & \\
\hline \multicolumn{6}{|l|}{ Recipient related } \\
\hline Recipient age ( $<50$ or $\geq 50$ y) & $\begin{array}{l}311 / 185 \\
(63 / 37 \%)\end{array}$ & $0.467(0.171-1.275)$ & 0.137 & & \\
\hline Gender (male/female) & $\begin{array}{c}298 / 198 \\
(60 / 40 \%)\end{array}$ & $1.939(0.710-5.297)$ & 0.197 & & \\
\hline Retransplantation $(\mathrm{y} / \mathrm{n})$ & $\begin{array}{c}67 / 429 \\
(14 / 86 \%)\end{array}$ & $1.442(0.400-5.202)$ & 0.576 & & \\
\hline Duration of dialysis (y) & $3.2 \pm 2.5$ & $1.111(0.944-1.308)$ & 0.207 & & \\
\hline Total mismatches $(\mathrm{n})$ & $2.5 \pm 1.2$ & $1.049(0.688-1.601)$ & 0.824 & & \\
\hline
\end{tabular}

Categorical values are presented as number and continues values as mean \pm SD. In case of categorical variables, the reference category for the odds ratio is the first mentioned. 


\section{Long-term graft function}

Graft function of functioning grafts assessed with multivariable linear regression analysis, did not differ between the DCD and the DBD groups (48 \pm 20 vs. $53 \pm 21 \mathrm{ml} / \mathrm{min}(p=0.35)$ at 3 months and $62 \pm 14$ vs. $57 \pm 22 \mathrm{ml} / \mathrm{min}(p=0.26)$ at 5 years) (Table 4.4$)$.

Table 4.4 Long-term function with exclusion of recipients with primary non-function.

\begin{tabular}{lccccc}
\hline & $\mathrm{n}$ & $\mathrm{DCD}$ & $\mathrm{n}$ & $\mathrm{DBD}$ & $\mathrm{p}$-value \\
\hline GFR 3 months & 68 & $48 \pm 20$ & 206 & $53 \pm 21$ & 0.35 \\
GFR 1 year & 66 & $57 \pm 17$ & 194 & $58 \pm 21$ & 0.78 \\
GFR 2 years & 61 & $57 \pm 19$ & 196 & $56 \pm 22$ & 0.52 \\
GFR 3 years & 46 & $60 \pm 19$ & 175 & $56 \pm 21$ & 0.27 \\
GFR 4 years & 42 & $60 \pm 17$ & 172 & $56 \pm 23$ & 0.31 \\
GFR 5 years & 31 & $62 \pm 14$ & 169 & $57 \pm 22$ & 0.26 \\
\hline
\end{tabular}

GFR $\left(\mathrm{ml} / \mathrm{min} / 1.73 \mathrm{~m}^{2}\right)$ presented as mean \pm SD.

Death-censored graft survival in the DCD and the DBD groups was 84 and $88 \%$ after 1 year and $78 \%$ and $80 \%$ after 5 -years, respectively (Figure $4.1 \mathrm{~A}$ ). Overall 1-year graft survival was $83 \%$ in the DCD group and $85 \%$ in the DBD group; overall 5 year graft survival was $72 \%$ in both groups. After correction for confounding variables (donor age, transplantation year, cold ischemia time, recipient age and immunosuppressive regimen) the rate of death-censored graft failure was higher in the DCD group (hazard ratio 2.440 [95\% Cl 1.280 to $4.650 ; p=0.007]$ ) (Table 4.5). Donor age under 10 years was significantly associated with graft failure (hazard ratio $2.051[95 \% \mathrm{Cl} 1.393$ to 3.019; $p<0.001]$ ). Patient survival in the DCD and the DBD groups was $95 \%$ in both groups at 1 year, and $87 \%$ in the DCD and $86 \%$ in the DBD group at 5 years (Figure 4.1B). Also after correction for confounding variables, donor type was not associated with patient survival (hazard ratio 1.559 [95\% $\mathrm{Cl} 0.848$ to $2.867 ; \mathrm{p}=0.153]$ ) (Table 4.5).

Without correction for confounding variables, logrank tests comparing graft and patient survival between the DCD and the DBD groups did not show a statistical difference ( $p=0.590$ and 0.717$)$, respectively. 

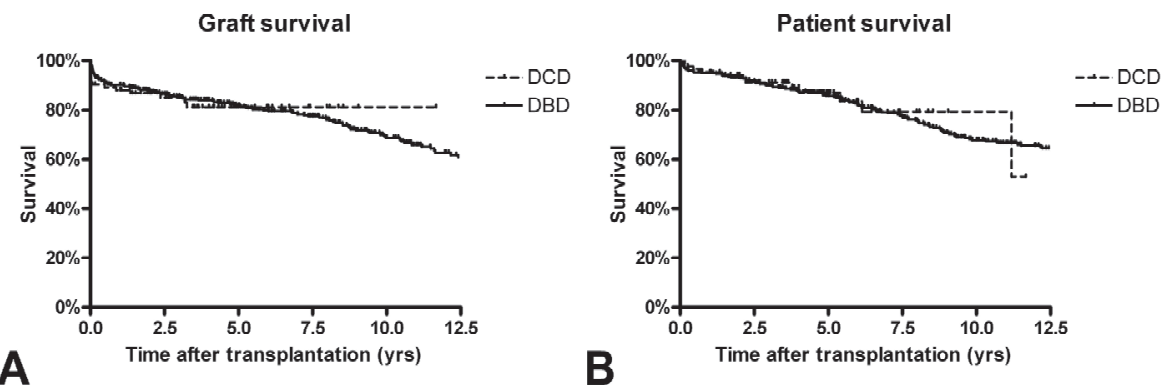

Figure 4.1 Graft survival (A) and patient survival (B) of kidneys from pediatric DCD (donation after cardiac death) and DBD (donation after brain death).

Table 4.5 Multivariable cox regression analysis for graft and patient survival.

\begin{tabular}{|c|c|c|c|c|}
\hline & \multicolumn{2}{|c|}{$\begin{array}{c}\text { Multivariable analysis } \\
\text { Graft survival }\end{array}$} & \multicolumn{2}{|c|}{$\begin{array}{l}\text { Multivariable analysis } \\
\text { Patient survival }\end{array}$} \\
\hline & OR $(95 \% \mathrm{Cl})$ & $\mathrm{p}$-value & OR $(95 \% \mathrm{Cl})$ & $\mathrm{p}$-value \\
\hline \multicolumn{5}{|l|}{ Donor related } \\
\hline Donor type (DCD/DBD) & 2.440 (1.280 to 4.650$)$ & 0.007 & 1.559 (0.848 to 2.867$)$ & 0.153 \\
\hline Donor age $(<10$ or $\geq 10 \mathrm{y})$ & 2.051 (1.393 to 3.019 ) & $<0.001$ & & \\
\hline Tx year (<1995 or $\geq 1995)$ & 1.671 (0.974 to 2.867$)$ & 0.063 & & \\
\hline \multicolumn{5}{|l|}{ Graft related } \\
\hline Cold ischemia time $(\mathrm{h})$ & 1.103 (0.987 to 1.040$)$ & 0.319 & & \\
\hline \multicolumn{5}{|l|}{ Recipient related } \\
\hline Recipient age (<50 or $\geq 50$ y) & 0.747 (0.500 to 1.117$)$ & 0.156 & 0.229 (0.160 to 0.329$)$ & $<0.001$ \\
\hline Duration of dialysis $(\mathrm{y})$ & & & 1.039 (0.979 to 1.102$)$ & 0.206 \\
\hline Induction therapy $(\mathrm{y} / \mathrm{n})$ & 0.707 (0.307 to 1.625$)$ & 0.414 & & \\
\hline Mycophenolate mofetil (y/n) & 0.798 (0.426 to 1.498$)$ & 0.483 & & \\
\hline Cyclosporine/tacrolimus (y/n) & 0.607 (0.378 to 0.974$)$ & 0.039 & & \\
\hline
\end{tabular}

Graft survival is death-censored. In case of categorical variables, the reference category for the odds ratio is the first mentioned.

\section{DISCUSSION}

We present the results of kidney transplantation in a consecutive series of 496 recipients of pediatric DCD and DBD donors, during a period of 25 years. This study is the first to compare pediatric DCD and DBD kidneys, using multivariable regression analyses.

Transplant recipients benefit from a superior life expectancy and improvement in quality of life compared with patients on dialysis treatment ${ }^{17-19}$. With the current shortage of organs for transplantation, attention has been directed towards expanding the donor pool with traditionally less used organs including organs from pediatric 
donors and organs from donors after cardiac death. DCD donors have become an important source of donor kidneys and currently represent up to $50 \%$ of all deceased donors in the Netherlands. Patient survival and graft survival of functioning grafts is similar to DBD donor kidneys ${ }^{3}$. Transplantation of pediatric DCD kidneys lags behind as the outcome is relatively unknown.

To assess the effect of warm ischemic injury on pediatric donor kidneys, graft function, and long-term graft and patient survival were compared between pediatric DCD and DBD kidney transplantation. Acceptable outcomes of pediatric DCD kidneys were obtained despite the higher percentage of PNF and DGF, as well as a higher rate of graft failure in the DCD group. In this study, we reported a 5-year graft survival rate of $78 \%$ in the pediatric DCD group vs. $80 \%$ in the pediatric DBD group. These survival rates are comparable with results of adult DCD and DBD transplantation, in which 5 -year death-censored graft survival rates of $63 \%$ to $83 \%$ for DCD transplantation and $71 \%$ to $84 \%$ for DBD transplantation are reported ${ }^{4,20-23}$.

The incidence of PNF was higher in DCD kidneys than in DBD kidneys. In both groups graft thrombosis was the most common cause of early graft loss. Small donor kidneys particularly from young aged donors with low initial flow are at increased risk for graft thrombosis and worse outcome ${ }^{24}$. This risk is aggravated by ischemia reperfusion injury caused by warm ischemia in DCD kidneys. Inflammatory response and edema jeopardize adequate graft perfusion with consequently low flow and graft thrombosis. Furthermore, the anastomoses of small pediatric donor vessels with the relatively large vessels may be a surgical challenge, particularly for kidneys from very young donors ${ }^{7,9}$. This also gives an increased risk of graft thrombosis, but counts for both DCD and DBD groups. However, this combined etiology of graft thrombosis makes it extremely difficult to identify a definite cause for graft thrombosis in the individual patient and in particular for DCD donor kidneys. We indeed found that donor age below 10 years is an independent predictor of PNF; however, a cut off age to simplify the decision, which DCD kidney should be transplanted and which not, could not be assessed. To improve the results of pediatric donor kidney transplantation, en bloc transplantation can be performed if the donor is below a certain age or weight ${ }^{9}$.

DGF occurred significantly more often in the DCD group and the period of DGF lasted longer. This is consistent with historical outcomes of adult DCD kidney transplantation ${ }^{4,5}$. The long-term graft survival of pediatric DCD grafts with DGF was similar to the graft survival of grafts with immediate function, which is also consistent with studies in adult donors ${ }^{25}$. This finding implies that DGF has no effect on the longterm outcome of DCD kidneys, while in DBD kidneys DGF is associated with worse long-term outcome and a higher incidence of chronic rejection ${ }^{26,27}$. 
The incidence of PNF of kidneys from pediatric DCD donors was relatively high and the quality of these kidneys may therefore be considered less than optimal. However, the alternative, treatment of continuing dialysis therapy until an optimal donor kidney is offered, is associated with a high mortality rate ${ }^{28}$. Indeed, kidneys from adult DCD donors provide a survival benefit compared with standard treatment, even though $12 \%$ of the kidneys failed in the first 3 months after transplantation. Furthermore, graft survival of kidneys from pediatric DCD donors that survive the immediate posttransplant period is excellent ${ }^{9,29,30}$.

Pediatric DCD programs may expand the donor pool substantially because withdrawal of life-sustaining treatment is a common setting in pediatric intensive care units (PICU). A review of literature reveals that $40-65 \%$ of deaths occurring in European PICUs follow withdrawal of treatment ${ }^{31}$, which is up to three times as much as the percentage of children who die after brain death. Although this percentage of planned withdrawals of treatment overestimates the number of potential DCD donors, routine use of the pediatric DCD donor has the ability to significantly increase organ donation ${ }^{32}$. There are ethical and practical considerations that may discourage centers to start pediatric DCD programs. These issues have been described before ${ }^{12,33}$. However, we showed that graft and patient survival using pediatric DCD kidneys are encouraging.

We conclude that pediatric DCD represents a valuable source of kidneys that has not been fully utilized. More widespread implementation of pediatric DCD programs may further increase the life expectancy of patients with ESRD in an era of kidney donor shortage. 


\section{REFERENCES}

1. A definition of irreversible coma. Report of the Ad Hoc Committee of the Harvard Medical School to Examine the Definition of Brain Death. JAMA 1968;205:337-40.

2. Rosenberg RN. Consciousness, coma, and brain death--2009. JAMA 2009;301:1172-4.

3. Wijnen RM, Booster MH, Stubenitsky BM, de Boer J, Heineman E, Kootstra G. Outcome of transplantation of non-heart-beating donor kidneys. Lancet 1995;345:1067-70.

4. Cho YW, Terasaki PI, Cecka JM, Gjertson DW. Transplantation of kidneys from donors whose hearts have stopped beating. N Engl J Med 1998;338:221-5.

5. Rudich SM, Kaplan B, Magee JC, Arenas JD, Punch JD, Kayler LK, Merion RM, Meier-Kriesche HU. Renal transplantations performed using non-heart-beating organ donors: going back to the future? Transplantation 2002;74: 1715-20.

6. Nghiem DD. En bloc transplantation of kidneys from donors weighing less than $15 \mathrm{~kg}$. into adult recipients. J Urol 1991;145:14-6.

7. Singh A, Stablein D, Tejani A. Risk factors for vascular thrombosis in pediatric renal transplantation: a special report of the North American Pediatric Renal Transplant Cooperative Study. Transplantation. 1997;63:1263-7.

8. Creagh TA, McLean PA, Spencer S, Cunningham P, Donovan MG, Walshe JJ, Murphy DM. Transplantation of kidneys from pediatric cadaver donors to adult recipients. J Urol 1991;146:951-2.

9. Bresnahan BA, McBride MA, Cherikh WS, Hariharan S. Risk factors for renal allograft survival from pediatric cadaver donors: an analysis of united network for organ sharing data. Transplantation 2001; 72:256-61.

10. Mazor R, Baden HP. Trends in pediatric organ donation after cardiac death. Pediatrics 2007;120: e960-6.

11. Kootstra G, Daemen JH, Oomen AP. Categories of non-heart-beating donors. Transplant Proc 1995;27:2893-4.

12. de Vries EE, Snoeijs MG, van Heurn E. Kidney donation from children after cardiac death. Crit Care Med 2010;38:249-53.

13. Snoeijs MG, Dekkers AJ, Buurman WA, van den Akker L, Welten RJ, Schurink GW, van Heurn LW. In situ preservation of kidneys from donors after cardiac death: results and complications. Ann Surg. 2007; 246:844-52.

14. Heineman E, Daemen JH, Kootstra G. Non-heart-beating donors: methods and techniques. Transplant Proc 1995;27:2895-6.

15. Mattman A, Eintracht S, Mock T, Schick G, Seccombe DW, Hurley RM, White CT. Estimating pediatric glomerular filtration rates in the era of chronic kidney disease staging. J Am Soc Nephrol 2006;17: 487-96.

16. Poge U, Gerhardt T, Palmedo H, Klehr HU, Sauerbruch T, Woitas RP. MDRD equations for estimation of GFR in renal transplant recipients. Am J Transplant 2005;5:1306-11.

17. Wolfe RA, Ashby VB, Milford EL, Ojo AO, Ettenger RE, Agodoa LY, Held PJ, Port FK. Comparison of mortality in all patients on dialysis, patients on dialysis awaiting transplantation, and recipients of a first cadaveric transplant. N Engl J Med 1999;341:1725-30.

18. McDonald SP, Russ GR. Survival of recipients of cadaveric kidney transplants compared with those receiving dialysis treatment in Australia and New Zealand, 1991-2001. Nephrol Dial Transplant 2002; 17:2212-9.

19. Rabbat CG, Thorpe KE, Russell JD, Churchill DN. Comparison of mortality risk for dialysis patients and cadaveric first renal transplant recipients in Ontario, Canada. J Am Soc Nephrol 2000;11:917-22.

20. Weber M, Dindo D, Demartines N, Ambuhl PM, Clavien PA. Kidney transplantation from donors without a heartbeat. N Engl J Med 2002;347:248-55.

21. Cooper JT, Chin LT, Krieger NR, Fernandez LA, Foley DP, Becker YT, Odorico JS, Knechtle SJ, Kalayoglu $M$, Sollinger HW, D'Alessandro AM. Donation after cardiac death: the university of wisconsin experience with renal transplantation. Am J Transplant 2004;4:1490-4.

22. Snoeijs MG, Winkens B, Heemskerk MB, Hoitsma AJ, Christiaans MH, Buurman WA, van Heurn LW. Kidney transplantation from donors after cardiac death: A 25-year experience. Transplantation 2010; 90:1106-12. 
23. Nicholson ML, Metcalfe MS, White SA, Waller JR, Doughman TM, Horsburgh T, Feehally J, Carr SJ, Veitch PS. A comparison of the results of renal transplantation from non-heart-beating, conventional cadaveric, and living donors. Kidney Int 2000;58:2585-91.

24. Snoeijs MG, Wiermans B, Christiaans MH, van Hooff JP, Timmerman BE, Schurink GW, Buurman WA, van Heurn LW. Recipient hemodynamics during non-heart-beating donor kidney transplantation are major predictors of primary nonfunction. Am J Transplant 2007;7:1158-66.

25. Renkens JJ, Rouflart MM, Christiaans MH, van den Berg-Loonen EM, van Hooff JP, van Heurn LW. Outcome of nonheart-beating donor kidneys with prolonged delayed graft function after transplantation. Am J Transplant 2005;5:2704-9.

26. Nicholson ML, Wheatley TJ, Horsburgh T, Edwards CM, Veitch PS, Bell PR. The relative influence of delayed graft function and acute rejection on renal transplant survival. Transpl Int 1996;9:415-9.

27. Brook NR, White SA, Waller JR, Veitch PS, Nicholson ML. Non-heart beating donor kidneys with delayed graft function have superior graft survival compared with conventional heart-beating donor kidneys that develop delayed graft function. Am J Transplant 2003;3:614-8.

28. Snoeijs MG, Schaubel DE, Hené R, Hoitsma AJ, Idu MM, ljzermans JN, Ploeg RJ, Ringers J, Christiaans $\mathrm{MH}$, Buurman WA, van Heurn LW. Kidneys from donors after cardiac death provide survival benefit. J Am Soc Nephrol 2010;21:1015-21.

29. Sureshkumar KK, Reddy CS, Nghiem DD, Sandroni SE, Carpenter BJ. Superiority of pediatric en bloc renal allografts over living donor kidneys: a long-term functional study. Transplantation 2006;82: 348-53.

30. Pape L, Hoppe J, Becker T, Ehrich JH, Neipp M, Ahlenstiel T, Offner G. Superior long-term graft function and better growth of grafts in children receiving kidneys from paediatric compared with adult donors. Nephrol Dial Transplant 2006;21:2596-600.

31. Moore P, Kerridge I, Gillis J, Jacobe S, Isaacs D. Withdrawal and limitation of life-sustaining treatments in a paediatric intensive care unit and review of the literature. J Paediatr Child Health 2008;44:404-8.

32. Koogler T, Costarino AT, Jr. The potential benefits of the pediatric nonheartbeating organ donor. Pediatrics 1998;101:1049-52.

33. Sung RS. Transplantation: Pediatric kidney donation after cardiac death. Nat Rev Nephrol 2010;6: 387-8. 


\section{ABSTRACT}

Background Donation after cardiac death (DCD) has shown to be a valuable extension of the kidney donor pool despite a higher percentage of primary non-function (PNF). Limiting the incidence of PNF is of vital importance. Renovascular resistance is believed to predict graft outcome, however the literature is inconsistent. Therefore, we studied whether renovascular resistance is associated with PNF and whether this parameter should be used to discard donor kidneys.

Materials and methods All transplanted DCD kidneys preserved by machine perfusion at our center between 1993 and 2007 were analyzed $(n=440)$. The effects of renovascular resistance on PNF, delayed graft function (DGF), and graft and patient survival were examined using multivariable analyses; predictive quality by calculating the area under the curve (AUC).

Results We showed that renovascular resistance at the start of machine perfusion was significantly and independently associated with PNF (OR 2.040, 95\% $\mathrm{Cl} 1.362$ to $3.056 ; p=0.001$ ), and DGF (OR $2.345,95 \% \mathrm{Cl} 1.110$ to $4.955 ; \mathrm{p}=0.025)$. Predictive quality was moderate $(0.609$, $95 \% \mathrm{Cl} 0.538$ to 0.681 ). Graft and patient survival were not associated with renovascular resistance.

Conclusion We conclude that renovascular resistance in DCD kidneys is an independent risk factor for PNF. The predictive value, however, is relatively low. 


\section{INTRODUCTION}

Kidney transplantation is the treatment of choice for patients with end stage renal disease $\mathrm{e}^{1-3}$. The increasing demand for organ donors has led to the use of alternative sources of grafts to expand the donor pool. One of these alternatives includes organs from donation after cardiac death (DCD). These kidneys suffer from a period of warm ischemia between cardiac arrest and cold flushing. As a result a higher percentage of kidneys suffer from primary non-function (PNF) and delayed graft function (DGF) ${ }^{4-6}$.

In recent years, kidney preservation by hypothermic machine perfusion has experienced renewed interest. In addition to the intended benefit of improved tissue preservation, machine perfusion also provides the opportunity to determine perfusion parameters including perfusion pressure, perfusion flow and renovascular resistance. These parameters have been advocated to predict graft function after transplantation $^{7-10}$. The assessment of organ viability is especially important in marginal kidneys with their increased risk of developing PNF. However, the value of machine perfusion parameters to predict PNF is relatively unknown, as the incidence of PNF after transplantation is generally low. DGF, as an alternative outcome measure, is less useful because DGF does not affect long-term survival in DCD kidneys ${ }^{4-6,11-14}$.

In a large group of marginal machine perfused DCD kidneys in which perfusion parameters were not used to discard the organs, we primarily studied whether renovascular resistance is independently associated with PNF and whether renovascular resistance can be safely used to discard donor kidneys. Additionally, we studied whether renovascular resistance is associated with DGF and long-term graft and patient survival.

\section{MATERIALS AND METHODS}

\section{Patients and study design}

All DCD kidneys, which were machine perfused at our center between March 1993 and May 2007 and were transplanted in the Eurotransplant region, as well as their contralateral kidney, were included in this study. This group consisted of (1) kidneys procured at our center, (2) kidneys taken to our center for machine preservation until transplanted elsewhere, or (3) kidneys procured elsewhere, but machine perfused until transplanted at our center. Kidneys were either accepted or discarded, based on donor characteristics, warm ischemia time, macroscopic appearance or anatomical variances of the graft. Kidneys were procured from donors after cardiac death according to the Maastricht DCD categories ${ }^{15-17}$. Maastricht categories 1 and 2 together were classified as uncontrolled. Collection, storage and use of patient data 
were performed in agreement with the code of conduct "use of data in health research" from the Dutch federation of biomedical scientific societies; ethics approval was not required. Donor, graft, machine perfusion and recipient characteristics were prospectively documented. The predonation GFR was estimated by the abbreviated Modification of Diet in Renal Disease formula (MDRD) ${ }^{18}$. The following graft characteristics were recorded: warm ischemia time, the period from circulatory arrest or stop of resuscitation until the initial cold flush of the kidneys; cold ischemia time, the period between the initial flush and the start of first anastomosis of the recipient operation; and the anastomosis period, the time to complete both vascular anastomoses. Short-term graft function after transplantation was classified as 1) PNF: inadequate renal function necessitating continuation of dialysis or retransplantation; 2) DGF: renal function which was ultimately life sustaining but required temporary dialysis after transplantation; and 3) IF: immediate renal function without the need of postoperative dialysis. Recipients were followed up for graft and patient survival. GFR was reported 3 months after transplantation and yearly thereafter. The allograft failure date was defined as the date of return to dialysis or retransplantation, whichever comes first.

\section{Preservation}

After organ recovery, kidneys were weighed and machine preserved on a Gambro PF-3B pulsatile perfusion machine (Gambro, Lund, Sweden) with Belzer's hypothermic machine preservation UW gluconate solution at a mean temperature of $4^{\circ} \mathrm{C}$. Added to the solution were $40 \mathrm{IU}$ of insulin, 200,000 $\mathrm{U}$ of penicillin and $16 \mathrm{mg}$ of dexamethasone. After connection of the kidney to the machine, perfusion flow was set to a systolic pressure of $55 \mathrm{mmHg}$, which was maintained during the first 60 minutes by adjusting machine flow. After 60 minutes, the renal flow was kept constant. Flow and pressure parameters were recorded at the start of machine perfusion, and after 1 , 2 and $4 \mathrm{~h}$ of perfusion ( $T_{0}, T_{1}, T_{2}$ and $T_{4}$, respectively). The renovascular resistance was calculated by dividing mean pressure by the registered flow and was corrected for kidney weight ( $\mathrm{mmHg} / \mathrm{ml} / \mathrm{min}$ per $100 \mathrm{~g}$ kidney weight). During machine perfusion, $\mathrm{pH}$ was adjusted to values $>7.10$, using sodium bicarbonate.

The immunosuppressive regimen evolved over the study period as different trials were conducted. Immunosuppression was mainly based on a combination of a calcineurin inhibitor (cyclosporine or tacrolimus) and prednisolone. Depending of the protocol at the time, these were combined with azathioprine, mycophenolate mofetil, sirolimus or daclizumab in recipients with an increased immunological risk (e.g., HLA immunization and retransplants). 


\section{Statistics}

Continuous variables were presented as mean \pm standard deviation unless explicitly noted otherwise. Categorical variables were presented as absolute numbers and percentages. Renovascular resistance of discarded kidneys was compared with the resistance of all transplanted kidneys and kidneys with PNF, using an independent samples t-test, and compared with their contralateral kidneys using a paired samples t-test. Multivariable logistic regression analysis was performed to identify whether renovascular resistance is an independent risk factor for PNF and DGF, correcting for known prognostic factors and significant variables from the univariable analyses. To avoid multicollinearity only renovascular resistance with the lowest $p$-value in univariable analyses was included in the model. The effect of renovascular resistance at each time point and the renovascular resistance area under the curve (AUC) on PNF and DGF were determined by univariable logistic regression analyses. Predictive measurements were performed by calculating a ROC curve. Positive and negative predictive values were computed using the predictive probability with maximum combination of sensitivity and specificity from the ROC curve, i.e. the point closest to the $[1,1]$-corner. We performed a Cox proportional hazard model to assess the association between renovascular resistance and graft survival in functioning grafts, censored for recipient death with a functioning graft, and patient survival. The longterm effects were visualized by the Kaplan-Meier curves, where renovascular resistance groups were created based on randomly chosen rounded numbers of renovascular resistance (in $\mathrm{mmHg} / \mathrm{ml} / \mathrm{min} / 100 \mathrm{~g}$ ) at $\mathrm{T}_{0}$ (group 1: $<1$, group 2: 1-1.99, group 3: $\geq 2$ ). A linear mixed model was used to analyze the association between renovascular resistance at $T_{0}$ and GFR, since it accounts for missing values due to graft failures or recipient death and for the repeated measurements within each recipient. P-values equal or lower than 0.05 were considered statistically significant. Statistical analysis was performed with SPSS for Windows version 16.0.

\section{RESULTS}

\section{Patients}

Between March 1993 and May 2007, 440 machine perfused DCD kidneys from 293 donors were transplanted in 439 patients; 2 kidneys were transplanted as a dual transplant. One hundred forty-six donors (50\%) had both kidneys machine perfused and transplanted, from 108 donors (37\%) only one kidney was machine perfused and from 39 donors (13\%) both kidneys were perfused but only one kidney was transplanted. Kidney discard $(n=39)$ was based on vascular anatomy $(n=8)$, no suitable recipient $(n=8)$, macroscopic appearance $(n=12)$, machine malfunction $(n=2)$, cancelled 
surgery due to recipients problems $(n=2)$, or unknown $(n=7)$. Donor, graft and recipient characteristics are summarized in Table 5.1. Mean donor age was $45 \pm 16$ years. Most kidneys were from controlled Maastricht category $3(n=285)$ or category $4(n=19)$ donors. The mean warm and cold ischemia times were 26 minutes and 28 hour, respectively. The mean kidney weight was $235 \mathrm{~g}$. Donors and recipients predominantly comprised men (63\% men; for donors and recipients).

Table 5.1 Baseline characteristics and their association with primary non-function.

\begin{tabular}{|c|c|c|c|c|c|}
\hline & & \multicolumn{2}{|c|}{ Univariable analysis } & \multicolumn{2}{|c|}{ Multivariable analysis } \\
\hline & & OR (95\% Cl) & $p$-value & OR $(95 \% \mathrm{Cl})$ & $\mathrm{p}$-value \\
\hline $\begin{array}{l}\text { Renovascular resistance } \mathrm{T}_{0} \\
(\mathrm{mmHg} / \mathrm{ml} / \mathrm{min} / 100 \mathrm{~g})\end{array}$ & $1.08 \pm 0.60$ & 1.972 (1.346 to 2.890$)$ & $<0.001$ & 2.040 (1.362 to 3.056$)$ & 0.001 \\
\hline Transplantation year ${ }^{a}$ & & $1.009(0.942$ to 1.081$)$ & 0.793 & & \\
\hline 1993-1997 & $106(24 \%)$ & & & & \\
\hline 1998-2002 & 225 (51\%) & & & & \\
\hline 2003-2007 & $108(25 \%)$ & & & & \\
\hline \multicolumn{6}{|l|}{ Donor related } \\
\hline Donor age (year) & $45 \pm 16$ & 1.019 (1.003 to 1.035$)$ & 0.023 & 1.016 (0.997 to 1.036$)$ & 0.106 \\
\hline Gender (male) & $271(63 \%)$ & 0.979 (0.596 to 1.610$)$ & 0.935 & & \\
\hline $\begin{array}{l}\text { Predonation eGFR } \\
\left(\mathrm{ml} / \mathrm{min} / 1.73 \mathrm{~m}^{2}\right)\end{array}$ & $76 \pm 31$ & $0.996(0.988$ to 1.004$)$ & 0.350 & $0.998(0.988$ to 1.008$)$ & 0.699 \\
\hline $\begin{array}{l}\text { Maastricht category } \\
\text { (uncontrolled) }\end{array}$ & $135(31 \%)$ & 1.029 (0.614 to 1.724$)$ & 0.914 & $1.145(0.586$ to 2.235$)$ & 0.692 \\
\hline \multicolumn{6}{|l|}{ Graft related } \\
\hline Warm ischemia time (min) & $26 \pm 11$ & 1.027 (1.005 to 1.048$)$ & 0.014 & 1.023 (0.999 to 1.049$)$ & 0.062 \\
\hline Cold ischemia time (h) & $28 \pm 8$ & 1.015 (0.986 to 1.045$)$ & 0.310 & 1.030 (0.987 to 1.075$)$ & 0.174 \\
\hline Anastomosis time (min) & $43 \pm 20$ & 1.002 (0.990 to 1.014$)$ & 0.709 & & \\
\hline \multicolumn{6}{|l|}{ Recipient related } \\
\hline Age (year) & $50 \pm 14$ & 1.015 (0.997 to 1.034$)$ & 0.105 & 1.012 (0.989 to 1.035$)$ & 0.303 \\
\hline Gender (male) & $271(63 \%)$ & 1.004 (0.613 to 1.645$)$ & 0.988 & & \\
\hline Re-transplantation & $367(15 \%)$ & 1.174 (0.583 to 2.362$)$ & 0.653 & & \\
\hline Duration of dialysis (year) & $3.5 \pm 2.7$ & 1.097 (1.012 to 1.189$)$ & 0.024 & 1.006 (0.999 to 1.014$)$ & 0.103 \\
\hline Total mismatches & $3 \pm 1$ & $0.958(0.770$ to 1.191$)$ & 0.698 & & \\
\hline PRA $>5 \%(n=168)$ & $18(11 \%)$ & $4.339(0.554$ to 33.965$)$ & 0.162 & & \\
\hline Cyclosporine/tacrolimus/none & $150 / 24 / 48$ & $0.828(0.488$ to 1.404$)$ & 0.483 & & \\
\hline & $(34 / 55 / 11 \%)$ & & & & \\
\hline Induction therapy & $56(15 \%)$ & 0.992 (0.464 to 1.686$)$ & 0.983 & & \\
\hline Sirolimus & $66(15 \%)$ & $0.884(0.464$ to 1.686$)$ & 0.709 & & \\
\hline Antimetabolite $^{\mathrm{b}}$ & $254(58 \%)$ & 1.187 (1.157 to 3.025$)$ & 0.011 & $1.736(0.978$ to 3.080$)$ & 0.060 \\
\hline
\end{tabular}

Renovascular resistance $\mathrm{T}_{0}$ : renovascular resistance at the start of machine perfusion. ${ }^{\text {a }}$ As continuous variable in the univariable analyses; ${ }^{\mathrm{b}}$ Azathioprine or mycophenolate mofetil.

\section{Short-term graft outcome}

Nine patients $(2 \%)$ were lost to follow up or died before short-term graft function could be defined. Kidneys transplanted in these patients were excluded from analysis. Among the others, 84 recipients developed PNF (19.5\%), 262 recipients DGF (61\%) and 
84 recipients IF (19.5\%). Resistance in all groups decreased during machine preservation (Figure 5.1, Table 5.2).

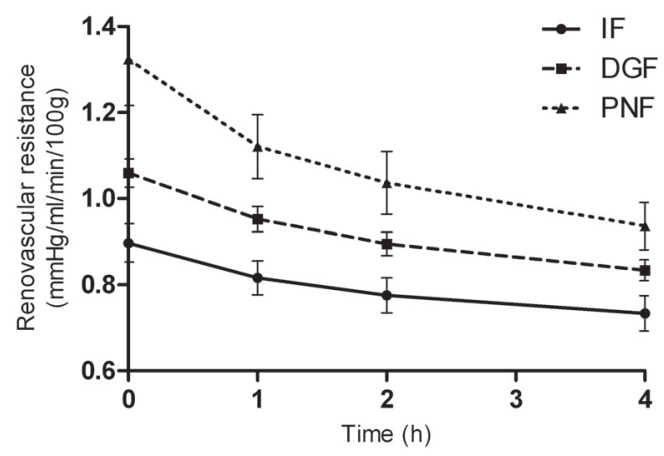

Figure 5.1 Renovascular resistance and its association with primary non-function (PNF), delayed graft function (DGF) and immediate function (IF). Data are presented as means and standard error of the mean.

Table 5.2 Univariable logistic regression analysis for the risk of A. primary non-function (PNF) and B. delayed graft function (DGF) in machine perfused kidneys.

\begin{tabular}{|c|c|c|c|c|c|c|}
\hline A & $\mathrm{N}$ & $\begin{array}{l}\text { Non PNF } \\
(n=346)\end{array}$ & $\mathrm{N}$ & $\begin{array}{c}\text { PNF } \\
(n=84)\end{array}$ & OR $(95 \% \mathrm{Cl})$ & $p$-value \\
\hline $\mathrm{RR}_{0}$ & 318 & $1.02 \pm 0.03$ & 74 & $1.32 \pm 0.11$ & 1.972 (1.346 to 2.890$)$ & $<0.001$ \\
\hline $\mathrm{RR} \mathrm{T}_{1}$ & 342 & $0.92 \pm 0.02$ & 84 & $1.12 \pm 0.07$ & 1.916 (1.263 to 2.906$)$ & 0.002 \\
\hline $\mathrm{RR} \mathrm{T}_{2}$ & 341 & $0.87 \pm 0.02$ & 83 & $1.04 \pm 0.07$ & 1.835 (1.182 to 2.850$)$ & 0.007 \\
\hline $\mathrm{RR} \mathrm{T}_{4}$ & 342 & $0.81 \pm 0.02$ & 83 & $0.94 \pm 0.05$ & 1.891 (1.122 to 3.188 ) & 0.017 \\
\hline AUC & 314 & $0.89 \pm 0.02$ & 72 & $1.09 \pm 0.07$ & 2.240 (1.353 to 3.709 ) & 0.002 \\
\hline B & $\mathrm{N}$ & $\begin{array}{c}\text { IF } \\
(n=84)\end{array}$ & $\mathrm{N}$ & $\begin{array}{c}\text { DGF } \\
(n=262)\end{array}$ & OR $(95 \% \mathrm{Cl})$ & $p$-value \\
\hline $\mathrm{RR}_{0}$ & 78 & $0.90 \pm 0.04$ & 240 & $1.06 \pm 0.03$ & 2.368 (1.212 to 4.628$)$ & 0.012 \\
\hline $\mathrm{RR} \mathrm{T}_{1}$ & 82 & $0.82 \pm 0.04$ & 260 & $0.95 \pm 0.03$ & 2.390 (1.156 to 4.942$)$ & 0.019 \\
\hline $\mathrm{RR} \mathrm{T}_{2}$ & 81 & $0.78 \pm 0.04$ & 260 & $0.89 \pm 0.03$ & 2.327 (1.088 to 4.978$)$ & 0.029 \\
\hline $\mathrm{RR} \mathrm{T}_{4}$ & 81 & $0.73 \pm 0.04$ & 261 & $0.83 \pm 0.02$ & 2.302 (1.025 to 5.168$)$ & 0.043 \\
\hline AUC & 76 & $0.80 \pm 0.04$ & 238 & $0.92 \pm 0.03$ & 2.580 (1.155 to 5.766$)$ & 0.021 \\
\hline
\end{tabular}

RR: renovascular resistance in $\mathrm{mmHg} / \mathrm{ml} / \mathrm{min} / 100 \mathrm{~g}$; AUC: area under the curve; IF: immediate function. Reported values are mean \pm standard error of the mean.

Renovascular resistance (in $\mathrm{mmHg} / \mathrm{ml} / \mathrm{min} / 100 \mathrm{~g}$ ) at $\mathrm{T}_{0}$ of discarded kidneys was higher than that of transplanted kidneys, 1.340 vs. $1.085(p=0.021)$ and comparable with kidneys with PNF 1.340 vs. 1.325 ( $p=0.930)$. A paired samples t-test, however, showed no significant difference in renovascular resistance between discarded kidneys $(n=39)$ and their contralateral transplanted kidneys (1.340 vs. 1.178 , respectively; $\mathrm{p}=0.412$ ). 
Renovascular resistance at each time point and renovascular resistance AUC were significantly associated with PNF, where the association was strongest at $\mathrm{T}_{0}$ with an odds ratio of $1.972(95 \% \mathrm{Cl} 1.346$ to $2.890 ; \mathrm{p}<0.001)$ (Table $5.2 \mathrm{~A})$. Other factors significantly associated with PNF in the univariable analyses include donor age (OR $1.019,95 \% \mathrm{Cl} 1.003$ to $1.035 ; \mathrm{p}=0.023$ ), warm ischemia time (OR $1.027,95 \% \mathrm{Cl} 1.005$ to $1.048 ; p=0.014$ ), recipients' duration of dialysis (OR 1.097, $95 \% \mathrm{Cl} 1.012$ to 1.189 ; $\mathrm{p}=0.024$ ), and whether or not an antimetabolite is given (OR 1.187, 95\% Cl 1.157 to 3.025; $\mathrm{p}=0.011$ ) (Table 5.1). In the multivariable analyses, renovascular resistance at $\mathrm{T}_{0}$ (OR 2.040, 95\% $\mathrm{Cl} 1.362$ to 3.056; $p=0.001$ ) remained a significant risk factor for PNF. Table 5.3 shows the categorized renovascular resistance at $T_{0}$ and its accompanying increasing percentage of PNF.

Table 5.3 Renovascular resistance values and their accompanying percentage of primary non-function.

\begin{tabular}{lcccccc}
\hline $\begin{array}{l}\text { Renovascular resistance } \mathrm{T}_{0} \\
(\mathrm{mmHg} / \mathrm{ml} / \mathrm{min} / 100 \mathrm{~g})\end{array}$ & $\geq 0.5$ & $\geq 1.0$ & $\geq 1.5$ & $\geq 2.0$ & $\geq 2.5$ & $\geq 3.0$ \\
\hline $\mathrm{N}$ & 369 & 160 & 61 & 26 & 12 & 7 \\
Primary non-function & $19 \%$ & $25 \%$ & $26 \%$ & $38 \%$ & $58 \%$ & $85 \%$ \\
\hline
\end{tabular}

The area under the ROC curve (AUC), sensitivity, specificity, positive and negative predictive value were determined for (a) renovascular resistance at $T_{0}$ alone, (b) a model including donor age, predonation eGFR, Maastricht category and warm ischemia time, and (c) model $b$ combined with renovascular resistance at $T_{0}$ (Table 5.4). The AUC of renovascular resistance alone was moderate $(0.609,95 \% \mathrm{Cl}$ 0.538 to 0.681 ). By adding renovascular resistance to model $b$, the AUC slightly increased (model b: $0.636 ; 95 \% \mathrm{Cl} 0.570$ to 0.702 vs. model c: $0.654 ; 95 \% \mathrm{Cl} 0.585$ to 0.723).

Table 5.4 Predictive values of renovascular resistance (RR) at $\mathrm{T}_{0}$.

\begin{tabular}{lccccc}
\hline & $\begin{array}{c}\text { AUC }(95 \% \mathrm{Cl}) \\
\text { (c statistic) }\end{array}$ & Sensitivity & Specificity & $\begin{array}{c}\text { Positive } \\
\text { predictive } \\
\text { value }\end{array}$ & $\begin{array}{c}\text { Negative } \\
\text { predictive } \\
\text { value }\end{array}$ \\
\hline Model a: renovascular & & & & & \\
resistance alone & $0.609(0.538$ to 0.681$)$ & 0.554 & 0.623 & 0.255 & 0.857 \\
Model b (without RR) & $0.636(0.570$ to 0.702$)$ & 0.524 & 0.694 & 0.297 & 0.855 \\
Model c (with RR) & $0.654(0.585$ to 0.723$)$ & 0.528 & 0.729 & 0.314 & 0.868 \\
\hline
\end{tabular}

Model b: donor age, predonation eGFR, Maastricht category and warm ischemia time; Model c: donor age, predonation eGFR, Maastricht category and warm ischemia time and renovascular resistance.

In functioning kidneys univariable analyses showed that renovascular resistance at each time point and renovascular resistance AUC were significantly associated with DGF (Table 5.2B). The same multivariable analysis as described above was repeated to 
determine risk factors for DGF. Renovascular resistance at $\mathrm{T}_{0}$ was an independent risk factor for DGF (OR 2.345, 95\% Cl 1.110 to 4.955; $p=0.025$ ).

\section{Long-term survival}

The median period of follow up after transplantation was 7.2 (range 0 to 16.2) years, including 21 patients (4.8\%) with incomplete follow-up. These patients were censored after a median follow up time of 2.7 years (range 0 to 11.3). Graft survival at 1 and 5 years after transplantation was $74 \%$ and $60 \%$, respectively. Mean GFR of functioning grafts was $36 \pm 18 \mathrm{ml} / \mathrm{min} / 1.73 \mathrm{~m}^{2}$ at 3 months, and $43 \pm 19 \mathrm{ml} / \mathrm{min} / 1.73 \mathrm{~m}^{2}$ at 5 years after transplantation. Patient survival was $76 \%$ and $67 \%$ after 1 and 5 years, respectively. Linear mixed models showed that the trend in GFR was not influenced by renovascular resistance at $T_{0}(p=0.875)$. Resistance at $T_{0}$ was also not significantly related to graft survival ( $p=0.199)$ or patient survival $(p=0.203)$.

Figure 5.2 shows graft survival of all transplanted grafts, delayed functioning and immediate functioning grafts, with resistance categorized in groups. Apparent differences in graft survival between the three resistance groups are mainly caused by PNF rate. Patient survival was similar in all groups (Figure 5.2B).
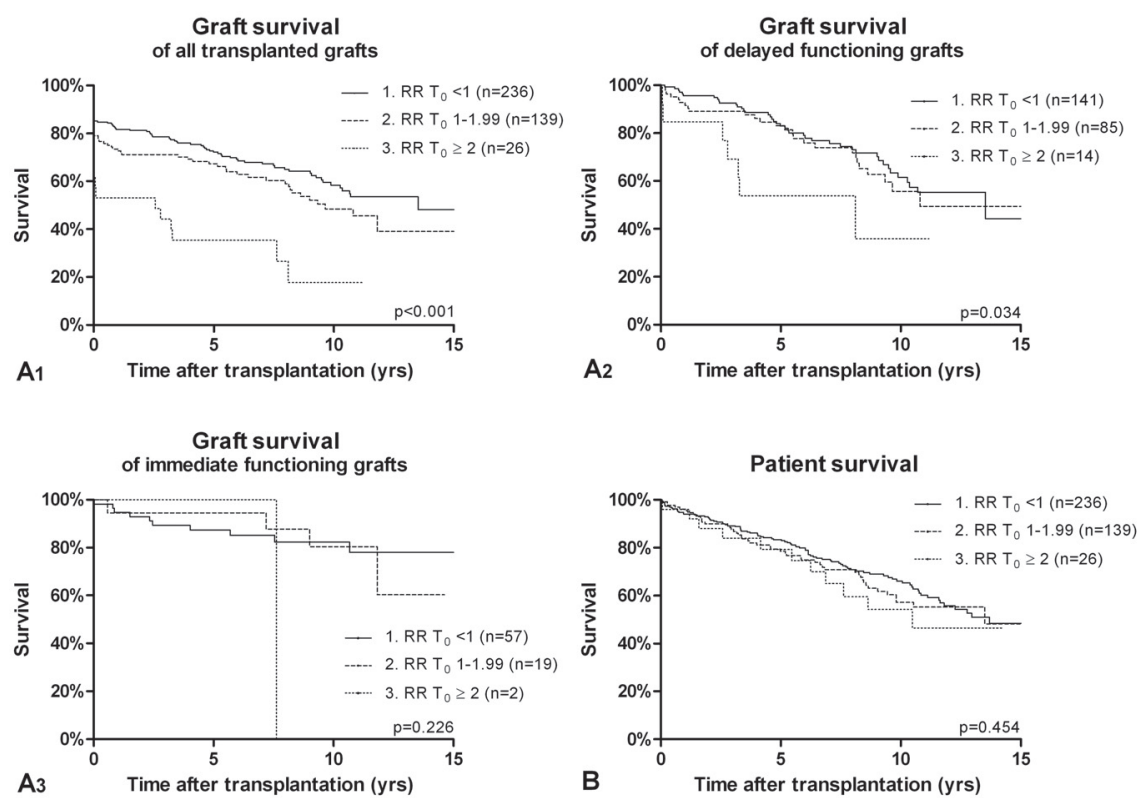

Figure 5.2 Graft and patient survival curves after transplantation of machine perfused donation after cardiac death (DCD) kidneys categorized by renovascular resistance in $\mathrm{mmHg} / \mathrm{ml} / \mathrm{min} / 100 \mathrm{~g}$ (RR), visualized by the Kaplan-Meier curves. (A) Graft survival, in (A1) all transplanted grafts and $(A 2)$ delayed functioning grafts and (A3) immediate functioning grafts, all censored for recipient death with functioning graft, and (B) patient survival 


\section{DISCUSSION}

The use of DCD kidneys provides a valuable extension of the donor pool to meet the constantly growing number of patients on the waiting list for kidney transplantation. Despite the higher percentages of PNF and DGF ${ }^{5,19}$, patients who receive a DCD kidney have better survival rates than patients who continue dialysis treatment while waiting for a kidney from a donor after brain death $(D B D)^{20}$. Moreover, DCD kidneys that overcome the early posttransplantation period function as long as DBD kidneys. Contrary to DBD kidneys, DGF in DCD kidneys hardly, if at all, affects graft survival ${ }^{4,5,13,14,21}$. Therefore it is essential to select kidneys that will never function from those which will either function immediately or after some time. The primary aim of the study was to determine if renovascular resistance, measured during machine perfusion, could provide additional information deciding which kidneys should be discarded and which kidneys have a good chance to eventually function.

The two major methods of preservation are cold storage and machine perfusion. Machine perfusion, generally used for extended criteria donors, has two potential advantages over cold storage. First, it may improve marginal kidneys by preventing interstitial edema, decreasing oxidative stress, improving ATP availability upon reperfusion and by washing out thrombi and harmful metabolic products ${ }^{22,23}$. Two recently published randomized controlled trials comparing both preservation methods showed conflicting results. Moers et al. demonstrated the benefit of machine perfusion compared to cold storage in DCD and DBD kidneys with a reduced risk of DGF and improved graft survival in the first year after transplantation ${ }^{24}$ whereas Watson et al. describe that machine perfusion does not offer advantages over cold storage for DCD kidneys ${ }^{25}$. Second, machine perfusion allows measurement of pretransplantation parameters such as perfusion flow, pressure and renovascular resistance, providing information about the quality of the graft. The evidence that renovascular resistance is a valuable predictor of transplant outcome is poor although several resistance cut off points have been described ${ }^{10,26}$. In Maastricht, from 1993, all procured DCD kidneys were preserved by machine perfusion regardless of preprocurement conditions, a group including very marginal kidneys with a high PNF rate. Therefore we were able to study variables associated with PNF including renovascular resistance by performing multivariable analyses.

Our results show that renovascular resistance at the start of machine perfusion $\left(T_{0}\right)$ is independently associated with PNF. Mean renovascular resistance decreases over time and this decline is more pronounced in PNF kidneys implying that the discriminatory value of renovascular resistance decreases towards transplantation. This is in line with results of Brook et al. ${ }^{27}$ showing that only early renovascular resistance until 60 minutes of machine perfusion accurately reflects differences in 
warm ischemia time in porcine kidneys. In human kidney transplantation the value of renovascular resistance at $T_{0}$ as discriminative time point has not been previously described. Earlier studies only report the mean value of perfusion parameters ${ }^{8,9,26,28}$, or values at $\mathrm{T}_{4}{ }^{10,29}$. Our finding, that recommends the use of renovascular resistance at $\mathrm{T}_{0}$, could be advantageous because early viability assessment enables to decide in an early stage whether or not to use the kidney for transplantation.

The predictive quality of renovascular resistance is moderate and the decision to either accept or discard a kidney remains multifactorial. Nevertheless, we think that renovascular resistance can be a valuable parameter next to other factors to decide whether to transplant a kidney or not. Moreover, in our series, 6 out of 7 kidneys with a renovascular resistance at $T_{0}$ of $>3.0 \mathrm{mmHg} / \mathrm{ml} / \mathrm{min} / 100 \mathrm{~g}$ resulted in $\mathrm{PNF}$, which is unacceptably high because transplantation of nonviable kidneys results in unnecessary risk of surgery and immunosuppression, and sensitizes the recipient for future transplants $^{30}$. Kidneys with DGF had a higher renovascular resistance than immediately functioning kidneys; this finding, however, should not have clinical implications, as long-term survival rates of DCD kidneys with DGF do not significantly differ from DCD kidneys with $\mathrm{IF}^{4,5,13,19,20,31}$.

The reported mean renovascular resistance is higher than values reported by others. First, this may be caused by the relatively poor quality of the perfused DCD kidneys, which becomes apparent from the relatively high percentage of PNF. Second, we have corrected the renovascular resistance for kidney weight, which generally implies a two to threefold increase of the measured resistance value.

We showed that differences in graft survival among transplanted grafts were mainly caused by the presence of PNF. In functioning kidneys there was no statistical association between graft survival and renovascular resistance at $T_{0}$; neither was patient survival associated with renovascular resistance. These findings indicate that renovascular resistance is particularly useful in predicting PNF.

There could have been a selection bias, if kidneys in our series were discarded based on renovascular resistance, but renovascular resistance was not a parameter to discard kidneys for transplantation. All kidneys were accepted for transplantation by the recipient's nephrologists, based on the combination of donor, graft and recipients characteristics. They were not informed of machine preservation parameters. Resistance of the discarded kidneys was equivalent to the resistance of transplanted contralateral kidneys. However, the number of kidneys that could be compared was too small to draw firm conclusions from this finding. Furthermore, unobserved arterial leakage during perfusion may have affected flow and pressure registration. This could have resulted in an underestimation of the measured renovascular resistance in poorly functioning kidneys. Moreover, the number of variables included into the analysis was 
limited to optimize statistical accuracy. This implies that other possibly relevant risk factors were not included in the multivariable risk analysis.

In conclusion, we demonstrated that renovascular resistance at the start of machine perfusion is an independent risk factor for PNF. The predictive value, however, is relatively low. 


\section{REFERENCES}

1. Wolfe RA, Ashby VB, Milford EL, Ojo AO, Ettenger RE, Agodoa LY, Held PJ, Port FK. Comparison of mortality in all patients on dialysis, patients on dialysis awaiting transplantation, and recipients of a first cadaveric transplant. N Engl J Med 1999;341:1725-30.

2. Rabbat CG, Thorpe KE, Russell JD, Churchill DN. Comparison of mortality risk for dialysis patients and cadaveric first renal transplant recipients in Ontario, Canada. J Am Soc Nephrol 2000;11:917-22.

3. McDonald SP, Russ GR. Survival of recipients of cadaveric kidney transplants compared with those receiving dialysis treatment in Australia and New Zealand, 1991-2001. Nephrol Dial Transplant 2002; 17:2212-9.

4. Weber M, Dindo D, Demartines N, Ambuhl PM, Clavien PA. Kidney transplantation from donors without a heartbeat. N Engl J Med 2002;347:248-55.

5. Cho YW, Terasaki PI, Cecka JM, Gjertson DW. Transplantation of kidneys from donors whose hearts have stopped beating. N EnglJ Med 1998;338:221-5.

6. Cooper JT, Chin LT, Krieger NR, Fernandez LA, Foley DP, Becker YT, Odorico JS, Knechtle SJ, Kalayoglu $M$, Sollinger HW, D'Alessandro AM. Donation after cardiac death: the university of wisconsin experience with renal transplantation. Am J Transplant 2004;4:1490-4.

7. Matsuno N, Konno O, Mejit A, Jyojima Y, Akashi I, Nakamura Y, Iwamoto H, Hama K, Iwahori T, Ashizawa T, Nagao T. Application of machine perfusion preservation as a viability test for marginal kidney graft. Transplantation 2006;82:1425-8.

8. Sung RS, Christensen LL, Leichtman AB, Greenstein SM, Distant DA, Wynn JJ, Stegall MD, Delmonico FL, Port FK.. Determinants of discard of expanded criteria donor kidneys: impact of biopsy and machine perfusion. Am J Transplant 2008;8:783-92.

9. Nyberg SL, Baskin-Bey ES, Kremers W, Prieto M, Henry ML, Stegall MD. Improving the prediction of donor kidney quality: deceased donor score and resistive indices. Transplantation 2005;80:925-9.

10. Mozes MF, Skolek RB, Korf BC. Use of perfusion parameters in predicting outcomes of machinepreserved kidneys. Transplant Proc 2005;37:350-351.

11. Renkens JJ, Rouflart MM, Christiaans MH, van den Berg-Loonen EM, van Hooff JP, van Heurn LW. Outcome of nonheart-beating donor kidneys with prolonged delayed graft function after transplantation. Am J Transplant 2005;5:2704-9.

12. Troppmann C, Gillingham KJ, Gruessner RW, Dunn DL, Payne WD, Najarian JS, Matas AJ. Delayed graft function in the absence of rejection has no long-term impact. A study of cadaver kidney recipients with good graft function at 1 year after transplantation. Transplantation 1996;61:1331-7.

13. Wijnen RM, Booster MH, Stubenitsky BM, de Boer J, Heineman E, Kootstra G. Outcome of transplantation of non-heart-beating donor kidneys. Lancet 1995;345:1067-70.

14. Gok MA, Buckley PE, Shenton BK, Balupuri S, El-Sheikh MA, Robertson H, Soomro N, Jaques BC, Manas DM, Talbot D. Long-term renal function in kidneys from non-heart-beating donors: A single-center experience. Transplantation 2002;74:664-9.

15. Kootstra G, Daemen JH, Oomen AP. Categories of non-heart-beating donors. Transplant Proc 1995; 27:2893-4.

16. Snoeijs MG, Dekkers AJ, Buurman WA, van den Akker L, Welten RJ, Schurink GW, van Heurn LW. In situ preservation of kidneys from donors after cardiac death: results and complications. Ann Surg 2007; 246:844-52.

17. de Vries EE, Snoeijs MG, van Heurn E. Kidney donation from children after cardiac death. Crit Care Med 2010;38:249-53.

18. Poge U, Gerhardt T, Palmedo H, Klehr HU, Sauerbruch T, Woitas RP. MDRD equations for estimation of GFR in renal transplant recipients. Am J Transplant 2005;5:1306-11.

19. Snoeijs MG, Winkens B, Heemskerk MB, Hoitsma AJ, Christiaans MH, Buurman WA, van Heurn LW. Kidney Transplantation From Donors After Cardiac Death: A 25-Year Experience. Transplantation 2010; 90:1106-12.

20. Snoeijs MG, Schaubel DE, Hené R, Hoitsma AJ, Idu MM, ljzermans JN, Ploeg RJ, Ringers J, Christiaans $\mathrm{MH}$, Buurman WA, van Heurn LW. Kidneys from donors after cardiac death provide survival benefit. J Am Soc Nephrol 2010;21:1015-21. 
21. Yarlagadda SG, Coca SG, Formica RN, Jr., Poggio ED, Parikh CR. Association between delayed graft function and allograft and patient survival: a systematic review and meta-analysis. Nephrol Dial Transplant 2009;24:1039-47.

22. Maathuis $\mathrm{MH}$, Manekeller S, van der Plaats A, Leuvenink HG, 't Hart NA, Lier AB, Rakhorst G, Ploeg RJ, Minor T. Improved kidney graft function after preservation using a novel hypothermic machine perfusion device. Ann Surg 2007;246:982-8.

23. McLaren AJ, Friend PJ. Trends in organ preservation. Transpl Int 2003;16:701-8.

24. Moers C, Smits JM, Maathuis MH, Treckmann J, van Gelder F, Napieralski BP, van Kasterop-Kutz M, van der Heide JJ, Squifflet JP, van Heurn E, Kirste GR, Rahmel A, Leuvenink HG, Paul A, Pirenne J, Ploeg RJ. Machine perfusion or cold storage in deceased-donor kidney transplantation. N Engl J Med 2009; 360:7-19.

25. Watson CJ, Wells AC, Roberts RJ, Akoh JA, Friend PJ, Akyol M, Calder FR, Allen JE, Jones MN, Collett D, Bradley JA. Cold machine perfusion versus static cold storage of kidneys donated after cardiac death: a UK multicenter randomized controlled trial. Am J Transplant 2010;10:1991-9.

26. Guarrera JV, Goldstein MJ, Samstein B, Henry S, Reverte C, Arrington B, Brown T, Coleman TK, Mattei G, Mendez N, Kelly J, Ratner LE. 'When good kidneys pump badly': outcomes of deceased donor renal allografts with poor pulsatile perfusion characteristics. Transpl Int 2009;23:444-6.

27. Brook NR, Knight AJ, Nicholson ML. Intra-renal resistance reflects warm ischaemic damage, and is further increased by static cold storage: a model of non-heart-beating donor kidneys. Med Sci Monit 2003;9:BR271-5.

28. Sonnenday CJ, Cooper M, Kraus E, Gage F, Handley C, Montgomery RA. The hazards of basing acceptance of cadaveric renal allografts on pulsatile perfusion parameters alone. Transplantation 2003;75:2029-33.

29. Daemen JH, de Vries B, Kootstra G. The effect of machine perfusion preservation on early function of non-heart-beating donor kidneys. Transplant Proc 1997;29:3489.

30. Billen EV, Christiaans MH, Lee J, van den Berg-Loonen EM. Donor-directed HLA antibodies before and after transplantectomy detected by the luminex single antigen assay. Transplantation 2009;87:563-9.

31. Sánchez-Fructuoso Al, Marques M, Prats D, Conesa J, Calvo N, Pérez-Contín MJ, Blazquez J, Fernández C, Corral E, Del Río F, Núñez JR, Barrientos A. Victims of cardiac arrest occurring outside the hospital: a source of transplantable kidneys. Ann Intern Med 2006; 145:157-64. 


\section{ABSTRACT}

Background Donation after cardiac death (DCD) increases the number of donor kidneys but is associated with more primary non-function (PNF) and delayed graft function (DGF). It has been suggested that biomarkers in the preservation solution of machine perfused kidneys may predict PNF although evidence is lacking.

Methods We analyzed the diagnostic accuracy of the perfusate biomarkers GST, LDH, H-FABP, redox-active iron, IL-18 and NGAL to predict PNF and DGF in 335 DCD kidneys, preserved by hypothermic machine perfusion at our center between 1 January 1997 and 1 January 2008. The diagnostic accuracy of these biomarkers to predict PNF was evaluated with the area under the receiver operator characteristics curves (AURC). Additionally, the risk of DGF and graft failure was assessed.

Results LDH and IL-18 concentrations were associated with PNF (OR 1.001, 95\%Cl 1.000 to 1.002 , $\mathrm{p}=0.005$ and $1.001,95 \% \mathrm{Cl} 1.000$ to $1.002, p=0.003$, respectively) in a multivariate analysis; the diagnostic accuracy for PNF was 'poor' for all biomarkers, but increased to 'fair' for redox-active iron and IL-18 in a multivariate analysis (AURC 0.701 and 0.700 , respectively). LDH and IL-18 concentrations were associated with DGF, biomarker concentration was not associated with 1-year graft survival.

Conclusions The diagnostic accuracy of the perfusate biomarkers GST, LDH, H-FABP, redox-active iron, IL-18 and NGAL to predict viability of DCD kidneys varies from 'poor' to 'fair'. Therefore, DCD kidneys should not be discarded because of high biomarker perfusate concentration. 


\section{INTRODUCTION}

Renal transplantation is the treatment of choice for patients with end stage renal disease on dialysis treatment ${ }^{1,2}$. The growing waiting list for kidney transplantation has led to the use of kidneys from donors after cardiac death (DCD) as alternative organ source. Kidneys from these donors inevitably suffer from a period of warm ischemia (WIT), resulting in a higher percentage of delayed graft function (DGF) and primary non-function (PNF) compared to kidneys from conventional brain-dead donors $(\mathrm{DBD})^{3-5}$.

In recent years, kidney preservation by hypothermic machine perfusion has experienced renewed interest. In addition to the intended benefit of improved tissue preservation, machine perfusion also provides the opportunity to assess organ viability with the help of perfusion parameters and biomarkers in the perfusate ${ }^{6,7}$. The assessment of organ viability is especially important in marginal kidneys with their increased risk of developing DGF and particularly PNF. Perfusate biomarkers including glutathione S-transferase (GST) and lactate dehydrogenase (LDH) are promising or accepted tools to accept or discard kidneys for transplantation ${ }^{8-10}$. However, the value of perfusate biomarkers to predict organ viability is not or hardly known. Previous studies only assessed the value of biomarker concentration in selected kidneys and described the improvement of the results of DCD transplantation after introduction of perfusate biomarkers to assess organ viability. Other studies included limited numbers of kidneys with an a priori good prognosis, and therefore without adequate power to determine if perfusate biomarker concentration can be safely used to discard valuable kidneys for transplantation ${ }^{10-14}$.

We evaluated the predictive value of the concentration of different perfusate biomarkers, GST, LDH, heart-type fatty acid binding protein (H-FABP) and redox-active iron of a large unselected group of DCD kidneys with a relatively poor prognosis and a high incidence of graft failure, in which perfusion parameters and biomarkers have not been used to discard the organs. Additionally, new potential biomarkers IL-18 and neutrophil gelatinase-associated lipocalin (NGAL) were measured.

\section{MATERIALS AND METHODS}

All DCD kidneys preserved with hypothermic pulsatile machine perfusion at our center between 1 January 1997 and 1 January 2008, which were transplanted within the Eurotransplant region, were analyzed. This included kidneys procured at our center and kidneys procured elsewhere which were either transplanted at our center or elsewhere. 


\section{Organ procurement and preservation}

Kidneys were procured from uncontrolled (category 1 and 2) and controlled donors (category 3 and 4 ) according to the Maastricht DCD categories ${ }^{15,16}$. Kidneys were preserved with in situ preservation using a double-balloon triple-lumen (DBTL) catheter or with direct aortic cannulation after rapid laparotomy ${ }^{16,17}$. After donor nephrectomy, the kidneys were weighed and placed in sterile organ chambers on Gambro PF-3B perfusion machines (Gambro, Lund, Sweden). Kidneys were perfused with $500 \mathrm{ml}$ of UW-MPS (Belzer MPS, Trans-Med Corporation, MN, USA) at a mean temperature of $4^{\circ} \mathrm{C}$. After connection of the kidney to the machine, perfusion flow was set to a systolic pressure of $55 \mathrm{mmHg}$, which was maintained during the first 60 minutes by adjusting machine flow. After this, renal flow was kept constant. During perfusion, $\mathrm{pH}$ was adjusted to values $>7.10$.

\section{Sample collection and measurement}

Perfusate samples for biochemical analysis were taken at 1, 2 and 4 hours of perfusion $\left(T_{1}, T_{2}\right.$ and $T_{4}$, respectively). Samples were immediately stored at $-80^{\circ} \mathrm{C}$. The assays used for detection of GST and LDH were routine assays from our local laboratory. GST activity was determined by measuring the enzyme-catalyzed conjugation of GST with 1-chloro-2,4-dinitrobenzene, using a spectrophotometer at $\lambda 340 \mathrm{~nm}$. LDH measurement is based on the measurement of $\mathrm{NAD}^{+}$formed via the enzymatic reaction of $L D H$ with pyruvate and $N A D H$, using a spectrophotometer at $\lambda 340 \mathrm{~nm}$. For H-FABP standard ELISA kits from Hycult Biotechnology (Human H-FABP ELISA kit, cat. number HK401) were used. For redox-active iron measurements, the bleomycin detectable iron assay, used before by our group, was applied ${ }^{18}$.

At $T_{0}-T_{4}$, machine perfusion characteristics (temperature, pressure, flow and renovascular resistance) were registered. Perfusate biomarker concentration is expressed per $100 \mathrm{~g}$ kidney weight.

Additionally, IL-18 and NGAL concentrations, of transplanted kidneys only, at 4 hours after start of machine perfusion were measured. For NGAL and IL-18, standard ELISA kits from Biorbyt were used (Human Lipocalin-2 ELISA kit, cat. number orb50149 and Human IL-18 ELISA kit, cat. number orb50153, respectively).

\section{Donor and recipient data}

Donor and perfusion characteristics were routinely recorded at our institution. Recipient follow-up data was kindly provided by the recipient transplant centers, and was periodically updated in our database. The following graft characteristics were recorded: WIT, the period from circulatory arrest or stop of resuscitation until the initial cold flush; CIT, the period between the initial flush and the start of first 
anastomosis; and the anastomosis period, the time to complete both vascular anastomoses. Short-term graft function after transplantation was classified as 1) PNF: permanent inadequate renal function necessitating continuation of dialysis or retransplantation; 2) DGF: renal function which was ultimately life sustaining but required temporary dialysis in the first week after transplantation; and 3) immediate function (IF): renal function without the need of postoperative dialysis.

The immunosuppressive regimen evolved over the study period and depended on different trials. Immunosuppression was mainly based on a combination of a calcineurin inhibitor (cyclosporin or tacrolimus) and prednisolone. Depending on the protocol at the time, these were combined with azathioprine, mycophenolate mofetil, sirolimus or daclizumab in recipients with an increased immunological risk (e.g. HLA immunization and re-transplants).

Collection, storage and use of patient data were performed in agreement with the code of conduct 'use of data in health research' from the Dutch Federation of Biomedical Scientific Societies (http://www.federa.org/); According to Dutch law, Institutional Review Board (IRB) approval was not required for scientific analysis of anonymous data.

\section{Statistical analysis}

Continuous variables are presented as means \pm standard deviations (SD) if approximately normally distributed, and as median and inter-quartile range (IQR) otherwise. Categorical variables are presented as percentages.

Biomarker concentrations at four hours after the start of machine perfusion $\left(\mathrm{T}_{4}\right)$ of discarded kidneys were compared with the biomarker concentrations of all transplanted kidneys and kidneys with PNF, using a Mann-Whitney-U test, and compared with their contralateral kidneys using a paired samples T-test or Wilcoxon signed rank test where appropriate.

The association between biomarker concentration at $T_{4}$ and transplant outcome was first tested with univariate logistic regression analysis. For each biomarker, a multivariate logistic regression model was then applied to the data, correcting for potential confounders based on clinically relevance. Additionally, Cox proportional hazards model was used to assess the effect of these biomarkers on graft failure of functioning kidneys within one year after transplantation, correcting for the same confounders.

The predictive value of individual biomarker concentrations and of biomarker concentrations in addition to clinically relevant confounders were assessed by the area under the ROC-curve (AURC).

Correlations between biomarkers and estimated GFR (eGRF), calculated with the abbreviated modification of diet in renal disease equation (MDRD), at one year after 
transplantation and between biomarkers and perfusate hemoglobin were evaluated with the Pearson's test for normally distributed data and the Spearman's test otherwise.

Graft survival censored for recipient death with a functioning graft was calculated with the Kaplan-Meier method; the log-rank test was used to compare the survival curves of the specific biomarker concentration below and above the median.

All analyses were performed using Statistical Package for the Social Sciences (SPSS) software version 16.0; a $p$-value $\leq 0.05$ was considered statistically significant.

\section{RESULTS}

\section{Patients}

Between January 1997 and 2007, 517 DCD kidneys were machine perfused. 153 of these kidneys were discarded, based on vascular anatomy (e.g. multiple renal arteries, renal artery stenosis), macroscopic appearance (e.g. poor flush-out, cysts, renal capsula tears), long WIT or if there were no suitable recipients. Of the remaining 364 kidneys, one pair of kidneys was a dual transplant and analyzed as one kidney. Excluded from analysis were 16 kidneys with major leakage at the arterial connection to the machine or without complete machine perfusion records, 10 kidneys transplanted outside the Eurotransplant region and two recipients who died with an unknown graft function. The remaining 335 machine perfused DCD kidneys entered analysis.

Donor, graft and recipient characteristics are summarized in Table 6.1. Mean donor age was $45 \pm 16$ years. Most kidneys were from controlled donors (73\%). The mean warm and cold ischemia times (CIT) were $26 \pm 11$ minutes and $27 \pm 6$ hours, respectively. Donors and recipients predominantly comprised of men (61\% and 63\%, respectively).

\section{Discarded kidneys}

GST and LDH concentrations (in $\mathrm{U} / \mathrm{l} / 100 \mathrm{~g}$ ) at $\mathrm{T}_{4}$ of discarded kidneys were higher than that of transplanted kidneys (median 101.3 vs. 59.1, $\mathrm{p}<0.001$ and 682.7 vs. 495.8, $\mathrm{p}<0.001$, respectively). Compared to the transplanted kidneys with PNF, GST was significantly higher in the discarded kidneys (median 65.6 vs. 101.3, $p<0.001$, respectively). A paired samples test however, showed no significant difference in GST $(n=25)$ and LDH $(n=22)$ concentrations between discarded kidneys and their contralateral transplanted kidney (median GST 80.0 vs. 88.2 and LDH 715.2 vs. 726.0, Wilcoxon signed rank test $p=0.989$ and $p=0.506$, respectively). 
Table 6.1 Baseline characteristics and their association with primary non-function.

\begin{tabular}{|c|c|c|c|}
\hline & & \multicolumn{2}{|c|}{ Univariate analysis } \\
\hline & & OR $(95 \% \mathrm{Cl})$ & $\mathrm{p}$ \\
\hline \multicolumn{4}{|l|}{ Donor related } \\
\hline Donor age (years) & $45 \pm 16$ & $1.017(0.998-1.035)$ & 0.076 \\
\hline Donor sex (male) & 205 (61\%) & $0.895(0.513-1.559)$ & 0.694 \\
\hline Donor creatinine $(\mu \mathrm{mol} / \mathrm{l})$ & $93 \pm 38$ & $1.002(0.995-1.009)$ & 0.612 \\
\hline Maastricht category (uncontrolled) & $91(27 \%)$ & $1.078(0.594-1.955)$ & 0.806 \\
\hline Donor center (MUMC / other) ${ }^{b}$ & 34 / $66 \%$ & $1.052(0.595-1.858)$ & 0.862 \\
\hline \multicolumn{4}{|l|}{ Graft related } \\
\hline Warm ischemia time (min) & $26 \pm 11$ & $1.029(1.004-1.054)$ & 0.024 \\
\hline Cold ischemia time $(\mathrm{h})$ & $27 \pm 6$ & $0.997(0.955-1.041)$ & 0.890 \\
\hline Of which machine perfusion time (h) & $21 \pm 6$ & $1.004(0.961-1.049)$ & 0.854 \\
\hline Anastomosis time (min) & $42 \pm 17$ & $1.015(1.000-1.030)$ & 0.051 \\
\hline $\mathrm{GST} \mathrm{T}_{4}(\mathrm{U} / \mathrm{l} / 100 \mathrm{~g})$ & $59.1(37.5-91.6)^{a}$ & $1.004(1.000-1.009)$ & 0.043 \\
\hline $\mathrm{LDH} \mathrm{T}_{4}(\mathrm{U} / \mathrm{l} / 100 \mathrm{~g})$ & $495(340-740)^{a}$ & $1.001(1.001-1.002)$ & 0.001 \\
\hline $\mathrm{H}-\mathrm{FABP}_{4}(\mathrm{pg} / \mathrm{l} / 100 \mathrm{~g})$ & $55.2(36.1-95.3)^{a}$ & $1.004(1.000-1.007)$ & 0.048 \\
\hline Redox-active iron $T_{4}(\mu \mathrm{mol} / \mathrm{l} / 100 \mathrm{~g})(\mathrm{n}=187)$ & $3.9 \pm 1.1$ & $1.522(1.077-2.152)$ & 0.017 \\
\hline IL-18 (pg/ml/100 g) (n=299) & $373(226-600)^{a}$ & $1.001(1.000-1.002)$ & 0.001 \\
\hline $\mathrm{NGAL} \mathrm{T}_{4}(\mathrm{ng} / \mathrm{ml} / 100 \mathrm{~g})(\mathrm{n}=290)$ & $18.4(10.2-29.1)^{\mathrm{a}}$ & $0.996(0.979-1.013)$ & 0.323 \\
\hline Renovascular resistance $T_{0}$ & $1.06 \pm 0.69$ & $1.896(1.306-2.752)$ & 0.001 \\
\hline \multicolumn{4}{|l|}{ Recipient related } \\
\hline Recipient age & $51 \pm 13$ & $1.011(0.990-1.033)$ & 0.294 \\
\hline Recipient sex (male) & $210(63 \%)$ & $0.854(0.494-1.477)$ & 0.572 \\
\hline Re-transplantation (yes) & $48(14 \%)$ & $0.911(0.418-1.988)$ & 0.815 \\
\hline Total HLA mismatches & $2.6 \pm 1.1$ & $0.906(0.705-1.165)$ & 0.443 \\
\hline Transplant center (regional / export) & $42 / 58 \%$ & $1.000(0.581-1.721)$ & $>0.999$ \\
\hline Kidney disease (renovascular / other) & $26 / 74 \%$ & $0.938(0.486-1.807)$ & 0.847 \\
\hline Dialysis time (years) & $3.1 \pm 2.4$ & $1.132(1.022-1.254)$ & 0.017 \\
\hline Dialysis type (hemodialysis) & 202 (61\%) & $1.170(0.670-2.045)$ & 0.581 \\
\hline Peak PRA & $4.1 \pm 14.1$ & $0.986(0.948-1.026)$ & 0.499 \\
\hline Cyclosporine/tacrolimus/none (\%) & $28 / 68 / 4 \%$ & $1.136(0.612-2.109)$ & 0.687 \\
\hline Anti-metabolite (yes) & $208(62 \%)$ & $0.601(0.350-1.031)$ & 0.065 \\
\hline Sirolimus (yes) & $60(18 \%)$ & $1.132(0.572-2.240)$ & 0.722 \\
\hline Induction therapy (yes) & $42(13 \%)$ & $1.105(0.501-2.437)$ & 0.805 \\
\hline
\end{tabular}

${ }^{\mathrm{a}}$ Expressed as median (interquartile range); ${ }^{\mathrm{b}}$ MUMC: Maastricht University Medical Centre

\section{Short-term graft function}

Of the transplanted kidneys, 67 kidneys developed PNF (20\%), 205 kidneys DGF (61\%) and 63 kidneys IF (19\%).

The perfusate concentrations of the different biomarker concentrations at $T_{4}$ of functioning kidneys and kidneys with PNF are shown in Table 6.2. In separate multivariate analyses of biomarker concentrations at $\mathrm{T}_{4}$, only $\mathrm{LDH}$ and IL-18 were independent risk factors for PNF and LDH, redox-active iron and IL-18 were independent risk factors for DGF (Table 6.3). 
Table 6.2 Differences in biomarker concentration of functioning kidneys and kidneys with PNF.

\begin{tabular}{lccc}
\hline & No PNF & PNF & P \\
\hline GST $(\mathrm{U} / \mathrm{l} / 100 \mathrm{~g})^{\mathrm{a}}$ & $55.7(36.5-87.7)$ & $65.6(48.1-100.7)$ & 0.034 \\
LDH $(\mathrm{U} / \mathrm{l} / 100 \mathrm{~g})^{\mathrm{a}}$ & $477.5(330.4-679.6)$ & $631.3(417.3-870.9)$ & 0.002 \\
H-FABP $(\mathrm{pg} / \mathrm{l} / 100 \mathrm{~g})^{\mathrm{a}}$ & $53.9(36.1-94.3)$ & $67.3(35.8-142.9)$ & 0.176 \\
Redox-active iron $(\mu \mathrm{mol} / \mathrm{l} / 100 \mathrm{~g})$ & $3.8 \pm 1.1$ & $4.3 \pm 1.1$ & 0.015 \\
IL-18 $(\mathrm{pg} / \mathrm{ml} / 100 \mathrm{~g})^{\mathrm{a}}$ & $357.6(225.7-533.5)$ & $472.9(227.0-933.4)$ & 0.031 \\
NGAL $(\mathrm{ng} / \mathrm{ml} / 100 \mathrm{~g})^{\mathrm{a}}$ & $17.6(10.2-29.2)$ & $19.3(10.4-26.1)$ & 0.953 \\
\hline
\end{tabular}

${ }^{a}$ Expressed as median (interquartile range)

The ROC-curves of all individual biomarker concentrations are shown in Figure 6.1A and $6.2 \mathrm{~B}$ with the area under the ROC-curve (AURC) and $95 \% \mathrm{Cl}$ shown between brackets. The predictive values of $\mathrm{LDH}$ and redox-active iron at $\mathrm{T}_{4}$ for PNF were highest, but poor. Adding biomarker concentrations to a multivariate model with clinical risk factors only (donor age, donor category, WIT, CIT, anastomosis time and renovascular resistance at $\mathrm{T}_{0}$ ) with an AURC of $0.686,95 \% \mathrm{Cl} 0.612-0.760$ (graph not shown), showed a modest improvement for $\mathrm{LDH}$, redox-active iron and IL-18 (Figure 6.1C and 6.1D).

A

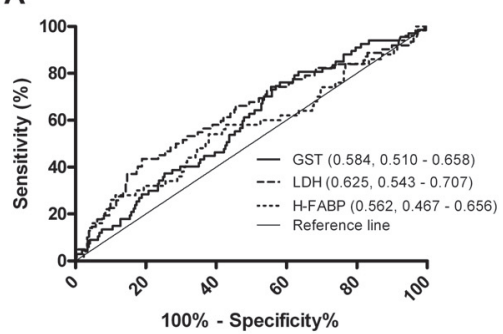

C

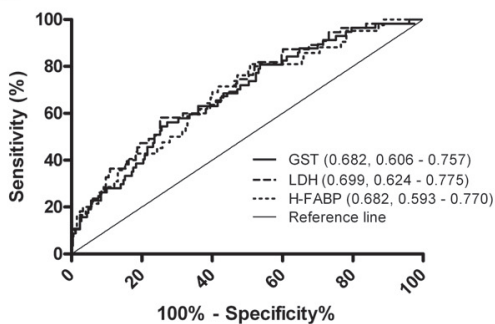

B

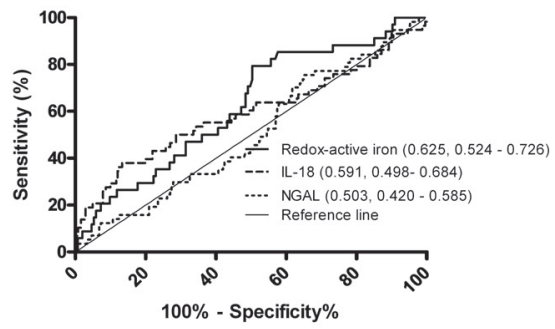

D

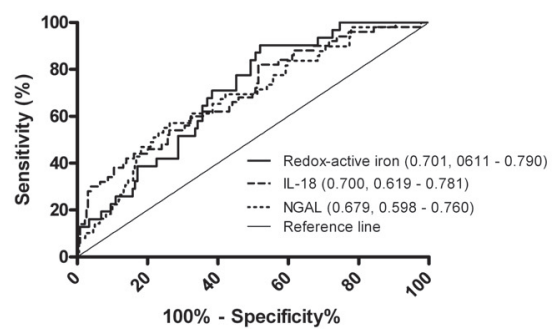

Figure 6.1 Receiver operating characteristics (ROC)-curve for PNF: (A) individual GST, LDH and H-FABP concentrations at $\mathrm{T}_{4},(B)$ individual redox-active iron, IL-18 and NGAL concentrations at $\mathrm{T}_{4},(\mathrm{C})$ ROC-curve of the multivariate model with individual biomarkers (GST, LDH and H-FABP); other variables are donor age, donor category (uncontrolled/controlled), warm ischemia time, cold ischemia time, anastomosis time and renovascular resistance at $T_{0}$ and (D) multivariate model with individual biomarkers (redox-active iron, IL-18 and NGAL), with the same variables as (C). The number in brackets indicates the area under the curve for each line and the accompanying $95 \% \mathrm{Cl}$. 
Redox-active iron and LDH concentrations were weakly correlated with perfusate haemoglobin concentration ( $r=.216, \mathrm{p}=0.004$ and $r_{s}=.362, \mathrm{p}<0.001$, respectively), indicating that iron and $\mathrm{LDH}$ release from erythrocytes still present in the graft after flush-out may represent a minor contribution to the perfusate redox-active iron and LDH concentration.

\section{Long-term graft survival}

The median follow-up after transplantation was 6.8 (IQR 4.0-9.3) years. Deathcensored graft survival at 1 and 5 years after transplantation was $76 \%$ and $68 \%$, respectively.

In multivariate Cox proportional hazards models, biomarker concentrations were not significantly associated with the risk of graft failure in the first year after transplantation (Table 6.3).

Only LDH was significantly correlated with eGFR at one year after transplantation $\left(r_{s}=-.177, \mathrm{p}=0.006\right)$. Other biomarkers showed a non-significant negative correlation with eGFR (data not shown), except for redox-active iron $\left(r_{s}=.023, \mathrm{p}=0.785\right)$.

Table 6.3 Multivariate analysis for primary non-function, delayed graft function and graft failure ${ }^{a, b}$.

\begin{tabular}{lcc}
\hline & Odds ratio $(95 \% \mathbf{C l})$ & $\mathbf{p}$ \\
\hline Risk of PNF (biomarker concentration at $\left.\mathrm{T}_{4}\right)$ & & \\
GST & $1.004(0.998-1.009)$ & 0.161 \\
LDH & $1.001(1.000-1.002)$ & 0.005 \\
H-FABP & $1.002(0.998-1.007)$ & 0.280 \\
Redox-active iron & $1.462(0.974-2.195)$ & 0.067 \\
IL-18 & $1.001(1.000-1.002)$ & 0.003 \\
NGAL & $0.999(0.980-1.018)$ & 0.919 \\
Risk of DGF (biomarker concentration at $\left.\mathrm{T}_{4}\right)$ & & \\
GST & $1.006(0.999-1.013)$ & 0.112 \\
LDH & $1.002(1.001-1.004)$ & 0.007 \\
H-FABP & $1.007(1.000-1.014)$ & 0.064 \\
Redox-active iron & $1.532(1.045-2.245)$ & 0.029 \\
IL-18 & $1.003(1.001-1.004)$ & 0.002 \\
NGAL & $1.000(0.982-1.018)$ & 0.994 \\
\hline & Hazards ratio (95\% Cl) & $\mathbf{p}$ \\
\hline Risk of graft failure within the first year posttransplant ${ }^{c}$ & & \\
GST & $0.993(0.978-1.008)$ & 0.348 \\
LDH & $0.998(0.996-1.001)$ & 0.223 \\
H-FABP & $0.987(0.969-1.005)$ & 0.165 \\
Redox-active iron & $0.999(0.552-1.808)$ & 0.997 \\
IL-18 & $1.000(0.998-1.002)$ & 0.996 \\
NGAL & $0.996(0.961-1.032)$ & 0.819 \\
\hline
\end{tabular}

a For each biomarker, a separate multivariate analysis was done. Only the odds ratios and the p-values of for the specific biomarker are given. $b$ Other variables in each model were donor age, donor category (uncontrolled/controlled), warm ischemia time, cold ischemia time, anastomosis time and renovascular resistance at T0. c Cox proportional hazards model of functional kidneys, censored for death with a functioning graft. 
Figure 6.2 shows the graft survival of all transplanted kidneys for biomarker concentrations below and above the mean or median. For GST, LDH and H-FABP, a concentration above the median resulted in a significantly shorter graft survival. Graft survival was equivalent for kidneys with redox-active iron, IL-18 and NGAL concentrations below or above the mean or median. Additionally, Cox proportional hazards model was used to see whether this effect of biomarker concentrations above the median persisted after correction for potential confounders. None of the biomarkers remained significant in this analysis (data not shown).
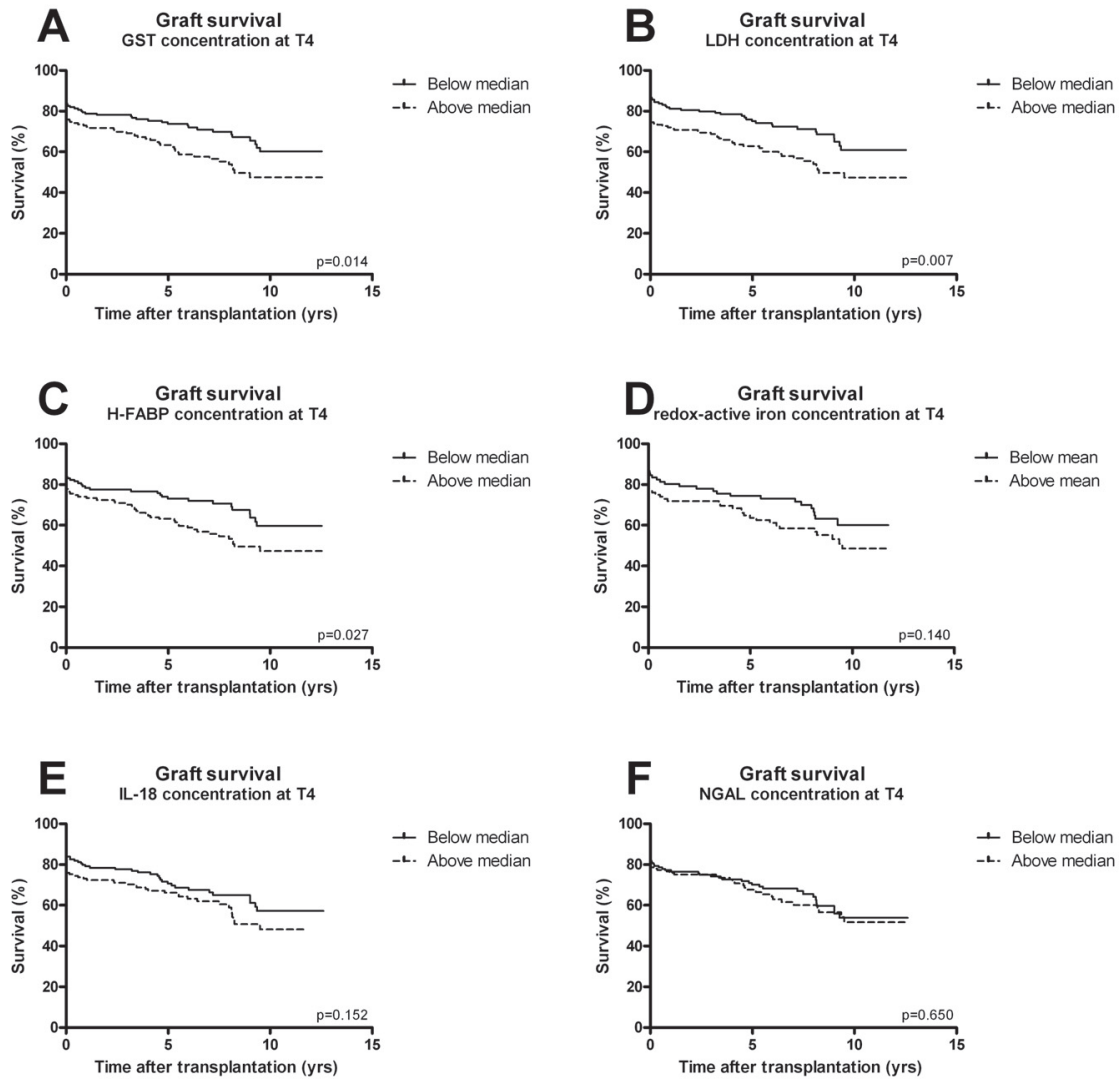

Figure 6.2 Kaplan-Meier graft survival curves of all transplanted machine perfused DCD kidneys. Graft survival of kidneys with A) GST, B) LDH, C) H-FABP, D) redox-active iron, E) IL-18 and F) NGAL concentrations below and above the mean or median concentration at $T_{4}$, all censored for recipient death with a functioning graft. 


\section{DISCUSSION}

Kidneys from DCD donors are a valuable extension of the donor pool, but have higher rates of DGF and, in some studies, PNF compared to kidneys from DBD donors ${ }^{4,19,20}$. Despite higher rates of DGF and PNF, recipients of DCD kidneys have better survival rates than patients who continue dialysis treatment while waiting for a kidney from a DBD donor ${ }^{21}$. The long-term graft survival of functioning DCD kidneys is similar to kidneys from DBD donors and between uncontrolled and controlled DCD kidneys; also the recipient survival does not differ significantly ${ }^{20,22}$

It remains a challenge to reduce the PNF rate of transplanted kidneys without the discard of too many viable organs. PNF is associated with unnecessary risks of surgery and immunosuppression and recipients may become sensitized to donor antigens which decreases the opportunities for retransplantation ${ }^{19}$. Interventions to reduce the risk of PNF include organ preservation by rapid laparotomy and direct aortic cannulation for controlled DCD donors, selection of kidneys from old DCD donors by histological assessment of pre-implantation biopsies and careful management of recipient hemodynamics during transplantation to ensure adequate reperfusion of the graft $^{16,23,24}$. Machine perfusion offers the opportunity for pre-transplant viability assessment of the procured kidney, and includes perfusion characteristics and perfusate biomarker concentrations. However, the predictive value of perfusate biomarkers to assess PNF remains unknown. Although Moers et al concluded that perfusate biomarker concentrations should not lead to kidney discard, the PNF percentage in this study, $2.3 \%$ overall and $2.7 \%$ in 75 DCD kidneys, makes predictive value assessment for PNF, the most important reason for kidney discard, virtually impossible ${ }^{12}$.

In Maastricht, for study purposes, all procured DCD kidneys were machine preserved, regardless of their condition, and included very marginal kidneys, which explains the high discard rate. Kidneys were not discarded because of machine perfusion characteristics: the data were not provided to the recipients' nephrologists, who decided to accept an organ for transplantation.

GST, an enzyme localized in the renal tubules, has been frequently used for viability testing $^{9,10,12}$. Also our group has shown a correlation between machine perfusate GST concentration and short-term kidney function ${ }^{10}$, high levels of GST are associated with worse short-term kidney function. However, when kidneys with high GST concentrations showed a favorable outcome, we discontinued its use for viability testing. Therefore, only kidneys transplanted since 1997 were included in this study.

In this study, LDH and IL-18 showed a significant association with early kidney function. LDH is a nonspecific cellular injury marker which is found in almost all body tissues. LDH measured in machine perfusate is either released by the perfused kidney 
or by hemolytic erythrocytes from the capillaries of the perfused kidneys ${ }^{25}$. DCD kidneys sustain a period of warm ischemia with stasis of blood in the organs. This may be associated with a relatively high concentration of erythrocytes and blood clots in the capillaries after a poor initial flush after cardiac arrest. This may explain the relatively good association of LDH and the initial graft function in this study as only DCD kidneys were included. In the present study, a weak correlation between LDH and hemoglobin was found. In other studies, with mainly kidneys from brain-dead donors, LDH was not correlated with early post-transplant outcome ${ }^{12}$.

Heart-type fatty acid binding protein is a cytosolic protein, localized in the distal tubules and is involved in transportation of free fatty acids from cytosol to mitochondria for catabolism. H-FABP has been associated with early release following tissue injury to the kidneys ${ }^{11}$. Its clinical value as perfusate viability marker is relatively unknown.

Redox-active iron has been implicated in the pathophysiology of $I / R$ injury in several organ systems. Redox-active iron is released during I/R injury and is believed to catalyze the formation of oxygen-free radicals, which are known to induce apoptotic and necrotic cell death and subsequent inflammatory responses ${ }^{26}$. In the present study, redox-active iron was strongly associated with PNF in the univariate analysis, but did not remain significantly associated when corrected for confounders.

Interleukin-18 (IL-18) is a pro-inflammatory cytokine produced by macrophages and other cell types present in the kidney during ischemia/reperfusion injury and contributes to inflammatory reactions such as modulation of macrophage activity. IL18 may promote immune or non-immune-mediated tissue damage via a multitude of mechanisms $^{27,28}$.

NGAL, also known as lipocalin-2, is generally expressed in several human tissues, including the kidney. NGAL expression is induced in injured epithelia and has recently been discovered as a novel biomarker of acute kidney injury ${ }^{29}$. However, in this study, NGAL concentration was not associated with short-term graft function.

Enzymes released after cell death relate to each other. However, most biomarkers represent a measure of different processes of ischemia/reperfusion injury, including cell death and inflammation, and biomarkers are present in different cells. Depending on the severity of the injury and the period of time afterwards, the association between ischemia/reperfusion injury and biomarker concentration may vary.

There are several potential confounders, which may influence the reliability of these biomarkers in this study, including the volume of preservation fluid used during in situ perfusion, prior to procurement, and the volume and period of flushing on the back-table. This will also result in a certain amount of wash-out of these biomarkers before these kidneys are connected to the perfusion machine. 
The concentration of biomarkers of machine perfused kidneys also depends on the proportion of the kidney which is perfused, and thus flow through the kidney. When parts of the renal microcirculation are occluded by thrombosis or edema, the flow $(\mathrm{ml} / \mathrm{min} / 100 \mathrm{~g})$ will be relatively low, which results in poor wash-out of biomarkers released from damaged cells. We have previously shown that renovascular resistance itself was associated with short-term graft function(30). Furthermore, it is unknown if age affects the perfusate biomarker concentration. This is difficult to assess as age itself is an important risk factor for poor kidney function in DCD kidneys ${ }^{31}$. Additionally, results may be biased by the unknown outcome of discarded kidneys. However, there are no possibilities to correct for this potential confounder.

All tested biomarkers except for NGAL were associated with PNF in the univariate analyses. As all these biomarkers were associated with PNF, separate multivariate analyses were done to correct for confounding factors. LDH and IL-18 remained significantly associated with PNF in the multivariate analyses. Associations with DGF are less important, and have little clinical implications, since long-term survival rates of DCD kidneys with DGF do not significantly differ from DCD kidneys with $\mathrm{IF}^{3,32-34}$. The predictive value of individual biomarkers for PNF was poor. Only redox-active iron and IL-18 improved to 'fair' after including clinically relevant confounders in a multivariate analysis.

We have shown for the first time that the diagnostic accuracy of the commonly used perfusate biomarkers GST, LDH and H-FABP and newly assessed biomarkers redox-active iron, IL-18 and NGAL in predicting viability of DCD kidneys is poor. These biomarkers should not lead to discard of DCD kidneys. Presently, there are no other potential viability markers which have shown an improvement in the assessment of kidney viability. 


\section{REFERENCES}

1. Wolfe RA, Ashby VB, Milford EL, Ojo AO, Ettenger RE, Agodoa LY, et al. Comparison of mortality in all patients on dialysis, patients on dialysis awaiting transplantation, and recipients of a first cadaveric transplant. N Engl J Med. 1999;341:1725-30.

2. Rabbat CG, Thorpe KE, Russell JD, Churchill DN. Comparison of mortality risk for dialysis patients and cadaveric first renal transplant recipients in Ontario, Canada. J Am Soc Nephrol. 2000;11:917-22.

3. Weber M, Dindo D, Demartines N, Ambuhl PM, Clavien PA. Kidney transplantation from donors without a heartbeat. N Engl J Med. 2002;347:248-55.

4. Cho YW, Terasaki PI, Cecka JM, Gjertson DW. Transplantation of kidneys from donors whose hearts have stopped beating. N Engl J Med. 1998;338:221-5.

5. Snoeijs MGJ, Heurn LWE v, van Mook NKA, Christiaans MH, van Hooff JP. Controlled donation after cardiac death: a European perspective. Transplant Rev. 2007;21:219-29.

6. Jochmans I, Moers C, Smits JM, Leuvenink HG, Treckmann J, Paul A, et al. Machine perfusion versus cold storage for the preservation of kidneys donated after cardiac death: a multicenter, randomized, controlled trial. Ann Surg. 2010;252:756-64.

7. Moers C, Smits JM, Maathuis MH, Treckmann J, van Gelder F, Napieralski BP, et al. Machine perfusion or cold storage in deceased-donor kidney transplantation. N Engl J Med. 2009;360:7-19.

8. St Peter SD, Imber CJ, Friend PJ. Liver and kidney preservation by perfusion. Lancet. 2002;359:604-13.

9. Navarro AP, Sohrabi S, Colechin E, Griffiths C, Talbot D, Soomro NA. Evaluation of the ischemic protection efficacy of a laparoscopic renal cooling device using renal transplantation viability assessment criteria in a porcine model. J Urol. 2008;179:1184-9.

10. Daemen JW, Oomen AP, Janssen MA, van de Schoot L, van Kreel BK, Heineman E, et al. Glutathione Stransferase as predictor of functional outcome in transplantation of machine-preserved non-heartbeating donor kidneys. Transplantation. 1997;63:89-93.

11. Gok MA, Pelzers M, Glatz JF, Shenton BK, Buckley PE, Peaston R, et al. Do tissue damage biomarkers used to assess machine-perfused NHBD kidneys predict long-term renal function post-transplant? Clin chim Acta. 2003;338:33-43.

12. Moers C, Varnav OC, van Heurn E, Jochmans I, Kirste GR, Rahmel A, et al. The value of machine perfusion perfusate biomarkers for predicting kidney transplant outcome. Transplantation. 2010;90:966-73.

13. Kievit JK, Nederstigt AP, Oomen AP, Janssen MA, Schoot L, Kootstra G. Release of alpha-glutathione Stransferase (alpha GST) and pi-glutathione S-transferase (pi GST) from ischemic damaged kidneys into the machine perfusate--relevance to viability assessment. Transplant Proc. 1997;29:3591-3.

14. Kievit JK, Oomen AP, Janssen MA, van Kreel BK, Heineman E, Kootstra G. Viability assessment of nonheart-beating donor kidneys by alpha glutathione S-transferase in the machine perfusate. Transplant Proc. 1997;29:1381-3.

15. Kootstra G, Daemen JH, Oomen AP. Categories of non-heart-beating donors. Transplant Proc. 1995;27:2893-4.

16. Snoeijs MG, Dekkers AJ, Buurman WA, van den Akker L, Welten RJ, Schurink GW, et al. In situ preservation of kidneys from donors after cardiac death: results and complications. Ann Surg. 2007;246:844-52.

17. Wind J, Snoeijs MG, van der Vliet JA, Winkens B, Christiaans MH, Hoitsma AJ, et al. Preservation of kidneys from controlled donors after cardiac death. Br J Surg. 2011;98:1260-6.

18. de Vries B, Snoeijs MG, von Bonsdorff L, Ernest van Heurn LW, Parkkinen J, Buurman WA. Redox-active iron released during machine perfusion predicts viability of ischemically injured deceased donor kidneys. Am J Transplant. 2006;6:2686-93.

19. Snoeijs MG, Winkens B, Heemskerk MB, Hoitsma AJ, Christiaans MH, Buurman WA, et al. Kidney transplantation from donors after cardiac death: a 25-year experience. Transplantation. 2010;90: 1106-12.

20. Barlow AD, Metcalfe MS, Johari Y, Elwell R, Veitch PS, Nicholson ML. Case-matched comparison of long-term results of non-heart beating and heart-beating donor renal transplants. $\mathrm{Br} J \mathrm{Surg}$. 2009;96:685-91. 
21. Snoeijs MG, Schaubel DE, Hene R, Hoitsma AJ, Idu MM, ljzermans JN, et al. Kidneys from donors after cardiac death provide survival benefit. J Am Soc Nephrol. 2010;21:1015-21.

22. Hoogland ER, Snoeijs MG, Winkens B, Christaans MH, van Heurn LW. Kidney Transplantation from donors after cardiac death: uncontrolled versus controlled donation. Am J Transplant. 2011;11: 1427-34.

23. Snoeijs MG, Buurman WA, Christiaans MH, van Hooff JP, Goldschmeding R, van Suylen RJ, et al. Histological assessment of preimplantation biopsies may improve selection of kidneys from old donors after cardiac death. Am J Transplant. 2008;8:1844-51.

24. Snoeijs MG, Wiermans B, Christiaans MH, van Hooff JP, Timmerman BE, Schurink GW, et al. Recipient hemodynamics during non-heart-beating donor kidney transplantation are major predictors of primary nonfunction. Am J Transplant. 2007;7:1158-66.

25. Cohen JA, Brecher ME, Bandarenko N. Cellular source of serum lactate dehydrogenase elevation in patients with thrombotic thrombocytopenic purpura. J Clin Apher. 1998;13:16-9.

26. de Vries B, Walter SJ, von Bonsdorff L, Wolfs TG, van Heurn LW, Parkkinen J, et al. Reduction of circulating redox-active iron by apotransferrin protects against renal ischemia-reperfusion injury. Transplantation. 2004;77:669-75.

27. Wu H, Craft ML, Wang P, Wyburn KR, Chen G, Ma J, et al. IL-18 contributes to renal damage after ischemia-reperfusion. J Am Soc Nephrol. 2008;19:2331-41.

28. Wang J, Long Q, Zhang W, Chen N. Protective effects of exogenous interleukin 18-binding protein in a rat model of acute renal ischemia-reperfusion injury. Shock. 2012;37:333-40.

29. Mishra J, Dent C, Tarabishi R, Mitsnefes MM, Ma Q, Kelly C, et al. Neutrophil gelatinase-associated lipocalin (NGAL) as a biomarker for acute renal injury after cardiac surgery. Lancet. 2005;365: 1231-8.

30. de Vries EE, Hoogland ER, Winkens B, Snoeijs MG, van Heurn LW. Renovascular resistance of machineperfused DCD kidneys is associated with primary nonfunction. Am J Transplant. 2011;11:2685-91.

31. Snoeijs MG, Schaefer S, Christiaans MH, van Hooff JP, van den Berg-Loonen PM, Peutz-Kootstra CJ, et al. Kidney transplantation using elderly non-heart-beating donors: a single-center experience. Am J Transplant. 2006;6:1066-71.

32. Renkens JJ, Rouflart MM, Christiaans MH, van den Berg-Loonen EM, van Hooff JP, van Heurn LW. Outcome of nonheart-beating donor kidneys with prolonged delayed graft function after transplantation. Am J Transplant. 2005;5:2704-9.

33. Wijnen RM, Booster MH, Stubenitsky BM, de Boer J, Heineman E, Kootstra G. Outcome of transplantation of non-heart-beating donor kidneys. Lancet. 1995;345:1067-70.

34. Sanchez-Fructuoso Al, Marques M, Prats D, Conesa J, Calvo N, Perez-Contin MJ, et al. Victims of cardiac arrest occurring outside the hospital: a source of transplantable kidneys. Ann Int Med. 2006;145:157-64. 


\section{ABSTRACT}

Background Kidney donation after cardiac death leads to vascular damage as a result of warm ischemia, affecting renovascular circulating volume. Novel ultrasound dilution techniques may be used to measure renovascular circulating volumes during hypothermic machine perfusion of donor kidneys.

Methods Renovascular circulating volumes of machine perfused porcine kidneys were repeatedly measured by ultrasound dilution at different perfusion pressures $(30,40,50$, and 60 $\mathrm{mmHg}$ ), durations of perfusion ( 1 and $24 \mathrm{~h}$ ) and warm ischemia times (15 and 45 minutes). Validity of ultrasound dilution was assessed by comparing volume changes after clamping of renal artery branches.

Results Repeatability of ultrasound dilution measurements of renovascular circulating volumes was good (mean coefficient of variation: 7.6\%). Renovascular circulating volumes significantly increased with higher perfusion pressures, remained constant over time, and significantly decreased with longer warm ischemia times. Changes in ultrasound dilution measurements after renal artery branch clamping did not correlate with changes in actual perfused volumes.

Conclusion Ultrasound dilution is a reproducible method to assess renovascular circulating volumes in machine perfused kidneys that is susceptible to changes in warm ischemia times. Future studies should evaluate the value of renovascular volume in pre-transplant kidney viability testing. 


\section{INTRODUCTION}

Kidney transplantation in patients with end stage renal disease leads to superior life expectancy and better quality of life compared to dialysis ${ }^{1}$. In the past decades there is an increasing shortage of donor kidneys. Organs from donors after cardiac death (DCD) have become generally accepted to expand the donor pool and meet the demand for additional donor kidneys. However, transplantation of DCD kidneys is associated with an increased incidence of initial graft dysfunction ${ }^{2,3}$.

The higher incidence of graft dysfunction in DCD kidneys, compared to kidneys from donation after brain death (DBD) donors, can be attributed to the prolonged period of warm ischemia before organ procurement. This period of warm ischemia leads to more capillary damage due to thrombosis, vasoconstriction and edema, and may consequently result in a decreased renovascular circulating volume. Therefore, pre-implantation renovascular circulating volume of the kidney may be associated with the severity of warm ischemic injury and could be a valuable predictor of transplant outcome.

The dilution technique is used to measure circulating volume in hemodialyzer fibre bundles. It determines the dilution of an injected saline bolus with ultrasound flow probes before and after transit of the dialyzer. In hemodialyzer volume assessment this technique is accurate and its results reproducible ${ }^{4-6}$. The same technique can be used to measure renovascular circulating volume in donor kidneys. Renovascular circulating volume may be a valuable viability marker in ischemically damaged donor kidneys if measured before transplantation. Therefore, we studied the dilution technique to measure renovascular circulating volume in machine perfused porcine kidneys and determined if renovascular circulating volume is associated with warm ischemia time.

\section{RESULTS}

\section{Flow measurements}

The correlation between perfusate flow measured by ultrasound flow probes and derived from roller pump speed was very strong $(R=0.97,95 \% \mathrm{Cl}: 0.95-0.98, p<0.001$; Figure 7.1). Perfusate flow derived from roller pump speed was on average $11.0 \pm 8.0 \mathrm{ml}$ higher than perfusate flow measured by ultrasound flow probes. 


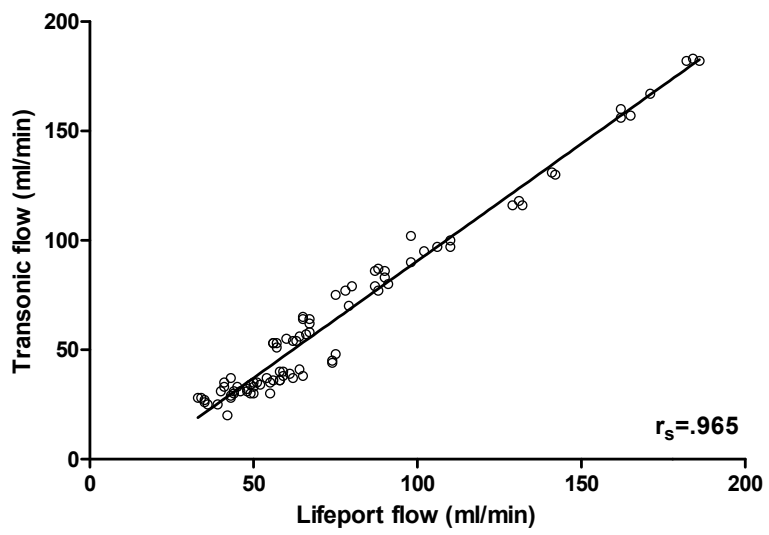

Figure 7.1 Correlation of flow between the machine perfusion system and ultrasound flow probes using spearman correlation coefficient.

\section{Repeatability and validation}

In one kidney, the series of measurements at a pressure of $30 \mathrm{mmHg}$ at $T_{1}$ failed because flow was too low. The mean coefficient of variation (CV) of renovascular circulating volume measured by ultrasound dilution was $7.6 \pm 6.2 \%$ (Table 7.1 ). The CV did not significantly change with different durations of perfusion ( 1 and 24 hour; mean CV $6.8 \pm 4.5 \%$ and $8.4 \pm 7.5 \%$, respectively; $p=0.166)$. The mean CV at a perfusion pressure of $30 \mathrm{mmHg}$ was higher than at $40 \mathrm{mmHg}(\mathrm{p}=0.007)$, but did not significantly change comparing other pressures ( 40 vs. $50 \mathrm{mmHg} ; \mathrm{p}=0.229 ; 50$ vs. $60 \mathrm{mmHg}$; $\mathrm{p}=0.978$ ). Excluding the $30 \mathrm{mmHg}$ measurements from the analyses showed a decrease of mean CV and SD from $7.6 \pm 6.2 \%$ to $6.2 \pm 3.6 \%$. Correlation of all volume measurements with flow and with resistance was good $\left(r_{s}=0.921\right.$ and $r_{s}=0.766$, respectively) (Figure 7.2).

Table 7.1 Characteristics of measurements at different pressures.

\begin{tabular}{lcccccc}
\hline $\mathrm{P}(\mathrm{mmHg})$ & Time & $\mathrm{N}$ & $\begin{array}{c}\mathrm{V} \\
(\mathrm{ml})\end{array}$ & $\begin{array}{c}\mathrm{CV} \\
(\%)\end{array}$ & $\begin{array}{c}\mathrm{Q} \\
(\mathrm{ml} / \mathrm{min})\end{array}$ & $\begin{array}{c}\mathrm{R} \\
(\mathrm{mmHg} / \mathrm{ml} / \mathrm{min})\end{array}$ \\
\hline 30 & $\mathrm{~T}_{1}$ & $8^{*} 6=48$ & $15.3 \pm 4.8$ & $11.5 \pm 6.7$ & $37.5 \pm 9.6$ & $0.76 \pm 0.20$ \\
& $\mathrm{~T}_{24}$ & $9^{*} 6=54$ & $15.9 \pm 8.2$ & $12.8 \pm 12.3$ & $39.6 \pm 15.3$ & $0.78 \pm 0.31$ \\
40 & $\mathrm{~T}_{1}$ & $9^{*} 6=54$ & $18.9 \pm 6.2$ & $6.8 \pm 2.1$ & $46.4 \pm 11.4$ & $0.82 \pm 0.19$ \\
& $\mathrm{~T}_{24}$ & $9 * 6=54$ & $21.0 \pm 8.1$ & $7.1 \pm 6.8$ & $51.7 \pm 18.9$ & $0.79 \pm 0.30$ \\
50 & $\mathrm{~T}_{1}$ & $9 * 6=54$ & $21.8 \pm 6.6$ & $4.9 \pm 2.3$ & $55.9 \pm 11.2$ & $0.85 \pm 0.18$ \\
& $\mathrm{~T}_{24}$ & $9 * 6=54$ & $23.4 \pm 7.9$ & $6.6 \pm 2.5$ & $62.9 \pm 22.4$ & $0.81 \pm 0.28$ \\
60 & $\mathrm{~T}_{1}$ & $9 * 6=54$ & $25.2 \pm 7.7$ & $4.7 \pm 2.1$ & $64.9 \pm 13.3$ & $0.88 \pm 0.18$ \\
& $\mathrm{~T}_{24}$ & $9 * 6=54$ & $24.9 \pm 8.1$ & $6.9 \pm 3.8$ & $75.1 \pm 24.3$ & $0.79 \pm 0.24$ \\
\hline
\end{tabular}

Variables as mean \pm standard deviation. $\mathrm{N}=$ number of measurements. $\mathrm{V}=$ volume $(\mathrm{ml}) . \mathrm{CV}=$ coëfficient of variation (\%). $Q=$ flow $(\mathrm{ml} / \mathrm{min}) . R=$ resistance $(\mathrm{mmHg} / \mathrm{ml} / \mathrm{min})$. 


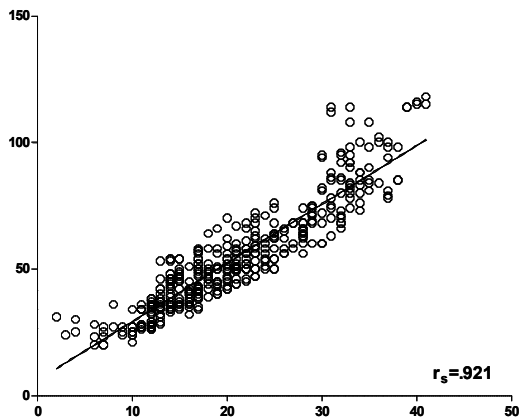

A

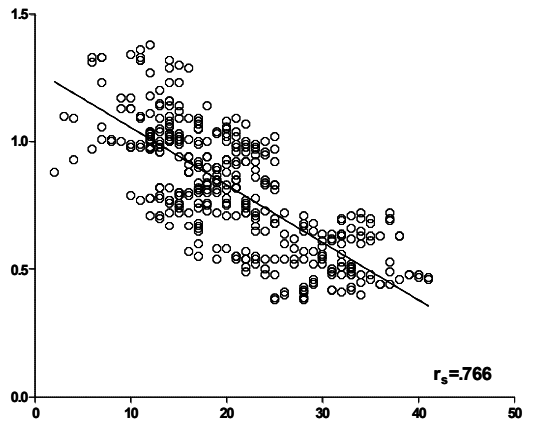

B

Figure 7.2 Correlation of flow $(\mathrm{ml} / \mathrm{min})(A)$ and resistance $(\mathrm{mmHg} / \mathrm{ml} / \mathrm{min})$ (B) measurements with renovascular circulating volume $(\mathrm{ml})$.

Renovascular circulating volumes measured by ultrasound dilution decreased after clamping of one of the renal arterial branches (from $25.6 \pm 8.9 \mathrm{ml}$ to $16.3 \pm 7.6 \mathrm{ml}$; $\mathrm{p}=0.028$ ). However, these changes in renovascular circulating volume were not correlated with changes in actual perfused volume as measured by methylene blue staining (Figure 7.3).

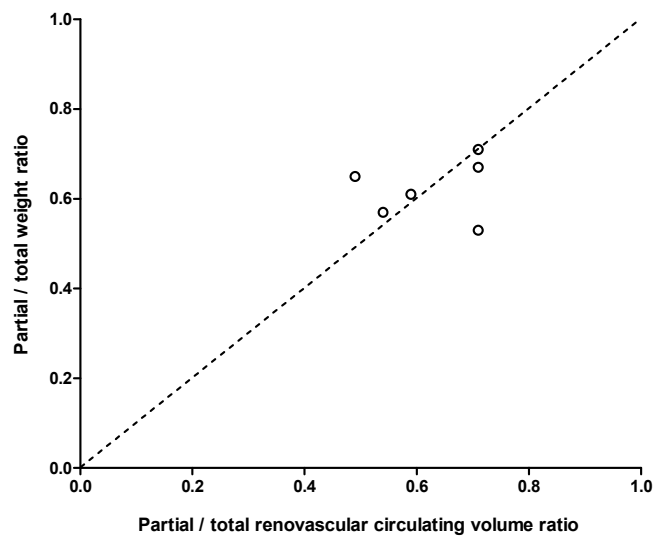

Figure 7.3 Correlation of volume/weight ratios of kidneys before and after clamping one the arterial branches and methylene blue staining. The dotted line represents equality of both circulatory volume and weight ratio. 


\section{Effect of perfusion pressure, duration of perfusion and warm ischemia time on renovascular circulation volume}

Per pressure $(30,40,50$ and $60 \mathrm{mmHg})$, renovascular circulating volume measured by ultrasound dilution did not differ between $T_{1}$ and $T_{24}(p=0.557 ; p=0.084 ; p=0.126$; $p=0.833$, respectively; Table 7.1). Renovascular circulating volume increased significantly with every $10 \mathrm{mmHg}$ increase of pressure at $T_{1}$ and for the increase from $30 \mathrm{mmHg}$ to $40 \mathrm{mmHg}$ at $\mathrm{T}_{24}$. Increasing the duration of hypothermic perfusion from 1 hour to 24 hours did not change renovascular circulating volumes (mean renovascular circulating volume $20.4 \pm 7.3 \mathrm{ml}$ and $21.5 \pm 8.7 \mathrm{ml}$, respectively; $p=0.078$ ).

The mean renovascular circulating volumes of kidneys with 15 minutes of warm ischemia were higher than of kidneys with 45 minutes of warm ischemia $(34.1 \pm 6.0 \mathrm{ml}$ vs. $26.8 \pm 5.3 \mathrm{ml}$, respectively; $\mathrm{p}=0.005)$ at $\mathrm{T}_{1}$, but did not significantly differ at $\mathrm{T}_{24}$ $(36.7 \pm 11.4 \mathrm{ml}$ vs. $27.3 \pm 8.0 \mathrm{ml}$, respectively; $p=0.059$ ).

\section{DISCUSSION}

Organs from DCD donors have rapidly increased the deceased donor pool, but suffer from warm ischemic injury resulting in a higher incidence of postoperative graft dysfunction. Pre-transplant assessment of DCD kidneys in order to select viable grafts for transplantation is crucial to obtain the best results after transplantation. Warm ischemia can lead to microvascular damage, affecting renovascular circulating volume. The dilution technique is a relatively simple method to measure intravascular volume and has not been used before in transplant surgery. As intravascular volume may be associated with organ viability, the dilution technique is a potentially valuable method to use in organ viability assessment. Therefore we determined the repeatability and the validity of this technique and we assessed the effect of warm ischemia on renovascular circulating volume in machine perfused porcine kidneys.

In 1897 the dilution technique was introduced for cardiac output measurement ${ }^{7}$. More recently this method has been applied to measure regional blood flow in heart and lungs and this application has gained wide acceptance ${ }^{8}$. Since 1995 a modification of the dilution technique has been used to measure shunt flow, recirculation and cardiac output during hemodialysis ${ }^{4,9}$. The current study is the first that applies the dilution technique to measure renovascular volume of machine perfused kidneys. Given the importance of pre-transplant viability testing in DCD kidneys, we have studied the feasibility of the dilution technique to measure renovascular circulating volume as a new potential viability marker.

We have shown that the dilution technique is a reproducible technique to measure renal blood flow in machine perfused porcine kidneys. The repeatability of the dilution 
method was good, with an acceptable CV of $7.6 \%$. Repeatability did not change with duration of perfusion, but did show changes at different perfusion pressures. CV at a pressure of $30 \mathrm{mmHg}$ showed a significant higher value than at $40 \mathrm{mmHg}$, indicating that measurements at low pressure and flow are less reliable. This is probably due to equipment adjustments and should be optimized.

If one of the renal arterial branches of the kidney was clamped, measured renovascular volume decreased for all kidneys. Nonetheless, a correlation between volume and weight ratio could not be demonstrated. In four of six kidneys, volume and weight ratio measurements after clamping one arterial branch were almost equivalent, but ratio's in two other kidneys were slightly off the line of equality of ratio's. One of the limitations is that, in all six kidneys, between 30 to $50 \%$ of the kidney was excluded from perfusion. Moreover, it is not possible to assess if differences between volume and weight ratio measurements are caused by differences in the initial perfusion of one kidney. One part of a kidney may be better perfused with a higher intravascular volume than another.

We think that pre-transplant viability assessment by the dilution technique could have advantages as compared to viability assessment by machine perfusion. Machine perfusion has two potential advantages over cold storage. Firstly, machine perfusion improves early graft function compared to cold storage by preventing interstitial edema, decreasing oxidative stress, improving adenosine triphosphate (ATP) availability and by washing out thrombi and metabolic products ${ }^{10-16}$. Secondly, machine perfusion allows early viability assessment by measuring perfusion characteristics, including flow, pressure and renovascular resistance, or biomarkers ${ }^{17-22}$. However, recent studies show that the value of these parameters to predict kidney transplant outcome is limited ${ }^{21,23,24}$. Machine perfusion characteristics could be influenced by leakage from the arterial connection due to atherosclerosis of the patch or by leakage from small arterial branches that have been damaged during procurement. In the dilution technique however, leakage cannot influence the measurements as an exact bolus of saline is assessed. However, the theoretical advantage of the dilution technique in viability testing has to be proven in clinical practice.

Renovascular volume decreased after a prolonged period of warm ischemia. This may be explained by the manifestation of edema. Cellular volume regulation depends on mechanisms that require sodium-potassium ATP-ase activity, which is limited by decreased ATP during ischemia ${ }^{25,26}$. The significant differences between renovascular circulating volumes between short and long ischemia did not sustain until 24 hours of machine perfusion. This is in line with previous studies, which demonstrate that perfusion differences decrease over time ${ }^{23,27}$. In the study we only compared different warm ischemia times at a machine perfusion pressure of $40 \mathrm{mmHg}$. This is the 
maximum perfusion pressure used at our and many other transplant centers to avoid microvascular injury. Higher perfusion pressures may open capillaries, with better perfusion but are also associated with vascular injury due to shear stress ${ }^{28-30}$. The finding that renovascular circulating volume is associated with warm ischemia time confirms our hypothesis on the relevance of renovascular circulating volume.

Further studies are necessary to assess the value of the dilution technique and renovascular volume measurements in human transplantation. Sterile flow probes for the renal artery and vein are available, which makes testing in human kidneys possible. The assessment of the effect of different pharmacological interventions during machine perfusion including vasodilating and antithrombolytic drugs on circulating volume could be a future application of the dilution technique.

We conclude that the dilution technique is a reproducible way to assess renovascular circulating volume in machine perfused porcine kidneys, that the technique is suitable to detect differences in warm ischemia time.

\section{METHODS}

The experiments were carried out with porcine kidneys, which were recovered from a regional slaughterhouse. Pigs were between 6 and 7 months of age and had a mean weight of $105 \mathrm{~kg}$. In the highly standardized slaughtering process, the time from death until recovery of the kidneys took exactly 15 minutes. After receiving an 'en bloc' pair of kidneys, kidneys were separated and then flushed with 0.5 I of HistidineTryptophan-Ketoglutarate (HTK) preservation solution for 20 minutes at the site. For transport to the preservation laboratory kidneys were temporarily stored on ice. Two hours after recovery, kidneys were connected to a pulsatile perfusion machine (LifePort Kidney Transporter (model \# LKT-100-P), Organ Recovery Systems, Des Plaines, USA) and perfused with $500 \mathrm{ml}$ University of Wisconsin (UW) solution. During machine perfusion, pressure $(\mathrm{mmHg})$, flow $(\mathrm{ml} / \mathrm{min})$, and resistance $(\mathrm{mmHg} / \mathrm{ml} / \mathrm{min})$ were recorded using the Lifeport Kidney Transporter.

According to national legislation, study approval by the local animal experiments committee (DEC) was not required. Our study did not interfere with the standardized slaughtering process; kidneys were obtained after death.

\section{Dilution technique}

Renovascular circulating volume was assessed with the dilution technique. This technique has been described in detail before by others ${ }^{6}$. Briefly, the renovascular circulating volume was measured with a dilution monitor (HDO2 haemodialysis FlowQC monitor, Transonic Systems Inc, Ithaca, NY) via two reusable ultrasound flow 
probes (Transonic H4E Flow Probes) installed at $2 \mathrm{~cm}$ distance from the kidney on the arterial tube and on a tube connected to the renal vein. The dilution monitor was connected to a computer installed with HD02 Dialysis Monitoring Software (Figure 7.4). The system was calibrated for UW solution. To obtain measurements we injected a saline bolus of $2 \mathrm{ml}$ into the arterial injection port. The indicator is first sensed by the arterial sensor that records the time and volume of injection. The indicator then travels through the renovascular system and is recorded by the venous sensor on the renal vein. The venous sensor measures the change in concentration of saline in the preservation fluid and the transit time through the renovascular system. The renovascular circulating volume is calculated by the equation $\mathrm{V}=\mathrm{Q} \times \mathrm{MTT}$. In this equation $Q$ is defined as the flow in the system and MTT (mean transit time) as the average transit time of the indicator. The first bolus was injected one hour after the start of perfusion $\left(T_{1}\right)$, to ensure a balanced state of perfusion. The additional volume within the tubing between vein or artery and sensors was kept constant by placing the sensors at a fixed distance to the kidney.

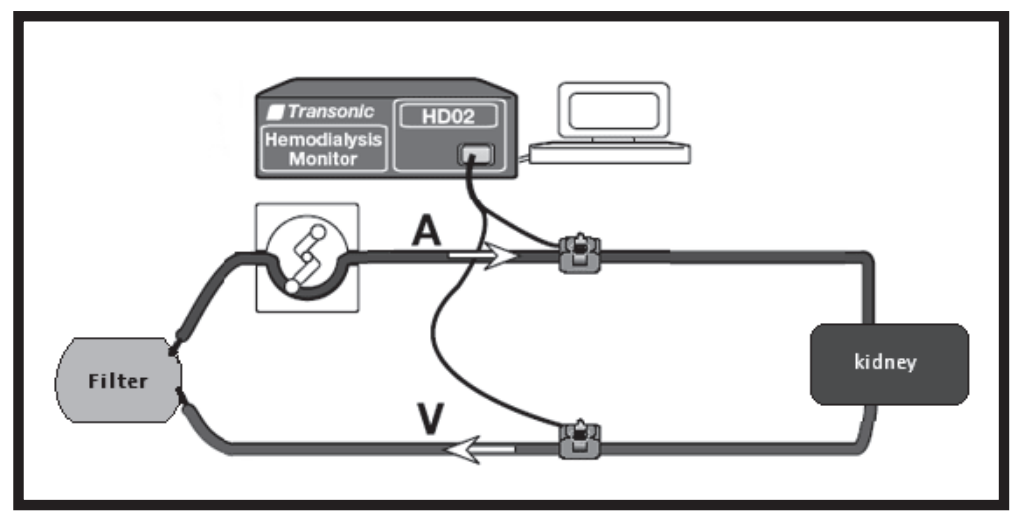

Figure 7.4 Schematic research setting. Sensors were placed in the perfusion machine on the arterial (A) tube, and on the venous tube (V), connected to the renal vein. The dilution monitor was connected to a computer installed with HD02 Dialysis Monitoring Software.

\section{Flow measurements}

To assess the correlation between measured flow by ultrasound flow probes and derived from roller pump speed, we performed simultaneous measurements of flow in six kidneys using at pressures of 40,50 and $60 \mathrm{mmHg}$. In total 87 paired measurements were done. Given the very strong correlation between flow measured by ultrasound 
flow probes and derived from roller pump speed, only flow data derived from roller pump speed was used in the calculations.

\section{Repeatability and validation}

To verify repeatability in measuring renovascular circulating volume, we performed sets of 6 measurements at different perfusion pressures $(30,40,50$ and $60 \mathrm{mmHg})$ in 9 kidneys. Per kidney and per pressure 6 boluses of saline were injected at one hour after the start of perfusion $\left(T_{1}\right)$ and after 24 hours of machine perfusion $\left(T_{24}\right)$. A total of 426 measurements (71 data sets) were done. In addition, of all measurements in this dataset we plotted the correlation of measured volume against flow as well as volume against resistance.

Although the dilution technique has shown to be accurate in estimating perfused volume in dialyzer circuits, there is no golden standard of measuring renovascular circulating volume. Therefore we verified validity of the dilution technique by comparing volume ratio and weight ratio in 6 partially perfused kidneys after the repeatability measurements were done at a pressure of $60 \mathrm{mmHg}$. One of the renal arterial branches was clamped and the measurements repeated. Next, a bolus of methylene blue was injected into the system, colouring the perfused part of the vascular system. The coloured tissue was macroscopically divided from the noncoloured tissue and the percentage of the weight of each part was assessed. Validity was determined comparing the renovascular circulating volume ratio and weight ratio of perfused and unperfused parts of the kidney.

\section{Effect of warm ischemia time on renovascular circulating volume}

To assess the effect of warm ischemia on renovascular circulating volume, we performed measurements in 5 kidney pairs. Each pair contained a kidney exposed to a mean of 15 minutes and a kidney exposed to a mean of 45 minutes of warm ischemia. After retrieval, this was realized by immediate cannulation of one of the renal arteries of the 'en-bloc' kidneys and connecting only this kidney to the perfusion fluid for initial flush. After the initial flush (20 minutes), kidneys were separated; the first kidney was stored on melting ice, and the contralateral kidney was stored at room temperature until 45 minutes of warm ischemia and then flushed. Measurements were performed after one hour of machine perfusion and after 24 hours $\left(T_{1}\right.$ and $\left.T_{24}\right)$ with a perfusion pressure of $40 \mathrm{mmHg}$.

\section{Data analysis}

Continuous variables are presented as means \pm standard deviations (SD) if normally distributed (histogram). Correlation coefficients were calculated with the Pearson test 
for normally distributed variables, and with the Spearman test otherwise. To determine repeatability, the coefficient of variation was calculated as the ratio of mean volume and standard deviation per dataset. Paired sample t-test was used to calculate the significance of differences between time points. Renovascular volume differences after clamping were calculated using the Wilcoxon Signed Rank test. We used a paired-samples t-test to analyse differences between the 15 and 45 minutes WIT groups.

Data analysis was done using SPSS 18.0 and Microsoft Excel 2007 for Windows. A pvalue below 0.05 was considered evidence of a significant difference. 


\section{REFERENCES}

1. Tonelli M, Wiebe N, Knoll G, Bello A, Browne S, Jadhav D, et al. Systematic review: kidney transplantation compared with dialysis in clinically relevant outcomes. Am J Transplant. 2011;11:2093109.

2. Keizer KM, de Fijter JW, Haase-Kromwijk BJ, Weimar W. Non-heart-beating donor kidneys in the Netherlands: allocation and outcome of transplantation. Transplantation. 2005;79:1195-9.

3. Snoeijs MG, Schaubel DE, Hene R, Hoitsma AJ, Idu MM, ljzermans JN, et al. Kidneys from donors after cardiac death provide survival benefit. J Am Soc Nephrol. 2010;21:1015-21.

4. Krivitski NM. Novel method to measure access flow during hemodialysis by ultrasound velocity dilution technique. ASAIO J. 1995;41:M741-5.

5. Krivitski NM, Kislukhin VV, Snyder JW, MacGibbon DR, Kuznetsova OA, Reasons AM, et al. In vivo measurement of hemodialyzer fiber bundle volume: theory and validation. Kidney Int. 1998;54:1751-8.

6. Krivitski NM. Theory and validation of access flow measurement by dilution technique during hemodialysis. Kidney Int. 1995;48:244-50.

7. Stewart GN. Researches on the Circulation Time and on the Influences which affect it. J Physiol. 1897;22:159-83.

8. Meier P, Zierler KL. On the theory of the indicator-dilution method for measurement of blood flow and volume. J Appl Physiol. 1954;6:731-44.

9. Krivitski NM, Depner TA. Cardiac output and central blood volume during hemodialysis: methodology. Adv Ren Replace Ther. 1999;6:225-32.

10. Gorbach AM, Leeser DB, Wang H, Tadaki DK, Fernandez C, Destephano D, et al. Assessment of cadaveric organ viability during pulsatile perfusion using infrared imaging. Transplantation. 2009;87: 1163-6.

11. Moers C, Smits JM, Maathuis MH, Treckmann J, van Gelder F, Napieralski BP, et al. Machine perfusion or cold storage in deceased-donor kidney transplantation. N Engl J Med. 2009;360:7-19.

12. Schold JD, Kaplan B, Howard RJ, Reed AI, Foley DP, Meier-Kriesche HU. Are we frozen in time? Analysis of the utilization and efficacy of pulsatile perfusion in renal transplantation. Am J Transplant. 2005;5: 1681-8.

13. Matsuoka L, Shah T, Aswad S, Bunnapradist S, Cho Y, Mendez RG, et al. Pulsatile perfusion reduces the incidence of delayed graft function in expanded criteria donor kidney transplantation. Am J Transplant. 2006;6:1473-8.

14. Jochmans I, Moers C, Smits JM, Leuvenink HG, Treckmann J, Paul A, et al. Machine perfusion versus cold storage for the preservation of kidneys donated after cardiac death: a multicenter, randomized, controlled trial. Ann Surg. 2010;252:756-64.

15. Taylor MJ, Baicu SC. Current state of hypothermic machine perfusion preservation of organs: The clinical perspective. Cryobiology. 2010;60:S20-35.

16. Yuan X, Theruvath AJ, Ge X, Floerchinger B, Jurisch A, Garcia-Cardena G, et al. Machine perfusion or cold storage in organ transplantation: indication, mechanisms, and future perspectives. Transpl Int. 2010;23:561-70.

17. Sung RS, Christensen LL, Leichtman AB, Greenstein SM, Distant DA, Wynn JJ, et al. Determinants of discard of expanded criteria donor kidneys: impact of biopsy and machine perfusion. Am J Transplant. 2008;8:783-92.

18. Matsuno N, Konno O, Mejit A, Jyojima Y, Akashi I, Nakamura Y, et al. Application of machine perfusion preservation as a viability test for marginal kidney graft. Transplantation. 2006;82:1425-8.

19. Guarrera JV, Goldstein MJ, Samstein B, Henry S, Reverte C, Arrington B, et al. 'When good kidneys pump badly': outcomes of deceased donor renal allografts with poor pulsatile perfusion characteristics. Transpl Int. 2010;23:444-6.

20. Hoogland ERP, De Vries EE, Christaans MHL, Winkens B, Snoeijs MGJ, Van Heurn LWE. The value of machine perfusion biomarker concentration in DCD kidney transplantations. Transplantation. In press.

21. van Smaalen TC, Hoogland ERP, van Heurn LWE. Machine perfusion viability testing. Current opinion in organ transplantation. In press.

22. Nyberg SL, Baskin-Bey ES, Kremers W, Prieto M, Henry ML, Stegall MD. Improving the prediction of donor kidney quality: deceased donor score and resistive indices. Transplantation. 2005;80:925-9. 
23. de Vries EE, Hoogland ER, Winkens B, Snoeijs MG, van Heurn LW. Renovascular resistance of machineperfused DCD kidneys is associated with primary nonfunction. Am J Transplant. 2011;11:2685-91.

24. Jochmans I, Moers C, Smits JM, Leuvenink HG, Treckmann J, Paul A, et al. The prognostic value of renal resistance during hypothermic machine perfusion of deceased donor kidneys. Am J Transplant. 2011; 11:2214-20.

25. Siedlecki A, Irish W, Brennan DC. Delayed graft function in the kidney transplant. Am J Transplant. 2011;11:2279-96.

26. Perico N, Cattaneo D, Sayegh MH, Remuzzi G. Delayed graft function in kidney transplantation. Lancet. 2004;364:1814-27.

27. Brook NR, Knight AJ, Nicholson ML. Intra-renal resistance reflects warm ischaemic damage, and is further increased by static cold storage: a model of non-heart-beating donor kidneys. Med Sci Monit. 2003;9:BR271-5.

28. Minor T, Manekeller S, Sioutis M, Dombrowski F. Endoplasmic and vascular surface activation during organ preservation: refining upon the benefits of machine perfusion. Am J Transplant. 2006;6:1355-66.

29. Patel SK, Pankewycz OG, Weber-Shrikant E, Zachariah M, Kohli R, Nader ND, et al. Effect of increased pressure during pulsatile pump perfusion of deceased donor kidneys in transplantation. Transplant Proc. 2012;44:2202-6.

30. Doorschodt BM, Schreinemachers MC, Behbahani M, Florquin S, Weis J, Staat M, et al. Hypothermic machine perfusion of kidney grafts: which pressure is preferred? Ann Biomed Eng. 2011;39:1051-9. 


\section{ABSTRACT}

The in vivo assessment of renal damage after ischemia reperfusion injury, such as in sepsis, hypovolemic shock or after transplantation, is a major challenge. This injury often results in temporary or permanent non-function. In order to improve the clinical outcome of the kidneys, novel therapies are currently being developed that limit renal ischemia reperfusion injury. However, to fully address their therapeutic potential, non-invasive imaging methods are required which allow the in vivo visualization of different renal compartments and the evaluation of kidney function. In this study, MRI was applied to study kidney oxygenation and function in a murine model of renal ischemia reperfusion injury at 7 Tesla. During ischemia, there was a strongly decreased oxygenation, as measured using blood oxygen level dependent $\mathrm{MRI}$, compared with the contralateral control, which persisted after reperfusion. Moreover, it was possible to visualize differences in oxygenation between the different functional regions of the injured kidney. Dynamic contrast-enhanced MRI revealed a significantly reduced renal function, comprising perfusion and filtration, at $24 \mathrm{~h}$ after reperfusion. In conclusion, MRI is suitable for the noninvasive evaluation of renal oxygenation and function. Blood oxygen level dependent or dynamic contrast-enhanced MRI may allow the early detection of renal pathology in patients with ischemia reperfusion injury such, as in sepsis, hypovolemic shock or after transplantation, and consequently may lead to an earlier intervention or change of therapy to minimize kidney damage. 


\section{INTRODUCTION}

The in vivo assessment of renal damage after ischemia reperfusion (I/R) injury, such as in sepsis, hypovolemic shock or after transplantation from donors after cardiac death, is a major challenge. When this injury is severe, it results in acute renal failure (ARF) with a high incidence of temporary or even permanent non-function. After reperfusion, there is a severely reduced blood flow, stasis and the accumulation of red and white blood cells ${ }^{1}$, probably resulting in ongoing ischemic damage to the already injured kidney. Of the different functional regions in the kidney, the outer medulla is especially vulnerable to ischemic damage ${ }^{2}$.

To improve the clinical outcome of ischemically damaged kidneys, novel therapies are being developed that limit $I / R$ injury ${ }^{3}$. However, to assess their therapeutic potential noninvasively at an early stage, new imaging methods are required that allow the evaluation of the function of different renal compartments in a longitudinal manner in both preclinical and clinical setups. In addition, longitudinal monitoring of renal performance after $\mathrm{I} / \mathrm{R}$ injury may provide more insight into the long term pathophysiological development, which in turn may aid in the improvement of therapies directed against I/R injury and ARF.

$\mathrm{MRI}$ is the most versatile non-invasive imaging method available today. Advantages are a superior spatial resolution and soft tissue contrast, which allow the differentiation between specific anatomical regions of the kidney (i.e. cortex, inner and outer medulla). In addition, MRI uses no ionizing radiation or nephrotoxic contrast agents and can therefore be safely repeated in the same patient. Here, two complementary MRI techniques, i.e. blood oxygen level dependent MRI and dynamic contrast-enhanced (DCE) MRI, were applied to study renal oxygenation and perfusion, respectively, in a murine model of $\mathrm{I} / \mathrm{R}$ injury.

Previously, BOLD-MRI has been shown to be useful in the evaluation of intrarenal oxygenation in humans $s^{4-8}$ and rodents ${ }^{9,10}$. The image contrast is based on susceptibility differences between oxyhemoglobin and deoxyhemoglobin. Although the former is diamagnetic, the latter contains an even number of unpaired electrons, which makes it paramagnetic $^{11}$. When the tissue oxygenation state is altered, the ratio between oxyhemoglobin and deoxyhemoglobin concentrations will change accordingly, resulting in a local change in magnetic susceptibility. These differences can be detected via changes in the apparent transverse relaxation rate $R_{2}{ }^{*}\left(=1 / T_{2}{ }^{*}\right)$, where an increase in $R_{2}{ }^{*}$ indicates a decreased oxygenation and vice versa. In the kidney, BOLD measurements have been found to be highly reproducible and robust ${ }^{12}$. Furthermore, cortical and medullary $R_{2}{ }^{*}$ as detected by BOLD MRI were found to be linearly related to renal $\mathrm{pO}_{2}$ as measured using invasive microelectrodes ${ }^{13}$. In addition, BOLD MRI 
allowed the differentiation between acute rejection and tubular necrosis in renal allograft dysfunction ${ }^{14}$.

As an alternative measure of the extent of renal injury after $1 / R$, DCE MRI measurements were included in the present study to estimate local renal perfusion. DCE MRI measurements aim to detect abnormal contrast agent wash-in and wash-out kinetics in diseased compared with healthy tissue. Subsequent analysis of the dynamic signal enhancement curves using pharmacokinetic multi-compartment modeling provides quantitative information on tissue perfusion and to correct for inflow effects, bolus length or cardiac function. Although DCE-MRI was primarily developed for oncological purposes, it has also been successfully applied to study normal renal function in humans ${ }^{15-17}$. However, only a few papers have described the application of DCE MRI in diseased kidneys ${ }^{18}$, or animal models of kidney disease ${ }^{19,20}$. The application of DCE MRI after renal I/R has not been described.

In this study, we applied noninvasive BOLD and DCE MRI to demonstrate the feasibility of monitoring renal oxygenation and function using a murine model of $\mathrm{I} / \mathrm{R}$ injury.

\section{EXPERIMENTAL DETAILS}

\section{Animal model}

All animal experiments were approved by the institutional ethics committee on the care for experimental animals. Nine male Swiss mice were anesthetized using $5 \%$ isoflurane (Abbott Laboratories Ltd, Queensborough, Kent, UK) in medical air. Animals were transferred to a dedicated animal bed with built-in mask for anesthesia gas supply during the MRI measurements. Body temperature and respiration rate were continuously monitored via an MR compatible small animal monitoring system (SA Instruments, Stony Brook, NY, USA). Normothermic conditions were maintained using a warm water heating pad. Pre-operative analgesia was induced by the administration of buprenorphine (Temgesic ${ }^{\circ}$, Schering-Plough, Utrecht, the Netherlands) $0.1 \mathrm{mg} / \mathrm{kg}$ subcutaneously. After baseline MRI measurements, mice underwent laparotomy with unilateral renal ischemia by clamping of the renal pedicle. Images were obtained during ischemia and at 1 and $24 \mathrm{~h}$ after reperfusion. Mice were transferred to an operating area outside the magnet room and were allowed to recover between imaging sessions at 1 and $24 \mathrm{~h}$ post reperfusion. For the final measurement session at $24 \mathrm{~h}$ after reperfusion, an infusion line was placed in the tail vein to allow contrast agent injection during the MRI examination. 


\section{MRI protocol}

All MR experiments were performed on a $30 \mathrm{~cm}$ horizontal bore $7 \mathrm{~T}$ Bruker Biospec 70/30 USR MRI scanner (Bruker Biospin GmbH, Ettlingen, Germany) interfaced to an AVANCE-II console. The BGA12-S mini-imaging gradient system was used (maximum gradient strength $720 \mathrm{mT} / \mathrm{m}$, slew rate $6000 \mathrm{~T} / \mathrm{m} / \mathrm{s}$ ) and images were acquired using a quadrature volume resonator (inner diameter $3.5 \mathrm{~cm}$ ). Automated linear and first order shimming was performed to minimize field inhomogeneities that may interfere with the gradient echo measurements.

Kidneys were localized using axial $T_{1}$ - and $T_{2}$-weighted spin echo images covering both kidneys completely. The TR/TE for $T_{1}$ - and $T_{2}$ weighted images were 1500/7.6 and $3000 / 40 \mathrm{~ms}$, respectively. The field of view was $4 \times 4 \mathrm{~cm}^{2}$ which, together with a $256 \times 256$ acquisition matrix resulted in a pixel size of $0.16 \times 0.16 \mathrm{~mm}^{2}$. On average, 191-mm-thick slices were recorded (range 16-20, depending on the kidney orientation in the magnet). Four signal averages were acquired to reduce motion artifacts.

\section{BOLD MRI}

The apparent transverse relaxation rate $R_{2}{ }^{*}\left(=1 / T_{2}{ }^{*}\right)$ was measured using a multi-slice multi-echo gradient echo sequence with TR $750 \mathrm{~ms}$, and TE in the range 4 to $34 \mathrm{~ms}$, with an echo interval of $6 \mathrm{~ms}$, and four signal averages. Geometrical image parameters (i.e. number and orientation of slices, field-of-view and matrix) were similar to the anatomical images.

\section{DCE MRI}

Dynamic imaging was performed using a gradient echo sequence with a TR and TE of 65 and $1.9 \mathrm{~ms}$, respectively, and a $35^{\circ}$ flip angle. As a compromise between whole renal coverage and temporal resolution, the acquisition matrix was reduced to $128 \times 128$, and only 10 axial slices were recorded with two signal averages. In total, 100 dynamic phases were acquired with a temporal resolution of $16 \mathrm{~s}$. The injection of $0.1 \mathrm{mmol} / \mathrm{kg}$ Gadovist (Bayer Schering Pharma, Berlin, Germany), diluted to a total volume of $100 \mu \mathrm{L}$, was started at phase 11 and followed by a $50 \mu \mathrm{L}$ saline flush. The total injection duration was approximately $20 \mathrm{~s}$.

\section{MRI analysis}

All data analysis was performed in Matlab (The MathWorks, Natick, MA, USA), unless stated otherwise. Regions of interest (ROIs) were drawn manually in MRIcro ${ }^{21}$ using both $T_{1}$ - and $T_{2}$-weighted anatomical images for correct delineation of the whole kidney and the different kidney regions. 
BOLD MRI

ROIs were drawn in the cortex, outer medulla, and inner medulla in three slices through the center of each kidney (Figure 8.1). $R_{2}{ }^{*}$ values were determined on a voxelby-voxel basis via nonlinear fitting of the gradient echo signal intensity function ${ }^{22}$ :

$$
S=S_{0} \cdot e^{-T E \cdot R_{2}^{*}}
$$

using the Levenberg-Marquardt optimization algorithm. Here, $S_{0}$ is a scaling factor depending on the proton density, TR, flip angle, pulse profile, and preamplifier gain.
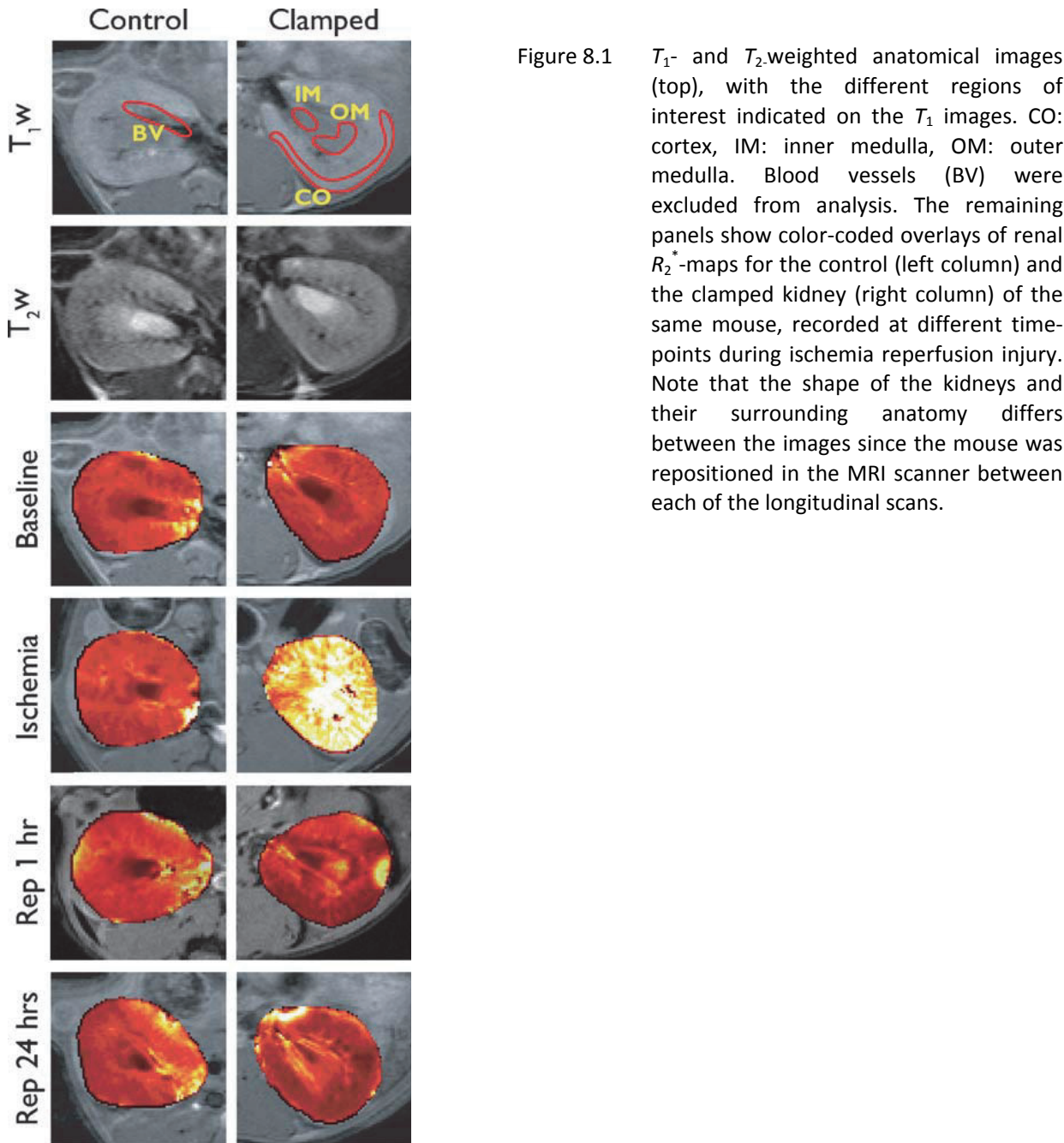

$$
\mathrm{R}_{2}^{*}\left(\mathrm{~s}^{-1}\right)
$$

0 


\section{DCE MRI}

First, dynamic data were spatially coregistered using the rigid body transformation algorithm in SPM2 (Wellcome Trust Centre for Neuroimaging, London, UK) to correct for possible animal motion during data acquisition. Second, the relative signal intensity changes $\Delta S(\mathrm{t})$ were calculated per voxel as

$$
\Delta S(t)=S(t) / S_{\text {pre }}-1
$$

where $S_{\text {pre }}$ is the average signal intensity of the 10 pre-contrast phases. Third, using phantoms with relatively low gadolinium concentrations ranging from 0 to $1.0 \mathrm{mM}$, the DCE MRI signal intensities were found to be linearly related to the gadolinium concentration. All phantoms contained $0.1 \mathrm{mM} \mathrm{MnCl}_{2}$ to mimic a background $T_{1}$ of muscle tissue ( 1000 ms). The linear coefficients as derived from the phantom experiment were used to convert in vivo $\Delta S(\mathrm{t})$ curves to $C(\mathrm{t})$ curves, where $C$ is the gadolinium concentration $(\mathrm{mM})$. Fourth, dynamic tissue enhancement curves $C_{\text {tissue }}(\mathrm{t})$ were analyzed using the two-compartment filtration model of Sourbron et al. ${ }^{16}$ :

$$
C_{\text {tissue }}(t)=V_{P} \cdot C_{P}(t)+F_{T} \cdot e^{-t / T_{T}} \otimes C_{P}(t)(2)
$$

where $V_{\mathrm{P}}$ is the relative plasma volume, $F_{\mathrm{T}}$ is the tubular flow, which was shown to be related to the glomerular filtration rate, and $T_{\mathrm{T}}$ is the tubular transit time. $C_{\mathrm{P}}(\mathrm{t})$ is the plasma gadolinium concentration in the kidney, which can be obtained from the arterial gadolinium concentration $C_{A}(t)$ according to:

$$
C_{P}(t)=T_{P}^{-1} \cdot e^{-t / T_{P}} \otimes C_{A}(t)(3)
$$

where $T_{\mathrm{p}}$ is the plasma transit time. The plasma flow $F_{\mathrm{p}}$, which is related to renal perfusion, can be calculated as $V_{\mathrm{p}} / T_{\mathrm{p}}$. As no reliable arterial input function could be obtained from the abdominal aorta, the input function was obtained from the erector spinae muscle using a reference region model with a vascular term ${ }^{23}$. The following values were assumed for the pharmacokinetic parameters of the reference muscle: $K^{\text {trans }}=0.15 \mathrm{~min}^{-1}, v_{\mathrm{p}}=0.025$, and $v_{\mathrm{e}}=0.1$. Voxels with an overall fit error of more than $50 \%$ were excluded from further analysis ${ }^{24}$. It should be noted that the twocompartment model applies to the kidney as a whole or to the cortex, but not to the medulla ${ }^{16,17}$. Consequently, DCE MRI analyses were concerned only the whole kidney and no distinction was made between the three functional regions as for BOLD MRI.

\section{Histology}

Kidneys were sectioned into $3 \mu \mathrm{m}$ slides and stained for histology with periodic acid-Schiff (PAS). Based on the method of Leemans et al. $^{25}$, the extent of tubular damage in the corticomedullary junction was scored by an experienced 
nephropathologist, who was blinded to which experimental group the samples belonged, using a scale from 0 to 5, representing no and extensive damage, respectively. The following criteria were assessed in 10 randomly chosen, nonoverlapping fields: tubular dilatation, cast deposition, brush border loss, and necrosis.

\section{Statistical analysis}

All values are presented as the mean \pm standard error, unless stated otherwise. Statistical analysis was performed using paired Student's t-tests in SPSS 17.0 (SPSS, Chicago, IL, USA). For DCE MRI data, the parameters $F_{\mathrm{P}}$ and $F_{\mathrm{T}}$ were first combined according to $O^{\prime}$ Brien and Läuter ${ }^{26,27}$ to obtain an overall measure that is more sensitive to changes in renal function than are the individual parameters. To this extent, values were standardized according to $z_{\mathrm{P}, \mathrm{T}}=\left(F_{\mathrm{P}, \mathrm{T}}-\right.$ mean $\left.\left(F_{\mathrm{P}, \mathrm{T}}\right)\right) / \mathrm{sd}\left(F_{\mathrm{P}, \mathrm{T}}\right)$. Next, $z_{\mathrm{P}}$ and $z_{\mathrm{T}}$ were averaged per kidney and the resulting summary measure was tested using a paired t-test. $\mathrm{P}<0.05$ was considered statistically significant.

\section{RESULTS}

Kidney size was measured in both clamped and control kidneys using anatomical $T_{2}$-weighted images covering both kidneys completely. At $24 \mathrm{~h}$ after reperfusion, no significant differences were found in either the total kidney volume or cortical volume between clamped and control kidneys (Table 8.1).

Table 8.1 Renal and cortical volumes of clamped and control kidneys, as measured on $T_{2}$-weighted anatomical MR images. No significant differences were found between clamped and control kidneys ( $p>0.05$ ). Notation: mean \pm standard error.

\begin{tabular}{lll}
\hline & Clamped & Control \\
\hline Renal volume $\left(\mathrm{mm}^{3}\right)$ & $541 \pm 21$ & $537 \pm 20$ \\
Cortical volume $\left(\mathrm{mm}^{3}\right)$ & $305 \pm 17$ & $285 \pm 16$ \\
\hline
\end{tabular}

\section{Renal oxygenation}

Figure 8.1 shows representative images of clamped and control kidneys from the same mouse, with a color-coded overlay of renal $R_{2}{ }^{*}$ at baseline, during ischemia and at various time points after reperfusion. During ischemia, $R_{2}{ }^{*}$ more than doubled in the clamped kidney relative to the control kidney, implying a strongly decreased oxygenation, which persisted after reperfusion.

For regional BOLD analysis, ROIs were defined in the cortex, inner medulla and outer medulla, based on tissue contrast on $T_{1}$ - and $T_{2}$-weighted anatomical images (Figure 8.1). Care was taken to exclude large veins. Table 8.2 shows the average $R_{2}{ }^{*}$ - 
values in these three functional regions during I/R injury. Compared with the control kidney, a significantly increased $R_{2}{ }^{*}$, i.e. decreased oxygenation, was found during ischemia for all regions of the clamped kidney. In the outer medulla, $R_{2}{ }^{*}$ - was significantly higher than in the control kidney up to $24 \mathrm{~h}$ after reperfusion. In contrast, in the cortex, a significantly lower $R_{2}{ }^{*}$, i.e. increased oxygenation, was found in the first $24 \mathrm{~h}$ post reperfusion, whereas in the inner medulla oxygenation returned to baseline level within $1 \mathrm{~h}$ after reperfusion.

Linear regression analysis of the $R_{2}{ }^{*}$ changes over time in the control kidney revealed no significant slopes (cortex and outer medulla) or a slope that was negligibly small $\left(\mathrm{d} R_{2}{ }^{*} / \mathrm{dt}=-0.009 \mathrm{~s}^{-1} / \mathrm{min}\right.$; inner medulla, not shown) compared with the ischemic effect in the injured kidney.

Table 8.2 $R_{2}{ }^{*}$ values at different time-points during ischemia reperfusion injury in the cortex, outer medulla, and inner medulla of clamped and contralateral control kidneys. ${ }^{*} \mathrm{p}<0.05$ compared with control kidney. Notation: mean \pm standard error.

\begin{tabular}{llcccc}
\hline & & Baseline & Ischemia & 1 hr post rep & 24 hrs post rep \\
\hline Cortex & Clamped & $68 \pm 7$ & $175 \pm 15^{*}$ & $57 \pm 5^{*}$ & $50 \pm 2 *$ \\
& Control & $72 \pm 6$ & $74 \pm 7$ & $70 \pm 6$ & $56 \pm 2$ \\
Outer medulla & Clamped & $67 \pm 11$ & $175 \pm 15^{*}$ & $97 \pm 13^{*}$ & $68 \pm 6^{*}$ \\
& Control & $72 \pm 11$ & $76 \pm 7$ & $65 \pm 6$ & $54 \pm 4$ \\
Inner medulla & Clamped & $53 \pm 9$ & $104 \pm 8 *$ & $48 \pm 6$ & $40 \pm 3$ \\
& Control & $58 \pm 10$ & $49 \pm 4$ & $50 \pm 6$ & $36 \pm 4$ \\
\hline
\end{tabular}

\section{Renal function}

DCE MRI was performed at $24 \mathrm{~h}$ post reperfusion to avoid any possible interference with BOLD measurements. Figure 8.2 shows a representative example of dynamic gadolinium-enhancement curves obtained in clamped and control kidneys. On average, the clamped and control kidneys showed peak enhancements of $0.63 \pm 0.12 \mathrm{mM}$ and $0.44 \pm 0.08 \mathrm{mM}$, respectively $(p=0.02)$. Both kidneys showed a higher perfusion than muscle tissue.

Anatomical images of mouse kidneys with color-coded overlays of the perfusion and filtration parameters $F_{\mathrm{P}}$ and $F_{\mathrm{T}}$, respectively, are shown in Figure 8.3. Compared with the control kidney, a marked reduction in both perfusion and filtration was observed in the clamped kidney. Averaged values of all DCE MRI derived functional parameters are summarized in Table 8.3. To obtain a summary measure that is more sensitive to changes in renal function than are the individual parameters, $F_{\mathrm{P}}$ and $F_{\mathrm{T}}$ were combined according to the method of $O^{\prime}$ Brien and Läuter ${ }^{26,27}$ (see Experimental details). This summary measure indicated a significantly lower renal function in the clamped kidney relative to the contralateral control ( $p=0.004$, Table 8.3). 


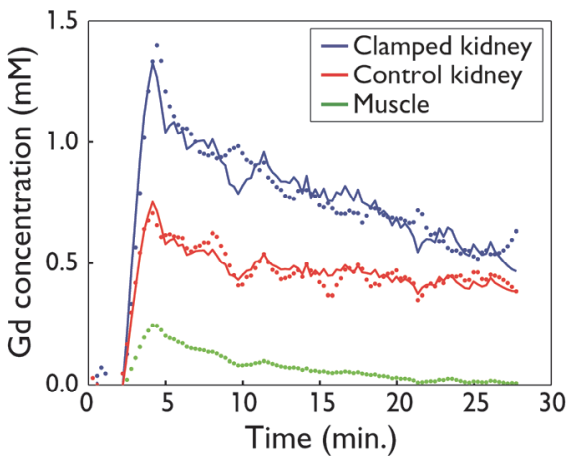

Figure 8.1 Dynamic gadolinium enhancement curves for the clamped kidney (blue), control kidney (red), and erector spinae muscle (green) of a representative mouse. The clamped kidney displays a stronger enhancement compared with the control kidney. Dotted lines represent the experimental data, whereas solid lines indicate the data fitted using the two-compartment filtration model.
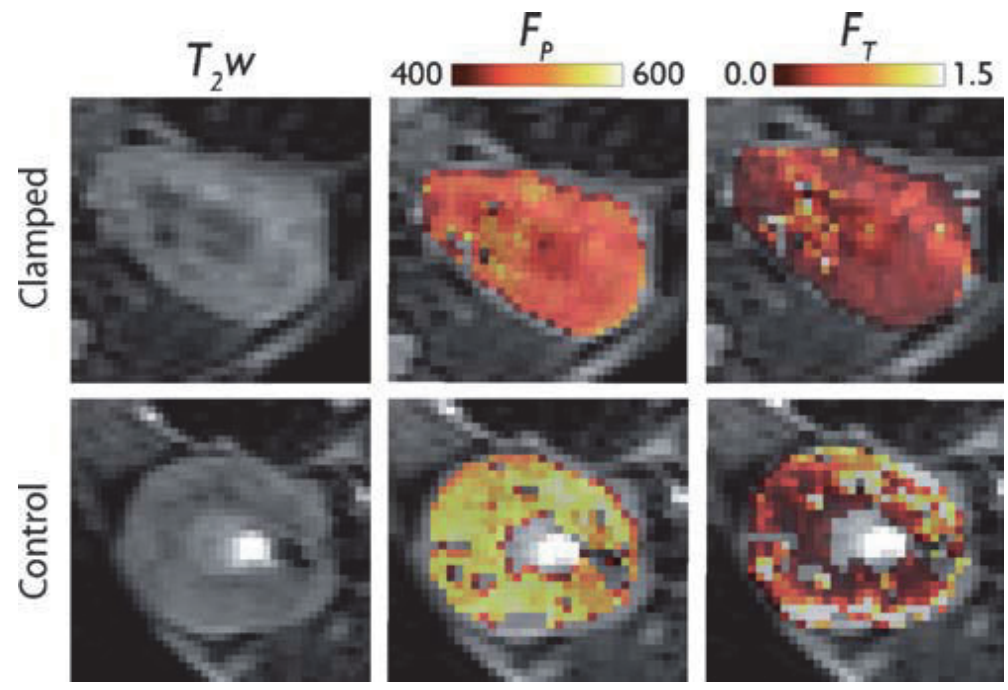

Figure 8.2 $\quad T_{2}$-weighted anatomical image (left) with color-coded overlay of the perfusion parameter $F_{\mathrm{P}}$ (middle, unit: $\mathrm{ml} / \mathrm{min} / 100 \mathrm{~cm}^{3}$ ) and the filtration parameter $F_{\mathrm{T}}$ (right, unit: $\mathrm{ml} / \mathrm{min} / 100 \mathrm{~cm}^{3}$ ) for a clamped (upper panels) and control (lower panels) kidney of the same mouse. 
Table 8.2 Whole kidney averaged pharmacokinetic parameters for clamped and control kidneys. An $\mathrm{O}^{\prime}$ Brien-Läuter test of the combined functional parameters $F_{\mathrm{P}}$ and $F_{\mathrm{T}}$ resulted in a highly significant difference between clamped and control kidneys $(p=0.004)$. $F_{\mathrm{p}}$ : plasma flow, related to renal perfusion; $F_{\mathrm{T}}$ : tubular flow, related to renal filtration; $T_{\mathrm{p}}$ : contrast agent plasma transit time; $T_{\mathrm{T}}$ : contrast agent tubular transit time; $V_{\mathrm{P}}$ : relative plasma volume. Notation: mean \pm standard error.

\begin{tabular}{lcc}
\hline & Clamped & Control \\
\hline$F_{\mathrm{P}}\left(\mathrm{ml} / \mathrm{min} / 100 \mathrm{~cm}^{3}\right)$ & $451 \pm 24$ & $481 \pm 26$ \\
$F_{\mathrm{T}}\left(\mathrm{ml} / \mathrm{min} / 100 \mathrm{~cm}^{3}\right)$ & $0.91 \pm 0.15$ & $1.04 \pm 0.16$ \\
$T_{\mathrm{P}}(\min )$ & $0.039 \pm 0.001$ & $0.037 \pm 0.001$ \\
$T_{\mathrm{T}}(\mathrm{min})$ & $210 \pm 91$ & $301 \pm 60$ \\
$V_{\mathrm{P}}\left(\mathrm{ml} / 100 \mathrm{~cm}^{3}\right)$ & $17.6 \pm 1.1$ & $17.7 \pm 1.0$ \\
\hline
\end{tabular}

\section{Histology}

Histological PAS staining confirmed extensive I/R injury in the clamped kidneys, whereas negligible damage was found in the contralateral control kidneys (Figure 8.4). The abundance of tubular dilatation, tubular casts, tubular necrosis and loss of brush borders throughout a major part of the medulla resulted in high injury scores in the clamped kidneys, which is a typical result $24 \mathrm{~h}$ after clamping.
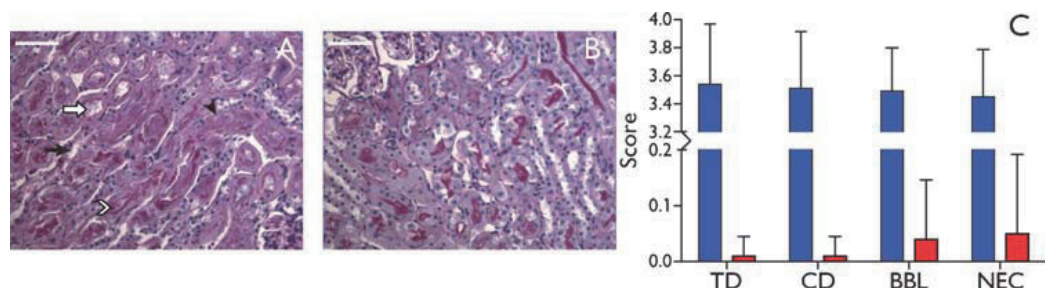

Figure 8.3 PAS-stained sections (magnification 100x) of a clamped (A) and a control kidney (B) showing extensive injury of the clamped kidney. Open arrow: tubular dilatation (TD). Open chevron: cast deposition (CD). Black arrow: brush border loss (BBL). Black arrowhead: necrosis (NEC). Bar: $50 \mu \mathrm{m}$. (C). Average histological scores of renal damage according to Leemans et al. ${ }^{25}$. Clamped and control kidneys are indicated in blue and red, respectively. Note the discontinuous y-axis, which was required to allow visualization of the extremely low values found in the control kidneys, compared with the high scores of the clamped kidneys. Values are presented as mean \pm standard deviation.

\section{DISCUSSION}

\section{Current findings}

In the present study, BOLD and DCE MRI were applied to study renal oxygenation and function, respectively, in a murine model of normothermic I/R injury. First, BOLD MRI revealed a significantly higher $R_{2}{ }^{*}$, indicating lower oxygenation, in the different 
regions of the clamped kidney relative to the contralateral control kidney (Table 8.2). Second, higher $R_{2}{ }^{*}$ values were found in the outer medulla compared with the cortex of the same kidney during $\mathrm{I} / \mathrm{R}$ injury. In contrast, the cortex of the clamped kidney showed a significantly reduced $R_{2}{ }^{*}$ compared with the control. This shows the applicability of BOLD MRI for the detection of changes in renal oxygenation. Third, ischemic tissue damage at $24 \mathrm{~h}$ post reperfusion was supported by the combination of DCE MRI derived pharmacokinetic parameters reflecting kidney function (Figure 8.3, Table 8.3). Dynamic gadolinium enhancement curves showed an increased enhancement of the injured kidney relative to the contralateral control (Figure 8.2). This might be related to an increased permeability of the renal microvasculature, which was shown to be maximal at $24 \mathrm{~h}$ post reperfusion and can be explained by a disruption of the actin cytoskeleton and a loss of adherens junctions between the endothelial cells ${ }^{28}$. The DCE MRI data were quantitatively described using a twocompartment filtration model combined with a reference region input function and showed a significantly reduced renal function (comprising perfusion and filtration) in the clamped vs control kidney.

During I/R injury, an increased workload and a consequently increased function might be expected for the contralateral kidney to compensate for the loss of function in the clamped kidney. However, no detectable changes were found for the cortex and outer medulla of the control kidney, as shown by the constant $R_{2}{ }^{*}$ during the entire experiment. The differences found between the clamped and control kidneys in these regions are therefore not considered to be biased by any possible compensatory mechanism of the control kidney.

Taken together, our results demonstrate that both BOLD and DCE MRI are suitable for the noninvasive study of $I / R$ injury in murine kidneys. In addition, BOLD MRI uniquely allowed a longitudinal evaluation of renal oxygenation and differentiation between the different functional regions of the kidney.

\section{Applicability of MRI}

Although BOLD MRI can be directly translated in to human studies, DCE MRI relies on the administration of a gadolinium-based, low-molecular- weight contrast agent. These agents were found to be related to an increased risk of nephrogenic systemic fibrosis (NSF) in patients with impaired renal function ${ }^{29}$. However, in the present study, the macrocyclic contrast agent Gadovist was applied, which was shown to be least associated with the development of $\mathrm{NSF}^{30,31}$ and can also be applied safely in patients with chronic kidney disease (up to stage $4^{32}$ ). It is therefore expected that DCE MRI with Gadovist can be safely translated into studies of I/R injury in humans.

Isoflurane has been shown to have a protective effect on renal I/R injury in rats via the attenuation of the inflammatory response ${ }^{33}$. Although significant differences 
between clamped and control kidneys were found in the present study, the use of isoflurane anesthesia may have reduced the extent of $I / R$ injury. However, ketamine/xylazine injection anesthesia was not feasible as the duration of anesthesia (maximum of $1 \mathrm{~h}$ ) is less than the time required for MRI (>1.5 h). The potential effect of the type of anesthesia on the BOLD and DCE MRI results is a topic of future research. In addition, future studies investigating the effects of novel therapeutics aimed at reducing renal $I / R$ injury should consider the effect of anesthesia.

The applied temporal resolution of $16 \mathrm{~s}$ probably resulted in undersampling of the dynamic gadolinium enhancement curves. The resulting discretization errors have been shown to strongly affect the flow parameters $F_{\mathrm{P}}$ and $F_{\mathrm{T}}{ }^{34}$. Based on the results described previously by Lopata et al. ${ }^{35}$ and Jaspers et $a .^{36}$ in tumor and muscle tissue, undersampling is estimated to result in an $F_{\mathrm{P}}$ value which is too low. However, a general limitation of pharmacokinetic parameters derived by DCE MRI is the absence of an accurate validation method. Although immunohistochemical investigation of microvessel density is considered as a surrogate validation method for DCE MRI in tumor tissue, it cannot be used to assess renal function. Undersampling will have the largest influence for tissues with high flow, i.e. the control kidney. Consequently, differences between clamped and control kidneys are expected to become larger at faster sampling rates. Improved temporal resolution can be obtained by acquiring a smaller number of slices, at the cost of whole kidney coverage, or using parallel imaging techniques.

\section{Preclinical and clinical perspectives}

BOLD and DCE MRI are suitable for the noninvasive and longitudinal investigation of renal I/R injury. As our methods were developed in mice, they can be applied directly in preclinical studies on the development of novel drugs which protect against $I / R$ injury during or after kidney transplantation. In addition, dedicated MRI protocols for murine imaging open up the way for studies in transgenic or knock-out animals. This may provide more insight into the effects of various genes in kidney (dys)function and the response to renal I/R injury.

Both BOLD and DCE MRI can be easily translated into human studies. With respect to the potential risk of NSF, however, it is advised to monitor serum creatinine levels in DCE MRI examinations. Creatinine was not measured in the current study as the presence of the healthy contralateral kidney ensured a normal global kidney function. In addition, creatinine provides no information on single kidney function.

In addition to studying renal I/R injury caused by sepsis, hypovolemic shock or after transplantation, the presented MRI methods could also be applied to assess renal injury in patients receiving medication with known renal side-effects, including nephrotoxic xenobiotics ${ }^{5}$, cytostatic drugs, or radiation therapy. Regular non-invasive 
monitoring with BOLD and/or DCE MRI may allow the early detection of renal pathology in these patients, and consequently may lead to an earlier intervention or change in therapy to minimize kidney damage. 


\section{REFERENCES}

1. Sutton TA, Fisher CJ, Molitoris BA. Microvascular endothelial injury and dysfunction during ischemic acute renal failure. Kidney Int 2002;62:1539-49.

2. Brezis M, Rosen S. Hypoxia of the renal medulla--its implications for disease. The New England journal of medicine 1995;332:647-55.

3. Aydin Z, van Zonneveld AJ, de Fijter JW, Rabelink TJ. New horizons in prevention and treatment of ischaemic injury to kidney transplants. Nephrol Dial Transplant 2007;22:342-6.

4. Djamali A, Sadowski EA, Samaniego-Picota M, Fain SB, Muehrer RJ, Alford SK, Grist TM, Becker BN. Noninvasive assessment of early kidney allograft dysfunction by blood oxygen level-dependent magnetic resonance imaging. Transplantation 2006;82:621-8.

5. Hofmann L, Simon-Zoula S, Nowak A, Giger A, Vock P, Boesch C, Frey FJ, Vogt B. BOLD-MRI for the assessment of renal oxygenation in humans: acute effect of nephrotoxic xenobiotics. Kidney Int 2006;70:144-50.

6. Prasad PV, Edelman RR, Epstein FH. Noninvasive evaluation of intrarenal oxygenation with BOLD MRI. Circulation 1996;94:3271-5.

7. Thoeny HC, Zumstein D, Simon-Zoula S, Eisenberger U, De Keyzer F, Hofmann L, Vock P, Boesch C, Frey FJ, Vermathen P. Functional evaluation of transplanted kidneys with diffusion-weighted and BOLD MR imaging: initial experience. Radiology 2006;241:812-21.

8. Tumkur SM, Vu AT, Li LP, Pierchala L, Prasad PV. Evaluation of intra-renal oxygenation during water diuresis: a time-resolved study using BOLD MRI. Kidney Int 2006;70:139-43.

9. Li LP, Ji L, Lindsay S, Prasad PV. Evaluation of intrarenal oxygenation in mice by BOLD MRI on a 3.0T human whole-body scanner. J Magn Reson Imaging 2007;25:635-8.

10. Li LP, Ji L, Santos EA, Dunkle E, Pierchala L, Prasad P. Effect of nitric oxide synthase inhibition on intrarenal oxygenation as evaluated by blood oxygenation level-dependent magnetic resonance imaging. Invest Radiol 2009;44:67-73.

11. Haacke EM, Brown RW, Thompson MR, Venkatesan R. Magnetic Properties of Tissue: Theory and Measurement. Magnetic Resonance Imaging Physical Principles and Sequence Design. 1 ed. New York: John Wiley \& Sons, Inc.; 1999:741-79.

12. Simon-Zoula SC, Hofmann L, Giger A, Vogt B, Vock P, Frey FJ, Boesch C. Non-invasive monitoring of renal oxygenation using BOLD-MRI: a reproducibility study. NMR Biomed 2006;19:84-9.

13. Pedersen M, Dissing TH, Morkenborg J, Stodkilde-Jorgensen H, Hansen LH, Pedersen LB, Grenier N, Frokiaer J. Validation of quantitative BOLD MRI measurements in kidney: application to unilateral ureteral obstruction. Kidney Int 2005;67:2305-12.

14. Sadowski EA, Fain SB, Alford SK, Korosec FR, Fine J, Muehrer R, Djamali A, Hofmann RM, Becker BN, Grist TM. Assessment of acute renal transplant rejection with blood oxygen level-dependent MR imaging: initial experience. Radiology 2005;236:911-9.

15. Dujardin M, Sourbron S, Luypaert R, Verbeelen D, Stadnik T. Quantification of renal perfusion and function on a voxel-by-voxel basis: a feasibility study. Magn Reson Med 2005;54:841-9.

16. Sourbron SP, Michaely HJ, Reiser MF, Schoenberg SO. MRI-measurement of perfusion and glomerular filtration in the human kidney with a separable compartment model. Invest Radiol 2008;43:40-8.

17. Michaely HJ, Sourbron S, Dietrich O, Attenberger U, Reiser MF, Schoenberg SO. Functional renal MR imaging: an overview. Abdom Imaging 2007;32:758-71.

18. Dujardin M, Luypaert R, Vandenbroucke F, Van der Niepen P, Sourbron S, Verbeelen D, Stadnik T, de Mey J. Combined T1-based perfusion MRI and MR angiography in kidney: first experience in normals and pathology. Eur J Radiol 2009;69:542-9.

19. Sadick M, Schock D, Kraenzlin B, Gretz N, Schoenberg SO, Michaely HJ. Morphologic and Dynamic Renal Imaging With Assessment of Glomerular Filtration Rate in a pcy-Mouse Model Using a Clinical 3.0 Tesla Scanner. Invest Radiol 2009;44:469-75.

20. Sari-Sarraf F, Pomposiello S, Laurent D. Acute impairment of rat renal function by $L$-NAME as measured using dynamic MRI. MAGMA 2008;21:291-7.

21. Rorden C, Brett M. Stereotaxic display of brain lesions. Behav Neurol 2000;12:191-200. 
22. Haacke EM, Brown RW, Thompson MR, Venkatesan R. Introductory Signal Acquisition Methods: Free Induction Decay, Spin Echoes, Inversion Recovery and Spectroscopy. Magnetic Resonance Imaging Physical Principles and Sequence Design. 1st ed. New York: John Wiley \& Sons, Inc. 1999:111-38.

23. Faranesh AZ, Yankeelov TE. Incorporating a vascular term into a reference region model for the analysis of DCE-MRI data: a simulation study. Phys Med Biol 2008;53:2617-31.

24. de Lussanet QG, Backes WH, Griffioen AW, van Engelshoven JM, Beets-Tan RG. Gadopentetate dimeglumine versus ultrasmall superparamagnetic iron oxide for dynamic contrast-enhanced MR imaging of tumor angiogenesis in human colon carcinoma in mice. Radiology 2003;229:429-38.

25. Leemans JC, Stokman G, Claessen N, Rouschop KM, Teske GJ, Kirschning CJ, Akira S, van der Poll T, Weening JJ, Florquin S. Renal-associated TLR2 mediates ischemia/reperfusion injury in the kidney. J Clin Invest 2005;115:2894-903.

26. Läuter J. Exact $t$ and $F$ tests for analyzing studies with multiple endpoints. Biometrics 1996;52:964-970.

27. O'Brien PC. Procedures for comparing samples with multiple endpoints. Biometrics 1984;40:1079-87.

28. Sutton TA, Mang HE, Campos SB, Sandoval RM, Yoder MC, Molitoris BA. Injury of the renal microvascular endothelium alters barrier function after ischemia. Am J Physiol Renal Physiol 2003;285:F191-8.

29. Agarwal R, Brunelli SM, Williams K, Mitchell MD, Feldman HI, Umscheid CA. Gadolinium-based contrast agents and nephrogenic systemic fibrosis: a systematic review and meta-analysis. Nephrol Dial Transplant 2009;24:856-63.

30. Shellock FG, Spinazzi A. MRI safety update 2008: part 1, MRI contrast agents and nephrogenic systemic fibrosis. AJR Am J Roentgenol 2008;191:1129-39.

31. van der Molen AJ. Nephrogenic systemic fibrosis and the role of gadolinium contrast media. J Med Imaging Radiat Oncol 2008;52:339-50.

32. Chrysochou C, Buckley DL, Dark P, Cowie A, Kalra PA. Gadolinium-enhanced magnetic resonance imaging for renovascular disease and nephrogenic systemic fibrosis: critical review of the literature and UK experience. J Magn Reson Imaging 2009;29:887-94.

33. Lee HT, Ota-Setlik A, Fu Y, Nasr SH, Emala CW. Differential protective effects of volatile anesthetics against renal ischemia-reperfusion injury in vivo. Anesthesiology 2004;101:1313-24.

34. Michaely HJ, Sourbron SP, Buettner C, Lodemann KP, Reiser MF, Schoenberg SO. Temporal constraints in renal perfusion imaging with a 2-compartment model. Invest Radiol 2008;43:120-8.

35. Lopata RG, Backes WH, van den Bosch PP, van Riel NA. On the identifiability of pharmacokinetic parameters in dynamic contrast-enhanced imaging. Magn Reson Med 2007;58:425-9.

36. Jaspers K, Aerts HJ, Leiner T, Oostendorp M, van Riel NA, Post MJ, Backes WH. Reliability of pharmacokinetic parameters: small vs. medium-sized contrast agents. Magn Reson Med 2009;62: 779-87. 


\section{Chapter 9}

General discussion and summary

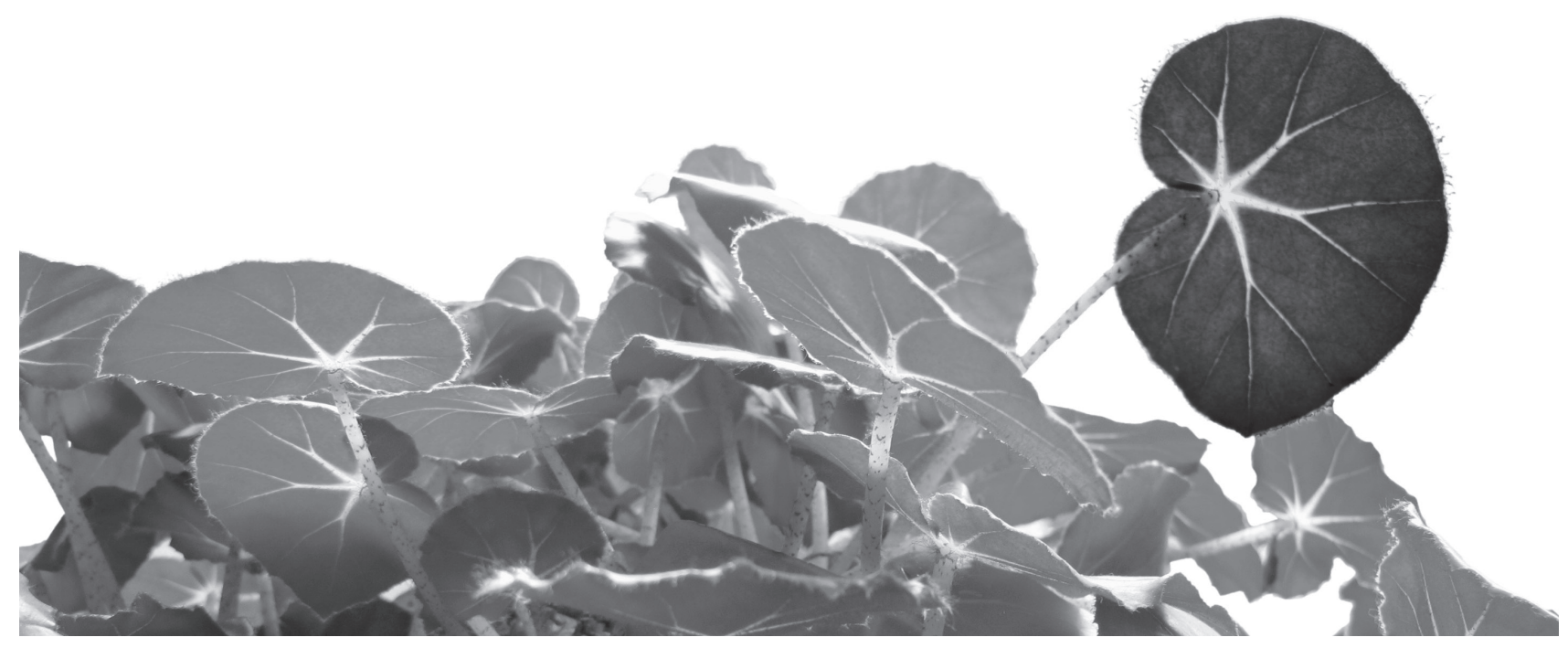




\section{GENERAL DISCUSSION AND SUMMARY}

\section{Part I - Exploring quantity; a pediatric perspective}

Kidney transplantation in patients with end stage renal disease leads to superior life expectancy and better quality of life compared with dialysis treatment. In the past decades there is an increasing shortage of donor kidneys. Donation after cardiac death (DCD) has become a generally accepted method to expand the donor pool and meet the demand for additional donor kidneys. However, in contrast to donation after brain death (DBD), kidneys from DCD donors suffer from higher percentages of primary nonfunction (PNF) and delayed graft function after transplantation due to an inevitable period of warm ischemia between cardiac arrest and the start of organ preservation. At present, no more than $25 \%$ of patients on the waiting list receive a kidney transplant annually, still leaving the majority of waiting list patients on dialysis treatment. This illustrates the need for further exploration of the available donor pool. Therefore, a subgroup of DCD donors was explored in the first part of this thesis: the pediatric donor after cardiac death. Pediatric DCD donation is an underutilized source of donors that we have described and examined to optimize its use.

In Chapter 2 we gave an overview of pediatric donation in general. We reviewed the specific aspects of kidney transplantation with pediatric donors, including the risk of postoperative graft thrombosis due to the small renal vessels, hyperfiltration injury and the principle of 'en bloc' transplantation. Age, kidney size, and donor weight are used to decide if donor kidneys should be transplanted as double grafts ('en bloc') or as two single grafts; variation among centers exists.

Both pediatric DBD and DCD donation were discussed. In the Netherlands the percentage of DCD kidneys among procured kidneys from pediatric donors is relatively high compared with the United States, $20 \%$ vs. $8 \%$ respectively. In contrast to pediatric DBD kidney transplantation little is known about pediatric DCD kidney transplantation. Based on literature early graft failure of pediatric DBD donor kidneys is slightly higher than of adult donor kidneys, particularly for the youngest donors. The high rate of graft failure in the youngest group is mainly caused by graft thrombosis. If kidneys were transplanted 'en bloc' pediatric donor grafts have equivalent graft survival as kidneys from ideal donors (donors aged 19 to 36 years), despite the slightly higher percentage of initial graft loss of kidneys from the youngest. Finally, we reported a decrease in the pediatric donor kidney transplantation (DBD and DCD) over the past two decades and consequently decided to further explore pediatric donation after cardiac death.

In Chapter 3 we examined the current position of pediatric DCD donation in the Netherlands and reported the 10-year experience, strategy, early results and ethical 
concerns of pediatric DCD donation. In this study we presented the largest series of kidney transplantations from pediatric DCD donors in literature. We gave a detailed description of the techniques to harvest the organs without prolonging warm ischemic injury of DCD organs. Firstly, we described in situ preservation on the intensive care unit (ICU); a technique in which vascular access is obtained via the femoral artery for intravascular cooling of the kidneys. A double-balloon triple-lumen catheter allows selective perfusion of the abdominal aorta, flushing and cooling the kidneys. The second technique is the rapid laparotomy in which, after cardiac arrest, direct cannulation of the aorta takes place in the operating room. For controlled donors we prefer withdrawal of treatment in the ICU followed by rapid laparotomy, as logistical requirements can be arranged before withdrawal of treatment. In this way end of life care remains uncompromised without unnecessarily prolonging the warm ischemia time. This results in shorter warm ischemia times, lower rates of discard and lower rates of PNF. In spite of limited literature on outcome and the existing ethical concerns on pediatric donation, pediatric DCD transplantation has resulted in an expansion of the pediatric donor pool with more than $30 \%$ in the Netherlands.

The outcome of pediatric DCD kidney transplantation in the Netherlands was excellent and comparable with an earlier study on pediatric DCD kidney transplantation and with the results of adult DCD kidney transplantation. Therefore we conclude that pediatric DCD donors can safely be added to the existing donor pool.

Additionally, in Chapter 4, as no literature on this topic was available we compared the results of pediatric DCD kidneys with those from pediatric DBD kidneys, transplanted in the same time period. Recipients of kidneys from DCD and DBD donors $<18$ years of age, donated in the Netherlands between January 1981 and July 2006, were included in this study. 91 patients were transplanted with kidneys from pediatric DCD donors whereas 405 patients received a kidney from pediatric DBD donors. We found that grafts from DCD donors were associated with higher percentage of PNF $(9 \%$ vs. $2 \%, p<0.05)$ and delayed graft function ( $48 \%$ vs. $8 \%, p<0.05)$ compared with DBD donor grafts. Donor age is an independent predictor of PNF, however a cut off age to simplify the decision which DCD kidney should be transplanted and which not could not be defined. After transplantation the estimated glomerular filtration rate did not differ between groups. After correction for confounding variables the risk of graft failure was slightly higher in the DCD group. Patient survival, however, was similar between groups. The relatively poor short-term outcome in the DCD group is in line with the results of adult DCD kidney transplantation, which are also slightly worse than the results of adult DBD kidney transplantation. Therefore we conclude that pediatric DCD kidneys can safely be added to the donor pool. We hope these studies encourage centers to start pediatric DCD programs throughout the world. 


\section{Part II - Exploring quality; viability testing}

Between organ procurement and transplantation there is an opportunity to select kidneys for transplantation and to decide which will be transplanted and which not. Discarding too many kidneys will enlarge the waiting list for kidney transplantation. On the other hand primary non-function after kidney transplantation is a serious complication since patients receiving these grafts are unnecessarily exposed to the risks of surgery and immunosuppression. In addition, they may become sensitized to donor antigens, reducing the opportunities for retransplantation. To minimize the number of erroneously discarded kidneys as well as to minimize transplants resulting in $\mathrm{PNF}$, we examined pre-transplant techniques to predict graft function after transplantation. In addition to the intended benefit of improved tissue preservation, machine perfusion provides the opportunity to determine perfusion parameters such as renovascular resistance and analysis of machine perfusate. Renovascular resistance is clinically used to discard kidneys for transplantation. However, the value of renovascular resistance during machine perfusion to predict PNF is relatively unknown as the incidence of PNF after transplantation in generally low.

In Chapter 5 we questioned if renovascular resistance, measured during machine perfusion, is associated with PNF and if this parameter should be used in the decision to either accept or discard a kidney. Due to the liberal acceptance rate for DCD kidneys at the Maastricht University Medical Centre, the results after transplantation were associated with a relatively high rate of PNF, which makes statistical analysis for PNF possible. Our results showed that renovascular resistance at the start of machine perfusion is significantly associated with PNF. The predictive quality however, was moderate and the decision to either accept or discard a kidney remains multifactorial. Graft and patient survival were not associated with renovascular resistance. Although we cannot present a threshold for renovascular resistance to discard kidneys and renovascular resistance cannot be used as a stand-alone assessment tool, we think that renovascular resistance can be a valuable addition to the deciding process we already use.

Next to renovascular resistance, biomarkers in the preservation solution of machine perfused kidneys have been used to predict PNF although evidence is lacking. Therefore, in Chapter 6, we analyzed the diagnostic accuracy of the perfusate biomarkers GST, LDH and H-FABP to predict PNF and DGF. We concluded that the diagnostic accuracy of the perfusate biomarkers LDH, GST and H-FABP to predict viability of DCD kidneys is poor. Therefore, we do not advise to discard kidneys only because of high biomarker perfusate concentration. 
The higher incidence of graft dysfunction in DCD kidneys compared with kidneys from DBD is largely attributed to the prolonged period of warm ischemia before organ procurement. This period of warm ischemia leads to more capillary damage due to thrombosis, vasoconstriction and edema, and may result in decreased renovascular circulating volume. Next to the earlier mentioned pre-transplant viability testing methods we investigated renovascular circulating volume measurement by the ultrasound dilution technique. This technique was originally used to measure circulating volume in hemodialyzer fiber bundles. However, in Chapter 7, we determined the validity of renovascular circulating volume measurement with the ultrasound dilution technique, in machine perfused kidneys. We showed that the ultrasound dilution technique is a valid and reproducible technique to measure renovascular volume. The repeatability of the dilution method was good with a relatively small standard deviation and an acceptable coefficient of variation $(8 \% \pm$ $5.2 \%)$. Subsequently, we demonstrated that differences in warm ischemia time are reflected by renovascular circulating volume. Future experiments will focus on measurements in human kidneys to correlate circulating volume with graft outcome.

In addition to pre-transplant tools, to estimate transplant outcome we explored post-transplant investigations that might be helpful to reduce further damage to the organ after transplantation. The reduction of initial flow in ischemically damaged kidneys after transplantation is responsible for further ischemic damage. Novel therapies are being developed that limit renal ischemia reperfusion injury. However, to fully address their therapeutic potential, noninvasive imaging methods are required that allow the in vivo visualization of different renal compartments and the evaluation of kidney function. In Chapter 8 we applied functional MRI (Blood Oxygenation Level Dependent (BOLD) and Dynamic Contrast Enhanced (DCE)) to establish these goals. It is known that the renal medulla, whose scarce blood supply optimizes the concentration of the urine, under physiological conditions, is poorly oxygenated. In a murine model for renal ischemia reperfusion injury differences in oxygenation between the functional regions of the kidney were visualized. We showed that the outer medulla (the region of the thick ascending limbs) of the ischemically damaged kidneys had a significantly lower oxygenation status than contralateral kidneys up to 24 hours after ischemia reperfusion injury as compared with the cortex. DCE MRI revealed a significantly reduced renal function of the ischemically damaged kidney, comprising perfusion and filtration, at 24 hours after reperfusion. We therefore concluded that MRI is suitable for the noninvasive evaluation of renal oxygenation and function. MRI may allow the early detection of renal pathology in transplanted patients and consequently may lead to an earlier intervention or change of therapy to minimize kidney damage. 
In this thesis, in order to fully utilize available donor kidneys, we provided information, procedures, and outcome of pediatric donation after cardiac death. We concluded that ethical considerations can be overcome, end of life care is maximized by withdrawal of treatment in ICU and most important, we conclude that although the incidence of PNF is slightly higher in DCD than in DBD kidneys, the long term outcome of pediatric DCD kidneys is excellent. Subsequently, in order to prevent PNF in DCD kidneys prior to transplantation we studied three ways to predict graft outcome. Firstly, we showed that renovascular resistance of DCD kidneys during machine perfusion is significantly associated with PNF, however its predictive value is low. Secondly, we assessed that the value of perfusate biomarkers concentration in machine perfused kidneys has a poor predictive value for PNF. Thirdly, we studied a novel method that calculates renovascular circulating volume in pig kidneys. We showed its validity and demonstrated an association with warm ischemia time. Further studies are necessary to confirm that this method is a promising new way to predict graft function. In order to prevent kidneys to result in PNF after transplantation we studied BOLD and DCE MRI as a noninvasive method to detect renal pathology. This may lead to an earlier intervention or change of therapy in transplant recipients. 


\section{Samenvatting}

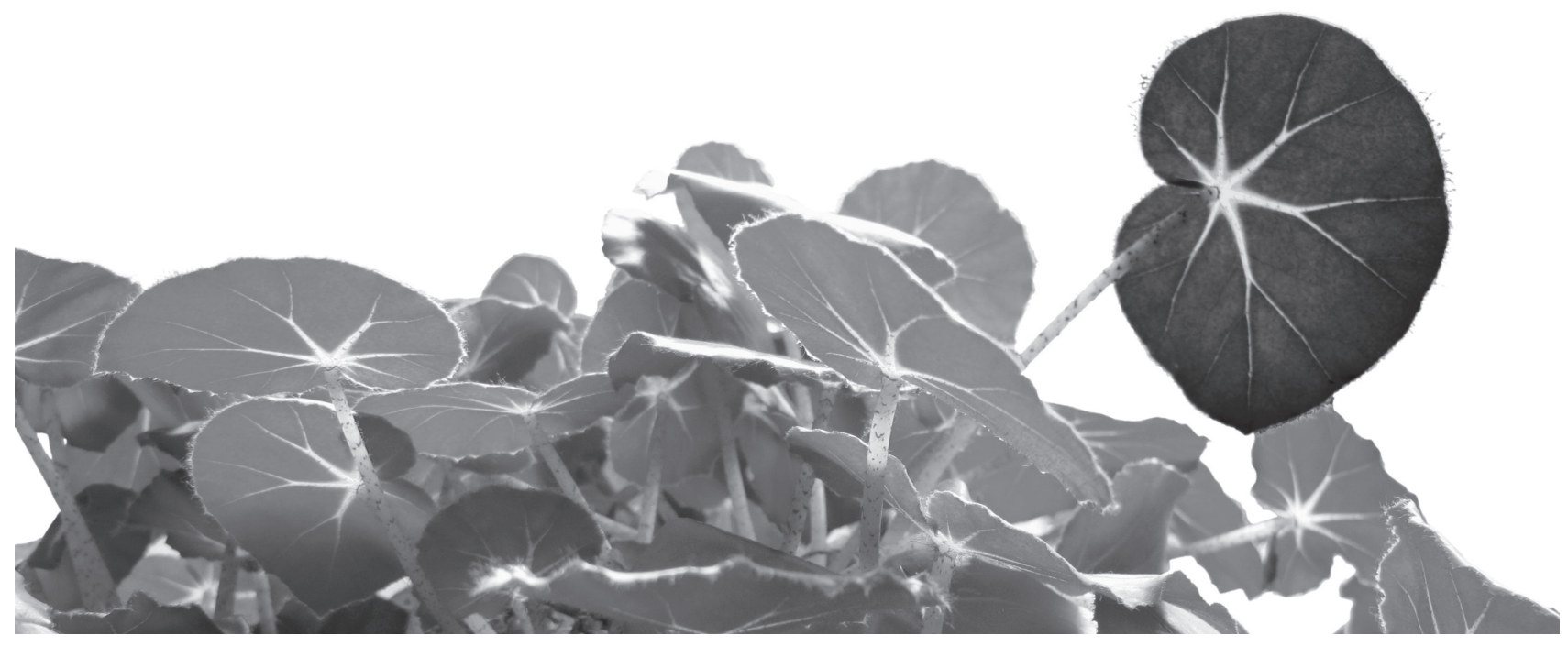




\section{SAMENVATTING}

Niertransplantatie bij patiënten met eindstadium nierfalen leidt, in vergelijking met dialyse, tot een betere levensverwachting en kwaliteit van leven. Er bestaat echter een toenemend tekort aan donornieren. Naast orgaandonatie na hersendood, waarbij organen tot uitname worden voorzien van zuurstofrijk bloed, wordt er sinds enkele decennia gebruik gemaakt van orgaandonatie na hartstilstand. In tegenstelling tot nieren van orgaandonatie na hersendood, leidt orgaandonatie na hartstilstand tot een hoger percentage vertraagde transplantaatfunctie of primaire non-functie door een onvermijdelijke periode van warme ischemie (afwezigheid van zuurstofrijke circulatie) tussen hartstilstand en orgaanpreservatie. Desalniettemin heeft orgaandonatie na hartstilstand in Nederland een belangrijke plaats verworven in de huidige donatiepraktijk. Alhoewel naast orgaandonatie na hartstilstand en hersendood ook levende donoren een groot aandeel hebben verkregen in de donorpool, ontvangt jaarlijks slechts $25 \%$ van de patiënten op de wachtlijst een nier. Dit komt neer op een gemiddelde wachttijd van 4 jaar. Een bredere toepassing van orgaandonatie na hartstilstand kan het aantal niertransplantaties 2,5 tot 4 maal doen stijgen, hetgeen voldoende is om de wachtlijst voor niertransplantatie te verkorten of zelfs te elimineren. Om de groep donoren na hartstilstand verder uit te breiden wordt in dit proefschrift aandacht besteed aan een subgroep donoren: de kinderdonor.

\section{Deel I: Kwantiteit verbetering van nierdonatie na hartstilstand}

In hoofdstuk 2 worden alle aspecten rondom kinderdonatie en transplantatie kort beschreven. Zowel kinderdonatie na hartstilstand als na hersendood wordt besproken. Zoals bekend uit de huidige literatuur, komt transplantaatfalen op de korte termijn vaker voor bij kindernieren dan bij volwassen nieren. Dit geldt hoofdzakelijk voor de allerjongste donornieren. Een veel voorkomende complicatie van transplantatie van een kindernier is het postoperatief optreden van trombose van de transplantatienier; een gevolg van de kleine niervaten en de relatief hoge flow in een klein orgaan (hyperfiltratie schade). 'En bloc' transplantatie komt aan bod, het transplanteren van twee nieren in één ontvanger. De leeftijd en het gewicht van de donor, evenals de grootte van de donornier worden gebruikt om een afweging te maken tot het al dan niet en bloc transplanteren van de nieren. Richtlijnen hieromtrent variëren tussen verschillende centra. In Nederland is het percentage donoren na hartstilstand binnen de kinderdonoren hoog in vergelijking met bijvoorbeeld de VS, $20 \%$ vs. $8 \%$, respectievelijk. We zien een dalend totaal aantal kinderdonoren in de laatste 20 jaar. Daarom hebben we in hoofdstuk 3 het gehele proces van kinderdonatie na hartstilstand in Nederland weergegeven. We beschrijven de ethische bezwaren, de procedure en het resultaat na transplantatie. Deze studie rapporteert de grootste serie 
kinderdonornieren na hartstilstand verschenen in de literatuur. We geven een gedetailleerde beschrijving van de donatieprocedure zoals deze in Maastricht wordt toegepast met specifieke aandacht voor end of life care. We geven de voorkeur aan het staken van de behandeling van een donor na hartstilstand op de intensive care, om optimale zorg rondom het einde te waarborgen. We hopen dat deze procedure wordt overgenomen in nieuwe protocollen betreffende kinderdonatie na hartstilstand. Ondanks beperkte literatuur betreffende de resultaten en de ethische kwesties, heeft kinderdonatie na hartstilstand ertoe geleid dat de donorpool voor nieren in ons centrum met $30 \%$ is toegenomen. De resultaten van kindernierdonatie na hartstilstand zijn goed; vergelijkbaar met een grote studie uit de VS dat de resultaten beschrijft van volwassen nierdonatie na hartstilstand. Daarom concluderen we dat kinderdonoren na hartstilstand op ethisch verantwoorde wijze en met goede resultaten de donorpool kunnen vergroten.

In hoofdstuk 4 hebben we de resultaten van kinderdonornieren na hartstilstand vergeleken met de resultaten van kinderdonornieren na hersendood. Alle ontvangers van nieren afkomstig van kinderdonoren na hartstilstand en na hersendood $<18$ jaar, getransplanteerd tussen januari 1981 en juli 2006, werden geïncludeerd in deze studie. 91 patiënten werden getransplanteerd met een nier van een kinderdonor na hartstilstand, 405 patiënten ontvingen een nier van een kinderdonor na hersendood. Nieren van donoren na hartstilstand waren significant geassocieerd met een hoger percentage primaire non-functie ( 9 vs. $2 \%$ ). De donor leeftijd blijkt een onafhankelijke voorspeller voor primaire non-functie te zijn. De nierfunctie is gelijk in beide groepen maar na correctie voor verstorende variabelen is het risico op nierfalen in de groep nieren na hartstilstand hoger. Patiënt overleving was hetzelfde in de twee groepen. Ondanks de slechtere resultaten op de korte termijn in de groep nieren na hartstilstand, zijn de resultaten van deze studie vergelijkbaar met de resultaten van volwassen donatie na hartstilstand. Zodoende kunnen we concluderen dat nieren van kinderdonoren na hartstilstand veilig kunnen worden toegevoegd aan de donorpool. We hopen dat deze studies overige centra aanmoedigen tot het starten van 'kinderdonatie na hartstilstand'-programma's.

\section{Deel 2: Kwaliteitverbetering van nierdonatie na hartstilstand}

$\mathrm{Na}$ donatie en voorafgaand aan transplantatie zal elke nier, afhankelijk van de eigenschappen van de donor(nier) zoals leeftijd, voorgeschiedenis en warme ischemietijd, al dan niet worden geaccepteerd voor transplantatie. Het afwijzen van een te groot aantal nieren zal de wachtlijst doen verlengen. Het accepteren van te veel nieren daarentegen, met andere woorden, een hoog percentage primaire non-functie na transplantatie, is een ernstige complicatie. Patiënten die een nier ontvangen met primaire non-functie worden onnodig blootgesteld aan de risico's van de operatie en 
van immunosuppressieve behandeling. Alhoewel patiënten na primaire non-functie hun wachttijd bij Eurotransplant behouden, wordt de mogelijkheid tot retransplantatie beperkt door immunologische sensibilisatie tegen antigenen van de donor.

Om het aantal nieren dat resulteert in primaire non-functie te verminderen, hebben we technieken onderzocht die een voorspelling van de nierfunctie mogelijk maken alvorens over te gaan tot transplantatie. Ondanks dat nierdonatie na hartstilstand bewezen heeft een waardevolle toevoeging te zijn op de huidige donorpool, gaat, zoals eerder beschreven, transplantatie van deze nieren gepaard met een hoger percentage primaire non-functie. Naast het voordeel van machine preservatie op de uitkomst van de nieren, biedt machine preservatie ook mogelijkheden om de transplantaatuitkomst te voorspellen. De perfusiesnelheid en de vaatweerstand schetsen de toestand van het renale vaatbed en zijn zo een weerslag van de ischemische schade die voorafgaand aan orgaanuitname is geleden. De vaatweerstand is de weerstand die berekend wordt door de in de machine opgewekte flow te delen door de pompdruk van de machine. Veel onderzoek is gedaan naar de waarde van deze vaatweerstand in het voorspellen van de nierfunctie vlak na transplantatie. Echter, vanwege de relatief kleine groep nieren met primaire nonfunctie is het slecht mogelijk om statistisch significante uitspraken te doen. Omdat we in Maastricht vanaf 1993 alle nieren van donoren na hartstilstand op de machine hebben gepreserveerd en dit een groep betreft van zeer marginale nieren, resulteerde dit in een relatief hoog percentage primaire non-functie.

Zodoende hebben we in hoofdstuk 5 onderzocht of de vaatweerstand geassocieerd is met primaire non-functie en of deze parameter kan worden gebruikt in de besluitvorming tot het al dan niet accepteren van een nier voor transplantatie. De resultaten laten zien dat de vaatweerstand aan het begin van machine perfusie significant geassocieerd is met primaire non-functie. De werkelijk voorspellende waarde is echter beperkt. De beslissing om een nier te accepteren dan wel af te keuren voor transplantatie blijft een multifactorieel proces. Met andere woorden, de vaatweerstand is wel een risicofactor voor primaire non-functie, maar er kan geen grenswaarde worden gegeven waarboven een nier moet worden afgekeurd. Desondanks zal de vaatweerstand een waardevolle aanvulling zijn op het besluitvormingsproces dat reeds gebruikt wordt.

Een andere techniek, welke zou kunnen worden toegepast tijdens machine preservatie om primaire non-functie na transplantatie te kunnen voorspellen, is het meten van biomarkers in de preservatievloeistof. Biomarkers zijn eiwitten die uit beschadigde tubulaire epitheelcellen lekken zoals lactaat dehydrogenase (LDH), glutathion-S-transferase (GST) en fatty-acid binding protein (FABP). Literatuur hierover is schaars. Daarom hebben we, in hoofdstuk 6, de diagnostische waarde van de biomarkers GST, LDH en H-FABP geëvalueerd, om zowel vertraagde transplantaat- 
functie als primaire non-functie te kunnen voorspellen. We concluderen dat de diagnostische waarde van GST, LDH en H-FABP slecht is en adviseren om nieren niet af te wijzen op basis van enkel een hoge concentratie biomarkers.

Zoals eerder beschreven kan de hogere incidentie van primaire non-functie in nieren van donoren na hartstilstand worden toegeschreven aan de periode van warme ischemie. Deze periode van warme ischemie leidt tot meer schade aan de capillairen door trombose, vasoconstrictie en oedeem en kan resulteren in een verminderd vaatvolume van de nier. Zodoende onderzochten we een geheel nieuwe techniek om het vaatvolume te bepalen: de 'ultrasound dilution technique'. Hiermee zou de nierfunctie na transplantatie kunnen worden voorspeld. Deze techniek werd oorspronkelijk gebruikt om het circulerende volume in hemodialyse apparatuur te bepalen. In hoofdstuk 7 hebben we de validiteit en reproduceerbaarheid van deze techniek bepaald in varkensnieren tijdens machine perfusie. We laten zien dat de 'ultrasound dilution technique' een valide techniek is om het vaatvolume van een nier te meten. De reproduceerbaarheid van de techniek was goed met een relatief kleine standaarddeviatie en een acceptabele variatiecoëfficiënt ( $8 \% \pm 5.2 \%)$. Daarnaast laten we zien dat de verschillen in warme ischemie worden weerspiegeld in het vaatvolume van de nier. Toekomstige experimenten zullen zich richten op metingen in humane nieren, om het vaatvolume van de nier te kunnen correleren met de uitkomst na transplantatie.

Naast de genoemde methoden om vóór transplantatie de functie van de nier te voorspellen keken we naar methoden om ná transplantatie de functie van de nier te evalueren. Om ischemische schade te beperken worden frequent nieuwe therapieën ontwikkeld. Echter om de volledige therapeutische waarde te kunnen analyseren zijn niet-invasieve beeldvormende technieken nodig voor de in vivo visualisatie van de verschillende compartimenten van de nier en evaluatie van de nierfunctie. In hoofdstuk 8 werd functionele (blood oxygenation level dependent (BOLD) en dynamic contrast enhanced (DC)) MRI ingezet om deze doelen te verwezenlijken. Het is bekend dat onder fysiologische omstandigheden de medulla van de nier slecht geoxygeneerd is om de concentratie van de urine te optimaliseren. Na het selectief klemmen van de nierarterie laten we inderdaad zien dat de buitenste medulla (de regio van de dikke opstijgende lissen van Henle) van muizennieren na 45 minuten warme ischemie significant slechter is geoxygeneerd dan die van de contralaterale nier tot zo'n 24 u ur na ischemie/reperfusie. In de cortex daarentegen is dit verschil niet aantoonbaar. DCE MRI laat een significant gereduceerde nierfunctie zien in de ischemisch beschadigde nieren. Zowel perfusie als filtratie zijn verminderd in de aangedane nier, beide tot 24 uur na de toegebrachte schade. Concluderend is MRI een geschikte methode voor niet-invasieve beeldvorming van de oxygenatie en de functie van de nier. MRI heeft de potentie om nier-pathologie in een vroeg stadium op te sporen en kan daardoor leiden 
tot optimalisatie van onderzochte technieken, eerdere interventie of verandering van therapie om verdere nierschade te voorkomen.

In dit proefschrift, met het oog op de verbetering van het aantal en de kwaliteit van beschikbare donoren, wordt een uiteenzetting gegeven van de overwegingen, de procedure en de resultaten van het gebruik van nieren van kinderdonoren na hartstilstand. We concluderen dat ethische overwegingen kunnen worden overkomen en dat end of life care niet in het gedrang komt wanneer een medisch zinloze behandeling op de intensive care wordt gestaakt. Alhoewel de incidentie van primaire non-functie hoger is in kinderdonoren na hartstilstand dan na hersendood, is de uitkomst van kindernierdonatie uitstekend. Tevens, om het aantal nieren resulterend in primaire non-functie terug te dringen, hebben we een tweetal technieken onderzocht dat informatie geeft over de nierfunctie na transplantatie. Ten eerste laten we zien dat de vaatweerstand van donornieren na hartstilstand significant geassocieerd is met primaire non-functie. Ten tweede werd de voorspellende waarde van biomarkers (GST, LDH en H-FABP) in de perfusie vloeistof bepaald en adviseren we om nieren niet af te wijzen enkel op basis van een hoge concentratie biomarkers. Ten slotte hebben we een nieuwe techniek bestudeerd om het circulerende volume in varkensnieren te meten; de 'ultrasound dilution technique'. We laten zien dat de techniek valide en reproduceerbaar is en tonen aan dat er een relatie is met de duur van de warme ischemie. Nader onderzoek met humane nieren is nodig om de klinische relevantie ervan aan te tonen. Om op niet-invasieve wijze de functie van de nier ná transplantatie te kunnen beoordelen hebben we BOLD en DCE MRI onderzocht in muizennieren. Dit zou in de toekomst kunnen leiden tot in vivo evaluatie van nieuwe therapieën en snelle detectie van niet-functionerende nieren. 


\section{List of publications}

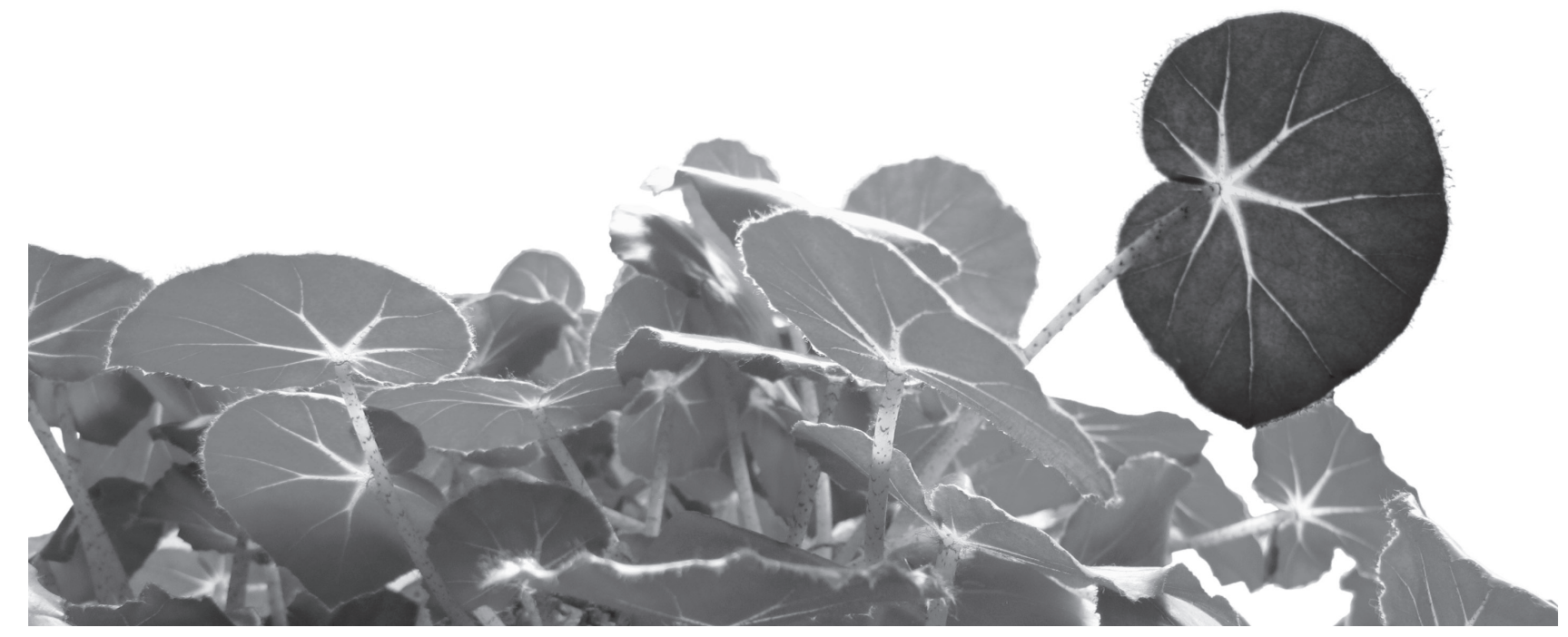




\section{LIST OF PUBLICATIONS}

de Vries EE, van Smaalen T, Boer J, Hoogland ERP, Krivitski NM, Snoeijs MGJ, van Heurn LWE. Measurement of renovascular circulating volume during hypothermic organ perfusion. Transplantation 2013;95:1100-4.

Hoogland ERP, de Vries EE, Christiaans MHL, Winkens B, Snoeijs MGJ, van Heurn LWE. The value of machine perfusion biomarker concentration in DCD kidney transplantations. Transplantation 2013;95:603-10.

de Vries EE, Hoogland ERP, Wind J, Snoeijs MGJ, van Heurn LWE. Transplantation of kidneys from pediatric DCD donors: a comparison with DBD donors. Nephrology Dialysis Transplantation 2013;28:220-6.

Witteman BP, Strijkers R, de Vries E, Toemen L, Conchillo JM, Hameeteman W, Dagnelie PC, Koek GH, Bouvy ND. Transoral incisionless fundoplication for treatment of gastroesophageal reflux disease in clinical practice. Surg Endosc 2012;26:3307-15.

de Vries EE, van Adrichem NPH, Dom PGB, Kooistra A. Case report. Knieklachten bij prostaatcarcinoom; een uitzonderlijke locatie voor metastasering. Tijdschrift voor Urologie 2011;1:114-5.

de Vries EE, Hoogland ERP, Winkens B, Snoeijs MG, van Heurn LWE. Renovascular resistance of machine perfused DCD kidneys is associated with primary non - function. American Journal of Transplantation 2011;11:2685-91.

Snoeijs MG, Vaahtera L, de Vries EE, Schurink GW, Haenen GR, Peutz-Kootstra CJ, Buurman WA, van Heurn LW, Parkkinen J. Addition of a water-soluble propofol formulation to preservation solution in experimental kidney transplantation. Transplantation 2011;92:296-302.

de Vries EE, Oostendorp M, Slenter JMGM, Peutz-Kootstra CJ, Snoeijs MGJ, Post MJ, van Heurn LWE, Backes WH. Magnetic resonance imaging of renal oxygenation and function after normothermic ischemiareperfusion injury. NMR Biomed 2011;24: 194-200.

van Heurn LWE, de Vries EE. Kidney transplantation and donation in children. Pediatric Surgery International 2009;25:385-93. 
Dankwoord

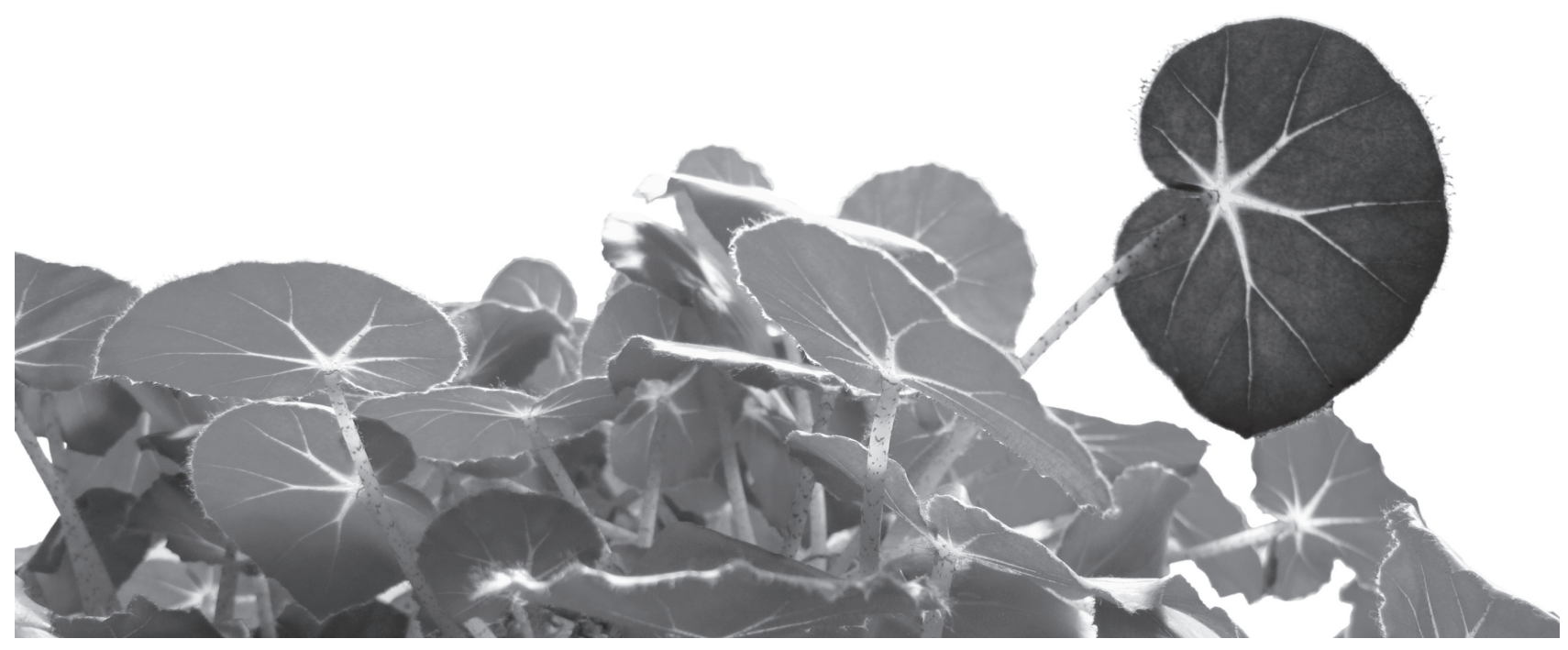




\section{DANKWOORD}

Yes! Na enig oponthoud is het proefschrift af. Ik realiseer me nu dat schrijven, zeker in geval van het dankwoord, mooi kan zijn. Echter, zonder de hulp van een heleboel vrienden en collega's was dit boekje nooit tot stand gekomen. Ik neem dan ook graag de ruimte hier iedereen te bedanken.

Mijn promotor: professor dr. L.W.E. van Heurn, beste Ernst, je zal wel gedacht hebben. Een kleine verrassing was het toen ik je vertelde dat ik graag het proefschrift wilde afschrijven. Ik wil je bedanken voor je begeleiding, je ruimte voor eigen ideeën en overleg, de kritische blik op mijn manuscripten, de tijd die je vrijmaakte in je drukke agenda, het begrip toen ik opstapte, je open ontvangst bij mijn terugkomst en dank voor je vertrouwen.

Dr. M.G.J. Snoeijs, "professor" Snoeijs, beste Maarten, dank. Vele ideeën, uitgewerkt in dit proefschrift zijn van jouw hand. Jij bent een bron van inspiratie op wetenschappelijk vlak. Ik heb bewondering voor je creatieve, georganiseerde en gedisciplineerde werkwijze. Ondanks onze verschillende karakters heb ik ontzettend veel van je geleerd en was dit boekje zonder jou nooit tot stand gekomen.

Leden van de promotiecommissie, prof. dr. C.H.C. Dejong, prof. dr. T.M. van Gulik, prof. dr. P.E.V.A. van Kerrebroeck, prof. dr. D. Talbot, prof. dr. L.J.I. Zimmermann, hartelijk dank voor het plaatsnemen in mijn promotiecommissie en het lezen en beoordelen van dit proefschrift.

Allerbeste collega's van het preservatielab, (John), Wim, Tineke, Pieter, Tim, Monique en Marloes. Lang geleden waagde ik mij aan de sollicitatie voor het kidneyracerschap en afscheid nemen is me tot op heden niet gelukt. Ook jullie hebben een groot aandeel in het afronden van mijn promotie. Niet voor niks keer ik op onverwachte momenten steeds weer terug. De geweldige werksfeer die jullie creëren evenals de gezelligheid, ook buiten werk, is uniek! Ontzettend bedankt voor jullie eeuwige geduld, behulpzaamheid en dank voor jullie interesse en medeleven in alles wat ik deed en nog steeds doe.

Beste collega's van 5! Zonder team van medeploeteraars is promoveren niet leuk en niet leerzaam. Bedankt voor jullie wetenschappelijke, statistische, technische, praktische en sociale bijdrage, jullie kennis en kunde tezamen is spectaculair. In het bijzonder wil ik bedanken: Mo, Bas, Maartje, Simon, Irma, Jacco, Bas H, Caroline, Charlotte, Kirsten, Kaatje, Joep D, Tim L, Robert, Sander, Geertje \& Tim, Froukje, Iris, Ruben, Kim en Nina. Bedankt voor de koffie op 4. 
Beste Carine Peutz-Kootstra en Bart de Vries, hartelijk dank voor de verwerking en beoordeling van de coupes.

Beste Marlies, Jos en Walter Backes. Hartelijk dank voor de fijne samenwerking aan het BOLD MRI stuk. Marlies, dank voor je geduldige bijdrage aan zaken zoals Matlab en het mij leren prikken van een infuus in de staartvene van een muis; klussen die ik voorheen als onmogelijk zou hebben beschouwd. Jos, dank voor de gezellige dagen bij de MRI en Walter, fijn dat ons stuk is wat het is.

Nicole Bouvy, als jonge student klopte ik bij jou aan voor extra-curriculaire activiteiten. Met open armen werd ik ontvangen en maakte ik onder jouw vleugels kennis met de (experimentele) chirurgie, de wetenschap, congressen en collega's, laparoscopie, de varkens op 't proefdierlab en het geven van bevlogen presentaties. Je stond aan de basis van mijn keuze te willen worden wat ik word.

En dan; lieve vriendinnen uit Maastricht (in chronologische volgorde); Sanne, in de eerste belangrijke weken Maastricht werden we lid bij dezelfde vereniging en startten we samen de studie GW. Nog steeds kom ik je op willekeurige momenten overal tegen. Dit zegt wat. Lieve dames van de jaarclub - Marike, Margot, Willemijn, Nicole, Annemiek, Kim, Anouk, Madeleine, Karlijn en Hetty - als spuitelf sloot ik bij jullie aan, dank voor de gezellige maandagavonden en voor de vriendschappen die eruit voortvloeiden. Dames van MDD Cumbonadea, hè ja, waarom ook niet: Liedje, Jackie, en Fien, Marie, Els, B, Mo, Tam, Appels, Sop, Maris, Ank, Jeta, Ankies, Kris, Brech, Arie, Sanne, Pas, Fem, Mootje, Vanes, Es, Kim, Clara, Carli, Marjo, Nien, Lon, Brech vd P, Ka, Alf, Sjef, An, Lot, Leo, Jessy, Jenny, Tilly, Lotte, Mu en Fi, een rijkere verbreding binnen de studententijd had ik niet kunnen wensen. Jullie hebben me gevormd en afgeleverd als degene die ik ben. "Dames met durf en daadkracht" lees ik op onze site, zo is 't maar net. Creatief? Hmm, dit besteed ik nog steeds liever uit. Stationnies, Anouk, Marielle, Madeleine, Go, Yvette en Liselotte als huisgenoten deelden we lief en leed. Dit heeft geleid tot een warme vriendschap voor altijd (laten we de weekendjes Maastricht erin houden). Lieve Matthijs, ... dank voor alles. Dank ook vele anderen die mijn (verlengde) studententijd in Maastricht tot een groot succes hebben gebracht. Jullie hebben hier allemaal op een eigen manier een zeer waardevolle rol in gehad. Mede dankzij jullie heb ik me gevormd tot wie ik ben en was ik in staat tot het starten en afronden van dit proefschrift. Hartelijk dank voor jullie steun en toeverlaat te allen tijde!

Beste Colette de la Rosette, als een van de studentes in jouw restaurant in Maastricht heb ik je leren kennen. Het was meer dan gewoon een bijbaan. De 
consciëntieuze doch prettige werksfeer onder jouw leiding gaf mij precies wat ik nodig had in de uren die ik over had naast de co-schappen. De gesprekken aan het einde van de avond heb ik altijd als zeer waardevol ervaren. Je hebt me vertrouwen gegeven, dank je wel.

Collega's uit 't OLVG, ik wil jullie bedanken voor een geweldige start van de opleiding in Amsterdam. Als hecht team werkten we hard, hebben we gelachen en maakten we tijd voor collegiale bonding in de Ys, après-ski bar of kasteel Vaeshartelt. Ook buiten het werk zochten we samen uitdagingen: hopelijk hebben we de Marmotte inmiddels tot een succesvol einde gebracht. Lieve Emma, Ralph en Syb, als uro-maatjes hebben we veel prille werkervaringen gedeeld, ik hoop nog veel met jullie te mogen samenwerken.

Lieve vriendinnen, paranimfen, lieve Sarah en Johanne. Studievriendinnen zijn we, maar ik kan je zeggen; dat zijn de beste! Los van de vele clubjes als studentenvereniging, commissies of sportgroepjes vonden wij elkaar binnen ons jaar geneeskunde. Jullie ambitie sprong eruit. Op een zeer positieve manier heeft jullie voorbeeld, enthousiasme en vertrouwen geleid tot het resultaat dat nu voor ons ligt. Daarnaast was (en is) er altijd ruimte voor afleiding op elk ander vlak, kroeg of balkon als ik (of jij) 't niet meer zag zitten, steeds een nieuwe sportieve uitdaging, een eeuwig logeeradres en een fantastische tijd in Maastricht! Mooi dat er in de jaren van dit proefschrift zo een hechte vriendschap is ontstaan. Laten we proosten op een net zo mooie toekomst. Lieve vrienden, lieve Marc en Joep. Dank voor jullie mannelijke relativatie op z'n tijd onder het genot van een goed glas wijn of bier.

Ook wil ik graag mijn proefschrift bedanken; je onderbreking leidde tot hervatting maar nu met geweldig resultaat!

Lieve ouders, dank voor de zorgeloze jeugd en daarmee alle mogelijkheden die jullie voor mij hebben gecreëerd. Lieve pap, onze gelijkenissen onthullen zich met de jaren. Met jouw wetenschappelijke achtergrond komt dit proefschrift niet uit de lucht vallen. Je teleurstelling was groot toen het er niet meer leek te komen. Je vreugde des te meer toen ik besloot het af te ronden. Lieve mam, je grenzeloze interesse, ongeloof en trots doen mij goed. Er is niemand die vaker heeft geïnformeerd of er al een 'datum' was. Lieve Elian, lieve zus, dank voor je luisterend oor en oppeppende woorden, maar bovenal voor onze vriendschap. Lieve Laurens, yo bro, ook jij kunt meer dan je denkt! 


\section{Curriculum Vitae}

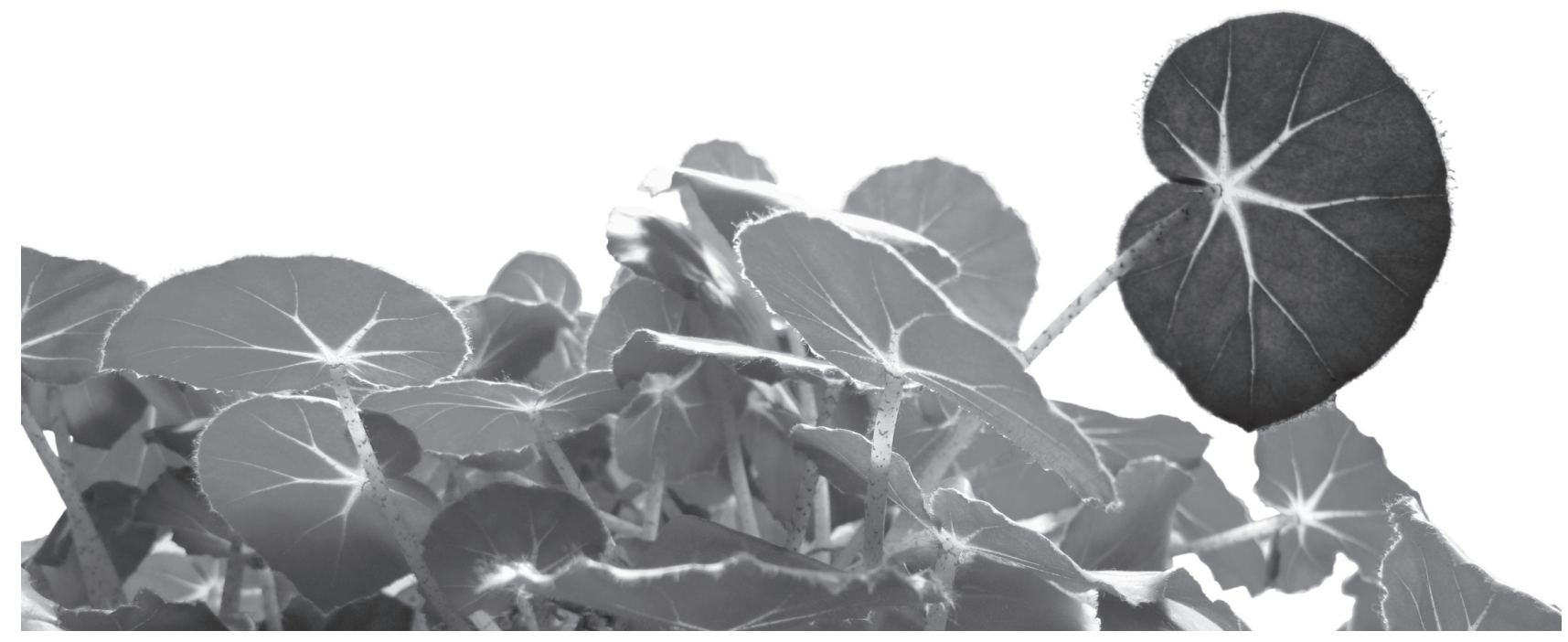




\section{CURRICULUM VITAE}

Eva de Vries werd op 16 oktober 1981 geboren te Groningen. Na het behalen van het Gymnasium aan het Fioretti College te Lisse (1991-1999) vertrok zij naar Maastricht voor de studie gezondheidswetenschappen aan de Universiteit Maastricht. Na een jaar werd haar propedeuse behaald en na twee jaar werd ze ingeloot voor geneeskunde aan de Universiteit Maastricht. In het eerste jaar daarvan bemachtigde zij een bijbaan als student assistent ("kidney-racer") bij het "Preservatielab" (laboratorium nierdonatie- en transplantatie) in het Maastricht Universitair Medisch Centrum (20012004). Tijdens de co-schappen (2004-2007) werkte zij als student onderzoeker onder leiding van Dr. N.D. Bouvy binnen de vakgroep algemene heelkunde. Na haar studie, in september 2007, pakte zij het onderzoek naar nierdonatie op en startte als artsonderzoeker onder leiding van Prof. dr. L.W.E. van Heurn dit promotieonderzoek bij de algemene heelkunde. In februari 2009 verruilde zij Zuid Limburg voor Amsterdam en werkte een jaar als ANIOS algemene heelkunde in het Slotervaartziekenhuis. Van januari 2010 tot juli 2010 werkte zij als ANIOS urologie in het Meander Medisch Centrum te Amersfoort waarna zij werd aangenomen voor de opleiding urologie onder leiding van Prof. dr. Th.M. De Reijke in het Academisch Medisch Centrum te Amsterdam. Van augustus 2010 tot januari 2011 werkte Eva nog enkele maanden fulltime aan het promotieonderzoek in Maastricht. Per januari 2011 startte zij met 2 jaar chirurgie onder leiding van Dr. M.F. Gerhards in het Onze Lieve Vrouwe Gasthuis te Amsterdam als onderdeel van de opleiding urologie. Sinds 1 januari 2013 krijgt de medische specialisatie urologie meer vorm nu zij werkt als AIOS urologie in het Medisch Centrum Alkmaar onder leiding van Dr. S.D. Bos. 
Abbreviations

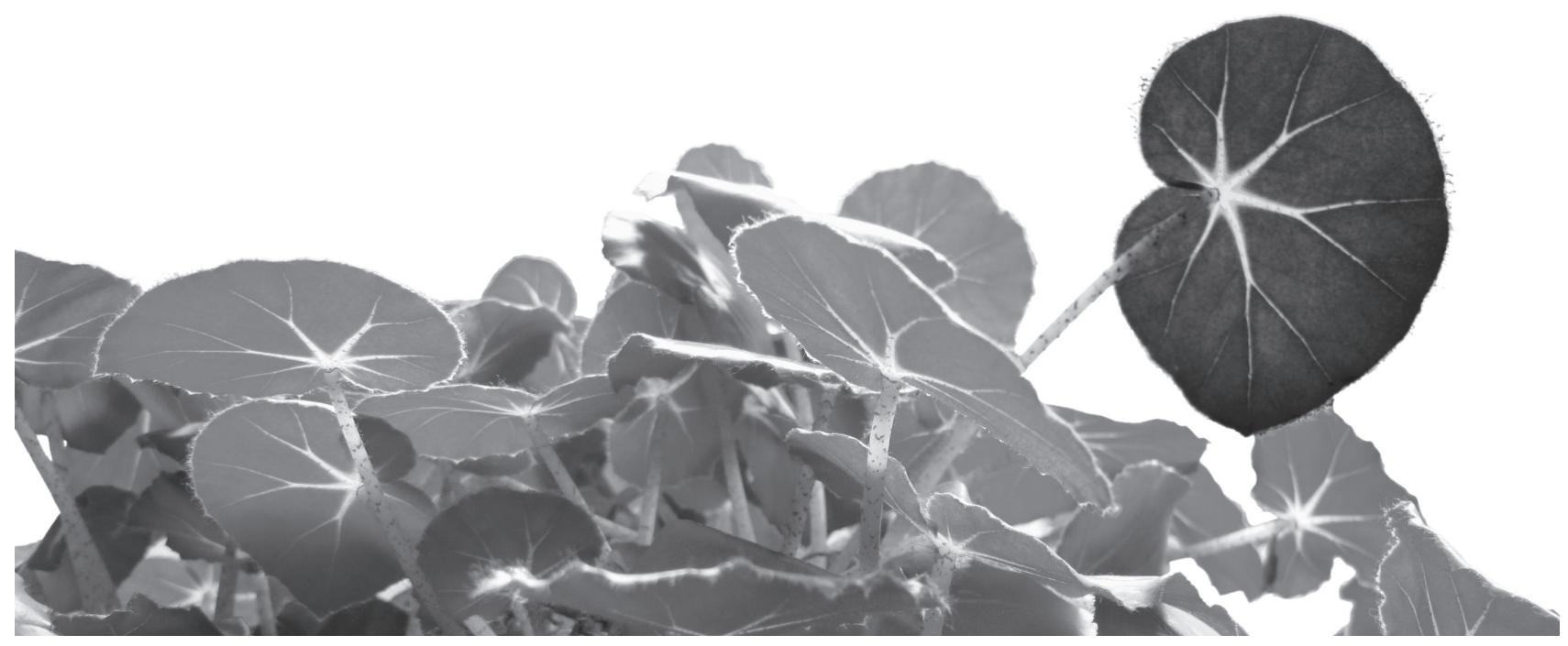




\section{ABBREVIATIONS}

ACS American College of Surgeons

ARF acute renal failure

ATP adenosine triphosphate

AUC area under the curve

AURC area under the ROC-curve

BBL brush border loss

BOLD blood oxygen level dependent

$\mathrm{Cl} \quad$ confidence interval

CIT cold ischemia time

CV coefficient of variation

DBD donors/donation after brain death

DBTL double-balloon triple-lumen

DCD donors/donation after cardiac death

DCE dynamic contrast-enhanced

DEC animal experiments committee

DGF delayed graft function

EBV Epstein Barr virus

ECMO extra corporeal membrane oxygenator

eGFR estimated glomerular filtration rate

ELISA enzyme-linked immuno sorbent assay

ESRD end stage renal disease

FABP's fatty-acid binding proteins

FSGS focal segmental glomerulosclerosis

GFR glomerular filtration rate

GST $\quad \alpha$-glutathione S-transferase

$\mathrm{HB}$ heart-beating

HBD heart-beating donor/donation

$\mathrm{H}-\mathrm{FABP}$ heart type fatty-acid binding protein

HLA human leucocyte antigen

HTK histidine tryptophan ketoglutarate

ICU intensive care units

IF immediate function

IL interleukin

IM inner medulla

IQR inter-quartile range

$\mathrm{I} / \mathrm{R} \quad$ ischemia reperfusion

$\mathrm{LDH} \quad$ lactate dehydrogenase 


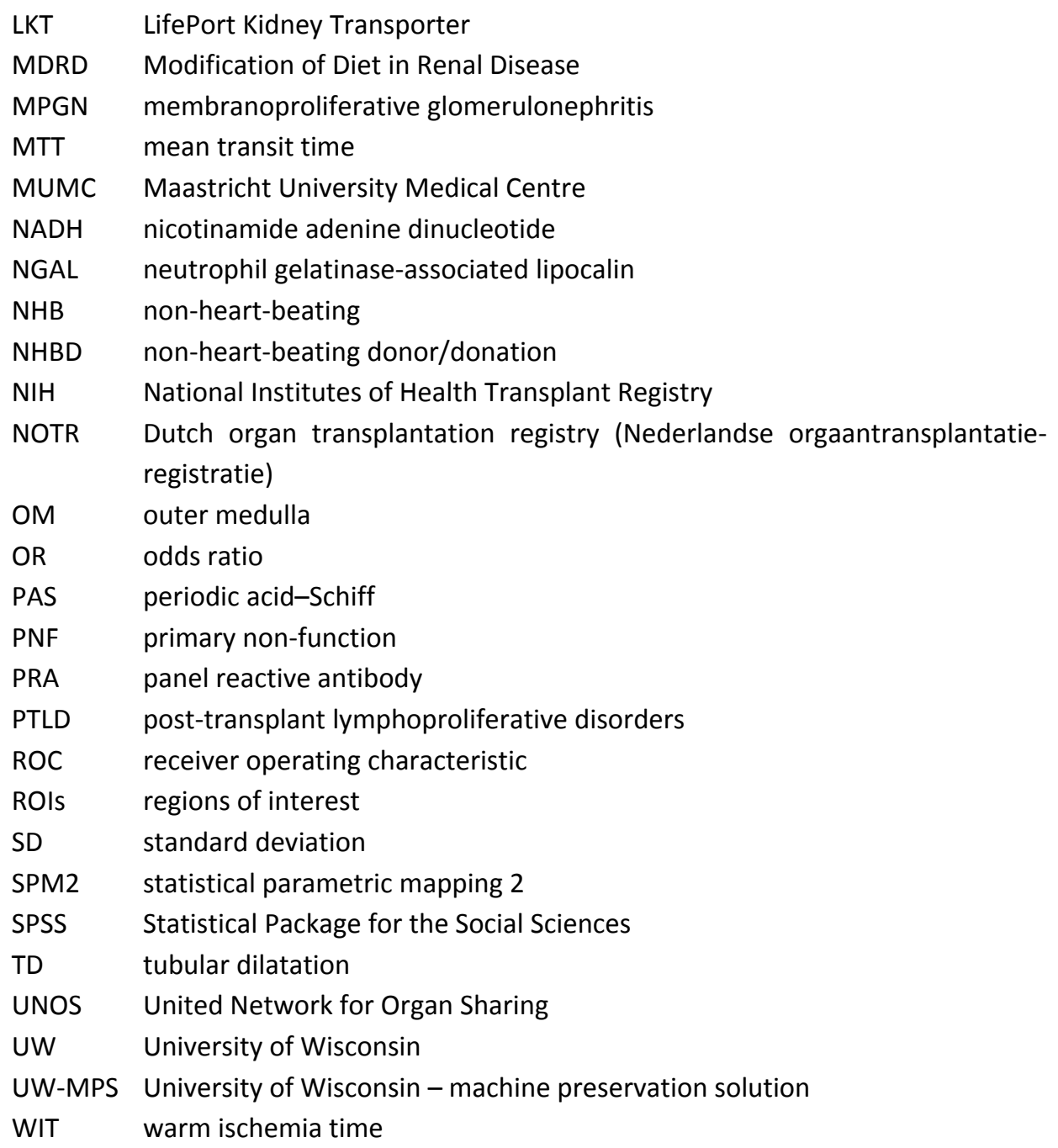

